\title{
Bacharelado em Nutrição da Unincor e iniciação à pesquisa \\ Com a palavra os nossos estudantes
}

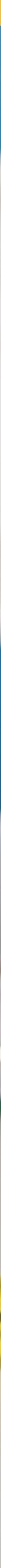

\section{Galdino Sousa}

[Organizadort]

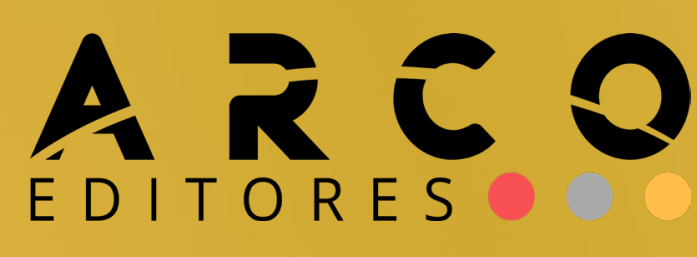




\section{Bacharelado em Nutrição da Unincor e iniciação à pesquisa}

Com a palavra os nossos estudantes

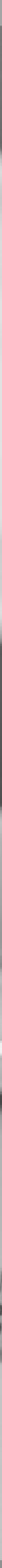

\section{Galdino Sousa}

[Organizadort]
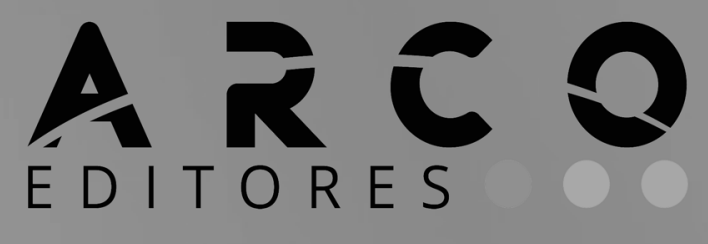


\section{CONSELHO EDITORIAL}

Prof. Dr. Adilson Tadeu Basquerote Silva

UNIDAVI/SC

http://lattes.cnpq.br/8318350738705473

Profa. Msc. Jesica Wendy Beltrán UFCE- Colômbia

http://lattes.cnpq.br/0048679279914457

Profa. Dra Fabiane dos Santos Ramos UFSM- Santa Maria/RS

http://lattes.cnpq.br/0003382878348789

Dr. João Riél Manuel Nunes Vieira de Oliveira Brito

UAL - Lisboa- Portugal.

http://lattes.cnpq.br/1347367542944960

Profa. Dra. Alessandra Regina Müller

Germani

UFFS- Passo Fundo/RS

http://lattes.cnpq.br/7956662371295912

Prof. Dr. Everton Bandeira Martins

UFFS - Chapecó/SC

http://lattes.cnpq.br/9818548065077031

Prof. Dr. Erick Kader Callegaro Corrêa UFN- Santa Maria/RS

http://lattes.cnpq.br/2363988112549627

Prof. Dr. Pedro Henrique Witchs

UFES - Vitória/ES

http://lattes.cnpq.br/3913436849859138

Prof. Dr.Thiago Ribeiro Rafagnin

UFOB

http://lattes.cnpq.br/3377502960363268
Prof. Dr. Mateus Henrique Köhler

UFSM- Santa Maria/RS

http://lattes.cnpq.br/5754140057757003

Profa. Dra. Liziany Müller

UFSM- Santa Maria/RS

http://lattes.cnpq.br/1486004582806497

Prof. Dr. Camilo Darsie de Souza

UNISC- Santa Cruz do Sul/RS

http://lattes.cnpq.br/4407126331414

Prof. Dr. Dioni Paulo Pastorio

UFRGS - Porto Alegre/RS

http://lattes.cnpq.br/7823646075456872

Prof. Dr. Leonardo Bigolin Jantsch

UFSM- Palmeira das Missões/RS

http://lattes.cnpq.br/0639803965762459

Prof. Dr. Leandro Antônio dos Santos

UFU- Uberlândia/MG

http://lattes.cnpq.br/4649031713685124

Dr. Rafael Nogueira Furtado

UFJF- Juiz de Fora/MG

http://lattes.cnpq.br/9761786872182217

Profa. Dra. Angelita Zimmermann

UFSM- Santa Maria/RS

http://lattes.cnpq.br/7548796037921237

Profa. Dra. Francielle Benini Agne

Tybusch

UFN - Santa Maria/RS

http://lattes.cnpq.br/4400702817251869

Copyright (c) Arco Editora, alguns direitos reservados.

Copyright do texto (c) 2022 os autores e as autoras.

Copyright da edição (c) 2022 Arco Editora. 
Diagramação e Projeto Gráfico : Gabriel Eldereti Machado

Imagen capa: $w w w$ freepik.com

Revisão: dos/as autores/as.

Dados Internacionais de Catalogação na Publicação (CIP) (Câmara Brasileira do Livro, SP, Brasil)

Bacharelado em nutrição da UninCor e iniciação à pesquisa [livro eletrônico] : com a palavra os nossos estudantes / organização Galdino Sousa. -Santa Maria, RS : Arco Editores, 2022. PDF

ISBN $978-65-89949-72-5$

1. Nutrição - Estudo e ensino 2. Nutrição - Ensino superior 3. Estudantes - Nutrição - Brasil I. Sousa, Galdino.

$22-102045$

$\mathrm{CDD}-613.207$

Índices para catálogo sistemático:

1. Nutrição : Ensino superior 613.207

Maria Alice Ferreira - Bibliotecária - CRB-8/7964

\section{do $10.48209 / 978-65-89949-72-5$}

O padrão linguístico-gramatical, bem como o sistema de citações e referências bibliográficas são prerrogativas de cada autor. Da mesma maneira, o conteúdo e teor de cada capítulo é de inteira e exclusiva responsabilidade de seu respectivo autor. 


\section{APRESENTAÇÃO}

Ao longo do ano de 2021 o organizador desta obra, Galdino, atuou como professor universitário ministrando as disciplinas de Trabalho de Conclusão de Curso (TCC) I e II do curso de bacharelado em Nutrição da Universidade Vale do Rio Verde (UninCor), em Minas Gerais. Os trabalhos de conclusão de curso são fundamentais para que os estudantes se aproximem da pesquisa na graduação, caminhando em direção ao princípio da indissociabilidade entre ensino, pesquisa e extensão da universidade. Diante disso, em parceria com as professoras do curso de Nutrição Brunna Sullara Vilela Rodrigues, Ana Luiza Rodrigues Pellegrinelli e Vivian Silva Borges apresentamos neste livro nossas produções junto aos nossos estudantes/orientandos.

\section{Desejamos uma boa leitura!}

Prof. Dr. Galdino Rodrigues de Sousa.

Professor e orientador do Mestrado Profissional em Gestão,

Planejamento e Ensino da Unincor. Professor da Faculdade de Educação da UFJF 


\section{SUMÁRIO}

\section{CAPÍTULO 1}

AVALIAÇÃO DO COMPORTAMENTO ALIMENTAR EM MORADORES DA CIDADE DE NEPOMUCENO MG DURANTE A PANDEMIA DA COVID-19.

Jean Henrique Delfino

Brunna Sullara Vilela Rodrigues

doi: 10.48209/978-65-89949-72-1

\section{CAPÍTULO 2}

ANÁLISE DO CONHECIMENTO DE INDIVÍDUOS DIABÉTICOS EM RELAÇÃO A ALIMENTAÇÃO.

Pâmela Rodrigues Inácio

Brunna Sullara Vilela Rodrigues

doi: 10.48209/978-65-89949-72-2

\section{CAPÍTULO 3}

DESAFIOS E DIFICULDADES PARA ADERIR E MANTER UM PLANEJAMENTO DIETÉTICO

Luís Gustavo Borges

Brunna Sullara Vilela Rodrigues

doi: 10.48209/978-65-89949-72-3

\section{CAPÍTULO 4}

A ATUAÇÃO DO NUTRICIONISTA DA ATENÇÃO BÁSICA NO TRATAMENTO DE DOENÇAS CRÔNICAS NÃO TRANSMISSÍVEIS: PERCEPÇÃO DOS USUÁRIOS DO SISTEMAS ÚNICO DE SAÚDE. .86

Letícia Aparecida Costa Luz

Ana Luiza Rodrigues Pellegrinelli

doi: 10.48209/978-65-89949-72-4 


\section{CAPÍtuLO 5}

ALIMENTOS QUE AJUDAM DA PREVENÇÃO DO ALZHEIMER......108

Yanka Lorena Gomes de Assis

Ana Luiza Rodrigues Pellegrinelli

doi: 10.48209/978-65-89949-72-0

CAPÍtulO 6

AUTOPERCEPÇÃO DE GANHO DE PESO NO PERÍODO DE ISOLAMENTO SOCIAL DURANTE A PANDEMIA DA COVID-19......131

Bruna Marina Melo de Andrade

Ana Luiza Rodrigues Pellegrinelli

doi: 10.48209/978-65-89949-72-6

\section{CAPÍtULO 7}

SELETIVIDADE ALIMENTAR NO TRANSTORNO DO ESPECTRO AUTISMO (TEA) 166

Bruna Andrade Silva

Ana Luiza Rodrigues Pellegrinelli

doi: 10.48209/978-65-89949-72-7

\section{CAPÍTULO 8}

RELAÇÃO ENTRE IMAGEM CORPORAL E TRANSTORNOS ALIMENTARES EM ADOLESCENTES DO SEXO FEMININO..............195

Eduarda Gomes dos Santos

Ana Luiza Rodrigues Pellegrinelli

doi: 10.48209/978-65-89949-72-8

\section{CAPÍTULO 9}

O USO DOS NUTRICOSMETICOS NO TRATAMENTO PARA LONGEVIDADE.

Elaine de Jesus Oliveira

Simone da Silva Rodrigues

Vivian Silva Borges

doi: 10.48209/978-65-89949-72-9 


\section{CAPÍTULO 10}

CAFÉ DA MANHÃ: PREVALÊNCIA DO CONSUMO E QUALIDADE NUTRICIONAL ENTRE ADOLESCENTES

Mateus do Carmo e Silva

Vivian Silva Borges

doi: 10.48209/978-65-89949-72-A

\section{CAPÍTULO 11}

AVALIAÇÃO DO CONSUMO DE ALIMENTOS FUNCIONAIS EM ADULTOS.

Maria Eduarda de Oliveira Nepomuceno

Vivian Silva Borges

doi: 10.48209/978-65-89949-72-B

SOBRE O ORGANIZADOR.

292

SOBRE AS AUTORAS E OS AUTORES 


\section{doi $10.48209 / 97 / 8-65-89949-7 / 2-1$}

\section{CAPITULO $\mathbb{1}$}

\section{A VAHACÇÃO DO COMPORHAMIENHO}

AHMENTHR FM

\section{MORADORES DA CIDADE} DE NIPOMUCENO-MG DURANTHE A PANDEDMIA DA COVID 19

Jean Henrique Delfino Brunna Sullara Vilela Rodrigues 


\section{INTRODUÇÃO}

Há mais de um ano o mundo está sofrendo com a pandemia da Covid-19, que é causada pelo coronavírus SARS-CoV-2. O mundo vem sendo muito prejudicado pela doença ocasionando elevados números de óbitos e tem-se procurado várias maneiras de combater vírus. E, por se tratar de uma doença nova, muito tem se estudado sobre formas de minimizar seus efeitos, como o desenvolvimento da vacina sendo usada de forma emergencial, ou até mesmo com o isolamento de forma emergencial como maneira de prevenção ao vírus (Aquino et al., 2020).

Entre as várias maneiras de evitar o vírus de forma não farmacológica podemos citar a alimentação equilibrada e saudável, que acompanhada com a prática regular de exercícios físicos podem evitar muitas complicações, como as doenças crônicas não transmissíveis (DCNTs) que são fatores agravantes para quem é infectado pelo coronavírus (L. O. de Sousa et al., 2021).

Com as informações coletadas será possível perceber como se encontra o comportamento alimentar dos moradores da cidade de Nepomuceno-MG durante o isolamento social da pandemia da covid-19? Quais os resultados poderão ser que o isolamento social prejudicou sim o comportamento alimentar dos indivíduos, fazendo que eles se alimentassem de forma inadequada. Ou até mesmo que o isolamento social não prejudicou o comportamento alimentar dos indivíduos, e que eles estão se alimentando de forma adequada. Todavia, poderemos identificar o comportamento alimentar no período de setembro a outubro de 2021 durante $\mathrm{o}$ isolamento social da pandemia da Covid-19 em moradores da cidade de Nepomuceno-MG, analisando a presença de restrição cognitiva, alimentação emocional e descontrole alimentar. Porém, também averiguando a frequência da prática de atividade física bem como a avaliando a associação entre a restrição cognitiva, alimentação emocional e descontrole alimentar em conjunto a prática de atividade física dos moradores. 
O isolamento social pode impulsionar as pessoas a terem a uma ingesta alimentar bem superior ao normal, ou até mesmo de forma compulsiva, podendo acometer o aparecimento de inúmeras patologias como as doenças crônicas não transmissíveis. Desse modo, o presente estudo ressalta os benefícios adquiridos através da alimentação, e que é necessário transmitir informação de forma educativa e consciente á população, para que haja mudanças positivas nos hábitos alimentares (Lima \& Soares, 2020).

\section{REFERENCIAL TEÓRICO}

\subsection{Pandemia da Covid-19}

A Covid-19 se trata de uma infecção respiratória aguda ocasionada pelo coronavírus SARS-CoV-2, considerada de caráter potencialmente grave, possuindo alta transmissibilidade e distribuída de forma mundial. O vírus pode ser propagado por vários meios, desde um aperto de mão, tosse, espirro ou por gotículas respiratórias contendo o SARS-CoV-2, e também da mesma maneira que os demais vírus respiratórios (BRASIL, 2021).

Atualmente o mundo está sofrendo com a pandemia da Covid-19, que é uma doença que teve seu início em dezembro de 2019, sendo detectada em Wuhan, China. Com o crescimento exacerbado no número de casos, óbitos e países afetados pelo vírus, a Organização Mundial da Saúde (OMS) anunciou em 30 de janeiro de 2020, que o acontecimento se tratava na verdade de uma Emergência de Saúde Pública de Importância Internacional (ESPII). Sendo declarada no Brasil como ESPII, em 3 de fevereiro de 2020 (Garcia \& Duarte, 2020). E nos demais países a pandemia da Covid-19 foi declarada pela OMS em 11 de março de 2020.

O Brasil foi o primeiro país sul-americano a ter um caso relatado de Covid-19, sendo confirmado dia 26 de fevereiro de 2020, no estado de São Paulo. Atualmente, o país enfrenta um terrível cenário epidemiológico na qual diaria- 
mente confirma-se vários novos casos e um grande número de óbitos ocasionados pela doença (Garcia \& Duarte, 2020).

Em função da ausência de medidas preventivas e/ou terapêuticas específicas para a Covid-19 e por ser transmitida rapidamente, a OMS recomendou que os governos adotassem inicialmente intervenções não farmacológicas, com maior foco nas medidas classificadas como de caráter individual, como o uso de máscaras, álcool em gel, restrição de locais públicos a fim de evitar aglomerações (Beeching et al., 2020).

\subsection{Isolamento social}

No Brasil, o fechamento de escolas, universidades bem como os comércios considerados não essenciais foram algumas das medidas adotadas pelos estados e municípios. Os trabalhadores foram orientados e/ou obrigados a desenvolver suas atividades de trabalho em casa. Autoridades públicas locais chegaram a decretar lockdown em várias cidades e havia multas para as pessoas e os estabelecimentos que descumprissem tais medidas protetivas (Malta, Szwarcwald, et al., 2020).

A principal medida adotada no Brasil foi distanciamento social, a fim de evitar aglomerações e consequentemente a propagação do vírus, mantendo uma distância mínima de um metro e meio entre as pessoas, assim como as medidas preventivas como a utilização de máscaras, álcool em gel por exemplo. Posteriormente, foi adotado o isolamento social, que impedia as pessoas de saírem de casa, o que evitaria a circulação do vírus, podendo sair se fosse realmente essencial. Já os suspeitos de estarem infectados, ou seja, aqueles que apresentavam alguns sintomas proveniente da contaminação pelo vírus, deveriam ficar confinados em quarentena por quatorze dias, que é o período de incubação do vírus, tempo que ele leva para se manifestar e o indivíduo através do exame, ter certeza se contraiu o vírus ou não (de Souza \& Graça, 2020). 
O isolamento social é inevitavelmente umas das medidas mais eficazes para a prevenção da Covid-19, evitando assim, a transmissão direta do vírus de pessoas para pessoa. Porém, podendo acarretar em algumas manifestações clinicas e comportamentais atingindo negativamente as pessoas como o estado psicológico em relação às mudanças impostas ao estilo de vida, prática esportiva e também sobre o consumo excessivo de bebidas alcoólicas, consumo de alimentos não saudáveis e o tabagismo (Malta, Gomes, et al., 2020).

Podemos destacar ainda em relação ao isolamento social, que foi ocasionado pela pandemia, aumentou significativamente as taxas de desemprego e redução de renda, levando a tona uma triste realidade de vulnerabilidade que a população brasileira se encontra nos tempos atuais (Bezerra et al., 2020).

\subsection{Saúde do adulto}

Muitos fatores influenciam na imunidade do ser humano, como sono, alimentação, atividade física e fatores emocionais. Nutrir-se vai muito além do ato de satisfazer a fome, é um componente primordial do desenvolvimento e da saúde humana. Logo, uma alimentação saudável está relacionada diretamente a fatores como a concepção, gestação e o aleitamento materno apropriado (Pereira et al., 2020).

Nesse contexto, a saúde mental é essencial para a saúde como um todo, sendo definida pela OMS como um estado de bem-estar no qual as pessoas realizam suas próprias habilidades, lidam com o estresse do dia a dia, trabalham produtivamente sendo capazes de contribuir com a comunidade. Dessa maneira, a proteção, promoção e a restauração da saúde mental são fundamentais para a sociedade (Pereira et al., 2020).

Além disso, uma alimentação saudável está relacionada a um crescimento adequado e consequentemente, a uma melhora do sistema imunológico o que acarretará em um menor risco obter problema futuros. Desse modo, o ato de se 
alimentar de forma equilibrada e saudável é capaz de evitar diversas doenças como diabetes e hipertensão arterial e promover saúde (Juniior, 2020).

Um fator significativo para determinar o estado de saúde e longevidade de uma pessoa é o seu estado nutricional. Entretanto, a nutrição do indivíduo é influenciada por diversos fatores sociais e econômicos, que estão ligados as escolhas e aos padrões alimentares da população (Juniior, 2020).

\subsection{Características do comportamento alimentar}

Desde a metade do século XX, o mundo vem passando por um processo conhecido como transição nutricional, decorrente da urbanização e modernização. A transição nutricional se caracteriza pelo declínio acentuado da subnutrição e também do significativo aumento de peso e obesidade. Mudanças ocasionadas por vários motivos, como questões econômicas, sociais e demográficas, influenciando diretamente no estado nutricional e consequentemente na saúde dos indivíduos (R. Sousa, 2019).

Os alimentos podem ser consumidos de várias formas. Santos, (2008) afirma que "nos tornamos o que comemos". Pois a experiência do comer cria a identidade do ser humano, tanto de forma individual e coletiva, no qual cada um segue uma cultura ou simplesmente escolhe uma forma de se alimentar.

Segundo (VIEIRA, 2021) doenças crônicas não transmissíveis (DCNT) como diabetes, hipertensão, obesidade e cardiovascular são ocasionadas pelos maus hábitos alimentares, sendo necessária uma melhor atenção para as mesmas. As DCNT estão totalmente ligadas a fatores de risco conhecidos por todos, tais como a inatividade física, tabagismo, álcool e principalmente por uma alimentação desregrada. Segundo o Ministério da Saúde estima-se que 57,4 milhões de pessoas são portadoras de DCNT no Brasil.

Atualmente com a maior facilidade em adquirir alimentos ultraprocessados industrializados, as pessoas optam por consumir alimentos ricos em gordura e 
carboidratos principalmente, em contrapartida, ocasionando um menor consumo dos alimentos ricos em micronutrientes como as frutas, vegetais e verduras (Durães, 2020).

\subsubsection{Comer consciente versus comer emocional}

Assuntos relacionados à dieta e alimentação são bem difundidos atualmente entre a população. A quantidade de informações que a mídia apresenta diariamente sobre o tema tem grande influência nas escolhas alimentares das pessoas. A publicidade, e o marketing por trás desses produtos, induzem inconscientemente os consumidores a comprarem e comerem determinados alimentos, que muitas vezes não são alimentos saudáveis (Alcantara et al., 2018).

Segundo o Guia Alimentar para a População Brasileira do Ministério da Saúde (2014), uma alimentação balanceada consiste no consumo dos alimentos e não dos nutrientes, no qual deve ser centrada em boas práticas alimentares, havendo significado cultural e social. Os alimentos contem forma, textura, cor, gosto e aroma. De Souza Lima; Ferreira Neto; Pereira Farias, (2015) apontam que toda substância nutritiva é considerada como um alimento, em geral, sendo tudo aquilo que os indivíduos ingerem para se manterem vivos. Já os nutrientes são substancias químicas importantes, presentes em qualquer tipo de alimento, possuindo funções próprias no organismo em geral.

Desse modo, integrando a constituição dos alimentos, como as proteínas, carboidratos, lipídeos e os minerais, trazendo inúmeros benefícios para o organismo. Entretanto os alimentos não podem se resumir apenas aos nutrientes, algo que vem ocorrendo atualmente, onde as pessoas muitas vezes esquecem o verdadeiro significado de uma boa alimentação. Que é levar em consideração o prazer de se alimentar, o comer consciente e não por emoção, compulsão, e sempre visando uma boa qualidade nutricional, optando por alimentos saudáveis, como os in natura e minimamente processado (Klotz-Silva et al., 2016). 
O comer emocional se caracteriza por uma exagerada ingestão alimentar em resposta às emoções dos indivíduos, como as negativas, porém, o bom humor também pode provocar um aumento da ingestão dos alimentos. Entre os principais fatores que desencadeiam o comer emocional, podemos enfatizar o estado de humor negativo, como sentir-se triste, ansioso, deprimido, tenso e entediado. As mulheres se mostram ser o grupo mais afetado por este quadro, independentemente do peso, estando muito abaixo, acima ou até mesmo em seu peso ideal (Moura \& Nava, 2020).

Todavia, o comer emocional merece uma atenção especial por vários motivos. Normalmente $\mathrm{o}$ ato de comer para essas pessoas está associado a uma resposta a determinada aflição psicológica e não aos sinais fisiológicos da fome. Além disso, os estudos veem demonstrando que o comer emocional está relacionado a uma baixa autoestima e sentimentos indevidos ao próprio corpo que afetam a qualidade de vida do indivíduo, uma vez que o comer emocional é uma condição em que o consumo de calorias é aumentado, levando a um aumento de peso corporal, gerando o risco de desenvolvimento de doenças (Moura \& Nava, 2020).

\subsubsection{Restrição alimentar e ganho de peso}

A insatisfação com a imagem corporal é uma das condições que predispõem há um comportamento alimentar inadequado (Ferreira et al., 2018). A qual, na maioria das vezes é decorrente de uma busca desenfreada por um padrão de beleza imposto pela sociedade de forma geral, levando as pessoas a comportamentos drásticos como restrição, compensação, compulsivos e/ou purgativos (Ferreira et al., 2018).

Estudos recentes apontam que os distúrbios referentes à insatisfação corporal e alterações do comportamento alimentar em sua maioria iniciam-se na adolescência, porém, também podem ocorrer na fase adulta, devido a uma enor- 
Bacharelado em Nutrição da UninCor e iniciação à pesquisa: Com a palavra os nossos estudantes

me preocupação com o padrão de beleza imposto pela sociedade. A maior prevalência de insatisfação corporal acontece no sexo feminino. Essa condição está associada com o estado nutricional do indivíduo, pois quanto mais baixo e/ou mais elevado for o peso, índice de massa corporal (IMC) da pessoa, maior será o descontentamento e insatisfação corporal (Ferreira et al., 2018).

A restrição calórica de forma leve visando a perda de peso, associada à prática de exercício físico moderado, contribuem para melhorar a resposta imunológica e reduzir as possíveis complicações decorrente de inúmeras doenças como as DCNT, impostas principalmente aquelas pessoas com excesso de peso. Desse modo, nutricionistas e profissionais de educação física podem contribuir para a adesão de bons hábitos alimentares e práticas regulares de exercícios durante o período de isolamento social, o que evitaria mudanças indesejadas no peso e principalmente sobre a saúde. Em outra vertente, existe varias pessoas sob um eminente risco de desnutrição, o que compromete o sistema imune em relação á uma infecção ocasionada pela Covid-19 (Durães, 2020).

Entre as principais DCNT que mais acometem as famílias brasileiras em relação ao perfil alimentar em geral é a obesidade, a hipertensão arterial e a diabetes. Segundo a OMS, elas correspondem aos principais fatores do risco de morte e doenças no mundo inteiro. Sobretudo por uma crescente elevação no consumo de alimentos ultraprocessados, ricos em gorduras, açúcar e sódio e combinados com uma diminuição da ingesta de alimentos in natura e minimamente processados (Aline Ester da Silva Cruz, 2016).

Segundo ALVARES; SANTANA, (2020) apontaram uma associação positiva entre o aparecimento de perturbações no comportamento alimentar em relação ás dietas, sobretudo, sobre a restrição cognitiva juntamente a alimentação emocional. Pessoas que estão realizando algum tipo de programa visando perda de peso e comportamentos de dieta, ou seja, em estado de restrição cognitiva alimentar, prevalentemente as do gênero feminino, apresentavam um número mais 
elevado no grau de ansiedade e também possuíam maiores chances de desenvolver modelos alimentares incomuns caracterizados por fases de auto restrição combinada com a ingestão compulsiva. Ocasionando um excessivo consumismo dos alimentos intitulados como não saudáveis, como modo de se sentir confortável e distraído em relação aos seus sentimentos de ansiedade.

\subsection{Prática de atividade física em adultos}

A atividade física é considerada uma importante ferramenta para a melhoria da saúde, sendo recomendada à população em geral, entretanto, respeitando as especificidades pertinentes de cada indivíduo. Com inúmeros benefícios à saúde tais como bem-estar físico e mental, controle do peso, redução do risco de doenças entre outras, a atividade física exerce um papel mais que representativo sobre vários processos cognitivos, em diferentes faixas etárias, como as crianças, adultos e idosos da população (Juniior, 2020).

Dessa forma, a atividade física promove importantes transformações na composição corporal, e sobre a massa magra como um importante agente no controle do excesso de peso nas crianças, adolescentes, adultos e idosos. Pois tem como resultado, a diminuição dos quadros de distúrbios psicossociais, depressivos, baixa autoestima, isolamento, e posteriormente, influenciando positivamente sobre várias doenças como, obesidade, diabetes, cardiovasculares e hipertensão (Farias et al., 2015).

No Brasil e em outros vários países, locais para a prática de atividade física como academias e parques foram fechados na intenção de diminuir a proliferação do vírus. Entretanto, ficar longos períodos em casa representa um desafio significativo para aqueles fisicamente ativos. Baixos níveis de pratica de atividade física são capazes de gerar efeitos negativos nas pessoas relacionados a processos cognitivos somados ao próprio estresse ocasionado pelo isolamento social, como o aumento do peso pelo estado de sedentarismo (Crochemore-Silva et al., 2020). 
Bacharelado em Nutrição da UninCor e iniciação à pesquisa: Com a palavra os nossos estudantes

Atividades físicas podem ser realizadas em casa, em decorrência da pandemia, com o auxílio da tecnologia, através de vídeos de exercícios ou aplicativos, entretanto, sempre com a orientação de um profissional de educação física capacitado. Já as atividades físicas que forem ser realizadas ao ar livre recomenda-se que sejam individuais, para evitar aglomerações, sempre com o uso de máscaras e respeitando todos os procedimentos necessários a fim de evitar a propagação do vírus (Juniior, 2020).

\subsection{Efeitos do isolamento social no comportamento alimentar}

O isolamento social pode interferir diretamente no padrão de compra da população no que diz respeito ao gênero alimentício e consequentemente do consumo alimentar. A população com enorme receio de ficar sem produtos em casa, devido a escassez de muitos alimentos pelo medo de não ter o que comer em casa, tendem a optar produtos menos perecíveis e práticos, como os processados e ultraprocessados, ao invés dos alimentos in natura (Oliveira et al., 2020).

Porém, é indispensável uma alimentação equilibrada, pois ela acarreta inúmeros benefícios ao organismo para o enfrentamento dessa doença, pois um sistema imunológico fortalecido acaba se tornando a melhor defesa do organismo contra os agentes infecciosos, como os vírus, bactérias e parasitas. Desse modo, lembrando-se da grande importância que segurança alimentar nos traz no que diz respeito á saúde e, sobretudo na higienização dos alimentos, uma vez que os alimentos podem ser contaminados, e posteriormente acometer mais pessoas com o vírus (Justo, 2020).

De acordo com Dos Reis Verticchio; De Melo Verticchio, (2020), alguns sentimentos como ansiedade, tristeza e depressão estão intimamente ligados às mudanças no padrão alimentar e consequentemente no ganho ou perda de peso. Logo, torna-se importante um estudo que possa analisar como o tempo de confinamento social pode interferir nas mudanças comportamentais sobre a 
alimentação e criar alternativas para essa condição, gerando mudanças também no peso da população.

Durante o período de isolamento social as divulgações de propagandas sobre produtos do gênero alimentício acabaram de certa forma ficando ainda mais atrativas, sobretudo porque as pessoas passaram a ficar mais tempo em casa vendo televisão e/ou em outras mídias sociais, o que aliou-se as necessidades emocionais aumentando os desejos individuais, por aqueles alimentos (Santos et al., 2012).

\section{MATERIAIS E MÉTODOS}

Esse projeto de pesquisa se trata de um estudo transversal, de natureza aplicada, caráter quantitativo e objetivo descritivo.

É transversal (ou seccional), pois a pesquisa será realizada em um curto período de tempo, em um determinado momento, ou seja, em um ponto no tempo (FONTELLES et al. 2009).

Caracterizado de natureza aplicada, por seu interesse prático, ou seja, em que os resultados possam ser aplicados ou utilizados, imediatamente, com o fim de solucionar os problemas decorrentes no momento (MARCONI; LAKATOS, 2017).

O objetivo da pesquisa é quantitativo, pois atua sobre um problema humano ou social, baseada em um teste de uma determinada teoria sendo composta por variáveis quantificadas em números, das quais, são analisadas estatisticamente, com o objetivo de determinar se as generalizações previstas na teoria se sustentam ou não (Resende et al., 2014).

É também, descritivo, pois visa observar, registrar e descrever as características de um determinado fenômeno ocorrido em uma amostra ou população, sem, no entanto, analisar o mérito de seu conteúdo (FONTELLES et al. 2009). 
Bacharelado em Nutrição da UninCor e iniciação à pesquisa: Com a palavra os nossos estudantes

O estudo foi realizado na cidade de Nepomuceno-MG durante o período de pandemia da Covid-19 no período de setembro a outubro do presente ano de 2021. Foram incluídos na pesquisa 113 residentes da cidade de Nepomuceno-MG, do sexo masculino e feminino com idade entre 18 e 59 anos. Sendo excluídos os residentes de outras cidades.

Antes de responder os questionários os voluntários receberam o Termo Consentimento Livre Esclarecido (TCLE) (APÊNDICE A) e após o aceite, um texto explicativo que os deixarão cientes de que se tratava de uma pesquisa. $O$ autor, orientador e instituição de ensino serão identificados no momento do envio do questionário para os participantes.

O presente estudo foi submetido ao Comitê de Ética em Pesquisa da Universidade Vale do Rio Verde - UninCor sob o parecer número 4.940.083. O presente estudo respeita os preceitos estabelecidos pela Resolução 466/12 de dezembro de 2012. Sendo respeitados os princípios de anonimato, privacidade e sigilo profissional. O participante do estudo teve autonomia para decidir se aceitava ou não participar do estudo. Pode deixar de participar da pesquisa em qualquer momento, caso deseje, sem sofrer penalidade alguma. As entrevistas tiveram início após a aprovação do projeto de pesquisa pelo Comitê de Ética em Pesquisa da Universidade Vale do Rio Verde - UninCor. A pesquisa respeitou os aspectos culturais, sociais e familiares do entrevistado.

Para avaliar o comportamento alimentar dos participantes foi utilizado um questionário online: Three Factor Eating Questionnaire - versão reduzida de 21 itens (TFEQR-21) foi traduzida e validada para o Brasil por NATACCI \& FERREIRA, 2011 (ANEXO A). É um instrumento autoaplicável, composto por três escalas que avaliam: (a) restrição cognitiva (RC) medida por 6 itens e que está relacionada à proibição alimentar como forma de controlar/modificar o peso ou a forma corporal; (b) descontrole alimentar (DA) medido por 6 itens e que está relacionado a propensão para comer exageradamente em resposta a estados 
Bacharelado em Nutrição da UninCor e iniciação à pesquisa: Com a palavra os nossos estudantes

emocionais negativos, como solidão, ansiedade e depressão; (c) alimentação emocional $(\mathrm{AE})$ medida por 9 itens e que está relacionado à tendência de perder o controle alimentar na presença da fome ou de estímulos externos.

A pontuação total de cada comportamento gera um escore que varia de 0 a 100 pontos, sendo que quanto maior o escore maior a propensão ao comportamento alimentar avaliado. Não há uma proposta de classificação dos escores, portanto, os mesmos serão utilizados como variável numérica contínua (NATACCI \& FERREIRA, 2011).

Para avaliação da prática de AF foi utilizado o Questionário Internacional de Atividade Física (IPAQ - International Physical Activity Questionnaire) - IPAQ versão curta, que foi desenvolvido pela Organização Mundial de Saúde, o Centro de Controle e Prevenção de Doenças dos Estados Unidos e o Instituto Karolinska da Suécia reuniram proeminentes pesquisadores da área a fim de desenvolverem e testarem um instrumento para medidas de atividades físicas de uso internacional, no ano de 1998. O IPAQ contém perguntas em relação às atividades que realiza no trabalho, deslocar-se para algum lugar, lazer, exercício, como parte das suas atividades em casa ou no jardim, tempo de caminhada e tempo sentado. As questões foram estruturadas para fornecer contagens separadas sobre atividades de intensidade vigorosa, moderada, caminhadas e tempo sentado, sendo que estas foram respondidas com referência à última semana (ANEXO B).

Foi utilizado a plataforma digital "Google Forms", para o desenvolvimento do questionário, e os aplicativos de mensagens WhatsApp e Instagram para divulgar e encaminhar o link do questionário para os participantes.

A utilização de questionário on-line é considerada de baixo risco de coação, apesar disto, existe a possibilidade de ocorrer constrangimento ao responder o questionário e alterações na autoestima provocadas pela evocação de memórias ou por reforços na conscientização sobre uma condição física ou psicológica restritiva ou incapacitante. 


\section{RESULTADOS E DISCUSSÃO}

Os resultados dessa pesquisa envolvem uma amostra de 113 pessoas, onde $72 \%$ são do sexo feminino e $28 \%$ do sexo masculino. Ambos os sexos detêm uma média de idade de $26,59 \pm 8,12$ anos.

Mais da metade das pessoas possuem uma renda mensal de mais de 1,5 salário- mínimo. Onde 14\% não possuem nenhuma renda mensal e 5\% recebem menos que meio salário-mínimo, 27\% possuem de 1 salário-mínimo até 1,5 salário-mínimo e $35 \%$ possuindo mais de 1,5 salário-mínimo.

Tabela1. Dados sociodemográficos dos participantes.

\begin{tabular}{ccc}
\hline Sexo & N & $\%$ \\
\hline Masculino & 81 & $72 \%$ \\
\hline Renda mensal & 32 & $28 \%$ \\
\hline Não tenho nenhuma renda mensal & N & $\%$ \\
\hline Menos do que 0,5 salário-mínimo & 16 & $14 \%$ \\
De 0,5 salário-mínimo até 1 salário-mínimo & 6 & $5 \%$ \\
De 1 salário-mínimo até 1,5 salário-mínimo & 31 & $18 \%$ \\
Mais de 1,5 salário-mínimo & 40 & $35 \%$ \\
\hline
\end{tabular}

\section{Fonte:o autor (2021)}

Ao avaliar as subescalas do comportamento alimentar, através do TFEQ-R21, verificou-se que os participantes não apresentaram alto índice para nenhuma das questões abordadas abaixo (tabela 2). 
Tabela2. Resultados do teste TFEQ-R21

\section{Descontrole Alimentar Restrição Cognitiva Alimentação Emocional}

\begin{tabular}{ccccccc}
\hline & n & $\%$ & N & $\%$ & $n$ & $\%$ \\
Baixo & 46 & $41 \%$ & 31 & $27 \%$ & 50 & $44 \%$ \\
Médio & 40 & $35 \%$ & 66 & $58 \%$ & 31 & $27 \%$ \\
Alto & 27 & $24 \%$ & 16 & $14 \%$ & 32 & $28 \%$ \\
\hline
\end{tabular}

Fonte:o autor (2021)

Quanto à prática de atividade física, avaliada por meio do Questionário Internacional de Atividade Física (IPAQ - International Physical Activity Questionnaire) - IPAQ versão curta, a maioria dos participantes se dividiu entre muito ativo, ativo e irregularmente ativo $\mathrm{A}$ (tabela 3 ).

Tabela 3. Nível de atividade física dos participantes do estudo

\begin{tabular}{ccc}
\hline & N & $\%$ \\
\hline Muito Ativo & 27 & $24 \%$ \\
Ativo & 26 & $23 \%$ \\
Irregularmente Ativo A & 30 & $27 \%$ \\
Irregularmente Ativo B & 20 & $18 \%$ \\
Sedentário & 10 & $9 \%$ \\
\hline
\end{tabular}

Fonte:o autor (2021)

Ao avaliar as subescalas do comportamento alimentar e a prática de atividade física, foi identificada associação entre descontrole alimentar $(p=0,001)$ e atividade física e restrição cognitiva $(p=0,041)$ e atividade física. 
Bacharelado em Nutrição da UninCor e iniciação à pesquisa: Com a palavra os nossos estudantes

\section{DISCUSSÃO}

As consequências geradas pela Covid-19 afetaram significativamente os hábitos alimentares e comportamentais da população, especialmente pela adesão da educação digital, também sobre a pratica de atividades físicas e, sobretudo no âmbito alimentar, no que diz respeito a estocagem de alimentos e restrição alimentar (Leão \& Ferreira, 2021). Além disso, excesso de informações relacionadas ao cenário pandêmico criou uma sobrecarga de estresse nas pessoas, de modo que a comida fosse um escape para a situação.

Dos 113 participantes envolvidos na pesquisa, a sua grande maioria era do sexo feminino, portando, os resultados podem ter sofrido influência com essa condição. Pois, existe uma maior preocupação das mulheres em relação ao corpo, o que pode ser confirmado por (Campos et al., 2016), onde as mulheres acabam se expondo mais ao relacionar com o externo, e muitas vezes acabam caindo em armadilhas absurdas em relação ao corpo, o que as levam a tomar medidas extremas, as quais acabam desencadeando por sua vez, distúrbios alimentares.

A média de idade dos participantes foi de 26,59 anos, e sua maioria possuindo de 1 salário-mínimo até 1,5 salário-mínimo de renda mensal. Quanto maior o poder aquisitivo, consequentemente menor será o risco das famílias não terem uma ingestão alimentar adequada, no que diz respeito a ingerir a quantidade energética básica que necessitam (Jaime et al., 2018).

Ao analisar o questionário TFEQ-R21, observou-se que os índices obtidos não foram significativos para nenhuma das opções em questão, nem de descontrole alimentar, restrição cognitiva e alimentação emocional.

A literatura indica que durante a pandemia a alimentação emocional se tornou frequente entre os estudantes, que começaram a optar por alimentos específicos como os ultraprocessados e também passando a aumentar o número de refeições em funções das suas emoções (Electric, 2021). 
A alimentação emocional é o fator de maior influencia sobre o descontrole alimentar, pois dessa forma, faz com que as pessoas estejam mais susceptíveis frente ás emoções negativas a optarem por alimentos mais calóricos, o que desencadeará quadros de sobrepeso e possíveis obesidades (Lira, 2020).

Biagio et al., 2020, relatam relação significativa entre a restrição cognitiva com adesão ao descontrole alimentar, principalmente em indivíduos com excesso de peso. Altos níveis de descontrole alimentar estão predominantemente associados as escolhas alimentares, como por alimentos salgados e gordurosos, porém, o estudo não obteve associação significativas em relação a gorduras e sódio.

Esperavam-se índices um pouco maiores para as questões abordadas, pelo fato do estudo ser realizado durante o período de pandemia da Covid-19, mas não foi o que aconteceu.

Já em relação ao IPAQ versão curta mostrou que a maioria dos participantes se manteve ativos mesmo durante a pandemia, sendo muito ativos $24 \%$, ativo $23 \%$ e irregularmente ativo A $27 \%$, uma vez que as academias estiveram fechadas, períodos de isolamento social, os indivíduos em questão se preocuparam em se exercitar.

Desse modo, o primeiro estudo retratando a importância de seguir praticando atividades físicas mesmo em meio a pandemia da Covid-19 foi em Wuhan na China (Lima Junior, 2020), ou seja, ponto central da doença, onde as pessoas foram aconselhadas a seguirem ativas, mesmo em suas casas, ressaltando assim, a grande importância do exercício feito em casa ou ao ar livre como maneira de lidar com as consequências físicas e mentais impostas pela pandemia.

Com isso, presente estudo mostrou a associação entre duas variáveis apenas por meio dos questionários TFEQ-R21 e IPAQ, sendo elas o descontrole alimentar em relação a atividade física e da restrição cognitiva em relação a atividade física, quando avaliadas as subescalas do comportamento alimentar e a prática de atividade física respectivamente. 
Bacharelado em Nutrição da UninCor e iniciação à pesquisa: Com a palavra os nossos estudantes

A relação do sedentarismo associado ao descontrole alimentar por ser justificado por muitos fatores, (Gonsalves \& Cristina, 2020) nos mostra que no Brasil, os indivíduos andam cada dia mais estressados, uma vez que não detém conhecimentos para enfrentar as adversidades atribuídas ao cotidiano. Dessa forma, as pesquisas que compreendem o estresse como forma de associação, estimam os efeitos do corpo e mente e também, maneiras que estão relacionadas a qualidade de vida das pessoas.

O descontrole alimentar por sua vez tem uma correlação com o baixo nível de atividade física, pois pessoas com esse tipo de problema dificilmente fazem atividades físicas regularmente, pelo contrário, como nos mostra (Funcionários et al., 2019), quando analisamos os níveis de atividade física verificamos uma associação negativa ou seja, quanto maior o nível de atividade física, menor a prevalência da obesidade e dificilmente existirá uma quadro de descontrole alimentar associado.

Entretanto, fatores como as mudanças do humor também podem ser antecedentes no que diz respeito a um consumo exagerado de alimentos. A principal consequência do descontrole alimentar é o aumento do peso e consequentemente, da gordura corporal (Three et al., 2011).

A relação entre prática de atividade física e a restrição cognitiva pode ser compreendida por uma maneira abrupta encontrada pelas pessoas de tentar reduzir o seu peso. Conforme (Teixeira et al., 2014), ter o objetivo de preservar ou até mesmo diminuir o peso, é normal se ter um padrão alimentar mais restrito por parte dessas pessoas. Desse modo, até controlam a vontade de comer, entretanto, quando estão emocionalmente abalados, tendem a comer de forma exagerada.

Essa condição que está cada vez mais presente na sociedade como um todo, ainda mais com a alta valorização do corpo perfeito, principalmente pelo público feminino o que reflete principalmente nas academias, onde a adesão a dietas restritivas cresce cada vez mais, assim como a utilização de suplementos 
alimentares com o objetivo de reduzir ou aumentar o peso ou até mesmo a meIhorar a performance física. Desse modo, o público de maior relevância em relação a tais medidas são aqueles que praticam atividades físicas (Ramos, 2021).

\section{CONCLUSÃO}

De acordo com o presente trabalho, foi possível observar que a influência dos problemas psicológicos e suas respectivas consequências negativas que são acarretadas por eles na vida das pessoas, sobretudo durante a pandemia da COVID-19, não tiveram grandes impactos como se imaginava, o que veio a ser confirmado por muitos se manterem ativos fisicamente, entretanto, o que só poderia vir a ser confirmado com um estudo posterior assim que acabasse a pandemia.

Foi observado que o descontrole alimentar está intimamente associado a uma baixa prática de atividade física pelo fato dos indivíduos quando não estão bem se preocuparem mais com o seu bem-estar emocional comendo coisas não saudáveis muitas vezes, e não com a saúde nesses momentos, porém, podendo ocasionar quadros de severas restrições alimentares também em sua minoria.

\section{REFERÊNCIAS}

AQUINO, E. M. L. et al. Social distancing measures to control the COVID-19 pandemic: Potential impacts and challenges in Brazil. Ciencia e Saude Coletiva, v. 25, p. 2423-2446, 2020.

BARBOSA, Carla Ramirez Albuquerque. Estudo sobre o comportamento alimentar durante a pandemia de COVID-19. 2021.

BEECHING, N. J.; FLETCHER, T. E.; FOWLER, R. Doença do coronavírus. BMJ, Best Practice, v. 2019, p. Beeching, N. J., Fletcher, T. E., Fowler, R. (20, 2020.

BEZERRA, A. C. V. et al. Factors associated with people's behavior in social isolation during the covid-19 pandemic. Ciencia e Saude Coletiva, v. 25, p. 24112421, 2020. 
Bacharelado em Nutrição da UninCor e iniciação à pesquisa: Com a palavra os nossos estudantes

BICALHO, E.; VIEIRA, B. Avaliação do consumo alimentar durante o covid-19. Jim, v. 1, n. 2, p. 029-041, 2020.

BIAGIO, Leonardo Domingos; MOREIRA, Priscila; AMARAL, Cristiane Kovacs. Comportamento alimentar em obesos e sua correlação com o tratamento nutricional. Jornal Brasileiro de Psiquiatria, v. 69, p. 171-178, 2020.

CORREIA, Clarissa Cristina Gonçalves. Obesidade, práticas e sistemas de representações sociais. 2020.

BRASIL. Ministério da Saúde. Governo do Brasil. Brasil \#PÁTRIAVACINADA. Disponível em: < https://www.gov.br/saude/pt-br/vacinacao/>. Acesso em: 21/04/2021.

BRASIL. Ministério da Saúde: Guia Alimentar para a População Brasileira: promovendo a alimentação saudável. Normas e manuais técnicos: Brasilia, 2014.

DA CRUZ LEÃO, Gabrielle; DE SALES FERREIRA, José Carlos. Nutrição e mudanças alimentares em meio a pandemia COVID-19. Research, Society and Development, v. 10, n. 7, p. e11610716602-e11610716602, 2021.

DE ASSIS CAMPOS, Maria Teresa; CECÍLIO, Mariana Silva; PENAFORTE, Fernanda Rodrigues. Corpo-vitrine, ser mulher e saúde: produção de sentidos nas capas da Revista Boa Forma. DEMETRA: Alimentação, Nutrição \& Saúde, v. 11, n. 3, p. 611-628, 2016.

DE PAULA WERNECK, Gabriella; DE OLIVEIRA, Diana Ramos. Autoestima e Estereótipos do Comer Emocional. Revista Psicologia e Saúde, p. 117-130, 2021.

FARIA, Alceu Luiz; DE ALMEIDA, Simone Gonçalves; RAMOS, Theo Moraes. Impactos e consequências das dietas da moda e da suplementação no comportamento alimentar. Research, Society and Development, v. 10, n. 10, p. e441101019089- e441101019089, 2021.

DE SOUSA, Lailson Oliveira et al. Alimentação e imunidade: o papel dos alimentos na redução das complicações causadas pelo Covid-19. Brazilian Journal of Development, v. 7, n. 4, p. 38795-38805, 2021. 
Bacharelado em Nutrição da UninCor e iniciação à pesquisa: Com a palavra os nossos estudantes

DE SOUSA, Rosa Maria Antunes. Alimentação, Compras públicas e Desenvolvimento sustentável: O Caso Das Escolas. 2019. Tese de Doutorado. Universidade de Lisboa (Portugal).

DE SOUZA LIMA, R.; FERREIRA NETO, J. A.; PEREIRA FARIAS, R. DE C. Alimentação, Comida E Cultura: O Exercício Da Comensalidade. DEMETRA: Alimentação, Nutrição \& Saúde, v. 10, n. 3, p. 507-522, 2015.

DE SOUZA, M. C.; GRAÇA, R. L. Nível de atividade física de praticantes de exercício físico do sul de santa catarina durante a pandemia do covid-19. Trabalho de Conclusão de Curso (Graduação em Educação Física Bacharel) - Universidade do Sul de Santa Caratina - UNISUL., p. 1-17, 2020.

DOS REIS VERTICCHIO, D. V; DE MELO VERTICCHIO, N. Os impactos do isolamento social sobre as mudanças no comportamento alimentar e ganho de peso durante a pandemia do COVID-19 em Belo Horizonte e região metropolitana, Estado de Minas Gerais, Brasil. Research, Society and Development, v. 9, n. 9, p. e460997206-e460997206, 2020.

DURÃES, S. A. Implicações da Pandemia da Covid-19 nos Hábitos Alimentares Implications of the covid-19 pandemic in food habits. p. 1-20, 2020.

FARIAS, E. DOS S. et al. Effects of programmed physical activity on body composition in post-pubertal schoolchildren. Jornal de Pediatria (Versão em Português), v. 91, n. 2, p. 122-129, 2015.

FÁTIMA, M. DE; MOREIRA, U. A. 123 4. v. 24, n. 3, p. 283-299, 2020.

FERREIRA, P. D. A. A. et al. Caracterização do comportamento alimentar e estado nutricional de adultos. Motricidade, v. 14, n. 1, p. 252-258, 2018.

FONTELLES, M. J.; SIMÕES. G.; FARIAS, S. H.; FONTELLES, R. G. S. Metodologia da pesquisa científica: diretrizes para a elaboração de um protocolo de pesquisa. Revista Paraense de Medicina, v. 23, n. 3, p. 1-8,2009.

GARCIA, L. P.; DUARTE, E. Intervenções não farmacológicas para o enfrentamento à epidemia da COVID-19 no Brasil. Epidemiologia e servicos de saude : revista do Sistema Unico de Saude do Brasil, v. 29, n. 2, p. e2020222, 2020. 
Bacharelado em Nutrição da UninCor e iniciação à pesquisa: Com a palavra os nossos estudantes

JAIME, Patricia Constante et al. Um olhar sobre a agenda de alimentação e nutrição nos trinta anos do Sistema Único de Saúde. Ciência \& Saúde Coletiva, v. 23, p. 1829-1836, 2018.

JUNIOR, Luiz Cezar Lima. Alimentação saudável e exercícios físicos em meio à pandemia da COVID-19. Boletim de Conjuntura (BOCA), v. 3, n. 9, p. 33-41, 2020.

LIRA, Sandra Machado et al. Comportamento alimentar em estudantes da saúde na cidade de Quixadá, CE. Brazilian Journal of Health Review, v. 3, n. 3, p. 48644875, 2020.

JUSTO, G. F. A percepção do nutricionista sobre os hábitos alimentares de pacientes em trabalho "home office" durante a pandemia da Covid-19: um relato de experiência. The Journal of the Food and Culture of the Americas, v. 2, n. 2, p. $245-251,2020$.

LIMA, M. R. DA S.; SOARES, A. C. N. Alimentação saudável em tempos de COVID-19:o que eu preciso saber? Brazilian Journal of Health Review, v. 3, n. 3, p. 3980-3992, 2020.

MALTA, D. C. et al. A pandemia da COVID-19 e as mudanças no estilo de vida dos brasileiros adultos: um estudo transversal, 2020. Epidemiologia e servicos de saude : revista do Sistema Unico de Saude do Brasil, v. 29, n. 4, p. e2020407, 2020a.

MALTA, D. C. et al. Distanciamento social, sentimento de tristeza e estilos de vida da população brasileira durante a pandemia de COVID-19. Saúde em Debate, p. 1-22, 2020b.

MARCONI, M. A.; LAKATOS, E. M.; Fundamentos de metodologia científica. 5. ed. São Paulo: Atlas S.A. 2003.

MOURA, A. NAVA, A. Comer emocional: uma análise através de uma visão comportamental. Trabalho de conclusão de curso (Tcc) Nutrição - Uniceub faculdade de ciências da educação e saúde curso de nutrição - Centro Universitário de Brasília. Brasília, p.24, 2020. 
NATACCI, Lara Cristiane; FERREIRA JÚNIOR, Mario. The three factor eating questionnaire-R21: tradução para o português e aplicação em mulheres brasileiras. Revista de Nutrição, v. 24, p. 383-394, 2011

OLIVEIRA, T. C.; ABRANCHES, M. V.; LANA, R. M. Food (in)security in Brazil in the context of the SARS-CoV-2 pandemic. Cadernos de Saude Publica, v. 36, n. 4, 2020.

PEREIRA, M.D. et al. A pandemia de COVID-19, o isolamento social, consequências na saúde mental e estratégias de enfrentamento: uma revisão integrativa. Research, Society and Development, v. 9, n. 7, p. e652974548-e652974548, 2020.

SANTOS, C. D. C. et al. a Influência Da Televisão Nos Hábitos, Costumes E Comportamento Alimentar. Cogitare Enfermagem, v. 17, n. 1, p. 65-71, 2012.

SANTOS, LAS.; O corpo, o comer e a comida: um estudo sobre as práticas corporais e alimentares no mundo contemporâneo [online]. Salvador: EDUFBA, 2008. Disponível em:<https://static.scielo.org/scielobooks/38m/pdf/santos-9788523209087.pdf >. Acesso em: 21/04/2021.

VIEIRA, Tamires Quadros; BERLEZE, Kally Janaina. Relação entre o estado nutricional e o comportamento alimentar dos funcionários de uma escola estadual de Gravataí. RBONE- Revista Brasileira De Obesidade, Nutrição E Emagrecimento, v. 13, n. 79, p. 457-463, 2019.

VIEIRA, Thiago Sarmento et al. Fatores de risco modificáveis para doenças crônicas não transmissíveis em docentes que atuam na educação brasileira. 2021. 
doi 10.48209/978-65-89949-72-2

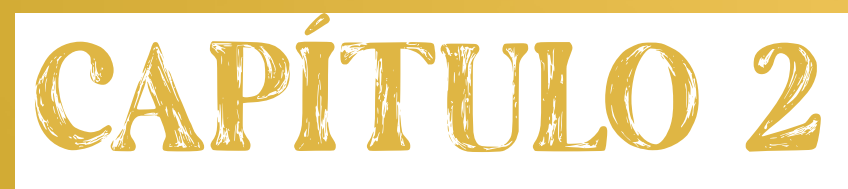

ANATISE DO

CONHIFCMMENTO

DE INDIVIDUOS DIABÉHCOS

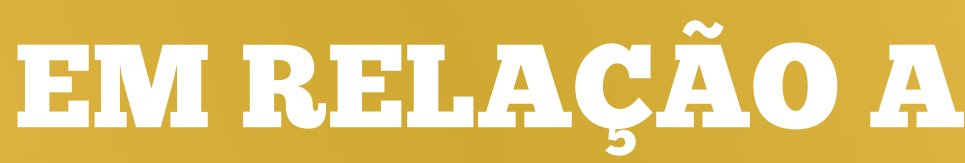
ATMMIENHACANO

Pâmela Rodrigues Inácio Brunna Sullara Vilela Rodrigues 


\section{INTRODUÇÃO}

De acordo com a Sociedade Brasileira de Diabetes (SBD, 2019), o diabetes mellitus é definido como um distúrbio metabólico, no qual o corpo não produz insulina ou não consegueutilizar adequadamente a quantidade que produz, levando à hiperglicemia, e quando não tratado adequadamente, pode ocasionar complicações graves a longo prazo. Pode ser classificado como diabetes mellitus tipo 1 , diabetes mellitus tipo 2 , diabetes mellitus gestacional ou outros tipos específicos.

O diabetes mellitus tipo 2 é frequentemente diagnosticado em adultos com idade acima dos 40 anos, mas atualmente também tem acometido crianças, adolescentes e jovens em razão de maus hábitos alimentares (RUBIRA et al., 2021). Uma alimentação equilibrada é a melhor estratégia para o controle de doenças crônicas não transmissíveis, assim, torna-se essencial para os indivíduos diabéticos, porque auxilia no controle glicêmico e previne futuras complicações (BERTONHI; DIAS, 2018). Porém a falta de conhecimento e as crenças acerca da alimentação podem influenciar na adesão ao tratamento nutricional.

Diante disso, tem-se o problema de pesquisa: Qual o conhecimento em Nutrição osindivíduos adultos portadores de diabetes mellitus tipo 2 possuem? E assim, temos a hipóteseque os portadores de diabetes mellitus tipo 2 não tem conhecimento adequado em Nutrição ea que os portadores de diabetes mellitus tipo 2 possuem conhecimento adequado em Nutrição. $O$ presente trabalho tem como objetivo analisar o conhecimento em nutrição de indivíduos adultos portadores de diabetes mellitus tipo 2 , a fim de identificar a presença decrenças disfuncionais em relação à alimentação nos participantes, conhecer as formas detratamento do DM2 utilizadas pelos participantes e promover e entregar material de educação em diabetes para os indivíduos estudados.

É de suma importância considerar que a alimentação auxilia na melhoria da qualidade de vida, seja de indivíduos saudáveis ou de indivíduos que apresen- 
tam algum tipo de patologia, e assim é possível observar que a prática educativa e informativa entre indivíduo e profissionais da saúde se apresenta com grande importância para promover o autocuidado e, consequentemente, ter uma vida saudável. $\mathrm{O}$ intuito desse trabalho se deve ao fato de que muitos indivíduos diabéticos não recebem orientações adequadas após o diagnóstico da patologia e, quando não há orientações corretas sobre a mesma, podem apresentar algumas percepções equivocadas em relação aos alimentos.

\section{REFERENCIAL TEÓRICO}

\subsection{Diabetes Mellitus}

O Diabetes Mellitus é caracterizado pela hiperglicemia no sangue, isso ocorre devido àfalta ou insuficiência da insulina, que é o hormônio produzido no pâncreas e responsável pela entrada da glicose nas células. É considerado uma doença crônica não transmissível e atinge proporções epidêmicas, com estimativa de 415 milhões de portadores de DM mundialmente (FERREIRA et al., 2020).

Os tipos de classificações para o diabetes mellitus são: DM tipo 1, DM tipo 2, DM gestacional e outros tipos específicos. O tipo 1, também é chamado de insulinodependente, é uma doença autoimune, onde a produção de insulina é insuficiente e o indivíduo necessita de doses diárias de insulina. No tipo 2, também chamado de diabetes do adulto, o organismo não produz insulina suficiente ou não consegue usá-la adequadamente. Já o DM gestacionalocorre durante a gravidez, geralmente diagnosticado no segundo ou terceiro trimestres da gestação, quando há um nível elevado de glicose no sangue e, em geral, isso se normalizada depois do parto (SBD, 2019).

É uma das doenças crônicas mais incidentes no mundo, e vem se tornando um problema de saúde pública, apresentando grandes taxas de morbidade e mortalidade. Estima- se que $90 \%$ dos casos diagnosticados com diabetes mellitus seja do tipo 2, uma doença pouco sintomática, o que pode dificultar que ela 
seja diagnosticada precocemente e assim não há um controle glicêmico logo no início da doença, devido à falta de conhecimento e de acompanhamento de um profissional especializado (LEITE et al., 2019).

O DM2 é diagnosticado com maior frequência em adultos com idade mais avançada, geralmente depois dos 40 anos. Mas também tem acometido crianças, adolescentes e adultos jovens em razão de hábitos alimentares e estilos de vida que favorecem a obesidade (RUBIRAet al., 2021).

\subsubsection{Diagnóstico}

Os critérios para o diagnóstico do diabetes são: glicemia em jejum igual ou superior a $126 \mathrm{mg} / \mathrm{dL}$, glicemia igual ou superior a $200 \mathrm{mg} / \mathrm{dL} 2$ horas após sobrecarga de $75 \mathrm{~g}$ de glicoseou glicemia casual igual ou superior a $200 \mathrm{mg} / \mathrm{dL}$. Costuma ser uma doença assintomática ou oligossintomática, mas, com menor frequência, pode apresentar poliúria, polidipsia, polifagiae perda de peso repentina (SBD, 2019).

Para confirmação do diagnóstico de DM é preciso repetir os exames alterados, de preferência que seja o mesmo exame alterado em segunda amostra de sangue, na ausência de sintomas inequívocos de hiperglicemia. Quando há a presença de sintomas, o indivíduo deve ser submetido à dosagem de glicemia ao acaso e independente do jejum, se o resultado for maior ou igual a $200 \mathrm{mg} / \mathrm{dL}$, não é necessário realizar segunda dosagem (SBD, 2019).

\subsubsection{Tratamento nutricional}

O tratamento nutricional busca os seguintes objetivos: Fornecer energia através dos nutrientes; manter e/ou reduzir a glicemia próxima aos níveis adequados; respeitar a quantidade e qualidade de alimentos e os horários das refeições para manter um bom controle glicêmico; atingir os níveis adequados de lipídeos séricos, reduzindo o risco de morbidades associadas, como as DCVs; 
promover educação em DM, de modo que o diabético entenda que é importante a mudança de hábitos para melhora na qualidade de vida, construindo conhecimentos, levando o indivíduo a compreender melhor a doença e escolher uma solução apropriada para o autocuidado, prevenção e tratamento das complicações agudas e crônicas (BERTONHI; DIAS, 2018).

É fundamental a fidelidade do paciente ao tratamento, ele precisa ser orientado a seguir tanto a prescrição de medicamentos como as mudanças de estilo de vida, que compreendem o seguimento do planejamento específico e a prática de atividade física. No caso do uso de medicamentos existem duas opções de tratamento: os antidiabéticos orais e a insulinoterapia. Os antidiabéticos orais são medicamentos que têm por finalidade diminuir a glicemia plasmática e mantê-la em níveis normais, são indicados para pessoas com DM2 quando só o planejamento alimentar e a atividade física não são capazes de obter o controle glicêmico adequado. Já a insulinoterapia é a aplicação intramuscular de insulina exógena diária para manutenção dos níveis glicêmicos. Pode ser prescrita tanto para diabéticos com DM1 quanto para os diabéticos que possuem DM2 e que tenham resistência insulínica ou comprometimento nas células beta (BERTONHI; DIAS, 2018).

A prática regular de atividades físicas também deve fazer parte do tratamento, pois auxilia na busca por um estilo de vida mais saudável e é preventivo a outros tipos de doenças, além do diabetes (SILVA et al., 2018).

\subsubsection{Recomendações nutricionais para DM2}

Manter uma alimentação equilibrada é a melhor estratégia para promoção da saúde e controle das doenças crônicas não transmissíveis. Assim, uma dieta adequada e saudável é essencial para as pessoas diagnosticadas com DM, porque auxiliam no controle glicêmico e previnem futuras complicações (BERTONHI; DIAS, 2018). 
Bacharelado em Nutrição da UninCor e iniciação à pesquisa: Com a palavra os nossos estudantes

É recomendado que o planejamento alimentar do indivíduo diabético seja fracionado em seis refeições diárias, sendo três refeições principais e três lanches. Realizar as refeições em horários regulares ajuda a evitar hipoglicemia, já que o nível anormalmente baixo de glicose no sangue pode ocorrer quando há um longo período sem se alimentar (SBD, 2014).

É preciso que o planejamento seja individualizado de acordo com idade, sexo, estado fisiológico, estado metabólico, prática de atividade física, doenças intercorrentes, hábitos socioculturais e socioeconômicos (LIMA et al., 2013).

A recomendação de carboidratos deve compor de 45 a $60 \%$ do valor energético totalda dieta, podendo variar de acordo com a individualidade. É necessário dar preferências para alimentos ricos em fibras. As fibras auxiliam no controle da glicemia após as refeições,porque retarda o esvaziamento gástrico e interfere na difusão da glicose no intestino delgado, além de ajudar a reduzir os níveis de colesterol no sangue e auxiliar no controle do peso, devido ao seu efeito de saciedade. Novas evidencias sugere que o consumo de fibra dietética total seja de $20 \mathrm{~g}$ para cada $1.000 \mathrm{kcal}$ ingeridas por homens e mulheres que possuem DM2 (SBD, 2019).

As proteínas devem compor 15 a $20 \%$ do valor energético total da dieta para portadores da doença com função renal normal, dando preferência a proteínas de alto valor biológico e fácil digestibilidade (SBD, 2019).

A ingestão de lipídios deve ser individualizada, considerando as condições clínicas, o perfil lipídico e a presença de fatores de risco cardiometabólico. É recomendado entre $25 \%$ a $35 \%$ do valor energético total da dieta, sendo que o consumo de ácidos graxos saturados deve ser controlado, uma vez que se associa a maior mortalidade entre indivíduos com diabetes eos ácidos graxos trans devem ser evitados em razão da sua forte associação a DCVs e seu impacto sobre a mortalidade cardiovascular (SBD, 2019). 


\subsubsection{Complicações}

Quando não há um controle glicêmico adequado, inúmeras complicações podem surgirna vida do diabético, estas podem ser classificadas em agudas e crônicas. As complicações agudas são aquelas que se instalam rapidamente, como a hipoglicemia e a cetoacidose diabética. Já as complicações crônicas se destacam por ter um alto índice de morbimortalidade, sendo que as mais frequentes são retinopatia diabética, nefropatia diabética, neuropatia diabética, doenças cardiovasculares e úlceras do pé diabético (BERTONHI; DIAS, 2018).

Uma das complicações mais graves do DM é o Pé Diabético, que pode ocasionar em amputação de membros inferiores ou parte deles. Geralmente ocorre por lesões nos pés desencadeadas devido a alterações vasculares periféricas e/ou neurológicas. Outros fatores que contribuem para o desenvolvimento do pé diabético são: tempo de diagnóstico, obesidade, HAS e falta de hábitos de higiene e cuidados com os pés (FONSECA; RACHED, 2019).

\subsection{Adesão ao tratamento}

O conhecimento nutricional e a condição de saúde, já é base para que o paciente diabético procure se auto cuidar e manter o controle da glicemia, mas isso, necessariamente, não são suficientes para garantir um comportamento alimentar adequado (MAEYAMA et al., 2020).

A OMS define a adesão como o grau em que o comportamento de uma pessoa tomar uma medicação, seguir uma dieta e/ou mudar o seu estilo de vida corresponde às recomendações estabelecidas com um profissional da saúde. Alguns fatores se destacam por afetar essa adesão, são eles: o paciente; o tipo de tratamento; a doença; os aspectos socioeconômicos e o sistema de saúde (FERNANDES; CALADO; ARAUJO, 2018). 
Além de identificar as barreiras que dificultam a adesão ao tratamento, também é necessário compreender o motivo de sua ocorrência. Essa compreensão permitirá que oprofissional da saúde aborde práticas mais eficazes e que possam, de fato, ajudar o paciente a conviver melhor com a doença (TESTON; SALES; MARQUES, 2017).

Estudos mostram que muitos diabéticos não aderem a todo o tratamento recomendado por a doença exigir cuidados especiais e mudanças de comportamento. Alguns dos fatores que explicam esse fato são orientações com baixa efetividade, dificuldades de adaptação aos horários para as refeições, evitar os doces e modificar o preparo das refeições (RAMOS; PRETTO; KLUG, 2014).

\subsection{Dificuldades no controle glicêmico}

Quando o paciente diagnosticado com a doença recebe recomendações restritivasocasionada pela dieta isso acaba interferindo no prazer do ato de comer e na interação social que a alimentação proporciona. A ingestão dos alimentos é bastante complexa e não significa apenas a ingestão de nutrientes e função fisiológica de saciar a fome, mas envolve uma série de significados, emoções e sentimentos, além de valores culturais específicos (MAEYAMA etal., 2020).

O sucesso no tratamento também depende do apoio da família e dos amigos para que odiabético entenda que é possível levar uma vida saudável e normal mesmo sendo portador de uma doença crônica. Deste modo, o portador de diabetes se sensibiliza sobre a necessidadedos cuidados em saúde como forma de melhorar sua vida cotidiana, trazendo mudanças também para aqueles que estão inseridos no mesmo meio social, evitando assim que indivíduos com predisposição ao diabetes desenvolvam também a doença (COSTA et al., 2011).

Dentre os aspectos dificultosos para o seguimento da dieta, também está a condição financeira do usuário ou da sua família, já que alguns produtos dietéti- 
cos têm um custo mais elevado e nem todos os pacientes conseguem adquiri-los. Alguns diabéticos relatam ter essa dificuldade para variarem sua dieta e/ou usarem alimentos diet e light (RAMOS; PRETTO; KLUG, 2014).

\subsection{Crenças}

As crenças em saúde têm sido consideradas como moduladoras e mediadoras decomportamentos em saúde, e um dos motivos que contribui para esse comportamento que pode comprometer o controle da doença é a percepção distorcida de fragilidade e risco. Uma atitude preventiva envolve a expectativa de resultados benéficos que podem conduzir odesenvolvimento de crenças disfuncionais, produzindo padrões de pensamentos automáticos negativos que geralmente são emocionalmente aflitivos e impedem que indivíduo atinja suas metas (OHNO; COUTO; TEODORO, 2018).

A predominância de crenças na vida do diabético pode indicar baixa adesão ao tratamento nutricional, quando as mudanças necessárias que precisam ser abordadas corretamente estão acontecendo de formas inadequadas. Muitas vezes o paciente não é chamado para o diálogo, para a tomada de decisão no processo de atendimento em saúde e acaba não recebendo orientações adequadas, seguindo assim suas crenças adquiridas durante avida acerca de como deve ser a alimentação do diabético (PONTIERI; BACHION, 2010).

\subsection{Importância da educação alimentar e nutricional}

A educação alimentar e nutricional é considerada um objeto de ação multiprofissional, intersetorial e transdisciplinar, onde o conhecimento e aprendizado é contínuo e permanente, busca promover autonomia aos hábitos saudáveis através de abordagens nutricionais e problematizadoras, assim é considerada uma peça importante na promoção de hábitos alimentares saudáveis, tornando-se uma estratégia indispensável no âmbito da alimentação e nutrição (FRANÇA; CARVALHO, 2017). 
A educação alimentar e nutricional em diabetes deve dar a possibilidade de o paciente tomar as decisões corretas por si só e auxiliar no desenvolvimento dessas habilidades, com a incorporação das ferramentas necessárias para atingir as metas estabelecidas em cada etapa dotratamento (FERREIRA et al., 2020).

Os profissionais de saúde, em geral, têm a missão de promover a meIhor adesão ao tratamento por meio de estímulos a mudanças comportamentais imprescindíveis ao efetivo controle da doença. Pesquisas demonstram que as orientações sobre autocuidado recebidas pelo paciente, as mudanças no estilo de vida e as habilidades para executá-las implicam prevenção e redução de complicações (NETA; SILVA; SILVA, 2015).

A relação entre profissional e paciente, as condições de tratamento, acesso ao serviço de saúde e ao medicamento prescrito são uns dos fatores que determinam a adesão do pacientea uma terapia. Deste modo, a linguagem do profissional deve ser clara e adequada aos objetivos, interesses e dificuldades dos indivíduos na hora de planejar atividades educativas (VIEIRA; MATIAS; QUEIROZ, 2021).

\section{MATERIAIS E MÉTODOS}

\subsection{Delineamento e amostra}

Esta é uma pesquisa transversal, de natureza aplicada, abordagem quali-quantitativa e objetivo descritivo. A escolha desse tipo de abordagem surgiu do interesse de obter percepções e informações pessoais de cada indivíduo.

A amostra de estudo é constituída por 50 indivíduos, de ambos os sexos, com idade entre 19 e 59 anos, diagnosticados com Diabetes Mellitus tipo 2. Participaram aqueles que estavam de acordo com a pesquisa, assinando o Termo de Consentimento Livre e Esclarecido - TCLE (APÊNDICE A). O presente estudo foi submetido ao Comitê de Ética em Pesquisa daUniversidade Vale do Rio Verde - UninCor, sob o parecer $n^{\circ} 5.011 .956$. O presente estudo respeita os preceitos estabelecidos pela Resolução 466/12 de dezembro de 2012. Foram respeitados 
os princípios de anonimato, privacidade e sigilo profissional. Os participantes do estudo tiveram autonomia para decidir se aceitava ou não participar. Foi possível deixar de participar da pesquisa em qualquer momento, caso desejasse, sem sofrer penalidade alguma. A pesquisa respeitou os aspectos culturais, sociais e familiares do entrevistado.

\subsection{Procedimentos de coleta}

Para avaliar o conhecimento sobre nutrição no DM2 e a presença de crenças disfuncionais relacionadas à alimentação foi utilizado o questionário desenvolvido por Fontinele et al., (2007), com 13 questões (ANEXO 1). A primeira parte é composta por questões objetivas, com duas opções, verdadeiro ou falso. As questões foram baseadas noteste utilizado em um estudo que avaliou o conhecimento sobre alimentação em nutrição entrepacientes com DM2.

Para caracterizar a amostra foi aplicado um breve questionário socioeconômico, desenvolvido pelo autor, com informações como idade, gênero, escolaridade e tempo de diagnóstico (APÊNDICE B).

Com o objetivo de compreender os tratamentos utilizados pelos voluntários para DM2 foi aplicado um questionário, elaborado pelo autor (APÊNDICE C), com informações sobre tratamento medicamentoso, alimentar ou prática de atividade física. Todos os questionários foram aplicados de forma on-line, através do Google Forms. O link para acesso aos questionários foi enviado via aplicativos de mensagens, como o WhatsApp e Instagram.

Os dados foram coletados no período de setembro a outubro de 2021. Após a coleta, as respostas foram avaliadas e, foi disponibilizado um e-book informativo (APÊNDICE D), elaborado pelo autor, com informações sobre alimentação e dicas importantes sobre o tratamento da patologia. Para a criação de todo o designer do e-book foi utilizado o aplicativo Canva, que é uma plataforma de design gráfico que permite aos usuários criar gráficos de mídia social, apresentações, pôsteres e outros conteúdos visuais (CANVA COMPANY PROFILE. CRAFT. 2020). 


\subsection{Análise estatística}

Os dados coletados foram tabulados em planilhas no Programa Microsoft Office Excele posteriormente analisados com auxílio do software IBM SPSS Statistical Package for the Social Sciences (SPSS), versão 20.0, sendo consideradas significativas as associações que apresentaram $(p<0,05)$.

\section{RESULTADOS}

Foram avaliados 50 indivíduos, sendo $80 \%$ do sexo feminino e $20 \%$ do sexo masculino, com idade média de 50,08 \pm 7,42 anos. Apresentaram renda média de $\mathrm{R} \$ 4.366,67$ e tempo de diagnóstico em média de $6 \pm 5,24$ anos. Já em relação ao nível de escolaridade, a maioria dos participantes possui ensino superior e ensino médio completo.

Tabela 1: Escolaridade dos participantes da pesquisa

\begin{tabular}{|c|c|c|}
\hline Grau de Escolaridade & $\mathrm{n}$ & $\%$ \\
\hline Analfabeto & 1 & 2 \\
\hline Fundamental Incompleto & 4 & 8 \\
\hline Fundamental Completo & 4 & 8 \\
\hline Ensino Médio Incompleto & 3 & 6 \\
\hline Ensino Médio Completo & 13 & 26 \\
\hline Superior & 25 & 50 \\
\hline & 50 & 100 \\
\hline
\end{tabular}

Fonte: O autor (2021).

Acerca dos métodos utilizados para o tratamento do DM2, a maioria dos participantes fazemo uso de insulina ou outro medicamento (88\%) e tem o hábito de praticar atividades físicas (70\%), como mostra a tabela 2. A atividade física mais citada foi a caminhada, praticada por 18 indivíduos (36\%), enquanto 15 dos outros participantes (30\%) não pratica atividade física regularmente. A figura 1 mostra as demais atividades físicas citadas pelos participantes. 
Bacharelado em Nutrição da UninCor e iniciação à pesquisa: Com a palavra os nossos estudantes

Tabela 2: Métodos utilizados para o tratamento

\begin{tabular}{|c|c|c|c|c|}
\hline \multicolumn{2}{|c|}{$\begin{array}{c}\text { Insulina e/ou } \\
\text { medicamento }\end{array}$} & \multicolumn{2}{c|}{$\begin{array}{c}\text { Prática de atividade } \\
\text { física }\end{array}$} \\
\hline \multirow{2}{*}{ Sim } & 44 & 88 & 35 & 70 \\
\hline Não & 6 & 12 & 15 & 30 \\
\hline & 50 & 100 & 50 & 100 \\
\hline
\end{tabular}

Fonte: O autor (2021).

Figura 1: Atividades físicas praticadas

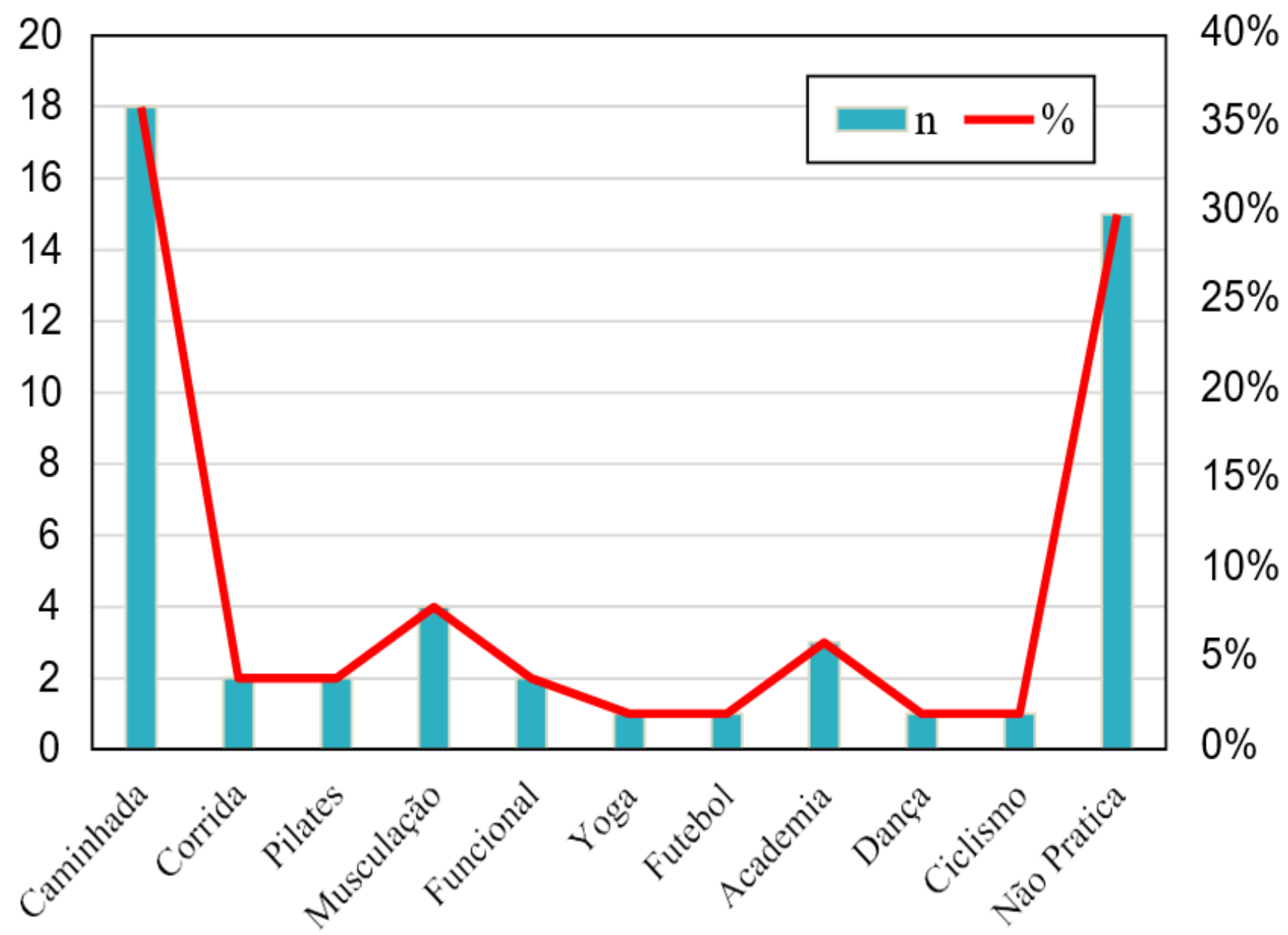

Fonte: O autor (2021). 
Dos participantes, 84\% afirmam ter uma alimentação balanceada, sendo $40 \%$ com acompanhamento profissional e $44 \%$ sem acompanhamento profissional. Os demais (16\%) não utilizam a alimentação balanceada como forma de tratamento.

Tabela 3: Sobre os cuidados com a alimentação

\begin{tabular}{|c|c|c|}
\hline Alimentação & $n$ & $\%$ \\
\hline Acompanhamento com nutricionista & 20 & 40 \\
\hline Sem acompanhamento com nutricionista & 22 & 44 \\
\hline Não possuem preocupação com a alimentação & 8 & 16 \\
\hline & 50 & 100 \\
\hline
\end{tabular}

Fonte: O autor (2021).

Ao avaliar as treze questões contidas no questionário de avaliação do conhecimento sobre nutrição, o número médio de acertos foi de 10,54 questões, representando $81 \%$ de respostas corretas, sendo considerado que a amostra apresenta bom conhecimento do assunto. As questões com maior percentual de acerto foram a questão 9 "A casca e o bagaço dos vegetais e frutas são fontes de fibras", e a questão 13 "Controlar o peso melhora a taxa de açúcar no sangue", ambas com percentual de acerto de $100 \%$. As questões que apresentaram menor percentual de acerto foram a questão 7, que abordava sobre "Óleos vegetais (Ex: óleo de soja e de girassol) não contêm colesterol" apresentando 36\% de acertos, seguida pela questão 3 "As pessoas com diabetes podem comer todos os tipos de frutas" apresentando $54 \%$ de acertos. 
Figura 2: Número de acertos das questões

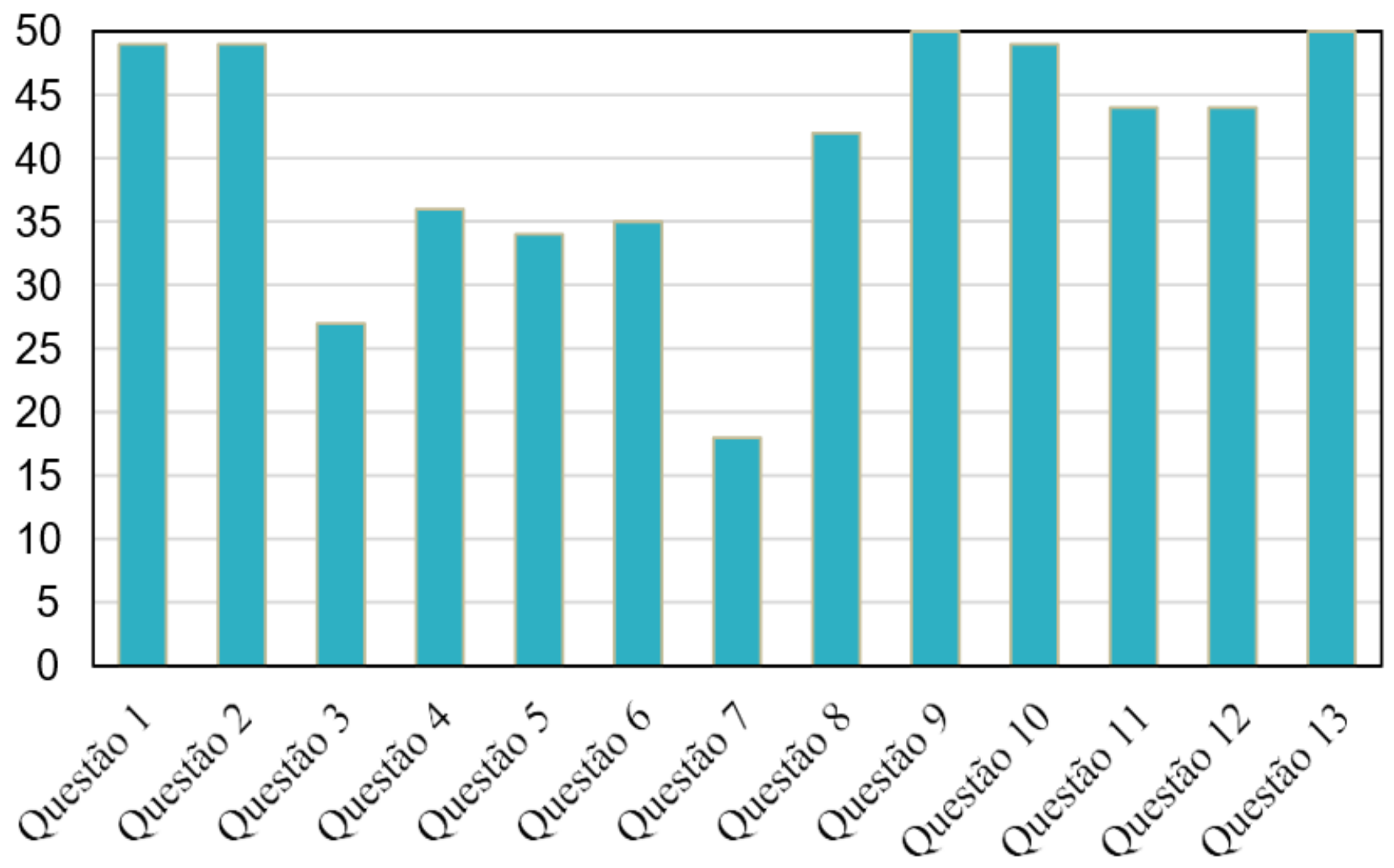

Fonte: O autor (2021).

A quantidade de acertos em cada questão foi classificada de acordo com a tabela

Tabela 4: Classificação das notas

\begin{tabular}{|c|c|c|c|}
\hline Intervalo & Classificação & Frequência & $\%$ \\
\hline $0-4$ & Insuficiente & 0 & 0 \\
\hline $5-7$ & Regular & 0 & 0 \\
\hline $8-9$ & Bom & 20 & 40 \\
\hline $10-13$ & Muito bom & 30 & 60 \\
\hline
\end{tabular}

Fonte: O autor (2021).

Com relação aos acertos, foi possível observar um nível de significância maior apenas para sexo $(p+=0,030)$. Verificou-se que não houve significância estatística quando avaliados segundo escolaridade, alimentação balanceada e prática de atividade física. 
Bacharelado em Nutrição da UninCor e iniciação à pesquisa: Com a palavra os nossos estudantes

\section{DISCUSSÃO}

Dos 50 participantes diabéticos investigados, a maioria é do sexo feminino, característica semelhante à de outros estudos. A tendência das mulheres de buscar mais informações sobre saúde, de acordo com Levorato et al., (2014), pode justificar o maior número de usuários deste sexo no presente estudo.

O nível de escolaridade pode ser considerado fator determinante para o desenvolvimento de conhecimento e habilidades para o autocuidado do diabetes (IQUIZE et al., 2017). Quando os indivíduos apresentam baixa escolaridade, consequentemente há dificuldade em ler e compreender condutas terapêuticas, trazendo, assim, riscos à saúde (SANTOS, et al., 2020). Nesta pesquisa, a maior parte dos participantes possuem ensino médio completo, apresentando maior conhecimento das questões abordadas, segundo Sardinha, Souza e Cavalcante (2018) o conhecimento é um fator de grande influência para a tomada de decisão em relação à própria saúde e predisposição a mudanças de comportamento. $A$ maior proporção dos participantes encontrou-se na faixa etária de 45 a 60 anos. A frequência de diabetes aumenta significativamente em indivíduos com idade mais avançada, como mostra os estudos de Iser et al. (2015) e de Flor e Campos (2017). É importante destacar que o DM vem se elevando também em populações jovens, assim como o desenvolvimento da síndrome metabólica, associada a doenças cardiovasculares na vida adulta (MALTA et al., 2019).

No que diz respeito ao tempo da doença, os usuários com DM2 apresentaram uma média de 6 anos de diagnóstico. Esperava-se que aqueles que apresentassem mais tempo de doença acertassem mais questões, porém, no estudo publicado por Santos et al. (2020) podemos ver que o tempo diagnóstico não garante que o usuário tenha conhecimento sobre a patologia, muito menos, meIhoria quanto à prontidão para o autocuidado.

Diversos métodos são utilizados para o tratamento do DM2, os mais comuns são: medicamentoso, incluindo a insulina, prática de atividade física e alimenta- 
Bacharelado em Nutrição da UninCor e iniciação à pesquisa: Com a palavra os nossos estudantes

ção equilibrada. Foipossível observar no presente estudo que grande parte faz o uso de insulina e/ou outro medicamento, onde o mais citado foi o medicamento oral, e $70 \%$ relataram praticar exercício físico, resultado que difere ao encontrado em um estudo realizado por Freitas EF et al. (2015) em que apenas $20 \%$ dos indivíduos analisados relataram praticar exercícios físicos regularmente.

Segundo a Sociedade Brasileira de Diabetes, a prática de exercício físico é determinante na prevenção do diabetes mellitus tipo 2 e no tratamento de todas as formas de diabetes mellitus. Representa uma estratégia de intervenção não medicamentosa capaz de gerar efeitos positivos, que incluem a redução do risco cardiovascular, promoção do bem-estare controle do peso corporal e da adiposidade. Fatores como a resistência à prática do exercício, o medo da hipoglicemia e a incapacidade de controlar a terapia nutricional e farmacológica são algumas das restrições que afastam os indivíduos com diabetes da prática esportiva (SBD, 2019), porém a atividade física traz qualidade de vida para estas pessoas e deve ser realizada de forma regular, sistemática e com o acompanhamento de um profissional de educação física, indicando a intensidade e o melhor exercício (KOLCHRAIBER et al., 2018).

O exercício físico mais citado foi a caminhada, esse tipo de atividade promove efeitos agudos importantes na modulação da glicose, adrenalina e noradrenalina, controle da pressão arterial, melhora na qualidade do sono, e em longo prazo melhora função cardiovascular, habilidades cognitivas e redução de doenças metabólicas. Assim, considerando os benefícios mencionados, é visto como um importante modelo de exercício para a população em geral (OJAet al., 2018).

Foi possível observar que a maioria das pessoas informou ter cuidados com a alimentação, a maior parte diz ser sem acompanhamento com nutricionista. Os participantes que não fazem acompanhamento com um profissional apresentaram o mesmo nível de conhecimento dos que fazem acompanhamento, diferenciando do estudo de Fontinele et al., (2007), que diz que pacientes que receberam orientação de nutricionista e equipe de saúde contendo nutricionista 
Bacharelado em Nutrição da UninCor e iniciação à pesquisa: Com a palavra os nossos estudantes

acertaram mais questões comparadas àqueles que tiveram orientações sem nutricionista.

Avaliando o conhecimento sobre nutrição dos participantes, verificou-se que grande parte não acertou a questão que falava sobre os óleos vegetais não conterem colesterol, resultado semelhante ao de Anunciação et al., 2012. O fator que pode explicar a quantidade deerros é que a população, em geral, pode ter dificuldade em diferenciar colesterol de outros tipos de gorduras (saturada e insaturada) (OLIVEIRA et al., 2017).

Grande maioria também errou ao responder à questão que dizia que diabéticos podem comer todos os tipos de frutas, marcando essa afirmativa como falsa. Muitos indivíduos diagnosticados com diabetes possuem uma interpretação errônea em relação ao açúcar presente nas frutas, assim evitando consumi-las. No entanto, a frutose que é o açúcar presente nas frutas, é diferente ao adicionado a doces e bebidas açucaradas, além das frutas conterem fibras em sua composição, que torna lento o processo de absorção no organismo, evitando picos glicêmicos (VARGAS et al., 2020).

A quantidade de acerto foi satisfatória para a questão que discutia sobre a casca e o bagaço dos vegetais e frutas serem fontes de fibras. A adesão de uma alimentação saudável, atendendo as recomendações de fibras alimentares representa benefícios para os portadores de diabetes (AMORIM et al., 2021). Outra questão que apresentou grande número de acertos foi sobre o controle de peso e a melhora da taxa de açúcar no sangue. Associando o excesso de peso como um fator de risco à incidência de diabetes, as Diretrizes da Sociedade Brasileira de Diabetes recomendam a redução e/ou controle de peso como uma das principais estratégias detratamento não farmacológico da doença (SBD, 2019).

Ao analisar a quantidade de acertos das questões propostas, foi possível constatar que $81 \%$ das mesmas apresentam respostas consideradas corretas, de tal maneira pode-se considerar que os participantes do estudo demonstram ter bom conhecimento do assunto, diferindo-se do estudo de SILVA-OLIVEIRA et 
al., (2018) que operou com o mesmo questionário de avaliação sobre alimentação em pacientes com diagnóstico de DM tipo 2 assistidos na UBS Bom pastor, em São João Del - Rei, MG, o qual obteve resultado em que a média de acertos das questões foi considerada baixa.

É importante ressaltar que a oferta de ações educativas é capaz de auxiliar a aquisição de práticas para o controle do diabetes e o seu autocuidado, além de sensificar sobre os riscos das complicações. A falta de conhecimento pode refletir em pouca importância para buscar os cuidados necessários, ou seja, descuido (SANTOS et al., 2020).

Considerando que o conhecimento nutricional se apresenta importante para auxiliar o indivíduo a buscar hábitos alimentares saudáveis e obter um bom controle metabólico da doença, o e-book elaborado pelo autor e disponibilizado para os participantes deste estudo é um material que pode auxiliar os diabéticos a aderir mudanças no comportamento alimentar e buscar atividades de autocuidado de maneira consciente.

\section{CONCLUSÃO}

Tendo em vista os aspectos observados, entende-se que a amostra analisada neste estudo apresenta resultado considerado satisfatório quanto ao conhecimento sobre alimentação para um indivíduo com diabetes mellitus. Não foi possível encontrar correlação significativa entre escolaridade, alimentação balanceada e prática de atividade física, porém, pelo fato de a coleta de dados realizar-se de maneira remota, em consequência, pode-se concluir que as pessoas que utilizam a internet possuem mais conhecimento em geral, assim, não foi possível abordar um número maior de pessoas com baixa escolaridade e possivelmente menor conhecimento. É sugerido que outros autores ampliem a amostra para este tipo de população e, deste modo, busquem mais resultados para o entendimento do assunto. 
Bacharelado em Nutrição da UninCor e iniciação à pesquisa: Com a palavra os nossos estudantes

Contudo, conhecer sobre alimentação é fator determinante na prevenção e, principalmente no tratamento do diabetes mellitus. A avaliação do conhecimento dos diabéticos sobre alimentação deve ser a primeira etapa para a tomada de decisão no direcionamento de ações e programas de educação em saúde.

\section{REFERENCIAS}

ANUNCIAÇÃO, Pamella Cristine et al. Avaliação do conhecimento sobre alimentação antese após intervenção nutricional entre diabéticos tipo 2. Revista Baiana de Saúde Pública, [S.L.], v. 36, n. 4, p. 986-1001, out./dez. 2012. Secretaria da Saude do Estado da Bahia. http://dx.doi.org/10.22278/2318-2660.2012.v36. n4.a793.

AMORIM, Gláucia et al. Conhecimento de indivíduos diabéticos sobre os benefícios e fontes da fibra alimentar. Saúde Coletiva (Barueri), [S.L.], v. 11, n. 60, p. 4640-4653, 5 jan. 2021. MPM Comunicaçao. http://dx.doi.org/10.36489/saudecoletiva.2021v11i60p4640-4653.

BERTONHI, Laura Gonçalves; DIAS, Juliana Chioda Ribeiro. Diabetes mellitus tipo 2: aspectos clínicos, tratamento e conduta dietoterápica. Revista Ciências Nutricionais Online,Bebedouro, v. 2, n. 2, p. 1-10, 2018.

BORBA, Anna Karla de Oliveira Tito et al. Conhecimento sobre o diabetes e atitude para o autocuidado de idosos na atenção primária à saúde. Ciência \& Saúde Coletiva, [S.L.], v. 24, n.1, p. 125-136, jan. 2019. FapUNIFESP (SciELO). http:// dx.doi.org/10.1590/1413-81232018241.35052016.

COSTA, Jorge de Assis et al. Promoção da saúde e diabetes: discutindo a adesão e a motivação de indivíduos diabéticos participantes de programas de saúde. Ciênc. saúdecoletiva, Rio de Janeiro, v. 16, n. 3, p. 2001-2009, Mar. 2011.

FERNANDES, Larissa de Siqueira; CALADO, Camila; ARAUJO, Claudia Affonso Silva. Redes sociais e práticas em saúde: influência de uma comunidade online de diabetes na adesão ao tratamento. Ciência \& Saúde Coletiva, [S.L.], v. 23, n. 10 , p. 3357-3368, out. 2018.

FERREIRA, Daniel Leonardo et al. O efeito da orientação preventiva multiprofissional em pacientes com diabetes mellitus. Revista Eletrônica Acervo Saúde, [S.L.], v. 1, n. 45, p. 1-11, 2 abr. 2020. 
Bacharelado em Nutrição da UninCor e iniciação à pesquisa: Com a palavra os nossos estudantes

FONSECA, Kathlem Pereira; RACHED, Chennyfer Dobbins Abi. COMPLICAÇÕES DO DIABETES MELLITUS. International Journal of Health Management, v. 1, p. 1-13, 2019.

FLOR, Luisa Sorio; CAMPOS, Monica Rodrigues. Prevalência de diabetes mellitus e fatoresassociados na população adulta brasileira: evidências de um inquérito de base populacional. Revista Brasileira de Epidemiologia, [S.L.], v. 20, n. 1, p. 16-29, mar. 2017.FapUNIFESP (SciELO). http://dx.doi.org/10.1590/19805497201700010002.

FONTINELE, Rejane da Silveira Santos et al. Avaliação do conhecimento sobre alimentaçãoentre pacientes com diabetes tipo 2. Com Ciências Saúde. V. 18 n. 3, p. 197-206, 2007.

FRANÇA, Camila de Jesus; CARVALHO, Vivian Carla Honorato dos Santos de. Estratégias de educação alimentar e nutricional na Atenção Primária à Saúde: uma revisão de literatura. Saúde em Debate, [S.L.], v. 41, n. 114, p. 932-948, set. 2017.

FREITAS EF, et al. Prevalência de diabetes mellitus e prática de exercício em indivíduos queprocuraram atendimento na estratégia saúde da família de Viçosa/ MG. Revista da EducaçãoFísica/UEM,2015; 26(4): 549-556.

IQUIZE, Roxana Claudia Condori et al. Educational practices in diabetic patient and perspective of health professional: a systematic review. Jornal Brasileiro de Nefrologia, [S.L.], v. 39, n. 2, p. 197-203, 2017. FapUNIFESP (SciELO). http:// dx.doi.org/10.5935/0101-2800.20170034.

ISER, Betine Pinto Moehlecke et al. Prevalência de diabetes autorreferido no Brasil: resultados da pesquisa nacional de saúde 2013. Epidemiologia e Serviços de Saúde, [S.L.], v. 24, n. 2, p. 305-314, jun. 2015. FapUNIFESP (SciELO). http://dx.doi.org/10.5123/s1679-49742015000200013.

KOLCHRAIBER, Flávia Cristiane et al. Nível de atividade física em pessoas com diabetes mellitus tipo 2. Revista Cuidarte, [S.L.], v. 9, n. 2, p. 2105-16, 4 maio 2018. Universidad de Santander - UDES. http://dx.doi.org/10.15649/cuidarte. v9i2.512. 
Bacharelado em Nutrição da UninCor e iniciação à pesquisa: Com a palavra os nossos estudantes

LIMA, Amanda Azevedo et al. A importância da dieta hospitalar na recuperação de pacientes diabéticos. Cadernos de Graduação - Ciências Biológicas e da Saúde, v. 1, n.16, p. 47-56,2013.

LEITE, Camila Palacio et al. Comportamento Alimentar de Portadores de Diabetes Mellitus tipo II atendidos em uma UBS / Food Behavior of Diabetes Mellitus type II carriers at a UBS. Id On Line Revista de Psicologia, [S.L.], v. 13, n. 47, p. 911-923, 28 out. 2019 Lepidus Tecnologia.

LEVORATO, Cleice Daiana; MELLO, Luane Marques de; SILVA, Anderson Soares da; NUNES, Altacílio Aparecido. Fatores associados à procura por serviços de saúde numa perspectiva relacional de gênero. Ciência \& Saúde Coletiva, [S.L.], v. 19, n. 4, p. 1263-1274, abr. 2014. FapUNIFESP (SciELO). http://dx.doi. org/10.1590/1413-81232014194.01242013.

MAEYAMA, Marcos Aurélio; POLLHEIM, Lielli Carine Fischer; WIPPEL, Mariellen; MACHADO, Carolina; VEIGA, Mariana Vilela. Aspectos relacionados à dificuldade do controle glicêmico em pacientes com Diabetes Mellitus tipo 2 na Atenção Básica. Brazilian Journal Of Development, [S.L.], v. 6, n. 7, p. 47352-47369, 2020.

MALTA, Deborah Carvalho et al. Prevalência de diabetes mellitus determinada pela hemoglobina glicada na população adulta brasileira, Pesquisa Nacional de Saúde. Revista Brasileira de Epidemiologia, [S.L.], v. 22, n. 2, p. 1-10, 2019. FapUNIFESP (SciELO). http://dx.doi.org/10.1590/1980-549720190006.supl.2.

MIELCZARSKI, Rodrigo Geisler; COSTA, Juvenal Soares Dias da; OLINTO, Maria Teresa Anselmo. Epidemiologia e organização de serviços de saúde: diabetes mellitus numa comunidade de porto alegre. Ciência \& Saúde Coletiva, [S.L.], v. 17, n. 1, p. 71-78, jan. 2012. FapUNIFESP (SciELO). http://dx.doi.org/10.1590/ s1413-81232012000100010.

NETA, Dinah Sá Rezende; SILVA, Ana Roberta Vilarouca da; SILVA, Grazielle Roberta Freitas da. Adesão das pessoas com diabetes mellitus ao autocuidado com os pés. Revista Brasileira de Enfermagem, [S.L.], v. 68, n. 1, p. 111-116, fev. 2015.

OHNO, Priscilla Moreira; COUTO, Luanna Dhannat Santos; TEODORO, Maycoln LeôniMartins. Cognições Disfuncionais em Pessoas com Diabetes Mellitus: Uma Revisão da Literatura. Revista E-Psi, [S. L.], v. 8, n. 1, p. 20-34, 2018. 
OJA, Pekka et al. Effects of frequency, intensity, duration and volume of walking interventions on CVD risk factors: a systematic review and meta-regression analysis ofrandomised controlled trials among inactive healthy adults. British Journal Of Sports Medicine, [S.L.], v. 52, n. 12, p. 769-775, 31 maio 2018. BMJ. http:// dx.doi.org/10.1136/bjsports-2017-098558.

OLIVEIRA, Mariana Cadaval de et al. Conhecimentos sobre fontes alimentares de colesterolentre usuários de uma clínica escola de nutrição. Revista Brasileira de Obesidade, Nutrição eEmagrecimento, São Paulo, v.11. n.66. p.459-468. Nov./Dez. 2017.

OLIVEIRA, Paula Barbosa de; FRANCO, Laércio Joel. Consumo de adoçantes e produtos dietéticos por indivíduos com diabetes melito tipo 2, atendidos pelo Sistema Único de Saúdeem Ribeirão Preto, SP. Arq Bras Endocrinol Metab, São Paulo, v. 54, n. 5, p. 455-462, 2010.

PONTIERI, Flavia Melo; BACHION, Maria Márcia. Crenças de pacientes diabéticos acerca da terapia nutricional e sua influência na adesão ao tratamento. Ciênc. saúde coletiva, Rio deJaneiro, v. 15, n. 1, p. 151-160, jan. 2010.

RAMOS, Camila Irigonhé; PRETTO, Alessandra Doumid Borges; KLUG, Jocilei Carniato. Adesão às recomendações alimentares de usuários portadores de diabetes tipo 2. Demetra: Alimentação, Nutrição \& Saúde, [S.L.], v. 9, n. 2, p. 561575, 13 out. 2014. Universidade deEstado do Rio de Janeiro.

RUBIRA, Letiane de Oliveira et al. The men and woman's selfcare with type 2 Diabetes Mellitus. Research, Society and Development, v. 10, n. 1, e27210111675, 2021 (CC BY 4.0) |ISSN 2525-3409 | DOI: http://dx.doi.org/10.33448/rsd-v10i1.11675

SANTOS, Aliny de Lima et al. Complicações microvasculares em diabéticos Tipo 2 e fatoresassociados: inquérito telefônico de morbidade autorreferida. Ciênc. saúde coletiva, Rio de Janeiro, v. 20, n. 3, p. 761-770, Mar. 2015.

SANTOS, Ivânia Maria dos et al. Conhecimento e atitudes de usuários com Diabetes Mellitusem uma unidade de ambulatório especializada. Revista Eletrônica Acervo Saúde, [S.L.], v. 12, n. 12, p. 01-10, 11 set. 2020. Revista EletronicaAcervo Saude. http://dx.doi.org/10.25248/reas.e4148.2020. 
Bacharelado em Nutrição da UninCor e iniciação à pesquisa: Com a palavra os nossos estudantes

SARDINHA, Ana Helia de Lima; SOUZA, Aline Santos; CAVALCANTE, Marcos Ronad Mota. Atitudes relacionadas ao diabetes mellitus: uma revisão integrativa / Attitudes related todiabetes mellitus: an integrative review. Nursing, São Paulo, v. 238 , n. 21 , p. $2080-2084$, mar. 2018.

SILVA, Rafael Santos da et al. A IMPORTÂNCIA DAATIVIDADE FÍSICA EM IDOSOS COM DIABETES: revisão bibliográfica. Revista Diálogos em Saúde, [S.L], v. 1, n. 2, p.144-158, dez 2018.

SILVA-OLIVEIRA, Eliane Moreto et al. Avaliação do conhecimento sobre alimentação entrepacientes com diabetes mellitus tipo 2 atendidos na Unidade Básica de Saúde Bom Pastor emSão João del-Rei - MG. Educação e Saúde: fundamentos e desafios, [S.I.], v. 1, n. 2, p. 49-63, nov. 2018. ISSN 2594-3820.

SOCIEDADE BRASILEIRA DE DIABETES. Diretrizes da Sociedade Brasileira de Diabetes 2013-2014. São Paulo, 2014.

SOCIEDADE BRASILEIRA DE DIABETES. Diretrizes da Sociedade Brasileira de Diabetes, 2019-2020. São Paulo, 2019.

VARGAS, Larissa Barz de et al. Avaliação da qualidade da dieta de pacientes diabéticos tipo 2 atendidos no Ambulatório de Nutrição da Universidade Federal de Pelotas. Revista da Associação Brasileira de Nutrição - Rasbran, [S.L.], v. 12, n. 1, p. 52-70, 23 nov. 2020.

Revista da Associacao Brasileira de Nutricao - RASBRAN. http://dx.doi. org/10.47320/rasbran.2021.1484.

VIEIRA, Mariana de Sousa Nunes; MATIAS, Karolina Kellen; QUEIROZ, Maria Goretti. Educação em saúde na rede municipal de saúde: práticas de nutricionistas. Ciência \& SaúdeColetiva, [S.L.], v. 26, n. 2, p. 455-464, fev. 2021. FapUNIFESP (SciELO).

TESTON, Elen Ferraz; SALES, Catarina Aparecida; MARCON, Sonia Silva. Perspectivas deindivíduos com diabetes sobre autocuidado: contribuições para assistência. Esc. Anna Nery, Rio de Janeiro, v. 21, n. 2, e20170043, 2017. 
doi $10.48209 / 978-65-89949-172-3$
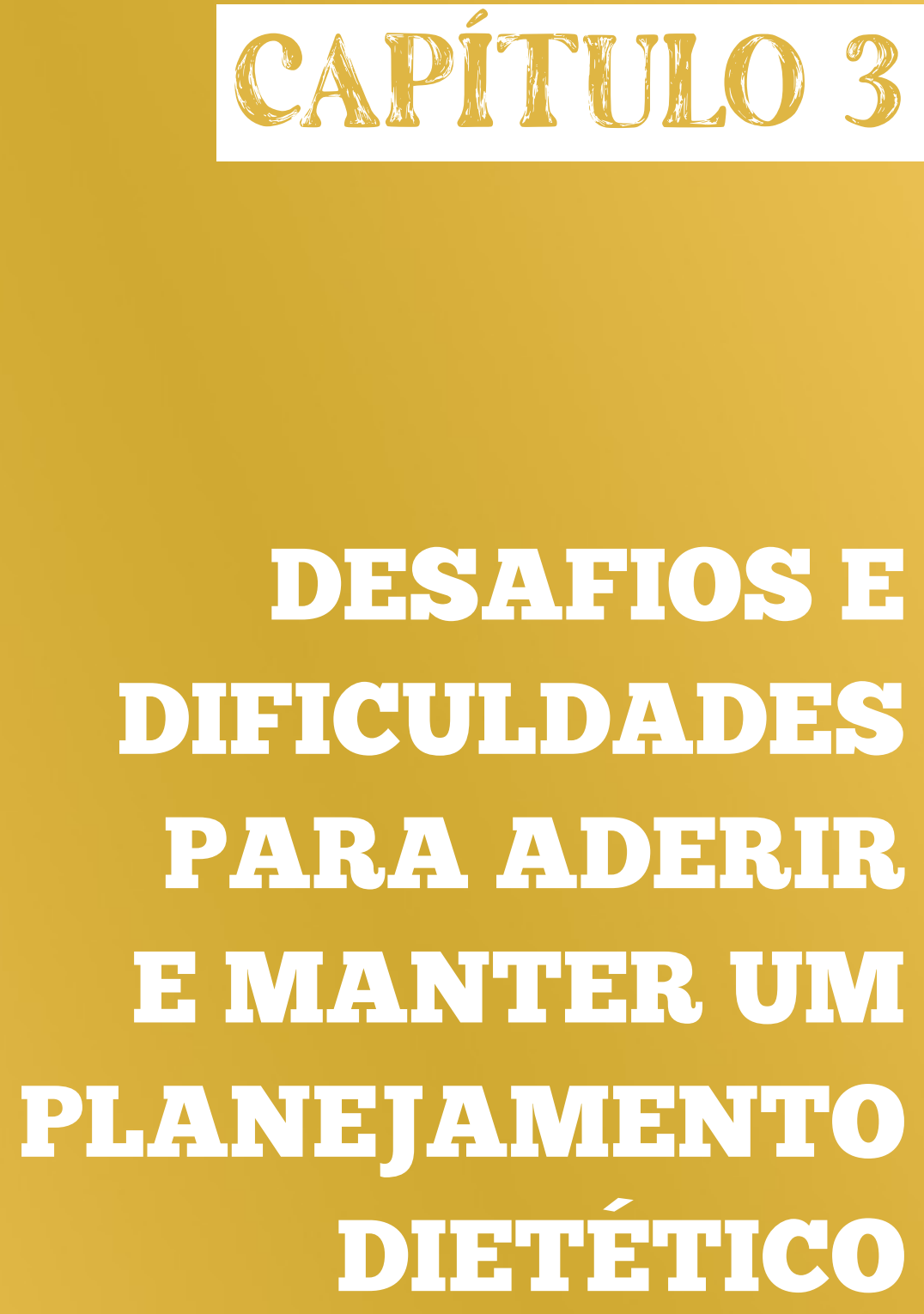

Luís Gustavo Borges Brunna Sullara Vilela Rodrigues 


\section{INTRODUÇÃO}

Os planejamentos dietéticos seguem um padrão alimentar que é adotado de forma continua com fins terapêuticos ou estéticos para emagrecimento, proporcionando mudanças no estilo de vida de indivíduos. Atualmente, os planejamentos tem sido relacionados de forma errônea a condutas inadequadas e a processos alimentares restritivos para perda de peso corporal. As práticas indiscriminadas de dietas restritivas limitam a busca pela qualidade de vida e geram um comportamento alimentar extremamente cansativo e conflituoso com o próprio corpo, além de não atenderem as necessidades nutricionais adequadas ao organismo do indivíduo (ESTRELA et al., 2017; MARANGONI e MANIGLIA, 2017; ALVARES e SANTANA, 2020; MACHADO et al., 2021).

Perante ao exposto, este trabalho apresenta a seguinte questão problema: Quais os desafios e dificuldades para adesão e manutenção de um planejamento dietético em adultos de diferentes classes econômicas? Nessa linha de raciocínio, elencamos as seguintes hipóteses: os adultos das classes D-E, apresentam dificuldades com relação ao custo do planejamento dietético; os adultos da classe A apresentam dificuldades em acompanhar e manter o ritmo do planejamento dietético; os adultos das classes C1 e C2, não apresentam dificuldades com relação ao custo do planejamento dietético, no entanto, não recebem orientações nutricionais adequadas e apresentam dificuldades para escolha dos alimentos; os adultos das classes B1 e B2, apresentam dificuldades em encontrar tempo para preparação dos alimentos.

Diante disso, o presente trabalho apresenta e tem como objetivo geral, identificar os principais desafios e dificuldades para a adesão e manutenção de um planejamento dietético em adultos de diferentes classes econômicas, além de apresentar também os objetivos específicos de identificar a classe econômica 
dos participantes da pesquisa; avaliar se há associação entre classe econômica e os desafios relatados; e realizar orientação sobre alimentação saudável para os adultos participantes.

Desta forma, se torna de suma importância compreender que o processo por detrás dos planejamentos dietéticos não acontece de forma simples e identificar os possíveis fatores que prejudicam a adesão e manutenção desses planejamentos dietéticos, que se diferem de acordo com as classes socioeconômicas dos indivíduos e como isso interfere na percepção sobre alimentação saudável, é de extrema relevância para o campo da área de nutrição (ALVARENGA et al., 2015; ESTRELA et al., 2017).

\section{REFERENCIAL TEÓRICO}

\subsection{Aspectos da adesão ao planejamento dietético}

Os planejamentos dietéticos são considerados um padrão alimentar que segue algumas recomendações nutricionais de acordo com as necessidades essenciais do indivíduo, onde propõem mudanças para fins terapêuticos quando se faz necessária ou para emagrecimento e hipertrofia. Os planejamentos se encontram em um grande conjunto, mediados e relacionados com os hábitos e estilo de vida, mas que atualmente, são vistos de forma inadequada e errônea (ALVARENGA et al., 2015; MARANGONI e MANIGLIA, 2017).

Estudos relatam que há uma certa insatisfação por restringir alguns alimentos e uma pressão interna em ignorar as tentações que surgem em diversos momentos, principalmente os de ansiedade e estresse. São diversos os desafios e dificuldades que cercam a adesão e manutenção dos planejamentos dietéticos e se faz muito necessária uma contemplação das individualidades e necessidades de cada paciente para identificação desses fatores (BORBA et al., 2018; TORRES, 2019). 


\subsubsection{Dietas restritivas}

A divulgação de dietas milagrosas que idealizam e enaltecem os corpos perfeitos, incentivam significantemente a busca pelo padrão de beleza ideal que é traçada como um objetivo. Diversos indivíduos desejam a aparência perfeita e agradável aos olhos da sociedade e optam por dietas restritivas visto que, independentemente dos meios, o emagrecimento dessa forma apresenta resultado rápido e em um curto período de tempo (MARANGONI e MANIGLIA, 2017).

Estas dietas tendem a ser extremamente restritivas e com grande diminuição da necessidade energética total e consequentemente, da redução da necessidade metabólica basal. A manutenção das dietas restritivas se torna inviável a longo prazo e alguns estudos apontam que o reganho do peso perdido é rápido e além disso, uma série de sinais clínicos decorrentes das deficiências de nutrientes aparecem. Entre eles estão: queda de cabelo frequente; fadiga excessiva; constipação intestinal ou diarreia; desregulação hormonal; anemia; aumento do colesterol sanguíneo; hipertensão arterial e dentre outros (MACHADO et al., 2021).

A atitude diante da dieta restritiva refere-se a perda de peso, no entanto, a diferença energética calórica causada pela restrição alimentar está intimamente associada com o grande aumento das ocorrências de doenças crônicas não transmissíveis, onde as práticas alimentares restritas e as oscilações de peso durante toda a vida, se tornam prejudiciais à saúde do indivíduo como fator de risco que leva ao desenvolvimento de doenças como a obesidade; diabetes; hipertensão e doenças cardiovasculares (SOIHET e SILVA, 2019).

\subsubsection{Custo financeiro}

A alimentação é complexa e as escolhas alimentares são influenciadas diariamente por muitos fatores, em especial os econômicos. No que diz respeito ao consumo de alimentos, a renda do indivíduo e outras questões financeiras, exer- 
cem grande influência visto que, com menores níveis de renda salarial, menor é a aquisição e acesso a alimentos considerados "saudáveis", como produtos de hortifruti, alimentos integrais, carnes magras e laticínios (BORGES et al., 2015).

O estado de saúde das famílias ou de indivíduos que se encaixam em classes de renda baixa, apresenta índices ínferos. Considerando a economia brasileira, famílias de baixa renda precisariam dobrar suas despesas com alimentação para atingir de fato uma alimentação adequada, comprometendo quase toda a renda familiar financeira. A falta de recursos financeiros para uma alimentação adequada, leva a um consumo intenso de ultraprocessados com custo mais acessíveis e que preencham a fome (OLIVEIRA e SILVA, 2014; ANDRADE et al., 2014; BORGES et al., 2015).

\subsubsection{Disponibilidade de tempo}

A falta de disponibilidade de tempo e planejamento pessoal para realizar a aquisição e preparo dos alimentos, é um forte fator do insucesso de uma má alimentação, onde há constante fracionamento de refeições diárias ou como na maioria dos casos, uma procura por refeições rápidas altamente calóricas e de fácil acesso. Esses fatores contribuem para resultados insatisfatórios que ocasionam em baixa autoestima e desencorajamento para com as mudanças de hábitos alimentares (OLIVEIRA e SILVA, 2014; TORRES, 2019).

A gestão do tempo não se caracteriza em apenas ter horas livres e sim pela organização do tempo disposto para comer e realizar refeições confortáveis, junto dos familiares. Desse modo, reavaliar a forma como o tempo tem sido aproveitado é de suma importância, visto que as práticas alimentares padronizadas requerem um maior tempo e atenção, para se ofertar uma maior qualidade de vida para si mesmo (SOUZA e NUNES 2014; BRASIL, 2014). 


\subsection{Relações interpessoais na mudança de hábitos}

Os indivíduos ao violarem ou cometerem falhas no seguimento da alimentação são desvalorizados e o prazer em obter relações sociais, é quase que nulo visto que, a falta de práticas saudáveis em relação ao peso corporal é entendida como algo ruim e discriminativo pelo meio social. Nesse mesmo contexto, quem adere a uma melhor alimentação, tende a atrair olhares de julgamento que leva a um isolamento social intenso, cortando relações com pessoas próximas e familiares, pois as tentações são grandes (OLIVEIRA e SILVA, 2014; OBARA; VIVOLO; ALVARENGA, 2018; TORRES, 2019).

O corpo é a representação da identidade do indivíduo e nesse sentido, a idealização da imagem corporal com base nas relações interpessoais reduz a autoestima e acarreta em sentimentos indesejáveis como a supressão social. Em diversas relações é formada a ideia de que o companheiro quando magro, é mais bonito e atraente levando muitas mulheres e em alguns casos homens, a realizarem dietas insanas para perda de peso no qual a longo prazo, geram episódios compensatórios na comida e culpa por não conseguir manter uma dieta (CECILIO et al., 2014; OLIVEIRA e SILVA, 2014; ALVARES e SANTANA, 2020).

\subsection{O planejamento dietético no avançar da idade}

A atenção voltada para a alimentação no avançar da idade se dá em atender a demanda necessária para nutrir o corpo que vem envelhecendo ao longo dos anos. Fatores limitantes e decisivos são relacionados diretamente com a baixa adesão a uma alimentação no avançar da idade como: hábitos alimentares adquiridos por anos; limitações em função de patologias; menores condições de mobilidade; autonomia pessoal e financeira; alterações das funções mastigatórias e digestivas, dentre outras (KUWAE et al., 2015). 
A manutenção do corpo com condições de saúde tem como base uma boa alimentação e de modo geral, indivíduos com idade mais avançada ou com limitações funcionais, tendem a atrofiar os músculos mastigatórios, prejudicando a mastigação e ocasionando em distúrbios na alimentação. Para que um planejamento dietético seja de fato efetivo, necessita proporcionar uma alimentação prazerosa, específica para suprir as necessidades fisiológicas com todos os nutrientes essenciais e que se dê em conjunto com uma força muscular adequada, que permita morder e triturar os alimentos (SOUZA e NUNES, 2014; KUWAE et al., 2015; PETRY; LOPES; CASSOL, 2019).

\subsection{Nível educacional e sua relação com a alimentação}

A educação é um processo constante nos meios sociais, mas que se difere de acordo com as épocas. Estudos apontam que pessoas de baixo nível educacional se tornam bem mais suscetíveis interpretações totalmente equivocadas a respeito dos alimentos e nutrição e apresentam evidencias que o desenvolvimento de medidas de proteção a saúde é de grande importância para um melhor entendimento sobre alimentação. O nível educacional influencia diretamente na adoção de hábitos saudáveis e orientações de um planejamento dietético, onde o baixo nível de entendimento e compreensão se relaciona com baixas condições de qualidade de vida (MOURA e MASQUIO, 2014; ANDRADE et al., 2014; SOUZA e NUNES, 2014).

A educação em nutrição é um importante indicador de adesão, pois facilita o discernimento do indivíduo através de meios eficientes que trazem benefícios e qualidade de vida. O período de mudança se difere de uma pessoa pra outra e levar em consideração as peculiaridades de cada paciente faz com que a intervenção nutricional seja vista como uma prática educativa que inclui todas as crenças e outros aspectos específicos do indivíduo no plano, gerando conscientização a respeito da alimentação (ESTRELA et al., 2017; TORRES, 2019). 


\subsection{Alimentação diante da cultura e religião}

A religião é um indicador que contribui para a formação dos hábitos e na forma como as pessoas se alimentam, levando em consideração as diversas restrições religiosas como: uma grande variedade de carnes que são restritas para consumo; restrição de alimentos crus ou preparações que utilizam sangue; rituais que envolvam jejum em períodos determinados; alimentos que não podem ser consumidos em algum dia especifico da semana; mistura de carnes com laticínios em uma preparação; dias específicos para se abster de carne bovina e dentre muitas outas (CASTRO; BOTELHO; ANDRADE, 2017; AMORIM e DIAS, 2019).

O Indivíduo dentro da cultura, passa a constituir hábitos alimentares baseados no que se pode e no que gosta de comer, respeitando os rituais e costumes religiosos dentro da cultura local. Esses aspectos culturais e religiosos determinam as escolhas que vão se modificando com o tempo e precisam ser trabalhados de modo que, seja possível fornecer alimentação dentro do que a cultura permite, com prazer de preencher as necessidades do comer durante a vida (AMORIM e DIAS, 2019).

\subsection{Educação alimentar e nutricional}

A Educação Alimentar e Nutricional se firma no atendimento, com o profissional ao demonstrar um lado humano, manifestando empatia pelo o próximo e colocando ele em foco, onde compreende as suas limitações, preferencias relacionadas aos alimentos que vão desde a aparência até o sabor, associando essas questões com a sensação de prazer em se alimentar, resgatando na memória, lembranças agradáveis para com a comida, facilitando a escolha dos alimentos e uma nova percepção sobre a abordagem alimentar e seus conceitos (AQUINO e MACEDO, 2018). 
Ofertar assistência adequada em um atendimento nutricional, é o principal meio de promoção de hábitos que contribuem com uma melhor qualidade de vida. É importante compreender que constantemente, aspectos dificultadores influenciam os comportamentos dos indivíduos e a alimentação precisa ser compreendida de modo que, esses aspectos não determinem o consumo e nem afetem o paciente. Diante disso, a Educação Alimentar e Nutricional tem sido cada vez mais procurada para aconselhamento, onde o propósito é justamente reconsiderar conceitos sobre alimentação (AQUINO e MACEDO, 2018).

\section{MATERIAIS E MÉTODOS}

\subsection{Delineamento e amostra}

Este é um estudo transversal, de natureza aplicada, abordagem qualitativa e objetivo descritivo. O método de pesquisa foi o descritivo, com o objetivo de descrever os fatos comportamentais da amostra participante em relação aos planejamentos dietéticos, estabelecendo uma relação entre os fatores do tema analisado. A pesquisa descritiva deixa muito bem delineado o que é, além de abordar outros aspectos como: descrição, registro, análise e interpretação de fenômenos atuais (MARCONI e LAKATOS, 2017). A pesquisa foi com abordagem qualitativa, possibilitando um aprofundamento em relação a percepção e no comportamento dos participantes, garantindo que todos os tópicos essenciais sejam abordados. A pesquisa qualitativa traz um aprofundamento sobre determinado saber e uma percepção diante da vivencia, através de experiências (SAMPIERI e LÚCIO, 2013; MINAYO, 2014).

A amostra do estudo foi composta por 60 indivíduos, de ambos os sexos com idade entre 19 e 59 anos que já realizaram alguma intervenção para perda de peso. Participaram aqueles que estiveram de acordo com a pesquisa, assinando o Termo de Consentimento Livre e Esclarecido - TCLE (ANEXO 1). O presente estudo foi aprovado pelo Comitê de Ética em Pesquisa da Universidade Vale do Rio Verde - UninCor, sob o parecer $n^{\circ} 4.955 .526$. O presente estudo respeitou 
os preceitos estabelecidos pela Resolução 466/12 de dezembro de 2012. Foram respeitados os princípios de anonimato, privacidade e sigilo profissional. O participante do estudo teve autonomia para decidir se aceitava ou não participar do estudo. Poderia deixar de participar da pesquisa em qualquer momento, caso desejasse, sem sofrer penalidade alguma. As entrevistas tiveram início após a aprovação do projeto de pesquisa pelo Comitê de Ética em Pesquisa da Universidade Vale do Rio Verde - UninCor. A pesquisa respeitou os aspectos culturais, sociais e familiares do entrevistado.

\subsection{Procedimentos de coleta}

A coleta de dados foi realizada no período de agosto e setembro de 2021 , no qual os referidos questionários foram aplicados de forma individual e online. Para a avaliação das práticas alimentares e da identificação dos possíveis desafios e dificuldades dos participantes na adesão dos planejamentos dietéticos, foi utilizado um questionário com base nas práticas alimentares, desenvolvido por Miller (2016) (ANEXO 2), que leva em conta aspectos como adesão de dietas; desistências e satisfação de dietas; com um total de 48 perguntas, abordando questões como por exemplo quantas dietas o indivíduo já fez ao longo da sua vida, se a dieta é elaborada por um profissional habilitado, dentre outras.

Para a identificação da classe socioeconômica, foi utilizado o "Critério de Classificação Econômica Brasil” (ANEXO 3), que é um questionário com base no domicílio e leva em conta aspectos como estrutura física da residência; bens materiais para consumo e uso particular; escolaridade do chefe da família. A classificação se deu através de um sistema de pontos com variáveis que incluíram aspectos domiciliares. De acordo com a pontuação, os indivíduos foram classificados em 6 classes, sendo as classes: A, B1, B2, C1, C2 e D-E.

Com o objetivo de orientar os participantes sobre comportamento alimentar e adesão a mudanças de hábitos, foi criado um E-book (APÊNDICE 1) e dis- 
ponibilizado a todos que participaram da pesquisa, com o objetivo de abordar uma nova perspectiva sobre as dietas, de modo que, a necessidade da prática de dietas seja vista de uma nova forma. A estruturação do E-book apresenta os seguintes tópicos principais: 1. Introdução; 2. Desmistificando dietas; 3. Comer intuitivo; 4. Uma nova perspectiva e 5. Considerações finais.

\section{RESULTADOS}

Foram analisados 60 indivíduos, sendo $78,3 \%$ do sexo feminino e $21,7 \%$ do sexo masculino, com idade média de 32,50 \pm 8,22 anos. Na tabela 1 foram apresentados os dados relativos à classe econômica dos participantes do estudo.

Tabela 1 - Perfil sociodemográfico dos entrevistados.

\section{Classe Socioeconômica}

$\mathbf{N}^{\circ}$

15

10

19

09

06

01
$\%$ 25,0 16,7 31,6 15,0

Classe C2

Classe D-E

Fonte: Próprio autor (2021).

Quando questionados sobre suas práticas alimentares, a maior parte dos indivíduos relataram perceber uma certa necessidade de mudanças em sua alimentação, com grande parte dos indivíduos afirmando saber como realizar essas mudanças (tabela 2). Quanto aos tipos de mudanças, destacam-se: "comer menos"; "consumir mais verduras"; "tirar o carboidrato". 
Tabela 2 - Práticas alimentares de adultos de diferentes classes socioeconômicas.

\section{Perguntas}

1 - Você acha que precisa melhorar sua alimentação?

Sim

56

93,3

Não

04

6,7

2 - Você pretende mudar?

Sim

Não

Não responderam

03

5,00

3 - Caso sim, você sabe como fazer essa mudança?

$\operatorname{Sim}$

Não

07

Não responderam

26 43,3

Fonte: Próprio autor (2021).

Acerca da prática de dietas, todos os indivíduos participantes relataram ter praticado em algum momento ou estão praticando uma dieta. Cabe ressaltar que quando questionados sobre o objetivo com dietas, a perda de peso foi o objetivo mais relatado pelos participantes. Quase toda a amostra alegou acreditar nos efeitos das mesmas (tabela 3). Dentre os motivos listados, destaca-se: "sem uma dieta é impossível alcançar uma mudança corporal". 
Tabela 3 - Sobre a prática de dietas já realizadas ou atuais.

\begin{tabular}{|c|c|c|}
\hline Perguntas & $\mathbf{N}^{\circ}$ & $\%$ \\
\hline \multicolumn{3}{|l|}{1 - Você já fez dieta alguma vez? } \\
\hline Sim & 60 & 100 \\
\hline Não & 0 & 0 \\
\hline \multicolumn{3}{|l|}{2 - Caso sim, você sabe quantas? } \\
\hline Menos de 05 dietas & 30 & 50,0 \\
\hline Mais de 05 dietas & 05 & 45,0 \\
\hline Não souberam responder & 03 & 5,00 \\
\hline \multicolumn{3}{|l|}{3 - Qual era o seu objetivo com dietas? } \\
\hline Perda de peso & 49 & 81,7 \\
\hline Hipertrofia & 05 & 8,3 \\
\hline Outros objetivos & 06 & 10,0 \\
\hline \multicolumn{3}{|c|}{4 - Você acredita que dietas são capazes de trazer resultados? } \\
\hline Sim & 54 & 90,0 \\
\hline Não & 06 & 10,0 \\
\hline
\end{tabular}

Fonte: Próprio autor (2021).

Quanto ao período de prática de dietas, grande parte da amostra alega manter uma dieta por pouco tempo, com o maior tempo de duração sendo de 04 meses e o menor de 07 dias. Na tabela 4 foram apresentados os dados relativos ao período de prática de uma dieta. 
Tabela 4 - Sobre o período de prática de dieta

\begin{tabular}{|c|c|c|}
\hline Perguntas & $\mathbf{N}^{\circ}$ & $\%$ \\
\hline \multicolumn{3}{|c|}{1 - Qual tempo médio você se mantém em uma dieta? } \\
\hline Menos de 05 meses & 40 & 66,7 \\
\hline Mais de 05 meses & 17 & 28,3 \\
\hline Não responderam ou não realizam uma dieta & 03 & 5,00 \\
\hline \multicolumn{3}{|c|}{2 - Quando você começa a dieta, como está sua motivação? } \\
\hline Ótima & 24 & 40,0 \\
\hline Boa & 26 & 43,3 \\
\hline Pouca & 08 & 13,3 \\
\hline Nenhuma & 02 & 3,3 \\
\hline \multicolumn{3}{|c|}{3 - Alguma delas foi elaborada por um nutricionista? } \\
\hline Sim & 47 & 78,3 \\
\hline Não & 13 & 21,7 \\
\hline
\end{tabular}

Fonte: Próprio autor (2021).

Na figura 1 são apresentados os dados característicos relativos à prática de dietas com ou sem acompanhamento de um nutricionista nas classes socioeconômicas. 
Figura 1 - Prática de dieta com ou sem acompanhamento nutricional nas classes econômicas.

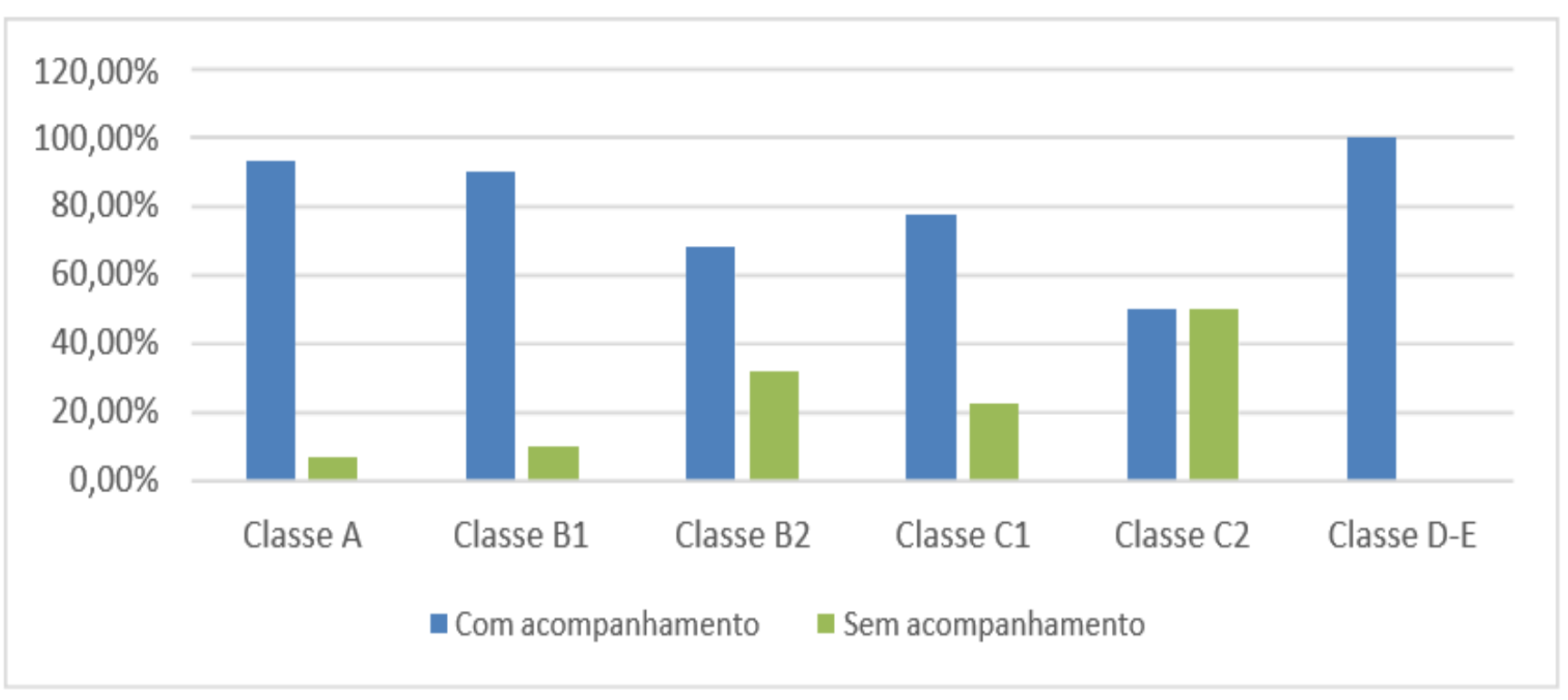

Fonte: Próprio autor (2021).

Em relação a satisfação com dietas, a maior parte da amostra alegou se sentir satisfeito, mesmo com falhas que levaram a desistência. Quanto aos motivos que levaram a desistência, destacam-se: "por falta de tempo"; "era muito restritiva e nada prazerosa".

Tabela 5 - Sobre a desistência e satisfação com dietas já realizadas ou atuais.

\begin{tabular}{|c|c|c|}
\hline Perguntas & $\mathbf{N}^{\circ}$ & $\%$ \\
\hline \multicolumn{3}{|l|}{1 - Você já desistiu de alguma dieta? } \\
\hline Sim & 42 & 70,0 \\
\hline Não & 09 & 15,0 \\
\hline Não responderam & 09 & 15,0 \\
\hline \multicolumn{3}{|c|}{2 - Caso sim, era julgado(a) em seu meio social? } \\
\hline Sim & 25 & 41,7 \\
\hline Não & 22 & 36,7 \\
\hline Não responderam & 13 & 21,7 \\
\hline
\end{tabular}


Bacharelado em Nutrição da UninCor e iniciação à pesquisa: Com a palavra os nossos estudantes

3 - Quais sentimentos você tem ao abandonar uma dieta?

\begin{tabular}{|l|c|l|}
\hline Decepção ou Frustação & 13 & 21,7 \\
\hline Tristeza ou Culpa & 12 & 20,0 \\
\hline Fracasso ou Incapacidade & 13 & 21,7 \\
\hline Não souberam responder & 22 & 36,6 \\
\hline
\end{tabular}

4 - Você se satisfez com alguma dieta que fez?

\begin{tabular}{|l|c|c|}
\hline Sim & 36 & 60,0 \\
\hline Não & 12 & 20,0 \\
\hline Não souberam responder & 12 & 20,0 \\
\hline
\end{tabular}

Fonte: Próprio autor (2021).

As informações coletadas sobre as dietas realizadas com e sem acompanhamento de um profissional nutricionista estão descritas na tabela 6 .

Tabela 6 - Sobre as dietas realizadas com ou sem acompanhamento de um nutricionista.

\begin{tabular}{|c|c|c|c|c|}
\hline \multirow[b]{2}{*}{ Perguntas } & \multicolumn{2}{|c|}{$\begin{array}{c}\text { Com } \\
\text { nutricionista }\end{array}$} & \multicolumn{2}{|c|}{$\begin{array}{c}\text { Sem } \\
\text { nutricionista }\end{array}$} \\
\hline & $\mathbf{N}^{\circ}$ & $\%$ & $\mathbf{N}^{\circ}$ & $\%$ \\
\hline \multicolumn{5}{|l|}{1 - Você cumpriu a dieta? } \\
\hline Tudo & 19 & 31,7 & 11 & 18,3 \\
\hline Metade & 19 & 31,7 & 13 & 21,7 \\
\hline Pouco & 12 & 20,0 & 16 & 26,7 \\
\hline Não responderam & 10 & 16,7 & 20 & 33,3 \\
\hline
\end{tabular}


Bacharelado em Nutrição da UninCor e iniciação à pesquisa: Com a palavra os nossos estudantes

2 - Sua dieta te deixava com fome?

\begin{tabular}{|l|c|c|c|c|}
\hline Sim & 21 & 35,0 & 19 & 31,7 \\
\hline Não & 31 & 51,7 & 17 & 28,3 \\
\hline Não responderam & 08 & 13,3 & 24 & 40,0 \\
\hline
\end{tabular}

3 - O preparo dos alimentos era trabalhoso?

\begin{tabular}{|l|c|c|c|c|}
\hline Sim & 21 & 35,0 & 0,9 & 15,0 \\
\hline Não & 31 & 51,7 & 27 & 45,0 \\
\hline Não responderam & 08 & 13,3 & 24 & 40,0 \\
\hline
\end{tabular}

4 - Sua dieta feria sua religião?

\begin{tabular}{|l|c|c|c|c|}
\hline Sim & 02 & 3,3 & 0 & 0 \\
\hline Não & 48 & 80,0 & 36 & 60,0 \\
\hline Não souberam responder & 10 & 16,7 & 24 & 40,0 \\
\hline
\end{tabular}

5 - O custo dos alimentos era adequado?

Sim

Não

Não responderam

\begin{tabular}{|c|c|c|c|}
\hline 32 & 53,3 & 25 & 41,7 \\
\hline 21 & 35,0 & 12 & 20,0 \\
\hline 07 & 11,7 & 23 & 38,3 \\
\hline
\end{tabular}

6 - Sua dieta era prazerosa?

\begin{tabular}{|l|c|c|c|c|}
\hline Prazerosa & 28 & 46,7 & 12 & 20,0 \\
\hline Pouco prazerosa & 24 & 40,0 & 23 & 38,3 \\
\hline Não responderam & 08 & 12,3 & 25 & 41,7 \\
\hline
\end{tabular}


Bacharelado em Nutrição da UninCor e iniciação à pesquisa: Com a palavra os nossos estudantes

7 - Você considerava sua dieta radical?

\begin{tabular}{|l|c|c|c|c|}
\hline Sim & 08 & 13,3 & 14 & 23,3 \\
\hline Não & 44 & 73,3 & 22 & 36,7 \\
\hline Não responderam & 08 & 13,3 & 24 & 40,0 \\
\hline 8- Você se sentia mais disposta (o) & & & & \\
\hline Sim & 42 & 70,0 & 22 & 36,7 \\
\hline Não & 08 & 13,3 & 14 & 23,3 \\
\hline Não responderam & 10 & 16,7 & 24 & 40,0 \\
\hline
\end{tabular}

Fonte: Próprio autor (2021).

Observa-se que em relação aos fatores que mais dificultam seguir uma dieta, dos 60 indivíduos, $28,3 \%$ alegam que a falta de tempo é o maior desafio; $8,3 \%$ alegam ser o custo financeiro o maior desafio; $20 \%$ alegam sentir fome durante a prática da dieta, sendo esse o maior desafio segundo os mesmos; $21,7 \%$ alegam ser por outros motivos e $21,7 \%$ não responderam.

Dentre os motivos diante aos fatores considerados os que mais dificultam o seguimento de uma dieta, destacam-se: "o orçamento e dificuldade com os alimentos dificultam bastante"; "a rotina cansativa do trabalho e estresse"; "vontade de comer mais"; "ter todos os alimentos"; "dificuldade para conseguir manter a dieta certinho"; "a quantidade exagerada de alimentos e o consumo de "comida" (batata, macarrão, mandioca, frango) em intervalos de refeições principais, além de me prender a alimentos que não estavam na dieta".

Na figura 2 são apresentados os dados característicos relativos aos fatores que mais dificultam seguir uma dieta nas classes socioeconômicas. 
Bacharelado em Nutrição da UninCor e iniciação à pesquisa: Com a palavra os nossos estudantes

Figura 2 - Fatores que mais dificultam seguir uma dieta para as diferentes classes econômicas.

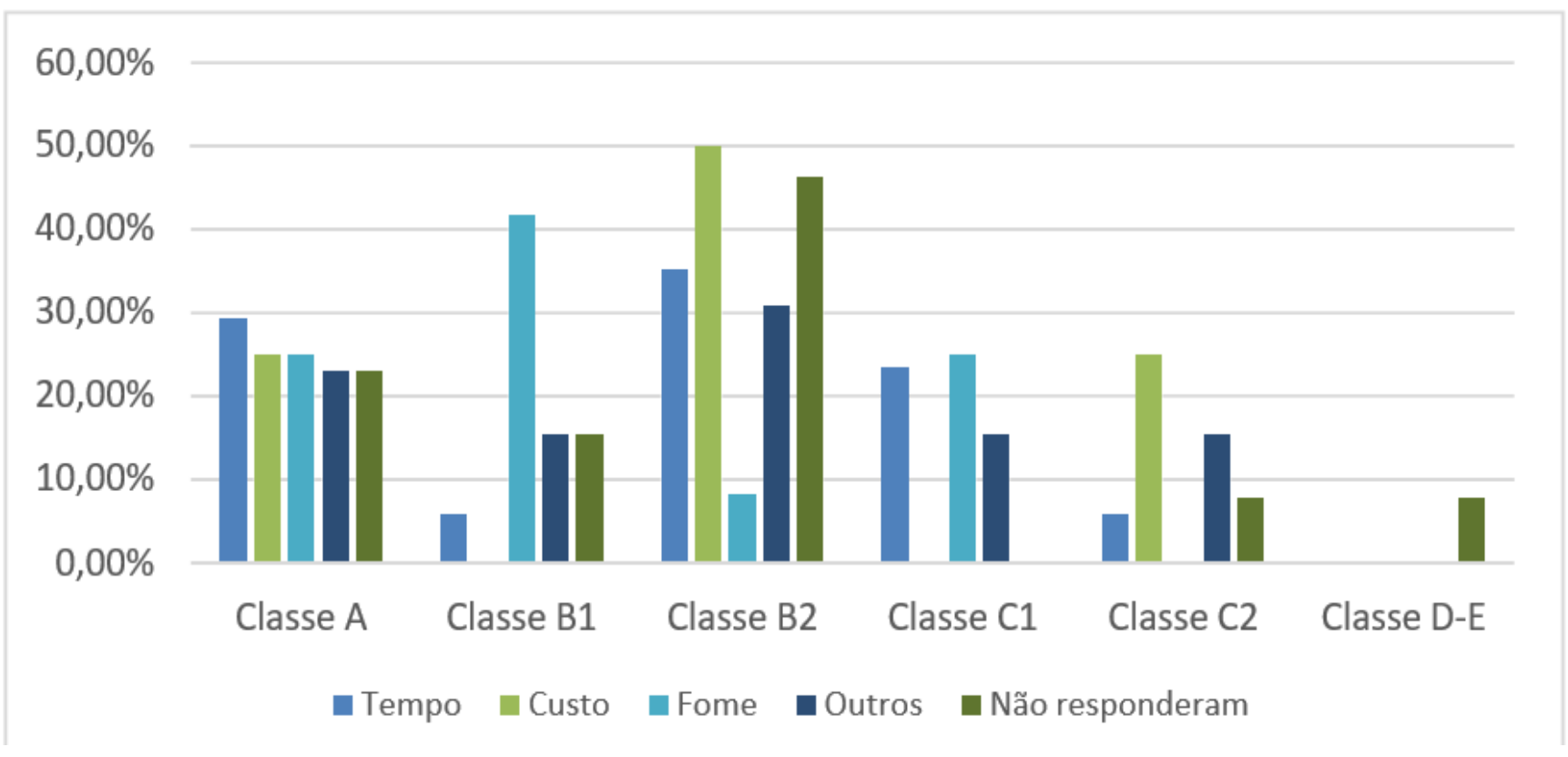

Fonte: Próprio autor (2021).

\section{DISCUSSÃO}

No presente estudo, foram analisados um total de 60 indivíduos, com a maior parte dos participantes da pesquisa com idade entre 19 a 24 anos (36,7\%), no entanto, neste estudo não houve correlação significativa entre essa variável. Desses 60 indivíduos, a maioria pertence ao sexo feminino, característica comum em estudos semelhantes, onde a propensão das mulheres em se preocuparem mais com a qualidade da alimentação do que os homens, pode justificar o maior número de participantes deste sexo no presente estudo (ASSUMPÇÃO et al., 2017).

Diante das práticas alimentares dos indivíduos participantes, 93,3\% percebem que precisam de mudanças em sua alimentação e grande parte dos mesmos, pressupõem saber o que fazer para realizar essas mudanças. No entanto, foi observado no presente estudo, que esses mesmos indivíduos acabam por não conseguir manter as mudanças por longos períodos de duração. Essa dificuldade em manter as mudanças alimentares pode ser justificada pelo fato de que 
Bacharelado em Nutrição da UninCor e iniciação à pesquisa: Com a palavra os nossos estudantes

na fase adulta, os hábitos alimentares ou outros hábitos de vida, não recebem a devida importância (LINDEMANN; OLIVEIRA; MENDOZA-SASSI, 2016).

Foi constatado que todos os indivíduos participantes já praticaram ou estão praticando uma dieta, onde em grande parte dos relatos, a perda de peso foi o objetivo mais presente e constante na pesquisa. Essa grande procura por dietas com objetivo de perda de peso pode ser fundamentada pela grande vontade e desejo dos indivíduos em ter uma aparência considerada mais atrativa e agradável, o que resulta em preocupação com o peso corporal, além de que, também acreditam ser necessário a perda de peso corporal para se viver com mais qualidade, disposição e saúde (VIANA, 2014; MACHADO et al., 2021).

Deve-se considerar também, que a crença dos participantes em relação a perda de peso através de dietas é conduzida por aspectos alimentares restritivos, onde percebe-se que os mesmos acreditam fielmente, que os resultados só serão positivos se houver algo a ser seguido ou em suas palavras, "se fecharem a boca". Essas associações são fundamentadas pela mentalidade de dieta inserida a muito tempo na sociedade, que nos ensina a consumir alimentos considerados permitidos e em horários estabelecidos por alguém ou até mesmo por si próprio, gerando receio de sentir fome, comer e engordar (ALVARENGA et al., 2015).

Ainda em relação a prática de dietas com objetivo de perda de peso, observa-se também no presente estudo, que os participantes demonstram uma valorização sobre essas dietas que propõem emagrecimento. É importante ressaltar que essa percepção e valorização existente sobre as dietas para perda de peso se dão pelo fato de que na maioria dos casos, os aspectos relacionados a saúde são deixados de lado e a quantidade de peso reduzido se torna o foco do tratamento, dando muita importância aos dados antropométricos aferidos durante o atendimento ou avaliação física (TAGLIETT et al., 2018).

Percebe-se no presente estudo, que a desistência de dietas é algo frequente na rotina dos indivíduos, onde $90 \%$ dos mesmos relataram ter desistido de todas as dietas que já realizaram. A desistência de uma dieta é influenciada por 
Bacharelado em Nutrição da UninCor e iniciação à pesquisa: Com a palavra os nossos estudantes

vários meios e padrões adotados ao longo do período de prática, demonstrando que a desistência da mesma se deve a diversos fatores que cercam o dia-a-dia dos indivíduos, como o custo para manter a dieta, a pressão para abrir mão de certos alimentos, falta de tempo, falta de organização, além da dificuldade de acesso a informações (LINDEMANN; OLIVEIRA; MENDOZA-SASSI, 2016).

No contexto socioeconômico, foi constatado que o número de indivíduos pertencentes a classe A representam uma porcentagem relevante para o presente estudo, sendo possível observar que para esses indivíduos, os desafios ou dificuldades relatadas são relacionados a preferências ou falta de tempo, descartando os outros. Todas essas associações podem ser explicadas pelo fato de que nesses domicílios, as quantidades de alimentos são consideradas suficientes, com acesso a mais variedade de alimentos através de uma renda satisfatória que cobre os gastos alimentares (BERTONCELO, 2019).

Verifica-se que as classes B1 e B2 são as que mais se destacam no presente estudo, com uma porcentagem predominante de $48,3 \%$ da amostra total. Observa-se que para esses indivíduos, os desafios ou dificuldades relatadas são variados, onde incluem os financeiros, falta de tempo, preparo dos alimentos, preferências, e dentre outros. As associações apresentadas são fundamentadas pelo fato de que nesses domicílios, as práticas alimentares não se resumem somente nos tipos de alimentos que se consome, mas também no acesso e na importância que se é dada ao se alimentar (BERTONCELO, 2019).

Quando se analisa as classes C1, C2 e D-E, percebe-se que as mesmas representam juntas no estudo, uma porcentagem superior à da classe $A$, sendo $26,7 \%$ da amostra total. Observa-se que para esses indivíduos, principalmente aqueles da classe D-E, os desafios ou dificuldades relatadas são influenciadas por um nível econômico mais baixo do que as demais classes, onde incluem principalmente o custo dos alimentos ou alimentos desconhecidos que não suprem as necessidades básicas, evidenciando uma dificuldade dos chefes da família em ofertar um consumo adequado dentro do domicílio (BERTONCELO, 2019). 
Bacharelado em Nutrição da UninCor e iniciação à pesquisa: Com a palavra os nossos estudantes

É possível observar que independente da classe socioeconômica, grande parte dos participantes conseguem se manter em uma dieta por menos de cinco de meses. Apesar de realizarem dietas por curtos períodos de tempo e consequentemente, por mais vezes ao ano, nota-se que os indivíduos ainda acreditam que as dietas são benéficas, o que pode ser justificada pelo fato de que vivemos com desejo de emagrecer, motivado por diversos fatores externos, opiniões e afirmações baseadas em artigos ou revistas que mundialmente, prezam pela estética corporal (ALVARENGA et al., 2015).

Questionados especificamente a respeito do custo por trás de uma dieta, a maior parte relatou ser um custo que é adequado ao seu orçamento. No entanto, uma minoria bem significativa para o presente estudo, relatou não ser adequado ao seu orçamento. Essa elevada adequação comprometedora ao orçamento proposto diante a um planejamento dietético pode ser justificada através dos rendimentos mensais familiares, onde muitos sobrevivem apenas com salário mínimo para cobrir todas as despesas do domicílio, impossibilitando a aquisição de alimentos de qualidade (BORGES et al., 2015).

Nota-se que diante a essas práticas de dietas, mais da metade dos participantes relataram ter tido ou estar tendo acompanhamento de um profissional nutricionista, onde $60 \%$ dos indivíduos relataram se sentir satisfeito ao realizar a dieta. Mesmo que esse resultado seja positivo para o campo da nutrição, percebe-se no estudo, que os indivíduos que procuraram um nutricionista, os objetivos foram de perda de peso ou estética. As associações apresentadas podem ser fundamentadas pela forma que o nutricionista é percebido em seu meio, onde na maioria dos casos, é visto como um profissional que propõe mudanças estéticas e em segundo plano, a saúde. (MENDES e NAKASU, 2020).

Em relação a percepção dos indivíduos diante a prática de dietas realizadas com auxílio de um nutricionista, a maior parte dos mesmos criticam essas dietas e acreditam que as mesmas deveriam ser mais liberais, maleáveis e flexíveis. Na percepção dos indivíduos participantes, o nutricionista ao propor uma 
Bacharelado em Nutrição da UninCor e iniciação à pesquisa: Com a palavra os nossos estudantes

dieta, não considera as suas possíveis dificuldades e peculiaridades e de certa forma, alguns nutricionistas ao trabalharem com perda de peso, optam por um método que realça a vulnerabilidade do paciente em cima do que se é proposto, tornando-o mais disposto ao fracasso (ARAÚJO et al., 2015).

Verifica-se também, que uma parcela menor de participantes nunca procurou um acompanhamento nutricional para nenhuma das dietas realizadas, nem mesmo por um simples atendimento através do Sistema Único de Saúde (SUS). Em relação a percepção desses indivíduos sobre essas dietas, os mesmos afirmam que essas causam fome e não ajudam na manutenção do peso. Os baixos índices de procura por acompanhamento nutricional podem ser justificados pelo fato de que os indivíduos recorrem a dietas altamente restritivas para se obter uma perda de peso rápida influenciados por vários meios, em específico, a mídia voltada para a estética corporal (XAVIER e MIAMOTO, 2015).

De maneira geral, nota-se que o ato de se alimentar e a forma como o peso corporal é visto, se diferenciam de um participante para outro. É importante ressaltar que a redução do peso corporal precisa ser associada com a melhora da qualidade de vida e quando se trata especificamente de alimentação, alguns significados perpassam o individual e se faz necessário o desenvolvimento de meios de intervenção para se propor uma devida educação alimentar, proporcionando orientações nutricionais precisas que auxiliem mudança de seus hábitos alimentares (ALVARENGA et al., 2015; TAGLIETT et al., 2018).

Percebe-se que as crenças dos indivíduos em cima da nutrição são incertas e para uma nova perspectiva em relação ao conhecimento nutricional, um e-book educativo sobre a prática de dietas foi elaborado com objetivo de ofertar devido conhecimento a todos. A nutrição ao discutir sobre o tema voltado para as dietas, pode trazer uma maior compreensão aos leitores acerca dos aspectos nutricionais, contribuindo diretamente para o processo de aprendizagem e a proposta de uma ferramenta tecnológica que proponha conhecimento, gera mudanças positivas de forma simples e prática (MÜLBERT e PEREIRA, 2016). 
De maneira geral, o estudo realizado apresentou algumas limitações importantes quanto a sua amostra, uma vez que, os resultados encontrados podem não ser totalmente fidedignos e com transparência, já que o caráter das respostas obtidas pode ser afetado por omissões ou distorções realizadas por parte dos entrevistados, comprometendo assim seu valor. Outra limitação se atribui diretamente ao tamanho da amostra do presente estudo, que ao se expressar em número reduzido, permite considerar os resultados obtidos somente para a população em questão.

\section{CONCLUSÃO}

Este estudo possibilitou analisar os aspectos envolvidos em um planejamento dietético que muitas vezes não são considerados e, tendo em vista os dados coletados e discutidos anteriormente, conclui-se que o sistema de classes socioeconômicas pode ter influência na adesão e manutenção de um planejamento dietético de adultos, no qual, embora todos percebam que sua alimentação precisa ser melhorada em algum aspecto, cada indivíduo apresenta um tipo de dificuldade e/ou desafio, causados por recursos financeiros, rotina e hábitos, assim como o acesso a alimentos e convívio familiar, que são impostos pela hierarquia das classes em que atualmente se encontram.

Ao longo do desenvolvimento deste trabalho, identificou-se uma ausência de estudos sobe o assunto, necessitando de um olhar apurado para as questões em torno da adesão a um planejamento dietético. Sugiro que outros autores apresentem estudos sobre este tema, afim de ampliar o entendimento do fenômeno estudado, ou para buscar confirmação científica dos resultados obtidos, evidenciando ao campo da nutrição, o outro lado dos planejamentos dietéticos propostos.

Contudo, uma vez que os desafios e dificuldades para aderir e manter um planejamento dietético em diferentes classes socioeconômicas sejam identificados, maior serão os níveis de procura por um atendimento nutricional adequado, 
Bacharelado em Nutrição da UninCor e iniciação à pesquisa: Com a palavra os nossos estudantes

que se proponha trabalhar com uma prática alimentar saudável, garantindo que as práticas futuras sejam com o devido conhecimento acerca da nutrição, com orientações e ensinamentos para realizar intervenções em sua alimentação de forma eficiente, sem restrições e sofrimentos, trazendo uma maior qualidade de vida a todos aqueles que desejam mudar seus hábitos alimentares.

\section{REFERÊNCIAS}

ALVARENGA, Marle; FIGUEIREDO, Manoela; TIMERMAN, Fernanda; ANTONACCIO, Cynthia Maria Azevedo (comp.). Nutrição Comportamental. Brasil: Editora Manole Ltda, 2015. 576 p.

ALVARES, Daniele Andreia; SANTANA, Aline Alves. Correlação entre dietas restritivas e o surgimento ou agravamento de transtornos alimentares. Pubsaúde, São Paulo, v. 4, a65, p. 1- 11, 16 nov. 2020.

AMORIM, Cynthia Padua do; DIAS, Alessandro Adrelle Eller. A igreja católica e suas influências na alimentação: uma perspectiva histórica. Revista Unitas, [S.I], v. 7, n. 2 , p. $4-18,2019$.

ANDRADE, João Marcus Oliveira; RIOS, Lorena Roseli; TEIXEIRA, Larissa Silva; VIEIRA, Fernanda Silva; MENDES, Danilo Cangussu; VIEIRA, Maria Aparecida; SILVEIRA, Marise Fagundes. Influência de fatores socioeconômicos na qualidade de vida de idosos hipertensos. Ciência \& Saúde Coletiva, [S.L.], v. 19, n. 8, p. 3497-3504, ago. 2014.

AQUINO, Rita de Cássia de; MACEDO, Irene Coutinho de. O "marco de referência de educação alimentar e nutricional para políticas públicas" no brasil no contexto do atendimento nutricional. Demetra: Alimentação, Nutrição \& Saúde, [S.L.], v. 13, n. 1, p. 21-35, 3 maio 2018.

ARAÚJO, Kênya Lima de; PENA, Paulo Gilvane Lopes; FREITAS, Maria do Carmo Soares de; DIEZ-GARCIA, Rosa Wanda. Estigma do nutricionista com obesidade no mundo do trabalho. Revista de Nutrição, [S.L.], v. 28, n. 6, p. 569579, dez. 2015.

ASSOCIAÇÃO BRASILEIRA DE EMPRESAS DE PESQUISA. Critério de Classificação Econômica Brasil. ABEP, São Paulo, 01 jun. 2019. 6 p. 
ASSUMPÇÃO, Daniela de; DOMENE, Semíramis Martins Álvares; FISBERG, Regina Mara; CANESQUI, Ana Maria; BARROS, Marilisa Berti de Azevedo. Diferenças entre homens e mulheres na qualidade da dieta: estudo de base populacional em campinas, São Paulo. Ciência \& Saúde Coletiva, [S.L.], v. 22, n. 2, p. 347-358, fev. 2017.

BERTONCELO, Edison. CLASSE SOCIAL E ALIMENTAÇÃO: padrões de consumo alimentar no brasil contemporâneo. Revista Brasileira de Ciências Sociais, São Paulo, v. 34, n. 100, p. 1-26, 2019.

BORBA, Anna Karla de Oliveira Tito; MARQUES, Ana Paula de Oliveira; RAMOS, Vânia Pinheiro; LEAL, Márcia Carrera Campos; ARRUDA, Ilma Kruze Grande de; RAMOS, Roberta Souza Pereira da Silva. Fatores associados à adesão terapêutica em idosos diabéticos assistidos na atenção primária de saúde. Ciência \& Saúde Coletiva, [S.L.], v. 23, n. 3, p. 953- 961, mar. 2018.

BORGES, Camila Aparecida; CLARO, Rafael Moreira; MARTINS, Ana Paula Bortoletto; VILLAR, Betzabeth Slater. Quanto custa para as famílias de baixa renda obterem uma dieta saudável no Brasil? Caderno de Saúde Pública, Rio de Janeiro, v. 31, n. 1, p. 137-148, 2015.

BRASIL. Guia alimentar para a População Brasileira. Ministério da saúde: secretaria de atenção à saúde. Departamento de atenção Básica. - 2. ed. Brasília: Editora MS, 2014.

CASTRO, Conrado Gomide; BOTELHO, Douglas de Oliveira; ANDRADE, Diego César Terra de. O que a cultura tem a nos falar sobre a alimentação saudável? Competência, Porto Alegre, v. 10, n. 1, p. 165-182, jul. 2017.

CECILIO, Hellen Pollyanna Mantelo; SANCHES, Rafaely de Cássia Nogueira; RADOVANOVIC, Cremilde Aparecida Trindade; MARCON, Sonia Silva. Percepções de mulheres obesas sobre a sexualidade. Reme: Revista Mineira de Enfermagem, [S.L.], v. 18, n. 4, p. 955-960, 13 out. 2014.

DIAS, Érika; PINTO, Fátima Cunha Ferreira. Ensaio: Avaliação e Políticas Públicas em Educação. Educação e Sociedade, Rio de Janeiro, v. 27, n. 104, p. 449-454, set. 2019. 
Bacharelado em Nutrição da UninCor e iniciação à pesquisa: Com a palavra os nossos estudantes

ESTRELA, Kelly Cristina Araujo; ALVES, Anna Carolina di Creddo; GOMES, Tatiana Teixeira; ISOSAK, Mistue. Adesão às orientações nutricionais: uma revisão de literatura. Demetra: alimentação, nutrição \& saúde, [S.I], v. 12, n. 1, p. 249274, ago. 2017.

KUWAE, Christiane Ayumi; CARVALHO, Maria Claudia da Veiga Soares; PRADO, Shirley Donizete; FERREIRA, Francisco Romão. Concepções de alimentação saudável entre idosos na Universidade Aberta da Terceira Idade da UERJ: normas nutricionais, normas do corpo e normas do cotidiano. Revista Brasileira de Geriatria e Gerontologia, Rio de Janeiro, v. 18, n. 3, p. 621-630, set. 2015.

LAKATOS, Eva Maria; MARCONI, Marina de Andrade. Metodologia do TrabaIho Cientifico - $8^{a}$ Ed. São Paulo: Editora Atlas S.A, 2017. 256p.

LINDEMANN, Ivana Loraine; OLIVEIRA, Riceli Rodeghiero; MENDOZA-SASSI, Raúl Andres. Dificuldades para alimentação saudável entre usuários da atenção básica em saúde e fatores associados. Ciência \& Saúde Coletiva, [S.L.], v. 21, n. 2, p. 599-610, fev. 2016.

MACHADO, Victoria Azevedo; PATRIANI, Gustavo Périco; BARROS, Júlia Passos; CINTRA, Isabelle Garcete; CHAUD, Daniela Maria Alves. Perfil de adultos residentes na cidade de São Paulo que seguem ou já seguiram dietas de emagrecimento. Vita Et Sanitas, São Paulo, v. 15, n. 1, p. 06-20, jan. 2021.

MARANGONI, Jhennifer Sienna; MANIGLIA, Fabíola Pansani. Análise da composição nutricional de dietas da moda publicadas em revistas femininas. Rasbran: Revista da Associação Brasileira de Nutrição, São Paulo, v. 8, n. 1, p. 31-36, jun. 2017.

MENDES, Fernanda Fonseca Barbosa; NAKASU, Maria Vilela Pinto. Percepção de nutricionistas sobre sua atuação profissional no contexto de supervalorização do corpo magro e escultural. Revista da Associação Brasileira de Nutrição Rasbran, [S.L.], v. 11, n. 1, p. 3-18, 23 set. 2020.

MILLER, Stephanie Silva Pereira. Análise dos fatores de não adesão à planos alimentares, em mulheres praticantes de atividade física. 2016. 24 P. Curso de Nutrição, Faculdade de Ciências da Educação e Saúde, Centro Universitário de Brasília - Uniceub, Brasília, 2016. 
MINAYO, Maria Cecília de Souza. O Desafio do Conhecimento: pesquisa qualitativa em saúde. 14a ed. São Paulo: Editora Hucitec, 2014. 416p.

MOURA, Andréia Ferreira de; MASQUIO, Deborah Cristina Landi. A influência da escolaridade na percepção sobre alimentos considerados saudáveis. Revista de Educação Popular, Uberlândia, v. 13, n. 1, p. 82-94, jun. 2014.

MÜLBERT, Ana Luísa; PEREIRA, Alice T. Cybis. A adoção do livro didático eletrônico para dispositivos móveis na educação superior a distância: motivações, dificuldades e estratégias de contorno. Novas Tecnologias na Educação, Santa Catarina, v. 14, n. 1, p. 1-9, jul. 2016.

OBARA, Angélica Almeida; VIVOLO, Sandra Roberta Gouvea Ferreira; ALVARENGA, Marle dos Santos. Preconceito relacionado ao peso na conduta nutricional: um estudo com estudantes de nutrição. Cadernos de Saúde Pública, [S.L.], v. 34 , n. 8, p. 2-14, 20 ago. 2018.

OLIVEIRA, Ana Paula da Silva Vasques; SILVA, Marília Marques da. Fatores que dificultam a perda de peso em mulheres obesas de graus I e II. Revista Psicologia e Saúde, Campo Grande, v. 6, n. 1, p. 74-82, jun. 2014.

PETRY, Jaqueline; LOPES, Andrea Cintra; CASSOL, Karlla. Autopercepção das condições alimentares de idosos usuários de prótese dentária. Codas, [S.L.], v. 31, n. 3, p. 1-9, jul. 2019.

SAMPIERI, Roberto Hernández.; COLLADO, Carlos Fernández.; LUCIO, María Del Pilar Baptista. Metodologia de pesquisa. 5. ed. Porto Alegre: Penso, 2013. $624 \mathrm{p}$.

SOIHET, Julie; SILVA, Aline David. Efeitos psicológicos e metabólicos da restrição alimentar no transtorno de compulsão alimentar. Nutrição Brasil, [S.L.], v. 18, n. 1, p. 55-62, 4 ago. 2019.

SOUSA, Ariele Edna Cristina de; NUNES, Renato Moreira. Avaliação da adesão terapêutica nutricional e sua relação com os modelos de mudança do comportamento alimentar. Hu Revista, Juiz de Fora, v. 40, n. 3-4, p. 1-9, dez. 2014. 
TAGLIETTI, Roberta Lamonatto; RIEPE, Sandra Bucco; MARONEZ, Talita Brugnera; TEO, Carla Rosane Paz Arruda. TRATAMENTO NUTRICIONAL PARA REDUÇÃO DE PESO: aspectos subjetivos do processo. Revista Brasileira de Obesidade, Nutrição e Emagrecimento, São Paulo, v. 12, n. 69, p. 101-109, fev. 2018.

TORRES, Andreia. Adesão ao tratamento dietético para o emagrecimento: da teoria à prática. Revista Brasileira de Nutrição Funcional, [S.L.], v. 43, n. 78, p. 40-46, 30 jun. 2019.

VIANA, Daniela Swelem de Oliveira. ANÁLISE NUTRICIONAL DAS DIETAS DA MODA. 2014. 29 f. TCC (Graduação) - Curso de Nutrição, Faculdade de Ciências da Educação e Saúde, Centro Universitário de Brasília - Uniceub, Brasília, 2014.

XAVIER, Michelle Papini; MIAMOTO, Juliana Maia. Estética e Nutrição: aliadas em busca do corpo perfeito. 2016. 19 f. Monografia (Especialização) - Curso de Nutrição, Centro Universitário do Sul de Minas Unis-Mg, [S.I], 2016. 


\section{doi $10.48209 / 978-65-89949-1 / 2-4$}

\section{CAPITURO 4}

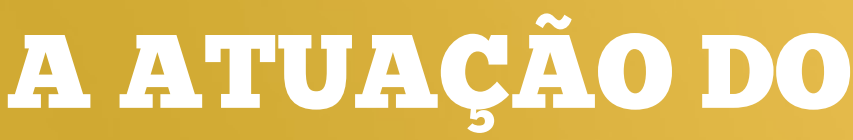 NUTRICIONISTHA

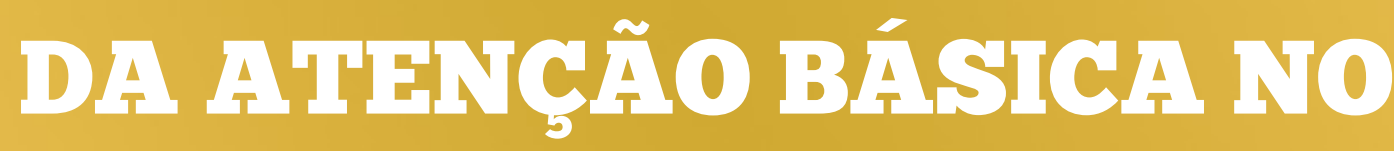 THATAMIFNTO DE DOENÇASS CRONICASS NÃO IHRANSMIISSIVISE: PERCEPCS ÃO DOS USUÁRIOS DO SHSHFMAAS ÚNICO DE SAÚDE}

Letícia Aparecida Costa Luz Ana Luiza Rodrigues Pellegrinelli 


\section{INTRODUÇÃO}

A Atenção Primária à Saúde (APS) também nomeada de Atenção Básica, é a porta de entrada para o Sistema Único de Saúde e deve garantir o acesso integral aos serviços de saúde aos usuários. Composta por uma equipe multiprofissional a APS deve desenvolver ações que visam a promoção à saúde, prevenção de agravos, diagnósticos, tratamento e reabilitação da saúde (FAUSTINO-SILVA; JUNG; LA PORTA, 2019).

A inserção do nutricionista na rede pública e em programas é fundamental, uma vez que o mesmo é o único capacitado para desempenhar ações de alimentação e nutrição para a comunidade, promovendo uma reeducação dos hábitos alimentares, prevenindo fatores de riscos e suas respectivas doenças, além de contribuir com a manutenção e reabilitação da saúde, fato este que reflete diretamente na condição epidemiológica do país (BARROS et al., 2019).

Diante disso este trabalho traz a seguinte questão problema: Como o usuário percebe a atuação do nutricionista no tratamento das doenças crônicas não transmissíveis (DCNT) na atenção básica em Três Corações? Nessa linha relaciona-se a seguinte hipótese: A falta de atendimento e suporte nutricional nas Unidades Básicas de Saúde dificulta o tratamento das DCNT dos usuários do Sistema Único de Saúde.

O objetivo geral deste trabalho é analisar a atuação do nutricionista no tratamento das doenças crônicas não transmissíveis (DCNT) na atenção básica, sob a perspectiva do usuário, em Três Corações-MG. Além de, identificar o tempo de espera para consultas com o nutricionista da atenção básica, verificar se o nutricionista oferece suporte adequado no tratamento aos pacientes com doenças crônicas não transmissíveis, entender quais intervenções o nutricionista aplica no tratamento das doenças crônicas e investigar se os usuários do Sistema Único de Saúde estão satisfeitos com o trabalho realizado pelo nutricionista. 
Um dos agravos de saúde da população brasileira é a insegurança alimentar e nutricional, devido a rápida mudança epidemiológica, condições nutricionais e as desigualdades sociais. Desse modo, encontra-se em ênfase o embate da função do nutricionista no contexto da Atenção Básica. Assim, o questionamento da atuação do profissional de nutrição na atenção primária à saúde, vai adiante do reconhecimento do nutricionista, mas de garantir o direito dos indivíduos que fazem uso do SUS, como uma forma de promover e prevenir os distúrbios da saúde, baseado em uma política governamental elaborada de forma legal com ampla presença da sociedade.

Nesse sentindo, não há outro profissional da saúde qualificado para encarregar-se na área de nutrição e alimentação posto nas comunidades, sendo capaz de executar ações positivas no cenário epidemiológico da população (TAVARES et al., 2018).

\section{REFERENCIAL TEÓRICO}

\section{Sistema Único de Saúde (SUS)}

O Sistema Único de Saúde é formado pelo conjunto da interação das ações e Serviços Públicos de Saúde, prestados por órgãos e instituições públicas à domínio das fundações mantidas pelo poder público. A inserção de serviços de saúde na comunidade é necessária para assegurar a integralidade da saúde mediante o processo de referência de serviços, sendo ele da rede regionalizada e hierarquizada (SANTOS, 2017).

O SUS é considerado o maior e mais íntegro sistema de saúde público do mundo, como um conjunto que engloba os cuidados assistenciais da atenção primária até aos serviços mais complexos como o transplante de órgãos, assegurando seus princípios doutrinários através do acesso universal e integral garantindo a igualdade e a equidade à população. Os serviços integrais na rede 
de atenção à saúde se tornaram um direito de todos os brasileiros, abrangendo todos os ciclos da vida, proporcionando qualidade de vida e redução dos agravos da saúde (BARROS et al., 2019).

\section{Atenção Básica}

A Atenção Básica tem por objetivo assegurar o acesso integral aos serviços de saúde, sendo considerada o primeiro contato com o sistema único de saúde, capaz de organizar o fluxo dos serviços nas redes de saúde, partindo dos mais simples aos mais complexos. Na Atenção Básica as intervenções nutricionais determinam a ampliação da qualidade da promoção de saúde e tratamento, principalmente nas DCNT, gestação, amamentação e primeira infância (LIMA et al., 2019).

A Portaria $n^{\circ} 2488$ de outubro de 2011, presume que a Atenção Básica tem como intuito de sistematizar o acesso nas intervenções de prevenção de danos, proteção à saúde, manutenção a saúde, tratamentos, diagnósticos e reabilitação. A portaria também sanciona que o atendimento deve ser focado nos pacientes e não somente na resolução do problema, pois, todo o contexto deve ter uma atenção continuada. Dessa forma, o Sistema Único de Saúde enfatiza e prioriza uma estratégia de orientação e atenção à saúde (CAMPOS; VIEIRA; PIRES, 2017).

Sendo a atenção primária à saúde a porta de entrada para o SUS, muitos desafios são enfrentados, pois muitos pacientes chegam trazendo problemas vagos e que não são relacionados a nenhuma doença orgânica específica. Sob essa circunstância, as DCNT estão sendo muito estudadas, devido sua relevância na procura por estratégias a fim de reduzir os fatores de riscos relacionados, visto que os mesmos estão associados a hábitos alimentares e estilo de vida (AZEVEDO et al., 2013). 
Bacharelado em Nutrição da UninCor e iniciação à pesquisa: Com a palavra os nossos estudantes

\section{Funções do Nutricionista na Atenção Básica no SUS}

A atuação do nutricionista na atenção básica à saúde é moldada pelo comprometimento e conhecimento no âmbito da epidemiologia, focado nos métodos e ações em saúde coletiva. Porém, a vigente ação na atenção primária a saúde está precária, se comparando a demanda epidemiológica nacional (CFN, 2015).

A importância do nutricionista na Atenção Básica se dá na promoção de saúde por meio de intervenções nutricionais, que objetivam realizar transições de comportamentos e atendimento que supre as necessidades de toda uma população, onde destaca-se todas as carências nutricionais relacionadas com deficiências de macro e micronutrientes, anemias, obesidade, diabetes e hipertensão, além de muitas outras doenças crônicas não transmissíveis presentes diariamente na Atenção Básica. Diante do exposto, o desenvolvimento de estratégias e programas para promoção e prevenção em saúde se firma em um trabalho em conjunto com outros profissionais e com apoio e compreensão do paciente (BARROS et al., 2019).

\section{Doenças Crônicas Não Transmissíveis (DCNTs) e SUS}

A Organização Mundial da Saúde considera doença crônica como aquela de progressão lenta, de longa duração e que possui efeitos de longo prazo. A maior parte das doenças crônicas não tem cura, porém podem ser prevenidas e tratadas através da constatação prévia e tratamento adequado (OMS, 2005).

O aumento de casos de pacientes com doenças crônicas não transmissíveis, ocorre devido as mudanças sociais econômicas, o envelhecimento, os hábitos alimentares e modo de viver. Dentre esses aspectos, há os fatores de risco que favorecem o desenvolvimento das DCNT, sendo eles: tabagismo, alimentação inadequada, uso prejudicial de álcool e sedentarismo (SILOCCHI e JUNGES, 2017). 
Bacharelado em Nutrição da UninCor e iniciação à pesquisa: Com a palavra os nossos estudantes

As Doenças Crônicas não transmissíveis representam cerca de $68 \%$ das mortes no mundo, visto que, $40 \%$ destas é apontada como precoce, pois ocorrem antes dos 70 anos de idade. As mesmas se distribuem em $80 \%$ das consultas na atenção primária e 60\% das internações hospitalares (SILOCCHI e JUNGES, 2017).

A época, preocupado com o presente contexto, o Ministério da Saúde em 2011, criou oPlano de Ações estratégicas para o enfrentamento das Doenças Crônicas Não Transmissíveis, visando instruir o país para enfrentar as DCNT nos sequentes dez anos. Esse plano tem por finalidade viabilizar o avanço e a inserção de políticas públicas ativas, integradas, sustentáveis, na redução dos aspectos de risco e prevenção e controle das DCNTs (SILOCCHI e JUNGES, 2017).

O Brasil tem indicado alterações no perfil de mortalidade brasileira populacional, devido ao aumento dos números de óbitos ocasionados por doenças crônicas não transmissíveis (DCNT), sendo uma grande preocupação no campo da saúde pública, visto que, esse crescimento reflete proporções epidêmicas em todo o mundo (ROCHA- BRISCHILIARI et al., 2014).

O impacto das doenças crônicas não transmissíveis reflete no setor econômico, visto que os valores com o tratamento são elevados, gerando inaptidão para o trabalho, ausência na frequência da rotina do trabalho e aposentadoria por invalidez. Desse modo, o faturamento familiar é comprometido, em razão do alto consumo de medicamentos e o índice de internações, resultado das complicações da DCNT (SATO et.al., 2017).

Durante os anos de 2011 a 2025 as despesas socioeconômicas relacionadas às DCNT são estimadas em US\$ 7 trilhões em países menos desenvolvidos, dessa forma, a redução global dos casos de DCNT proporcionaria uma condição socioeconômica mundial, pois, as despesas incluem assistência médica, aquisição de medicamentos, testes laboratoriais, acesso a atenção primária e orientações psicológicas (MALTA et al., 2017). 
A rápida transição da globalização tem influência direta nos hábitos alimentares, sedentarismo e alto consumo de alimentos ultraprocessados o que resultam no aumento das DCNT, visto que a prevalência de casos ocasiona em ausência de qualidade de vida, mortes prematuras e efeitos negativo socioeconômicos e familiares. Estudos apontam que as mesmas afetam em geral indivíduos de baixa renda, por apresentarem menores condições de acesso a postos e serviços de saúde, além de fatores de maior risco propícios ao desenvolvimento (MALTA et al., 2020).

O diabetes mellitus (DM) corresponde a uma disfunção metabólica na qual o corpo não produz insulina ou não consegue empregar adequadamente a insulina que produz. Incide dimensões epidêmicas, onde 425 milhões de pessoas são diagnosticadas com DM em todo o mundo. O aumento de ocorrências de indivíduos portadores de diabetes está relacionado a vários fatores como a transição nutricional e epidemiológica, sedentarismo, estilo de vida e excesso de peso (SBD, 2020).

A Hipertensão Arterial Sistêmica (HAS) é determinada pela elevação da pressão arterial $\geq 140 / 90 \mathrm{mmHg}$. Seu agravo está associado a fatores de riscos como obesidade, diabetes melito, dislipidemias e hábitos alimentares. Além de que, mantem-se relacionadas a episódios de doença renal crônica, insuficiência cardíaca, infarto agudo do miocárdio e acidente vascular encefálico. No Brasil a HAS atinge 36 milhões de indivíduos, colaborando para $50 \%$ dos óbitos relacionados a doença cardiovascular (SBC, 2016).

As Dislipidemias têm etiologia primária e secundária, nas primárias o distúrbio lipídico é de origem genética e as causas secundárias estão relacionadas a hábitos alimentares inadequados, a condições mórbidas e ao uso de medicamentos. A alimentação inadequada é percursora do aumento da mortalidade associadas a doenças cardiovasculares, onde o consumo excessivo de gorduras saturadas contribui para essa condição, por isso as intervenções nutricionais se 
fazem importante, visto que a mudança é relacionada e refletida na diminuição de eventos e mortes por problemas cardiovasculares (SBC, 2017).

A obesidade é uma condição de natureza multifatorial, e sua prevalência pode explicar o aumento de ocorrências de doenças crônicas não transmissíveis, pois está relacionada a enfermidade como hipertensão arterial, diabetes, dislipidemia, acidente vascular cerebral e também é indicada como importante situação que predispõe à mortalidade (SBC, 2019).

\section{Prevenção e Tratamento das DCNTs}

A prevenção das doenças crônicas não transmissíveis e de seus respectivos fatores de risco é primordial para garantir a redução de complicações, além de dispor de alta taxa de mortalidade, as DCNTs causam impactos econômicos para as famílias e a comunidade além de sobrecarregar o sistema único de saúde (SILOCCHI e JUNGES, 2017).

As equipes da atenção básica garantem consultas individuais e coletivas, acompanhamento domiciliar e atividades em grupos para os usuários portadores das doenças crônicas não transmissíveis. Para organizar a ação do cuidado, as redes de atenção em saúde juntamente com o município se organizam na execução do cuidado de acordo com a necessidade e a gravidade de cada paciente (BERTOLINI et al., 2020).

\section{Percepção dos usuários do SUS}

A utilização dos serviços de saúde pública se dá de acordo com a percepção do indivíduo em relação a sua saúde, onde a doença ou condição clínica é fator influenciador direto na procura de atendimento nos postos e serviços de saúde. Os pacientes portadores de DCNT por exemplo, são os quais mais acessam os serviços de saúde, fato este que explica o aumento das demandas por consultas de rotina (MALTA et al., 2017). 
A falta de recursos humanos dentro da atenção primária à saúde é uma das principais dificuldades encontrada nos municípios. Usuários do sistema único de saúde relatam que há deficiências associadas ao número de profissionais especialistas nas equipes. Nesse seguimento, afirmam que há uma demora acentuada entre o dia de agendamento até o dia da consulta ou do exame que será realizado (MOIMAZ et al., 2010).

A maioria dos usuários do SUS fazem uma avaliação positiva dos serviços prestados à comunidade, ainda que é observado algumas oposições quanto ao atendimento, como as longas filas de espera para obter assistência, a falta de receptividade por parte de atendentes, além das carências de matérias e recursos. Embora o SUS seja conhecido como uns dos mais completos sistemas de saúde pública do mundo, ainda assim comporta efeitos de problema de gestão e impactos econômicos (SOARES e CHEVITARESE, 2017).

\section{Quantitativo de nutricionistas na Atenção Básica}

Visto que as medidas de promoção de saúde e o acesso integral do cuidado tange uma prioridade no âmbito da saúde coletiva, a atenção básica abre espaço para o exercício do nutricionista dentro do sistema único de saúde. Com a criação do NASF no ano de 2008, a inserção do nutricionista na atenção básica se tornou ainda mais evidente (VASCONCELOS; SOUZA; SANTOS, 2015).

Em 2005 o Conselho Federal da Nutrição publicou a resolução CFN n 380, de 28 de dezembro de 2005 que foi revogada pela resolução $n^{\circ} 600$, de 25 de fevereiro de 2018, a qual dispões dos parâmetros numéricos mínimos de referência de um nutricionista por unidade básica de saúde, com carga horaria técnica semanal de 30 horas. Antes o quantitativo populacional era o balizador e, posteriormente, passou a ser carga-horária de trabalho dos profissionais membros (CFN, 2018). 


\section{MATERIAIS E MÉTODOS}

Trata-se de uma pesquisa aplicada exploratória, quantitativa, em caráter transversal que possibilita uma análise a partir das percepções dos usuários do SUS sobre a importância da inserção do nutricionista na Unidade Básica de Saúde (UBS). A pesquisa foi realizada em seis UBSs, localizadas na cidade de Três Corações-MG, as quais dispunham da presença de nutricionistas. A amostra foi determinada por usuários da rede de atenção primária à saúde, sendo incluídos homens e mulheres entre 18 e 59 anos.

Para coleta de dados foi aplicado um questionário de autoria própria com 13 perguntas sendo elas objetivas e discursivas, a fim de identificar o tempo de espera para consultas com o nutricionista da atenção básica, verificar se o nutricionista oferece suporte adequado no tratamento aos pacientes com doenças crônicas não transmissíveis, entender quais intervenções o nutricionista aplica no tratamento das doenças crônicas e, por fim, dados sociodemográficos dos participantes da pesquisa.

A coleta de dados foi realizada no período de agosto e setembro de 2021, no qual o referido questionário foi aplicado de forma individual e presencial, no formato de entrevista.

Para a participação nesta pesquisa os indivíduos deveriam ter idade entre 18 e 59 anos, serem atendidos pela nutricionista na atenção básica à saúde no SUS, possuírem alguma doença crônica não transmissível (DCNT), tais como: Obesidade, Diabetes Melittus, Hipertensão Arterial Sistêmica, Dislipidemia, entre outros. Além disso, foram excluídos da pesquisa aqueles pacientes que apresentam dificuldades de dialogar e que possuiam patologias mentais.

Ao fim da coleta de dados os questionários foram tabulados no Software Excel囚 e em seguida foi aplicada a técnica de análise de dados quantitativos, com análises estatísticas descritivas (percentual, média e desvio padrão ou mediana e intervalo de confiança), além de análises de correlação entre as variáveis. 
Adicionalmente, em respeito aos sujeitos do estudo, o questionário foi aplicado de forma individual para preservar o sigilo da identificação dos usuários entrevistados. Todos os participantes assinaram o Termo de Consentimento Livre e Esclarecido (TCLE). Além disso, a presente pesquisa foi submetida ao Comitê de Ética e Pesquisa (CEP) da Universidade Vale do Rio Verde - UninCor, via plataforma Brasil e aprovada sob CAAE de número 48602721.8.0000.5158.

\section{RESULTADOS E DISCUSSÃO}

A amostra da presente pesquisa constituiu-se de 50 adultos usuários do Sistema Único de Saúde de 18 a 59 anos e encontrou-se a média de idade de $44,6$ anos ( $D P \pm 13,5)$, no entanto a idade predominante do estudo é entre 50 e 59 anos, sendo maioria mulheres, representando $76 \%$ dos entrevistados, do qual maior parte da amostra do estudo é casada (48\%), a cor/etnia prevalente é a branca $(56 \%)$ e $44 \%$ possuem ensino médio completo (Tabela 1 ).

Foi constatado que a idade dominante do estudo é de 50 a 59 anos. Uma das hipóteses explicativas para tal, baseia-se em que os indivíduos só procuram a rede de saúde quando as doenças e complicações já estão instaladas (OLIVEIRA; LORENZATTO; FATEL, 2010).

Analisando o gênero da população estudada, observou-se um predomínio de procura de atendimento nutricional pelas mulheres, decorrentes de características pelas quais as mulheres se preocupam mais com hábitos saudáveis. Os homens se encontram mais resistentes quando se trata da procura de serviços de saúde (OLIVEIRA; LORENZATTO; FATEL, 2010).

Observando o grau de escolaridade da amostra, nota-se que a maior parte possui ensino médio completo, dessa forma, o alto nível de escolaridade contribui para a maior acessibilidade de informações, uma vez que, o indivíduo analfabeto ou com baixo nível de escolaridade apresenta dificuldade de compreensão e tem acesso limitado a determinadas informações por não dispor de meios de comunicação (CELESTINO e NEVES, 2009). 
Entre os usuários entrevistados, 44\% têm apenas uma Doença Crônica não Transmissível (DCNT) e apenas 4\% possuem quatro doenças associadas. O motivo predominante pelo qual os participantes buscaram acompanhamento nutricional foi pelo controle das DCNTs, representando $58 \%$ da amostra. Sendo que $82 \%$ dos pacientes relataram estar em assistência nutricional em menos de 1 mês. Sob outra perspectiva, apenas $4 \%$ estão recebendo orientações do nutricionista há mais de um ano (Tabela 1).

Com o aumento das doenças crônicas não transmissíveis foi despertado na população a importância do acompanhamento nutricional. A PNS (Pesquisa Nacional da Saúde) identificou um acréscimo do uso de serviços de saúde conforme o aumento do número de DCNT ou comorbidades, o que pode estar relacionado à maior percepção da gravidade da doença, dos seus riscos e de ameaça à saúde (MALTA et al., 2017).

Neste estudo, verificou-se que os pacientes estão em acompanhamento nutricional em menos de um mês, revelando que o profissional de nutrição está sendo demandado para promoção de saúde e prevenção de agravos. O nutricionista vem executando atribuições de grande importância na qualidade da promoção de saúde e tratamento, principalmente das DCNT, isso faz com que a procura pelo seu trabalho seja cada vez maior (CFN, 2017).

Tabela 1 - Análise descritiva das variáveis em estudo

\begin{tabular}{|c|c|c|}
\hline Variável & $\mathbf{N}^{\circ}$ & $\%$ \\
\hline \multicolumn{3}{|l|}{ PSF } \\
\hline Centro de Especialidades Médicas & 21 & 42 \\
\hline PSF Monte Alegre & 12 & 24 \\
\hline PSF São Pedro & 7 & 14 \\
\hline PSF Novo Horizonte & 1 & 2 \\
\hline PSF CAIC & 2 & 4 \\
\hline Assoditri & 7 & 14 \\
\hline
\end{tabular}


Bacharelado em Nutrição da UninCor e iniciação à pesquisa: Com a palavra os nossos estudantes

\begin{tabular}{|c|c|c|}
\hline \multicolumn{3}{|l|}{ Sexo } \\
\hline Feminino & 38 & 76 \\
\hline Masculino & 12 & 24 \\
\hline \multicolumn{3}{|l|}{ Cor / etnia } \\
\hline Branco & 28 & 56 \\
\hline Preto & 12 & 24 \\
\hline Pardo & 10 & 20 \\
\hline \multicolumn{3}{|l|}{ Estado civil } \\
\hline Solteiro & 16 & 32 \\
\hline Casado & 24 & 48 \\
\hline Divorciado & 3 & 6 \\
\hline Viúvo & 7 & 14 \\
\hline \multicolumn{3}{|l|}{ Escolaridade } \\
\hline Ensino fundamental incompleto & 19 & 38 \\
\hline Ensino fundamental completo & 2 & 4 \\
\hline Ensino médio incompleto & 3 & 6 \\
\hline Ensino médio completo & 22 & 44 \\
\hline Ensino superior completo & 2 & 4 \\
\hline Analfabeto & 2 & 4 \\
\hline \multicolumn{3}{|l|}{$N^{0}$ de doenças } \\
\hline Uma & 22 & 44 \\
\hline Duas & 19 & 38 \\
\hline Três & 7 & 14 \\
\hline Quatro & 2 & 4 \\
\hline \multicolumn{3}{|l|}{ Motivo da consulta } \\
\hline Controle de DCNT & 29 & 58 \\
\hline Controle de Diabetes & 4 & 8 \\
\hline Emagrecimento & 8 & 16 \\
\hline Reeducação alimentar & 9 & 18 \\
\hline
\end{tabular}




\begin{tabular}{|c|c|c|}
\hline \multicolumn{3}{|l|}{ Atendimento } \\
\hline Individual & 50 & 100 \\
\hline \multicolumn{3}{|l|}{ Tempo de acompanhamento } \\
\hline Menos de 1 mês & 41 & 82 \\
\hline Menos de 6 meses & 5 & 10 \\
\hline 6 meses ou mais & 1 & 2 \\
\hline 1 ano & 1 & 2 \\
\hline Mais de 1 ano & 2 & 4 \\
\hline \multicolumn{3}{|l|}{ Tempo de espera pela consulta } \\
\hline Menos de 1 mês & 38 & 76 \\
\hline 1 mês & 9 & 18 \\
\hline 2 meses & 3 & 6 \\
\hline \multicolumn{3}{|l|}{ Ações desenvolvida pelo nutricionista na $A B$} \\
\hline $\begin{array}{l}\text { Atendimento para adultos de } 18 \text { a } 59 \text { anos, adolescentes, } \\
\text { domiciliar, obesos, desnutridos, DCNT }\end{array}$ & 15 & 30 \\
\hline $\begin{array}{l}\text { Atendimento para adultos de } 18 \text { a } 59 \text { anos, adolescentes, obesos, } \\
\text { desnutridos, DCNT }\end{array}$ & 6 & 12 \\
\hline Atendimento para adultos de 18 a 59 anos, obesos, desnutridos, DCNT & 22 & 44 \\
\hline Atendimento para obesos, DCNT & 7 & 14 \\
\hline
\end{tabular}

Fonte: próprio autor (2021). 
A figura 1 representa as associações das doenças crônicas não transmissíveis. Destaca- se que $16 \%$ da amostra possui obesidade e $12 \%$ possuem diabetes e hipertensão arterial sistêmica (HAS) associadas. Ainda é possível observar que $10 \%$ da amostra possui somente HAS e $8 \%$ possuem somente diabetes. De outro modo, $8 \%$ da amostra é portadora de obesidade associada à HAS.

Conforme a pesquisa realizada em 2019 pela Vigilância de Fatores de Riscos e Proteção para Doenças Crônicas por Inquérito Telefônico (VIGITEL), 20,3\% dos brasileiros são portadores de obesidade, 83,1\% possuem hipertensão arterial e $7,4 \%$ da população possui Diabetes.

Figura 1 - Percentual de pessoas com patologias

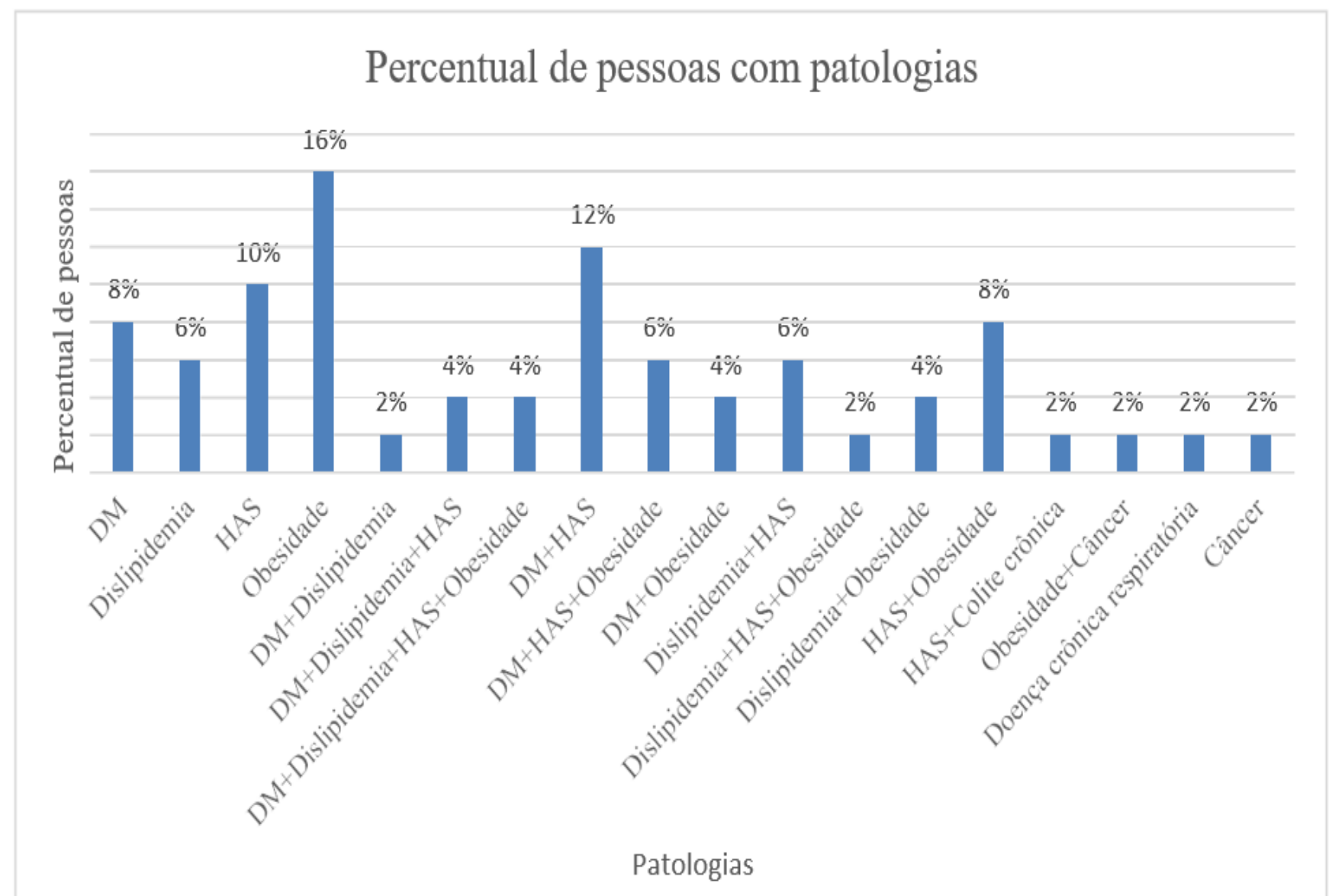

Fonte: próprio autor (2021). 
Em relação às questões sobre o atendimento com o nutricionista, observou-se que $76 \%(n=38)$ responderam que o número de vagas com o nutricionista é suficiente para a demanda da população do município e 100\% $(n=50)$ relataram que o tratamento desenvolvido pelo nutricionista é eficaz para suprir as necessidades da doença. No entanto, $100 \%(n=50)$ da amostra relataram não participar de nenhuma ação desenvolvida na atenção básica pelo nutricionista, porém, alguns participantes justificaram que antes do período da pandemia, alguns PSF dispunham de ações coletivas elaboradas pelo nutricionista (Figura 2).

Durante a coleta de dados nas UBS, foi possível observar que muitos dos pacientes não compareciam a consulta agendada, o que pode refletir na fila de espera pelo atendimento. No Centro de Especialidades Médicas (CEM) eram agendados 4 pacientes por dia e apenas 2 compareciam a consulta. Segundo Cruz et al (2018) o não comparecimento em consultas é um acontecimento frequente em todos os serviços de saúde da rede pública do Brasil. Sendo assim, estudos apontam que quanto maior o tempo entre o agendamento e a data efetiva da consulta, maior a probabilidade de não comparecimento.

Figura 2 - Atendimento com o nutricionista

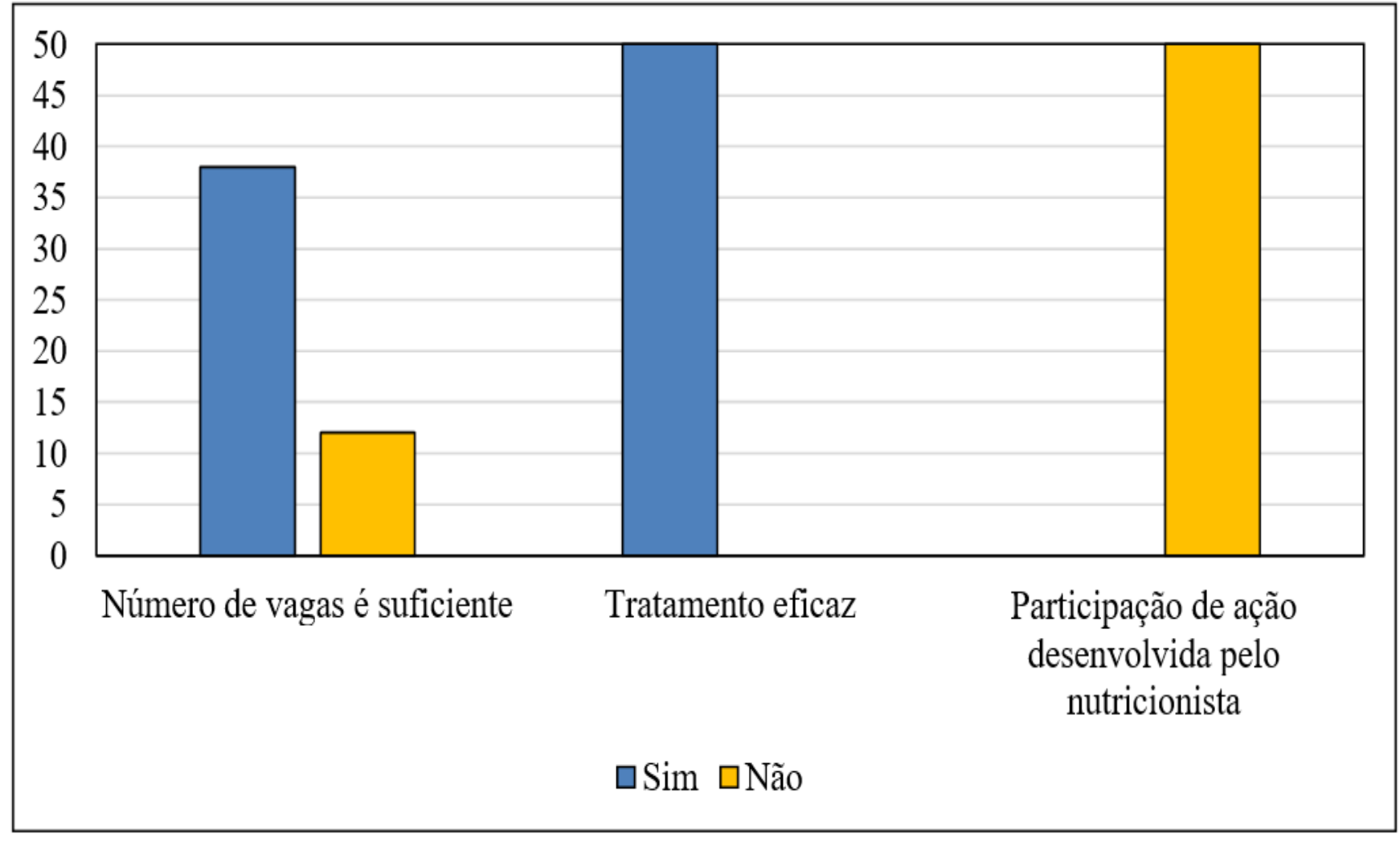

Fonte: próprio autor (2021). 
Realizou-se o teste Qui-quadrado com o objetivo de verificar se o sexo e a escolaridade influenciam nas demais variáveis. O teste não foi realizado para as variáveis estado civil, pois não é objetivo deste estudo e para as variáveis "atendimento", o "tratamento eficaz" e "participação em ação desenvolvida na atenção básica" todos os entrevistados deram a mesma resposta nestas perguntas, por isso, a análise não se faz eficaz (Tabela 2).

Tabela 2 - Resultado do Teste Qui-Quadrado comparando sexo e escolaridade com as demais variáveis

\begin{tabular}{|c|c|c|}
\hline Variáveis & Sexo & Escolaridade \\
\hline Cor/etnia & 0,509225546 & 0,131702313 \\
\hline Sexo & -- & 0,079014181 \\
\hline Escolaridade & 0,079014181 & -- \\
\hline No de doenças & 0,326354707 & 0,295044612 \\
\hline Doenças & 0,171293708 & 0,499289433 \\
\hline Motivo da consulta & 0,220458439 & 0,866886983 \\
\hline $\begin{array}{c}\text { Tempo de acompanhamento } \\
\text { Tempo de espera pela consulta }\end{array}$ & 0,250649094 & $0,001541275^{*}$ \\
\hline $\begin{array}{c}\text { Número de vagas para atendimento } \\
\text { com o nutricionista é suficiente }\end{array}$ & 0,100235472 & 0,581581164 \\
\hline $\begin{array}{c}\text { açes que o nutricionista realiza na } \\
\text { atenásica }\end{array}$ & 0,072140844 & 0,524897189 \\
\hline
\end{tabular}

* valor de $p<0,05$

Fonte: próprio autor (2021). 
Bacharelado em Nutrição da UninCor e iniciação à pesquisa: Com a palavra os nossos estudantes

Realizou-se correlação das variáveis com sexo e escolaridade e observou-se que essas varáveis correlacionadas no Qui-quadrado com a variável sexo não se obteve um resultado estatisticamente significativo. Sob outra perspectiva, as variáveis correlacionadas com escolaridade obtiveram-se um valor estatisticamente significativo $(p<0,05)$, correlacionando o tempo de acompanhamento com escolaridade. No entanto, o resultado relevante apresenta-se a partir das pessoas que tinham ensino fundamental completo, ensino superior completo e analfabeto em relação a seis meses ou mais de acompanhamento e nessas mesmas categorias apresentou-se também nas pessoas com 1 ano de acompanhamento nutricional.

Neste estudo, observou-se que a escolaridade é um fator que influenciou na prevalência de doenças crônicas não transmissíveis. Esse dado pode estar relacionado ao fato de que quanto menor o nível de conhecimento das doenças e seus respectivos riscos e complicações, mais é tardio a prevenção e o tratamento das DCNTs. É possível observar também, que indivíduos com maior nível de escolaridade tendem a consumir mais alimentos saudáveis e realizar a prática de atividade física, visto que são fatores fundamentais para a prevenção das DCNTs (SATO et.al., 2017).

\section{CONCLUSÃO}

Tendo em vista os argumentos apresentados, o nutricionista da atenção básica $(A B)$ oferece suporte eficaz no tratamento das doenças crônicas não transmissíveis. A população reconhece a importância do mesmo para tratamento e prevenção de inúmeras doenças, principalmente as DCNT e em parte os usuários do SUS estão satisfeitos com o trabalho realizado pelo nutricionista.

O estudo realizado apresentou limitações importantes quanto a sua população, pois os resultados encontrados podem não ser de total exatidão, uma vez que a qualidade das respostas pode ser afetada por omissões ou distorções por parte dos entrevistados, comprometendo assim seu valor real e influenciando em 
sua eficácia. Outra limitação se atribui ao tamanho da amostra, que ao se expressar em número reduzido, permite considerar os resultados obtidos somente para a população em questão.

Ao longo do desenvolvimento deste trabalho identificou-se uma ausência de estudos sobre este assunto. Sugiro que outros autores apresentem estudos sobre este tema afim de ampliar o entendimento do fenômeno estudado, ou para buscar confirmação cientifica dos resultados obtidos.

Contudo, uma vez que o município investe em ações para prevenir as DCNT, menor será a sobrecarga no Sistema Único de Saúde, pois, preconizar o controle dos principais fatores de risco e futuras complicações pode garantir que as gerações futuras não sofram o risco de adoecimento precoce devido essas doenças, além de reduzir os altos custos gerados na saúde pública.

\section{REFERENCIAS}

AZEVEDO, Ana Lucia Soares de. Doenças crônicas e qualidade de vida na atenção primáriaà saúde. Cad. Saúde Pública, Rio de Janeiro, v. 29, n. 9, p. 17741782, set. 2013

BARROS, Dayane de Melo et al. A atuação e importância do nutricionista no âmbito da saúde pública. Brazilian Journal Of Development, v. 5, n. 10, p. 1771517728, out. 2019.

BORTOLINI, Gisele Ane et al. Ações de alimentação e nutrição na atenção primária à saúdeno Brasil. Revista Panam Salud Publica, v. 44, n. 39, p. 1-8, 2020.

CAMPOS, Dalvan Antonio de; VIEIRA, Marcelo; PIRES, Rodrigo Otávio Moretti. Avaliação do processo de trabalho dos nutricionistas dos núcleos de apoio à saúde da família do Meio Oeste de Santa Catarina. Saúde e Transformação Social, Florianópolis, v. 8, n. 1, p. 84-97, 2017.

CARDIOLOGIA, Sociedade Brasileira de. $7^{\circ}$ Diretriz Brasileira de Hipertensão Arterial. Arquivos Brasileiros de Cardiologia, São Paulo, v. 107, n. 3, p. 1-83, 5 set. 2016. 
Bacharelado em Nutrição da UninCor e iniciação à pesquisa: Com a palavra os nossos estudantes

CARDIOLOGIA, Sociedade Brasileira de. Atualização da Diretriz brasileira de dislipidemiase prevenção da aterosclerose. Arquivos Brasileiros de Cardiologia, v. 109, n. 2, p. 1-76, ago. 2017.

CARDIOLOGIA. Sociedade Brasileira de. Atualização da Diretriz de Prevenção Cardiovascular da Sociedade Brasileira de Cardiologia - 2019. Arquivos Brasileiros de Cardiologia, v. 113, n. 4, p. 789-891, 2019.

CELESTINO, M.; NEVES, C. S. Perfil Socioecônomico E Estado Nutricional Dos Pacientes Atendidos Na Clínica De Nutrição Da Faculdade União Das Américas. Seminário Científico de Nutrição, v. 1, n. 1, 2009.

CONSELHO REGIONAL DE NUTRICIONISTA NN 5 . Entidades de nutrição reforçam a valorização dos nutricionistas. 02 de fevereiro de 2016. Disponível em: $<$ https://crn5.org.br/entidades-de-nutricao-reforcam-valorizacao-dos-nutricionistas/> Acesso em: 06 de novembro de 2018

Conselho Federal de Nutricionista. Resolução CFN no 600, de 25 de fevereiro de 2018. Disponível em: < https://www.cfn.org.br/wp- content/uploads/resolucoes/Res_600_2018.htm >. Acesso em: 31 mai. 2021

CRUZ, Danilson Ferreira da et al. A regulação da atenção à saúde bucal e o absenteísmo: cenários e possibilidades. Revista Família, Ciclos de Vida e Saúde no Contexto Social, v. 6, n. 2, p. 228, 5 abr. 2018.

DIABETES, Sociedade Brasileira de. Sociedade Brasileira de Diabetes. Editora CientíficaClannad, p. 1-489, 2019-2020..

FAUSTINO-SILVA, Daniel Demétrio; JUNG, Natália Miranda; JUNG, Natália Miranda.Abordagem comportamental como estratégia para o tratamento da obesidade na Atenção Primária à Saúde. Aps em Revista, v. 1, n. 3, p. 189-197, set/ dez. 2019.

LIMA, Maria Raquel Silva et al. A visão dos agentes comunitários de saúde sobre a importância do nutricionista na atenção básica. Brazilian Journal Of Health Review, v. 2, n.6, p. 6041-6049, nov/dez 2019.

MALTA, Deborah Carvalho et al. Doenças crônicas não transmissíveis e a utilização deserviços de saúde: análise da pesquisa nacional de saúde no Brasil. Revista de Saúde Pública, v. 51, n. 1, p. 1-10, 2017. 
Bacharelado em Nutrição da UninCor e iniciação à pesquisa: Com a palavra os nossos estudantes

MALTA, Deborah Carvalho et al. Doenças Crônicas Não Transmissíveis e fatores de risco eproteção em adultos com ou sem plano de saúde. Ciência e Saúde Coletiva, v. 25, n. 8, p. 2973-2983, ago. 2020.

MOIMAZ, Suzely Adas Saliba et al. Satisfação e percepção do usuário do SUS sobre o serviço público de saúde. Physis Revista de Saúde Coletiva, Rio de Janeiro, v. 20, n. 4, p.1419-1440, 2010

OLIVEIRA, A. F.; LORENZATTO, S.; SOUZA, E. C. F. Perfil de Pacientes que procuram atendimento nutricional. Revista Salus, v. 2, n. 1, p. 13-21, 2010.

O papel do nutricionista na atenção primária à saúde. Elisabetta Recine; Marília Leão; Mariade Fátima Carvalho; [organização Conselho Federal de Nutricionistas]. - 3.ed.- Brasília, DF:Conselho Federal de Nutricionistas, 2015.

Organização Mundial da Saúde. Prevenção de doenças crônicas: um investimento vital.Disponível em: < https://www.nescon.medicina.ufmg.br/biblioteca/imagem/1852.pdf > Acesso em: 23 mai. 2021.

ROCHA-BRISCHILIAR, Sheila Cristina et al. Doenças Crônicas não Transmissíveis e Associação com Fatores de Risco. Revista Brasileira de Cardiologia, v. 27, n. 1, p. 35-42,jan/fev. 2014.

SANTOS, Lenir. Região de saúde e suas redes de atenção: modelo organizativosistêmico dosus. Ciência e Saúde Coletiva, v. 22, n. 4, p. 1281-1289, 2017.

SATO, Tatiana et al. Doenças crônicas não transmissíveis em usuários de unidades de saúdeda família - prevalência, perfil demográfico, utilização de serviços de saúde e necessidades clínicas. Revista Brasileira de Ciências da Saúde, v. 21, n. 1 , p. $35-42,2017$

SILOCCHI, Cassiane; JUNGES, José Roque. Equipes de atenção primária: dificuldades nocuidado de pessoas com doenças crônicas não transmissíveis. Trab. Educ. Saúde. Rio de Janeiro, v. 15, n.2, p. 599-615, mar. 2017.

SOARES, Gabriela Ponce; CHEVITARESE2, Leila. SUS: Da teoria à prática. Revista Redede Cuidados em Saúde, p. 1-5, 2017. 
TAVARES, Helder Cardoso et al. A importância da inserção do profissional nutricionista nocampo da atenção primária em saúde. Rev. e-ciência V. 6, n. 2, p. 108 - 113. 2018.

TAVARES, Helder Cardoso et al. A importância da inserção do nutricionista na Unidade Básica de Saúde: percepção dos profissionais de saúde. Revista E-Ciência, Juazeiro do Norte, V. 4, n. 1, p. 89-98, out. 2016.

VASCONCELOS, Ivana Aragão Lira; SOUSA, Maria Fátima de; SANTOS, Leonor Maria Pacheco. Evolução do quantitativo de nutricionistas na Atenção Básica do Brasil: a contribuição dos núcleos de apoio à saúde da família e da estratégia saúde da família de 2007a 2013. Revista de Nutrição, Campinas, v. 28, n. 4, p. 431-450, ago. 2015. 
doi $10.48209 / 978-65-89949-12-0$

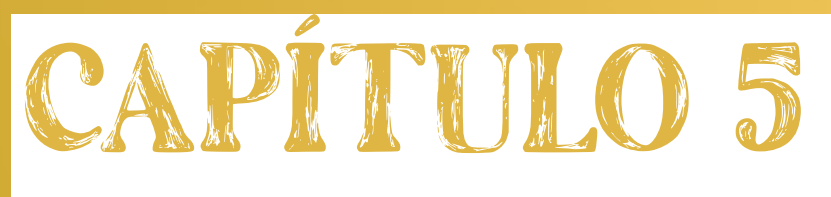

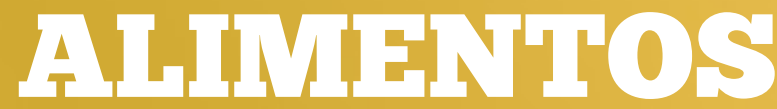

QUE A UDDAM DA

PREVIFNÇÃAO DO

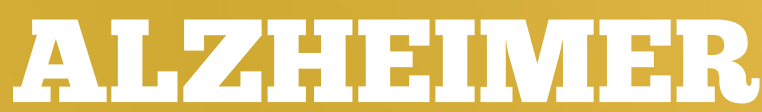

Yanka Lorena Gomes de Assis Ana Luiza Rodrigues Pellegrinelli 


\section{INTRODUÇÃO}

O Alzheimer é uma doença degenerativa e progressiva, dentre seus sintomas, estão presentes a perda irreversível das funções intelectuais, sendo perda da memória recente, alteração no humor, comportamento, linguagem, planejamento, raciocínio e julgamento, causando um grau significativo de dependência, carecendo de auxílio de seus familiares ou cuidadores (DIOGO, 2021; INSTITUTO ALZHEIMER BRASIL, 2021).

O indivíduo com essa demência tem sua saúde nutricional debilitada por efeito de algumas intercorrências como a dificuldade de mastigação, deglutição, em identificar os alimentos, falta de apetite, apatia pela alimentação, falta de conhecimento sobre a importância da alimentação agravam o risco de desnutrição e desidratação.

\section{REVISÃO DE LITERATURA}

\subsection{Alzheimer}

De acordo com o Instituto Brasileiro de Geografia e Estatística (IBGE, 2010), 20 milhões de pessoas no país tem 60 anos ou mais, o que significa cerca de $10 \%$ da população. Segundo a projeções da Organização Mundial de Saúde (OMS) de 1950 até 2025 a população brasileira aumentará em 15\% representando 32 milhões de pessoas com idade superior ou igual a 60 anos, alcançando o sexto lugar no ranking com maior quantidade de idosos no mundo (DIOGO, 2021).

A definição estabelecida no Protocolo Clínico e Diretrizes Terapêuticas Doença de Alzheimer, do Ministério da Saúde (2017, p. 3), afirma:

A doença de Alzheimer (DA) é um transtorno neurodegenerativo progressivo e fatal que se manifesta por deterioração cognitiva e da memória, comprometimento progressivo das atividades de vida diária e uma variedade de sintomas neuropsiquiátricos e de alterações comportamentais (BRASIL, 2017). 
O Alzheimer foi notado pela primeira vez em 1906 pelo doutor Alois Alzheimer., hoje representa de 50 a $70 \%$ dos casos de doenças que causam dependências e demênciassenis, dado que pessoas com mais de 65 anos tem a maior ocorrência da doença (Instituto Alzheimer Brasil, 2021).

No Brasil 1,6\% da população com idade de 65 até 69 anos sofre com essa demência e pessoas com mais de 84 anos pode alcançar a taxa38,9 \% (WEBER et al., 2019).

O passo mais importante para assegurar que a pessoa portadora do Alzheimer tenha uma qualidade de vida melhor é o diagnóstico precoce, desta forma garantindo planos adequados para o futuro (INSTITUTO ALZHEIMER BRASIL, 2021).

\subsection{Alimentação e Alzheimer}

O Programa Nacional para a Promoção da Alimentação Saudável Nutrição e Doença de Alzheimer, afirma que vitaminas B2 (riboflavina), B6 (piridoxina), B12 (metilcobalamina) B9 (ácido fólico) e vitamina C sãoessenciais para alguns compostos do Sistema Nervoso Central (SNC), como a dopamina e noradrenalina (NASCIMENTO 2020).

Principais nutrientes envolvidos na prevenção da doença de Alzheimer são: Vitamina B1 (Tiamina), Vitamina B6 (Piridoxina), Vitamina B9 (Folato), Vitamina B12 (Cobalamina), Vitamina C (ácido ascórbico), Vitamina E, Vitamina D, Selênio e Ômega 3 (BIGUETI et al., 2018).

\subsubsection{Antioxidantes}

Estudos indicam que as vitaminas $\mathrm{C}$ e $\mathrm{E}$, os flavonoidese o selênio podem evitar danos oxidativos que são ocasionados ou decorrentes da doença Alzheimer. Visto que esses elementos são possivelmente protetores na existência da demência, a alimentação apropriada através desses micronutrientes é mais recomendável do que a suplementação (CARDOSO; PAIVA, 2017). 


\subsubsection{Vitaminas do complexo B e Folato}

Em pacientes com a doença Alzheimer é percebido um baixo consumo de alguns micronutrientes, em especial o folato e a vitamina B12. O folato e a vitamina B12 estãosendo associados ao comprometimento cognitivo o que agrava o fator de risco para desnutrição.Além disso, com esses baixos níveis, acabam elevando a concentração de homocisteína, que é neurotóxico(CAMPOS et al., 2020).

Diferentes pesquisas apontaram uma combinação entre o consumo de alimentos ricos em vitaminas do complexo B e uma menor prevalência de desenvolver a doença Alzheimer, por outro lado com o crescimento nos níveis de homocisteínae declínio de vitamina B12, o risco de progredir a doença Alzheimer aumenta significativamente (CARDOSO; PAIVA, 2017).

\subsubsection{Vitamina D}

O consumo inferior ao recomendado de alimentos fonte de vitamina $D$ podem indicar um alto índice de desenvolvimento da doença Alzheimer, dado que é relevante na prevenção de doenças cardiovasculares e na neuroproteção, os mecanismos implícitos podem resultar no envolvimento das vias de proteína $A \beta$, metabólicas, vasculares, antioxidantes e anti- inflamatórias. A carência desta vitamina é frequente em idosos e pode acentuar a doença de Alzheimer, sendo necessário atingir os níveis recomendados (CARDOSO; PAIVA, 2017).

\subsubsection{Tiamina}

A doença de Alzheimer é caracterizada pela deficiência de tiamina que resulta em uma menor competência do metabolismo da glicose, hiperfosforilação da proteína TAU, formação de placa e alterações na memória. Diante estes dois fatores, a desregulação da glicose e a tiamina, uma ótima alternativa para elevar 
a quantidade de tiamina consumida são as leguminosas, já que é um alimento rico em tiamina e a liberação de glicose na corrente sanguínea é mais lenta, assim auxilia na promoção da demência. É essencial que o consumo das leguminosas sejam complementares a uma alimentação saudável, com todos os nutrientes necessários, por exemplo a dieta alimentar mediterrâneo (CARVALHO; REAL, 2015).

\subsection{Alzheimer e Comportamento Alimentar}

O idoso com a doença Alzheimer pode manifestar comprometimento no hábito alimentar e mudanças no apetite decorrente a progressão da doença e os consecutivos agravos neurológicos e cognitivos, assim indicando alto risco de disfagia e certificando que há associação entre as duas condições, a proporção que a doença avança (BRITO et al., 2020).

Os portadores desse demência apresentam perda ponderal considerável e são incontáveis as hipóteses que esclarecem a perda de peso nesses casos: elevado gasto energético, atrofia do córtex temporal mediano, dependência funcional, úlcera de decúbito, risco de quedas e infecções. Além do mais, as desordens do comportamento e as cognitivas podem afetar a nutrição, por exemplo dificuldades de mastigação e deglutição, desordens comportamentais que deixa-os lentos durante a alimentação e distraídos, dificultando hábitos alimentares apropriados. Por esses motivos pode ocorrer um desequilíbrio nutricional e resultar em perda de peso e deficiência de alguns nutrientes (MACHADO., 2009).

\section{MATERIAIS E MÉTODOS}

O presente estudo foi elaborado mediante a uma revisão de literatura referente a alimentos que ajudam na prevenção do Alzheimer, com a pesquisa e análise de dados obtidos a partir de artigos científicos. 
Conforme Santos e Candeloro (2006, p. 43).

A Revisão Bibliográfica também é denominada de Revisão de Literatura ou Referencial Teórico. A Revisão Bibliográfica é parte de um projeto de pesquisa, que revela explicitamente o universo de contribuições científicas de autores sobre um tema específico.

Os critérios de inclusão foram: o artigo estar indexado na base de dados do Google Acadêmico. Foram incluídos artigos no idioma português de acordo com os descritores (palavras-chave): Alimentação e Prevenção do Alzheimer, Prevenção e Alzheimer e Alimentos Funcionais e Doença Neurodegenerativa, com anos de publicação entre 2016 e 2021, onde foram encontrados 20060 artigos.

Foram selecionados primeiramente 139 artigos pela leitura de seus títulos, 98 desses não cumpriram com a finalidade da pesquisa e foram descartados. Dos que sobraram foram lidos o resumo de 57 artigos e foram excluídos pois os conteúdos não corresponderem com o objetivo deste trabalho. Dos artigos que restaram foram lidos integralmente, analisados e selecionados um total de 23 artigos.

Como o presente trabalho trata-se de uma revisão de literatura, foi necessário a submissão ao Comitê de Ética em Pesquisa (CEP). 


\section{RESULTADOS E DISCUSSÃO}

Tabela1: Artigos selecionados para a revisão.

\begin{tabular}{|c|c|c|c|c|}
\hline Linha & $\begin{array}{c}\text { Pesquisadorl } \\
\text { Ano }\end{array}$ & Nutriente & $\begin{array}{c}\text { Principais } \\
\text { fontes } \\
\text { alimentares }\end{array}$ & Mecanismo de ação \\
\hline Linha 1 & $\begin{array}{l}\text { Silva et al. } \\
\text { (2016). }\end{array}$ & Antioxidantes. & $\begin{array}{l}\text { Açafrão, } \\
\text { aveia, azeite } \\
\text { de oliva } \\
\text { e frutas } \\
\text { cítricas. }\end{array}$ & $\begin{array}{l}\text { O baixo consumo de alimentos an- } \\
\text { tioxidantes, tem como consequência } \\
\text { o aumento do estresse oxidativo, } \\
\text { que resulta em lesões encefálicas, } \\
\text { as quais, dessa maneira, estão } \\
\text { associadas a disfunções cognitivas. } \\
\text { Alguns estudos analisados tem } \\
\text { associado a disfunção mitocon- } \\
\text { drial à doença de Alzheimer. Essa } \\
\text { disfunção provoca alterações das } \\
\text { enzimas que participam das cadeias } \\
\text { transportadora de eletrões, produ- } \\
\text { ção de espécies relativas de oxigê- } \\
\text { nio, acarretando anomalias estrutu- } \\
\text { rais, estresse oxidativo e apoptose. } \\
\text { Todas essas modificações já foram } \\
\text { descritas em estádios iniciais da } \\
\text { doença de Alzheimer, antes da } \\
\text { deposição das placas } \\
\text { beta-amiloides e associadas à } \\
\text { fosforilação da proteína tau. }\end{array}$ \\
\hline Linha 2 & $\begin{array}{l}\text { Roque et al. } \\
\text { (2019). }\end{array}$ & $\begin{array}{c}\text { epigalocate- } \\
\text { quina- 3- } \\
\text { galato. }\end{array}$ & Chá verde. & $\begin{array}{l}\text { No chá verde está presente a } \\
\text { epigalocatequina-3- galato (EGCG) } \\
\text { que reduz a atividade da enzima } \\
\text { DYRK1A. Os níveis altos dessa } \\
\text { enzima estão associados ao maior } \\
\text { risco de Alzheimer. }\end{array}$ \\
\hline
\end{tabular}




\begin{tabular}{|c|c|c|c|c|}
\hline Linha 3 & $\begin{array}{c}\text { Moraes et al. } \\
\text { (2016). }\end{array}$ & Flavonóides. & Chá verde. & $\begin{array}{l}\text { Os flavonóides podem contribuir na } \\
\text { prevenção de doenças neurodege- } \\
\text { nerativas como o Alzheimer quando } \\
\text { ingeridos regularmente por meio de } \\
\text { uma dieta, em razão de seus efeitos } \\
\text { anticarcinogênico, antioxidantes, } \\
\text { antiinflamatórios, hipoglicemiantes } \\
\text { e antiaterogênicos, além de ativida- } \\
\text { des antivirais e antibacterianas, os } \\
\text { quais repercute-se de modo direto } \\
\text { na prevenção e tratamento de vá- } \\
\text { rias doenças neurodegenerativas. }\end{array}$ \\
\hline Linha 4 & $\begin{array}{c}\text { Cunha et al. } \\
\text { (2016). }\end{array}$ & Magnesio. & $\begin{array}{l}\text { Abacate, } \\
\text { nozes, } \\
\text { amêndoas, } \\
\text { leguminosas } \\
\text { e peixes. }\end{array}$ & $\begin{array}{l}\text { magnésio apresenta efeitos na } \\
\text { memória e aprendizagem nos seres } \\
\text { humanos. Níveis abaixo do reco- } \\
\text { mendado de magnésio no liquido } \\
\text { cefalorraquidiano podem ser um } \\
\text { fator motivador da degeneração } \\
\text { neural e como resultado do declínio } \\
\text { cognitivo devido a deficiência desse } \\
\text { mineral está associada com aumen } \\
\text { to do estresse oxidativo, fator este } \\
\text { que potencializa o surgimento da } \\
\text { doença de Alzheimer. }\end{array}$ \\
\hline Linha 5 & $\begin{array}{c}\text { Roque et al. } \\
\text { (2019). }\end{array}$ & Polifenóis. & Romã. & $\begin{array}{l}\text { Os polifenóis antioxidantes têm } \\
\text { obtido resultados que demonstra- } \\
\text { ram ser uma boa alternativa para } \\
\text { retardar a progressão da doença } \\
\text { Alzheimer. Um exemplo é a romã, } \\
\text { que é capaz de reduzir o dano oxi- } \\
\text { dativo, inibir citocinas, melhorar } \\
\text { a memória, função motora e reduzi } \\
\text { a ansiedade. }\end{array}$ \\
\hline
\end{tabular}




\begin{tabular}{|c|c|c|c|c|}
\hline Linha 6 & $\begin{array}{c}\text { Cardoso et al. } \\
\text { (2016). }\end{array}$ & Polifenóis. & $\begin{array}{c}\text { Cravo da } \\
\text { Índia, anis } \\
\text { estrelado e } \\
\text { cacau em pó. }\end{array}$ & $\begin{array}{l}\text { Os polifenóis são atuantes nas } \\
\text { células cerebrais, impedindo a ação } \\
\text { dos radicais livres, promovendo-as } \\
\text { proteção, de modo que os danos } \\
\text { degenerativos que geralmente são } \\
\text { causados por estresse oxidativo } \\
\text { sejam amenizados. }\end{array}$ \\
\hline Linha 7 & $\begin{array}{l}\text { Bigueti et al. } \\
\text { (2018). }\end{array}$ & Ômega 3. & $\begin{array}{c}\text { Salmão, } \\
\text { sardinhas, } \\
\text { atum, } \\
\text { mariscos, } \\
\text { truta, óleos } \\
\text { vegetais } \\
\text { (canola, soja } \\
\text { e linhaça) } \\
\text { e nozes. }\end{array}$ & $\begin{array}{l}\text { EPA e DHA ampliam a fluidez } \\
\text { da membrana plasmática, que } \\
\text { intervém na neurotransmissão e } \\
\text { na sinapse, alternado o } \\
\text { funcionamento do cérebro. }\end{array}$ \\
\hline Linha 8 & $\begin{array}{c}\text { Santos et al. } \\
\text { (2019). }\end{array}$ & Ômega 3. & $\begin{array}{c}\text { Salmão, } \\
\text { sardinhas, } \\
\text { atum, } \\
\text { mariscos, } \\
\text { truta, óleos } \\
\text { vegetais } \\
\text { (canola, soja } \\
\text { e linhaça) e } \\
\text { nozes. }\end{array}$ & $\begin{array}{l}\text { O ômega 3exerce o papel estrutural } \\
\text { e funcional nas células cerebrais, } \\
\text { células da glia e células dos } \\
\text { endotélios, além de atuar em } \\
\text { processos fisiológicos como a } \\
\text { formação da memória e do controle } \\
\text { da neuroinflamação. }\end{array}$ \\
\hline Linha 9 & $\begin{array}{c}\text { Oliveira et al. } \\
\text { (2018). }\end{array}$ & Ômega 3. & $\begin{array}{c}\text { Salmão, } \\
\text { sardinhas, } \\
\text { atum, } \\
\text { mariscos, } \\
\text { truta, óleos } \\
\text { vegetais } \\
\text { (canola, soja } \\
\text { e linhaça) e } \\
\text { nozes. }\end{array}$ & $\begin{array}{c}\text { O ômega } 3 \text { proporciona muitos } \\
\text { benefícios ao sistema } \\
\text { cardiovascular, ajuda a diminuir } \\
\text { o risco da perda, diminuição } \\
\text { cognitiva na terceira idade, modula } \\
\text { o quadro da dislipidemia, reduz o } \\
\text { processo de aterosclerose e atua } \\
\text { no controle da hipertensão arterial } \\
\text { combatendo os efeitos } \\
\text { pró-inflamatórios do ômega } 6\end{array}$ \\
\hline
\end{tabular}




\begin{tabular}{|c|c|c|c|c|}
\hline $\begin{array}{c}\text { Linha } \\
10\end{array}$ & $\begin{array}{l}\text { Melo e et al. } \\
\quad(2020) .\end{array}$ & Ômega 3. & $\begin{array}{l}\text { Salmão, } \\
\text { sardinhas, } \\
\text { atum, } \\
\text { mariscos, } \\
\text { truta, óleos } \\
\text { vegetais } \\
\text { (canola, soja } \\
\text { e linhaça) e } \\
\text { nozes. }\end{array}$ & $\begin{array}{l}\text { O ômega } 3 \text { é um nutriente } \\
\text { indispensável para a saúde mental } \\
\text { e, consequentemente, para uma } \\
\text { melhor qualidade de vida para } \\
\text { idosos, pois são de suma } \\
\text { importância para a estrutura e } \\
\text { função normal do cérebro, dado } \\
\text { que os fosfolipídios compostos por } \\
\text { esse ácido graxo têm uma } \\
\text { considerável função na tradução } \\
\text { dos sinais nervosos, } \\
\text { na integridade da } \\
\text { membrana celular e na sua fluidez. }\end{array}$ \\
\hline $\begin{array}{c}\text { Linha } \\
11\end{array}$ & $\begin{array}{c}\text { Borges et al. } \\
\quad(2021) .\end{array}$ & Ômega 3. & $\begin{array}{c}\text { Salmão, } \\
\text { sardinhas, } \\
\text { atum, } \\
\text { mariscos, } \\
\text { truta, óleos } \\
\text { vegetais } \\
\text { (canola, soja } \\
\text { e linhaça) e } \\
\text { nozes. }\end{array}$ & $\begin{array}{c}\text { O ômega } 3 \text { auxilia na } \\
\text { comunicação entre os } \\
\text { neurotransmissores, fazendo com } \\
\text { que a memória e a concentração } \\
\text { sejam fortalecidas. Sua ingestão é } \\
\text { recomendada, pois facilita } \\
\text { no processo de aprendizado. }\end{array}$ \\
\hline $\begin{array}{c}\text { Linha } \\
12\end{array}$ & $\begin{array}{c}\text { Lemes et al. } \\
\text { (2017). }\end{array}$ & Vitamina B1. & Pequi. & $\begin{array}{l}\text { A utilização do Caryocar brasiliense } \\
\text { Camb. na alimentação é benéfico } \\
\text { para a população, de uma forma } \\
\text { geral, por apresentar ação antio- } \\
\text { xidante, o que diminui os danos } \\
\text { oxidativos, podendo retardar o en- } \\
\text { velhecimento precoce das células e } \\
\text { evitar o desenvolvimento das } \\
\text { doenças neurodegenerativas. }\end{array}$ \\
\hline $\begin{array}{c}\text { Linha } \\
13\end{array}$ & $\begin{array}{l}\text { Balbino } \\
\text { (2021). }\end{array}$ & Vitamina B1. & $\begin{array}{l}\text { Legumes } \\
\text { verdes, frutas } \\
\text { e peixes. }\end{array}$ & $\begin{array}{c}\text { A deficiência de tiamina causa au- } \\
\text { mento da área ocupada por placas } \\
\text { no córtex, hipocampo e tálamo, e } \\
\text { induz inflamação em áreas } \\
\text { formadoras de placa. }\end{array}$ \\
\hline
\end{tabular}




\begin{tabular}{|c|c|c|c|c|}
\hline $\begin{array}{c}\text { Linha } \\
14\end{array}$ & $\begin{array}{l}\text { Nascimento } \\
\text { (2020). }\end{array}$ & Vitamina B6. & $\begin{array}{c}\text { Curcumina e } \\
\text { açafrão. }\end{array}$ & $\begin{array}{l}\text { Certas especiarias como } \\
\text { curcumina e o açafrão, } \\
\text { demonstraram em prevenir } \\
\text { a degradação cerebral em } \\
\text { experiencias com } \\
\text { ratos de laboratórios. }\end{array}$ \\
\hline $\begin{array}{c}\text { Linha } \\
15\end{array}$ & $\begin{array}{l}\text { Cunha et al. } \\
\text { (2019). }\end{array}$ & $\begin{array}{c}\text { Vitamina } \\
\text { B12. }\end{array}$ & $\begin{array}{c}\text { Salmão, } \\
\text { levedura } \\
\text { nutricional, } \\
\text { mexilhão, } \\
\text { bife de fígado } \\
\text { e leite. }\end{array}$ & $\begin{array}{c}\text { A deficiencia de B12 é mais } \\
\text { comum em idosos devido a uma } \\
\text { incapacidade de absorção no trato } \\
\text { gastrointestinal, ocasionando } \\
\text { aumento de homocisteína } \\
\text { contribuindo para o } \\
\text { desenvolvimento de } \\
\text { doenças neurodegenerativas. }\end{array}$ \\
\hline $\begin{array}{c}\text { Linha } \\
16\end{array}$ & $\begin{array}{c}\text { Fernandez et } \\
\text { al. (2016). }\end{array}$ & $\begin{array}{c}\text { Vitamina } \\
\text { B12. }\end{array}$ & $\begin{array}{c}\text { Salmão, } \\
\text { levedura } \\
\text { nutricional, } \\
\text { mexilhão, } \\
\text { bife de fígado } \\
\text { e leite }\end{array}$ & $\begin{array}{l}\text { O consumo inadequado do } \\
\text { alimentos fonte de vitamina B12 } \\
\text { pode acarretar estresse } \\
\text { oxidativo e o acúmulo de } \\
\text { radicais livres. }\end{array}$ \\
\hline $\begin{array}{c}\text { Linha } \\
17\end{array}$ & $\begin{array}{c}\text { Campos et al. } \\
\text { (2020). }\end{array}$ & $\begin{array}{c}\text { Vitamina } \\
\text { B12. }\end{array}$ & $\begin{array}{l}\text { Salmão, } \\
\text { levedura } \\
\text { nutricional, } \\
\text { mexilhão, } \\
\text { bife de fígado } \\
\text { e leite. }\end{array}$ & $\begin{array}{l}\text { o baixo consumo de } \\
\text { micronutrientes, especialmente } \\
\text { folato e vitamina B12 está presente } \\
\text { em pacientes com DA. } \\
\text { Os baixos níveis de folato estão } \\
\text { associados com comprometimento } \\
\text { cognitivo, o que se estabelece como } \\
\text { um fator de risco complementar } \\
\text { para outros comprometimentos, } \\
\text { como a desnutrição. } \\
\text { Além disso, baixos níveis de folato e } \\
\text { B12 aumentam a concentração } \\
\text { de homocisteína, que } \\
\text { é neurotóxico. }\end{array}$ \\
\hline
\end{tabular}




\begin{tabular}{|c|c|c|c|c|}
\hline $\begin{array}{c}\text { Linha } \\
18\end{array}$ & $\begin{array}{l}\text { Weber et al. } \\
\text { (2019). }\end{array}$ & Vitamina C. & $\begin{array}{c} \\
\text { Laranja, } \\
\text { Couve, } \\
\text { brócolis, } \\
\text { pimentão } \\
\text { amarelo, caju } \\
\text { e goiaba. }\end{array}$ & $\begin{array}{c}\text { a vitamina C executa função } \\
\text { a respeito da síntese de } \\
\text { neurotransmissores, como a } \\
\text { noradrenalina e dopamina, além de } \\
\text { produzir efeito como antioxidante } \\
\text { celular, protegendo neurônios } \\
\text { contra o estresse oxidativo. } \\
\text { A disfunção cognitiva tem sido } \\
\text { associada ao aumento do } \\
\text { estresse oxidativo ou a } \\
\text { deficiência em antioxidantes. }\end{array}$ \\
\hline $\begin{array}{c}\text { Linha } \\
19\end{array}$ & Priulli (2020). & Vitamina C. & $\begin{array}{c}\text { Laranja, } \\
\text { Couve, } \\
\text { brócolis, } \\
\text { pimentão } \\
\text { amarelo, } \\
\text { caju e } \\
\text { goiaba. }\end{array}$ & $\begin{array}{c}\text { Indivíduos com a doença } \\
\text { de Alzheimer têm geralmente } \\
\text { baixos níveis plasmáticos } \\
\text { de vitamina C e que a manutenção } \\
\text { de valores recomendados desta } \\
\text { vitamina pode ter uma função } \\
\text { protetora contra o declínio } \\
\text { cognitivo relacionado com a idade } \\
\text { e com a doença, demonstrando ser } \\
\text { uma vitamina a ter atenção tanto na } \\
\text { prevenção como após o } \\
\text { diagnóstico. A vitamina C é } \\
\text { absorvida de forma rápida e } \\
\text { eficiente, é um antioxidante solúvel } \\
\text { em água e apresenta } \\
\text { papel lipofílico nas } \\
\text { membradas, evitando o } \\
\text { estresse oxidativo. }\end{array}$ \\
\hline
\end{tabular}




\begin{tabular}{|c|c|c|c|c|}
\hline $\begin{array}{l}\text { Linha } \\
20\end{array}$ & $\begin{array}{l}\text { Mendes et al. } \\
\text { (2016). }\end{array}$ & $\begin{array}{l}\text { Vitamina do } \\
\text { complexo B. }\end{array}$ & $\begin{array}{l}\text { Levedo de } \\
\text { cerveja, } \\
\text { fígado, grãos } \\
\text { de cereais, } \\
\text { arroz, nozes } \\
\text { e leite. }\end{array}$ & $\begin{array}{c}\text { As deficiências de ácido fólico e } \\
\text { vitamina B12 e B6, resultam } \\
\text { no aumento dos níveis de } \\
\text { homocisteína, um fator de risco } \\
\text { para doenças cardiovasculares e } \\
\text { acidente vascular cerebral, } \\
\text { podendo estar relacionada com } \\
\text { um risco mais elevado de doença } \\
\text { Alzheimer. Assim, o consumo } \\
\text { adequado destes micronutrientes } \\
\text { pode diminuir o risco de doença } \\
\text { de Alzheimer, reduzindo } \\
\text { a homocisteína. }\end{array}$ \\
\hline $\begin{array}{l}\text { Linha } \\
21\end{array}$ & $\begin{array}{l}\text { Medeiros et } \\
\text { al. (2016). }\end{array}$ & Vitamina E. & $\begin{array}{c}\text { Óleo de } \\
\text { canola, } \\
\text { azeite, } \\
\text { castanha do } \\
\text { Pará e } \\
\text { amendoim. }\end{array}$ & $\begin{array}{c}\text { A vitamina E tem } \\
\text { função antioxidante protegendo os } \\
\text { neuronios de estresse oxidativo, } \\
\text { previne a alteração da proteína tau } \\
\text { hiperfosforilativa e seu consumo } \\
\text { insuficiente, entre outras vitaminas } \\
\text { antioxidantes, pode estar } \\
\text { relacionado com aumento de } \\
\text { desenvolvimento da doença } \\
\text { de Alzheimer. }\end{array}$ \\
\hline
\end{tabular}

Fonte: Próprio autor (2021)

A partir das análises dos estudos apresentados, é possível que de certa forma eles opinam de maneira precisa sobre a questão alimentar quanto a prevenção do desenvolvimento da doença de Alzheimer, enfatizando que os bons hábitos alimentares durante o decorrer da vida ajudam na prevenção ou regressão, do mesmo modo que os maus hábitos podem ajudar a desenvolver a doença. 
Bacharelado em Nutrição da UninCor e iniciação à pesquisa: Com a palavra os nossos estudantes

Os padrões de uma alimentação saudável como comer alimentos in natura, podem ajudar a diminuir o desenvolvimento da doença de Alzheimer, já indivíduos que não tem um padrão de alimentação saudável esse risco ao invés de diminuir vem aumentando nessa alimentação saudável, inclui as frutas, vegetais, grãos inteiros e carnes brancas como o frango e o peixe (SAMADI et al., 2019).

Conforme Silva et al. (2016), o baixo consumo de alimentos antioxidantes, tem como consequência o aumento do estresse oxidativo, que resulta em lesões encefálicas, as quais, dessa maneira, estão associadas a disfunções cognitivas. Alguns estudos analisados tem associado a disfunção mitocondrial à doença de Alzheimer. Essa disfunção provoca alterações das enzimas que participam das cadeias transportadora de eletrões, produção de espécies relativas de oxigênio, acarretando anomalias estruturais, estresse oxidativo e apoptose. Todas essas modificações já foram descritas em estádios iniciais da doença de Alzheimer, antes da deposição das placas beta-amiloides e associadas à fosforilação da proteína tau (Tabela I, linha 1); Lemes et al. (2017) complementam que os danos oxidativos podem ser prevenidos pelos agentes oxidantes, que são definidos como um grupo de várias moléculas naturais. Estes podem estar presentes, em baixas concentrações, como em maior quantidade, dependendo dos metabolitos secundários. O estresse oxidativo pode representar uma ameaça ao organismo, levando ao envelhecimento precoce celular e podendo provocar diversos malefícios.

Roque et al. (2019), ressaltaram que a no chá verde está presente a epigalocatequina- 3-galato (EGCG) que reduz a atividade da enzima DYRK1A. Os níveis altos dessa enzima estão associados ao maior risco de Alzheimer (Tabela I, linha 2); Garcia et al. (2016) realizaram um estudo onde encontraram resultados que permitem afirmar que o chá verde tem efeito neuroprotetor e antioxidante, protegendo de déficits de memória de reconhecimento em modelo animal de Doença de Alzheimer induzido pela proteína ß-amilóide. 
Bacharelado em Nutrição da UninCor e iniciação à pesquisa: Com a palavra os nossos estudantes

Moraes et al. (2016), encontraram que os flavonóides podem contribuir na prevenção de doenças neurodegenerativas como o Alzheimer quando ingeridos regularmente por meio de uma dieta, em razão de seus efeitos anticarcinogênico, antioxidantes, antiinflamatórios, hipoglicemiantes e antiaterogênicos, além de atividades antivirais e antibacterianas, os quais repercute-se de modo direto na prevenção e tratamento de várias doenças neurodegenerativas (Tabela I, linha 3); Segundo o estudo de Barbosa (2021) a utilização do flavonóide mostrou múltiplas ações neuroprotetoras, incluindo a prevenção de neurotoxicidade, com melhora da capacidade de memória e das funções cognitivas. Portanto, esse flavonóide podendo atuar na prevenção e tratamento da doença de Alzheimer.

Cunha et al. (2016), apontou que o magnésio apresenta efeitos na memória e aprendizagem nos seres humanos. Níveis abaixo do recomendado de magnésio no liquido cefalorraquidiano podem ser um fator motivador da degeneração neural e como resultado do declínio cognitivo devido a deficiência desse mineral está associada com aumento do estresse oxidativo, fator este que potencializa o surgimento da doença de Alzheimer (Tabela I, linha 4); Cunha et al. (2019) sugerem que o magnésio demonstrou efeitos do magnésio na aprendizagem e na memória nos seres humanos. Os baixos níveis de liquido cefalorraquidiano podem ser um fator promotor da degeneração neural e consequentemente declínio cognitivo uma vez que a deficiência desse mineral está associada com aumento do estresse oxidativo fator este que potencializa o surgimento da DA.

Segundo Roque et al. (2019), os polifenóis antioxidantes têm alcançados os resultados que confirmam ser uma boa alternativa para retardar a progressão da doença Alzheimer. Um exemplo é a romã, que é capaz de reduzir o dano oxidativo, inibir citocinas, melhorar a memória, função motora e reduzir a ansiedade (Tabela I, linha 5); Santana et al. (2018) confirmam que o Romã se destaca em relação a doença de Alzheimer, pois possui uma expressiva capacidade antioxidante e conteúdo de compostos bioativos, os quais estão intimamente relacionados com a promoção de diversas doenças crônicas não transmissíveis. 
Bacharelado em Nutrição da UninCor e iniciação à pesquisa: Com a palavra os nossos estudantes

Cardoso et al. (2016), mencionam que polifenóis são atuantes nas células cerebrais, impedindo a ação dos radicais livres, promovendo-as proteção, de modo que os danos degenerativos que geralmente são causados por estresse oxidativo sejam amenizados (Tabela I, linha 6); Existem evidencias que os polifenóis atenuam a neuropatia e o declínio cognitivo, além de reduzir a formação de placas beta amiloides no cérebro (Torres 2016).

Segundo Bigueti et al. (2018), o EPA e DHA ampliam a fluidez da membrana plasmática, que intervém na neurotransmissão e na sinapse, alternado o funcionamento do cérebro (Tabela I, linha 7); Entretanto devemos destacar que o consumo excessivo de qualquer alimento pode ser prejudicial à saúde e que apesar do ômega-3 ser considerado um alimento funcional, é importante ficar em alerta pois ele é uma gordura, assim agrega valor calórico aos alimentos. Neste caso, seu consumo deve ser realizado em alteração de outras gorduras e não apenas em adição ao restante da alimentação diária, sendo seu consumo estimulado dentro dos hábitos alimentares adequados (Silva et al, 2018).

Para Santos et al. (2019), o ômega 3 desempenha o papel funcionam e estrutural nas células cerebrais, células da glia e células dos endotélios, além de atuar em processos fisiológicos como a formação da memória e do controle da neuroinflamação (Tabela I, linha 8); Em um estudo suplementando ômega 3 (2g), intervalados até 150 dias de suplementação concomitantemente à atividade física, demonstrou melhora na função neuromuscular e em testes funcionais (PERUCHI et al, 2017).

Segundo Oliveira et al. (2018), o ômega 3 proporciona muitos benefícios ao sistema cardiovascular, ajuda a diminuir o risco da perda, diminuição cognitiva na terceira idade, modula o quadro da dislipidemia, reduz o processo de aterosclerose e atua no controle da hipertensão arterial combatendo os efeitos pró-inflamatórios do ômega 6 (Tabela I, linha 9); VIRIATO (2021) confirma que a o consumo regular recomendo de ômega 3 pode evitar a morte celular induzida pelas neurotoxinas e oferecer proteção aos neurônios dopaminérgicos. 
Melo et al. (2020), expressam que o ômega 3 é um nutriente indispensável para a saúde mental e, consequentemente, para uma melhor qualidade de vida para idosos, pois são de suma importância para a estrutura e função normal do cérebro, dado que os fosfolipídios compostos por esse ácido graxo têm uma considerável função na tradução dos sinais nervosos, na integridade da membrana celular e na sua fluidez (Tabela I, linha 10); Santos (2016) complementou que recentemente, foram propostas novas indicações terapêuticas para o ômega-3, tais como o tratamento de certas formas de doenças mentais.

Conforme Borges et al. (2021), o ômega 3 contribui na comunicação entre os neurotransmissores, atuando com que a memória e a concentração sejam fortalecidas. Sua ingestão é recomendada, pois facilita no processo de aprendizado (Tabela I, linha 11); O fornecimento de nutrientes relacionados e necessários a função, manutenção e funcionamento normal do cérebro, como ômega 3 podem contribuir na prevenção do desenvolvimento da doença no decorrer do processo de envelhecimento ( WEBER et al. 2019).

Lemes et al. (2017) mencionam que a utilização do pequi, ou Caryocar brasiliense Camb. de uma firma geral por apresentar ação antioxidante, o que diminui os danos oxidativos, é benéfico para a população, podendo retardar o envelhecimento precoce das células e evitar o desenvolvimento das doenças neurodegenerativa (Tabela I, linha 12); Batista et al. (2019) observaram a presença de compostos fenólicos no pequi, tais como ácido elágico e quercetina estão associados a ação anti-inflamatória e anti-demência.

Balbino (2021) ressaltou que a deficiência de tiamina causa aumento da área ocupada por placas no córtex, hipocampo e tálamo, e induz inflamação em áreas formadoras de placa. (Tabela I, linha 13); Pimenta et al. (2021) complementa que o baixo consumo de vitamina $\mathrm{B} 1$, pode resultar a várias consequências como degeneração de nervos periféricos, tálamo, corpos mamilares e cerebelo.

Nascimento (2020), discutem que especiarias como curcumina e o açafrão, demonstraram em prevenir a degradação cerebral em experiencias com ratos de 
laboratórios. (Tabela I, linha 14); Mendes et al. (2016) destaca que, a deficiência de vitamina B6, resulta no aumento dos níveis de homocisteína, podendo estar relacionada com um risco mais elevado de DA.

Segundo Cunha et al. (2019), a deficiência de B12 é mais comum em idosos devido a uma incapacidade de absorção no trato gastrointestinal, ocasionando aumento de homocisteína contribuindo para o desenvolvimento de doenças neurodegenerativas; (Tabela I, linha 15). De acordo com Campos et al. (2020) pacientes com baixos níveis de B12, assim como baixos níveis de vitamina folato, podem apresentar níveis de homocisteína elevados, o que, por sua vez, é neurotóxico e pode levar ou agravar alterações degenerativas. Os níveis mais baixos de folato se correlacionaram a um pior desempenho cognitivo, em particular na memória e velocidade psicomotora e o mesmo promove a regeneração da metionina a partir de homocisteína.

Fernandez et al. (2016), discorrem que o consumo inadequado dos alimentos fonte de vitamina B12 podem acarretar estresse oxidativo e o acúmulo de radicais livres; (Tabela I, linha 16). Em relação às deficiências de micronutrientes, Campos et al. (2020) sugerem que o baixo consumo de folato e vitamina B12 colaboram para um alto risco de desenvolvimento da doença Alzheimer e consequentemente com a mortalidade associada a baixos níveis de hemoglobina.

Campos et al. (2020), apontam que o baixo consumo de micronutrientes, especialmente folato e vitamina B12 está presente em pacientes com DA. Os baixos níveis de folato estão associados com comprometimento cognitivo, o que se estabelece como um fator de risco complementar para outros comprometimentos, como a desnutrição. Além disso, baixos níveis de folato e B12 aumentam a concentração de homocisteína, que é neurotóxico (Tabela I, linha 17); A vitamina B12, desempenha importantes funções metabólicas e neurotróficas no organismo, pessoas com a deficiência dessa vitamina podem apresentar neuropatia (Silva et al. 2016). 
Bacharelado em Nutrição da UninCor e iniciação à pesquisa: Com a palavra os nossos estudantes

Conforme Weber et al. (2019), a vitamina C executa função a respeito da síntese de neurotransmissores, como a noradrenalina e dopamina, além de produzir efeito como antioxidante celular, protegendo neurônios contra o estresse oxidativo. A disfunção cognitiva tem sido associada ao aumento do estresse oxidativo ou a deficiência em antioxidantes (Tabela I, linha 18); Dantas et al. (2019) complementam que a vitamina $\mathrm{C}$ é um importante antioxidante que promove proteção aos neurônios do dano oxidativo direta e indiretamente, além de restaurar a forma reduzida da vitamina $\mathrm{E}$.

Priulli (2020), ressaltou que indivíduos com a doença de Alzheimer têm geralmente baixos níveis plasmáticos de vitamina $\mathrm{C}$ e que a manutenção de valores recomendados desta vitamina pode ter uma função protetora contra o declínio cognitivo relacionado com a idade e com a doença, demonstrando ser uma vitamina a ter atenção tanto na prevenção como após o diagnóstico. A vitamina C é absorvida de forma rápida e eficiente, é um antioxidante solúvel em água e apresenta papel lipofílico nas membradas, evitando o estresse oxidativo (Tabela I, linha 19); De acordo com Silva et al. (2016) a vitamina $C$ tem sido associada a diversas funções no sistema nervoso central, inclusive na proteção contra a angiogénese, estresse oxidativo e neuromodulação.

Segundo Mendes et al. (2016), as deficiências de ácido fólico e vitamina B12 e B6, resultam no aumento dos níveis de homocisteína, um fator de risco para doenças cardiovasculares e acidente vascular cerebral, podendo estar relacionada com um risco mais elevado de doença Alzheimer. Assim, o consumo adequado destes micronutrientes pode diminuir o risco de doença de Alzheimer, reduzindo a homocisteína (Tabela I, linha 20); Bigueti et al. (2018) relatam que nos indivíduos que apresentam o nível plasmático de homocisteína maior que a média as vitaminas do complexo B podem colaborar com a sua diminuição e assim levar à diminuição da atrofia da massa cinzenta no cérebro e retardar o declínio cognitivo. 
Medeiros et al. (2016), afirma que a vitamina $E$ tem função antioxidante protegendo os neurônios de estresse oxidativo, previne a alteração da proteína tau hiperfosforilativa e seu consumo insuficiente, entre outras vitaminas antioxidantes, pode estar relacionado com aumento de desenvolvimento da doença de Alzheimer (Tabela I, linha 21); Padrões alimentares ricos em vitamina E podem atrasar a progressão da doença de Alzheimer, diminuindo o stresse oxidativo e mantendo a função cognitiva e pode ser manipulada como um tratamento eficaz para a doença. Entretanto, seu efeito em pacientes com essa patologia mostra variações consideráveis na sua função antioxidante e na sua capacidade de meIhorar as funções cognitivas. O consumo dos níveis recomendados dessa vitamina estão relacionados com o risco reduzido de DA na idade avançada (Priulli 2020).

\section{CONCLUSÃO}

É possível afirmar que alimentos fonte de ômega 3, vitaminas E, C, do complexo $\mathrm{B}$, polifenóis, magnésio e flavonoides podem auxiliar com a redução da incidência da doença de Alzheimer. Entretanto, tal consumo deve ser incluído ao longo da vida juntamente com hábitos alimentares saudáveis, ainda que os desfechos de alguns estudos ainda sejam discutíveis.

Existem relativamente poucos trabalhos hoje publicados sobre alimentação e prevenção do Alzheimer e não existe um padrão de suplementação estabelecida pelos estudos, então para prevenção é necessário uma alimentação adequada com acompanhamento nutricional ao longo da vida.

A conscientização da importante da alimentação é imprescindível para o entendimento da prevenção antes que a doença já estava instalada, pois o Alzheimer é uma doença progressiva, silenciosa e ainda não existem muitos estudos aprofundados e de longa data para que seja viável obter resultados conclusivos. 
Bacharelado em Nutrição da UninCor e iniciação à pesquisa: Com a palavra os nossos estudantes

\section{REFERENCIAS}

BALBINO, Carolina de Souza. A influência da alimentação no tratamento da doença de Alzheimer. Brazilian Journal of Health Review, Curitiba-PR, v.4, n.3, p. 10279-10293 maio./jun. 2021.

BIGUETI, Bruna de Cássia Pavan; LELLIS, Julia Zeitum de; DIAS, Juliana Chioda Ribeiro. Nutrientes essenciais na prevenção da doença de Alzheimer. Revista Ciências Nutricionais Online, v.2, n.2, p.18-25, 2018.

BRITO, Raquel Alves; BATISTA, Ana Débora Martins; MELO, Mateus Azevedo Ursulino; WALTER, Valeska Carneiro; RIBEIRO, Neyse Teixeira. Consumo alimentar do idoso portador de doença de alzheimer e a influência no estado nutricional: uma revisão. Braz. J. of Develop., Curitiba-PR, v. 6, n.5, p. 29616-29622, maio 2020.

BOFF, M.S.; SEKYIA, F.S.; BOTTINO, C.M.C. Prevalenceof dementia among Brazilian population: systematic review. Medical Jour nal, São Paulo-SP, v. 129, n.1, p. 46-50, 2011.

CAMPOS, Elizabeth Maria Coppola; ABREU, Felipe Almeida de; HAYAKAVA, Larissa Akimi; BOSCHI, Marcella Monteiro; SOUZA, Nadyne Porto de; MARQUES, RayraAzoia; CHAUD, Daniela Maria Alves. Nutrição e doença de Alzheimer: breve revisão. Revista Univap, São José dos Campos-SP, v. 26, n. 50, jul. 2020.

CARDOSO, B. R.; COZZOLINO, S. M. F. Estresse oxidativo na doença de Alzheimer: o papel das vitaminas $C$ e E. Rev. Soc. Bras. Alim. Nutr. $=$ J. Brazilian Soc. Food Nutr., São Paulo-SP, v. 34, n. 3, p. 249-259, dez. 2009.

CARDOSO, Sofia Alves; PAIVA, Isabel. Nutrição e alimentação na prevenção e terapêutica da demência. Revista da Associação Portuguesa dos Nutricionistas, Porto-Portugal, v. 11, p. 30-34, nov. 2017.

CARRETTA, Marisa Basegio; SCHERER, Sabrina. Perspectivas atuais na prevenção da doença de Alzheimer. Estud. Interdiscipl. Envelhec., Porto Alegre, v. 17, n. 1, p. 37-57, 2012.

CARVALHO, Teresa; REAL, Helena. Papel da tiamina presente nas leguminosas na prevenção e progressão da doença de Alzheimer. Revista Nutrícias, v. 24, p. 18-23, março 2015. 
Bacharelado em Nutrição da UninCor e iniciação à pesquisa: Com a palavra os nossos estudantes

DIOGO, Nubia Alves. Família e Alzheimer: As dificuldades enfrentadas nas modificações da dinâmica familiar. Rev. Longeviver, São Paulo-SP, Ano III, n. 9, Jan/ Fev/Mar. 2021.

FERNANDES, Janaína da Silva Gonçalves; ANDRADE, Márcia Siqueira de. Revisão sobre a doença de Alzheimer; diagnóstico, evolução e cuidados. Psicologia,Saúde \& Doenças, Osasco-SP, v. 18, n. 1, p. 131-140, jan. 2017.

FERNÁNDEZ, Shirley Steffany Muñoz; RIBEIRO, Sandra Maria Lima; CYRILLO, Denise Cavallini. A necessidade de avaliação do impacto econômico da intervenção nutricional na prevenção ou tratamento da doença de Alzheimer: uma revisão narrativa. Revista Brasileira de Ciências do Envelhecimento Humano (RBCEH), Passo Fundo-RS, v. 13, n. 1, p. 81-93, jan./abr. 2016.

GRACIANO, Annah Rachel; COZER, Andressa Meline; SANTANA, Vítor Marcilio Lima; OLIVEIRA, Júlia Maria Rodrigues de. Avaliação nutricional e risco de desnutrição em idosos com demências. Revista Saúde e Pesquisa, Maringá-PA, v. 11, n. 2, p. 293-298, maio/agosto 2018.

IAB - Instituto Alzheimer Brasil. História da doença de Alzheimer/ Visão geral sobre demência. Disponívelem:http://www.institutoalzheimerbrasil.org.br/. Acesso em: $23 / 03 / 2021$

LEMES, Erick de Oliveira; FERNANDES, Michele Maria Carlos; ROSA, Valeria Paiva; NASCIMENTO, Adriano Honorato. Levantamento da utilização do pequi (caryocarbrasiliense camb.) como agente antioxidante na prevenção de doenças neurodegenerativas. Revista Uniciências, v. 21, n. 2, p. 110-114, 2017.

MACHADO, Jacqueline; CARAM, Carmen Lucia Barreto; FRANK, Andrea Abdala; SOARES, Eliane de Abreu; LAKS, Jerson. Estado nutricional na doença de Alzheimer. Rev. Assoc. Med. Bras. Rio de Janeiro-RJ, v. 55, n. 2, p. 188-91, maio 2009.

NASCIMENTO, Gilvan Sales do. Mal de Alzheimer: considerações sobre prevenção. Editora Brilliant Mind, Campo Grande-MS, v.1, n. 1, p. 11-26, dez. 2020.

OLIVEIRA, Nayrene Amorin Carvalho; MAGALHÃES, Laryssa Alves; MATOS, Maria Rosimar Teixeira; ARAGÃO, Gislei Frota; BACHUR, Tatiana Paschoalette Rodrigues. A deficiência de tiamina e niacina como fator de risco para doenças neurológicas. Revista Infarma Ciências Farmacêuticas, Fortaleza-CE, v. 31, n. 2, p. 80-85, maio 2019. 
Bacharelado em Nutrição da UninCor e iniciação à pesquisa: Com a palavra os nossos estudantes

ROQUE, Samantha Assakawa Ludgero da Silva; OLIVEIRA, José Antônio Roque Ferreira; PIMENTA, Raphael Sanzio. A nutrigenômica como método de prevenção e tratamento de doenças. Revista Desafios, Palmas-TO, v. 6, n. 03, 2019.

SANTOS, Cibelle Ferreira dos; MARTINS, Fernanda Ribeiro Alonso; PEREIRA, Amanda Dionisio; VASQUES, Bruna do Val Moraes; BARROS, Gabriela Souza Rollo; QUINONES, Eliane Marta; GIOVANINI, Elaine Cristina; ARES, Nayara Cavalcanti. Mal de Alzheimer: uma revisão bibliografica. Revista Higei@-Revista Científica de Saúde, v. 2, n. 4, 2020.

SANTOS, Christianne Rosiak Gonzaga dos; CARDOSO, Camila Kellen de Souza. Efeito da suplementação de ômega 3 isolado ou associado em pacientes com doença de Alzheimer: uma revisão sistemática da literatura científica. Revista Urbanização e Habilitação, Goiânia-GO, v. 45, n. 4, p. 452-64, dez. 2019.

SANTOS, V. D.; CANDELORO, R. J. Trabalhos Acadêmicos: Uma orientação para a pesquisa e normas técnicas. AGE Ltda, Porto Alegre -RS, p. 149, 2006.

SILVA, Maria Janaina Bernarda da; PALORO, Marcela: HAMASAKI, Mike Yoshio. Estado nutricional e risco de doença de Alzheimer. Revista da Associação Portuguesa dos Nutricionistas, São Paulo-SP, v. 4, p. 24-27, março 2016.

SILVA, Saulo Victor e; MIRANDA, Francisca Cleice da Silva Soares Miranda; QUEIROZ, Samara Costa de; SOUSA, Juliany Caroline Silva de; SERQUIZ, Alexandre Coelho. Consumo alimentar de idosos com doença de Alzheimer. Revista Brasileira de Ciências do Envelhecimento Humano (RBCEH), Passo Fundo-RS, v. 17, n. 1, p. 8-20, jan./abr. 2020.

TAVARES, Thaíza Estrela; CARVALHO, Cecília Maria Resende Gonçalves de; características de mastigação e deglutição na doença de Alzheimer. Rev. CEFAC, v. 14, n.1, p. 122-137, Jan-Fev. 2012.

WEBER, Isabel Thereza Steffenon; CONTE Francieli Aline; BUSNELLO, Maristela Borin; FRANZ, Lígia Beatriz Bento. Nutrição e doença de Alzheimer no idoso: uma revisão. Estud. Interdiscipl. Envelhec., Porto Alegre-RS, v. 24, n. 3, p. 4561, 2019.

ZANARDO, Pamela Bueno; SPEXOTO, Maria Cláudia Bernardes; COUTINHO, Vanessa Fernandes. Benefícios do ômega-3 $(\omega-3)$ na doença de Alzheimer. Revista Inova Saúde, Criciúma-SC, vol. 3, n. 1, jul. 2014. 


\section{doi $10.48209 / 97 / 8-65-89949-1 / 2-6$}

\section{CAPITURO 6}

\section{AUUTOPERCEPÇÃO DE GANHO DE PESO NO PERIODO DE ISOLAAMIDNTO SOCIAL DURANTE A PANID ㅍMIIA DA COVID-19}

Bruna Marina Melo de Andrade Ana Luiza Rodrigues Pellegrinelli 


\section{INTRODUÇÃO}

O ser humano é social, emocional e racional, e esses aspectos constroem a percepção de mundo de cada indivíduo, e fatores externos diariamente interferem nesse processo de aprimoramento do comportamento alimentar, e justamente por este fato, que o estado de pandemia de corona vírus é um fator intensificador para o surgimento de transtornos alimentares e ganho de peso (FARAH, 2018).

Sabe-se que a imagem corporal é reflexo de uma projeção que a psique humana constrói, e, por isso, pode não ser correspondente a realidade, pois situações que sobrecarregam o emocional podem obstruir a verdade e levar a distorção da percepção da pessoa perante a própria imagem corporal (ALVARENGA et al., 2019).

A compulsão alimentar é uma das consequências do cenário de instabilidade que a pandemia propicia, pois às pessoas acabam buscando conforto emocional na comida, e quandoesse comportamento se torna recorrente, o indivíduo pode desenvolver compulsão alimentar, que é um reflexo de episódios recorrentes de comer exagerado (AGUIAR, 2019). O diagnósticoé feito por médico psiquiatra, e as motivações psicológicas do desenvolvimento desse transtorno envolve insatisfação corporal, dietas restritivas, tristeza, angústia, falta de perspectiva, busca por auxílio emocional e desordens psicológicas e emocionais (BANDEIRA,2020).

No que se refere a mentalidade de dieta, identifica-se que a restrição calórica é difícil demanter a longo prazo, causando distanciamento dos sinais de fome e saciedade e causam terrornutricional (BETTIN, 2017). Como reflexo, o período pós restrição pode ter como resultado ocomer emocional, que as emoções motivam as escolham alimentares, podendo até gerar a sensação de fome, porém não está associada a necessidade fisiológica, mas sim emocional, e após saciar essa vontade, pode haver sentimento de culpa (FOCHESATTO, 2020). 
Durante a pandemia o isolamento social, ansiedade, estresse, luto e medo podem repercutir em ganho de peso acentuado, pois as pessoas buscam na comida sensações de conforto e fuga da realidade (BEZERRA, 2020). Uma das consequências é o crescimento dos casos de obesidade, pois as pessoas estão buscando alimentos mais calóricos devido assensações emocionais que o consumo proporciona (OLIVEIRA, 2021).

Sabe-se que outro intensificador do ganho de peso é a inatividade física, isso acontece, pois, mesmo passando mais tempo em casa, os indivíduos encontram-se desmotivados para praticar algum exercício físico (SILVA, 2020).

Diante do exposto, a presente pesquisa tem como objetivo avaliar o ganho de peso na população adulta, durante o período de isolamento social devido a pandemia de SARS-COV nomunicípio de Três Corações e região.

\section{REFERENCIAL TEÓRICO}

\subsection{Mudanças na vida dos indivíduos pós pandemia}

Com a incerteza e aumento do COVID-19, ocasionam mudanças não só na saúde físicadas pessoas, como também na saúde mental, principalmente quando se trata em termos de emoções e cognição. Estudos relatam que essas mudanças psicológicas e emocionais provocadas pela pandemia podem aumentar o risco de desenvolver uma alimentação disfuncional, prejudicando o comportamento pessoal (LI et al., 2020; MONTEMURRO 2020;WANG et al., 2020). Essas possíveis mudanças de hábitos ocasionadas por esse cenário, bem como suas consequências, propuseram que muitos estudos fossem realizados baseados nesta atualidade que objetivam entender os danos causados devido ao isolamento social que afetou apopulação mundial (MALTA et al., 2020).

Visto o cenário em que o mundo vive atualmente, concluiu se que a pandemia do Covid 19 favoreceu a piora no estilo de vida e aumento de comporta- 
Bacharelado em Nutrição da UninCor e iniciação à pesquisa: Com a palavra os nossos estudantes

mentos de risco para a saúde, houve uma elevação em $5,8 \%$ no consumo de chocolates, biscoitos, tortas e 3,7\% no consumode salgadinhos, uma redução do consumo de hortaliças em torno de 4,3\% (MALTAet al., 2020).Vários estudos realizados mostram que o aumento do consumo de alimentos ultra processadosestá correlacionado com o excesso de peso e obesidade, apresentando, ainda, forte relação comproblemas cardiovasculares o (LOUZADA et al., 2015; REZENDE et al., 2016; JUUL et al., 2018).

Outros estudos realizados com brasileiros destacaram dados que provam a relação entre o alto consumo de carne com gordura, refrigerante e doces, com jovens de menor nível de instrução Steele e Colaboradores (2020). Caso ocorra a comprovação deste raciocínio, é necessária uma atenção maior para a situação, uma vez que a ingestão desses alimentos acarretaainda mais o risco de patologias como obesidade, hipertensão e diabetes (CLARO et al., 2015; ELIZABETH et al., 2020; STEELE et al., 2020).

Convergindo com os achados de Steele e colaboradores (2020), Robinson e colaboradores (2020) avaliaram alguns fatores como obesidade, hábito alimentar e prática de atividade física durante a pandemia de indivíduos adultos britânicos, obtendo dados de que os participantes homens, de baixa escolaridade e IMC alto estão relacionados com dieta de má qualidade, uma vez que $83 \%$ da amostra relatou ter alimentos não saudáveis dentro de casa.

Além disso, notou-se que os aspectos psicológicos estavam diretamente relacionados com as mudanças decorrentes da pandemia, uma vez que 847 participantes (42\% da amostra) 9relataram estar comendo mais por causa das suas emoções (ROBINSON et al., 2020). Assim, nota-se que o somatório desses fatos é um potencial causador de agravos na saúde física e mental, uma vez que o aumento desregular na ingesta alimentar (principalmente de alimentos não saudáveis) pode provir em doenças. Além disso, pode gerar um comer transtornado, já que o motivo desencadeador, em muitos casos, está sendo as emoções (ROBINSON et al., 2020). 
Bacharelado em Nutrição da UninCor e iniciação à pesquisa: Com a palavra os nossos estudantes

\subsection{Imagem corporal}

A imagem corporal é a performance que um indivíduo vê o seu corpo e faz de seu corpo em sua mente, somando com as sensações táteis, térmicas e de dor, afirma Schilder (1999). Hávárias sensações envolvidas quanto a visão de um esquema de corpo como: sensações musculares, sensações viscerais e a percepção de uma unidade do corpo, ou seja, do esquema corporal ou ainda, do modelo postural do corpo. Por tratar-se de uma representação, a imagemcorporal envolve os níveis emocionais, mentais e físicos, em cada ser humano, com respeito à visão de seu corpo. De acordo com o autor, a imagem corporal é compreendida através dos sentidos e envolve figurações e representações mentais, mas não é apenas uma acuidade ou mera representação (SCHILDER, 1999).

A imagem corporal relaciona-se a maneira com que a pessoa vê seu corpo, essa percepção envolve vários aspectos, psicológicos, comportamentais, emocionais, cognitivos e afetivos, isso significa que essa construção é um reflexo de um sistema complexo, que também sofre influências externas através de relacionamentos familiares e amorosos, de vínculos sociais, mídia e ambientes de convívio coletivo, como escola e trabalho (SOARES, 2020).

A imagem corporal é reflexo de uma projeção que a mente elabora, e não necessariamente é a verdade, pois o adoecimento psíquico leva a projeções irreais da situação, levando o indivíduo a desenvolver uma intensa autocobrança com intensa preocupação com a imagem, geralmente essa preocupação inicia-se na infância, com as experiências sociais, comparações e primeiras frustrações com o corpo, mas é na adolescência que existe o maior conflito de imagem, pois as mudanças corporais, oscilações hormonais e emocionais levam aoadolescente a se ver como insuficiente e imperfeito, o que pode levar a distorção de imagem e transtornos alimentares (ALVARENGA et al., 2019).

Atualmente, a sociedade vive-se num momento histórico-cultural que enfatiza a propagação de ideais de juventude e beleza aliado à obtenção de um corpo 
perfeito, que neste momento segue um padrão estético de extrema magreza. Com isto este enfoque exagerado sobre10 o corpo perfeito, acaba provocando um aumento na insatisfação com a imagem corporal depessoas que não percebem que este tipo de análise os leva a episódios de comportamentos queagridem não só seu físico (VERAS, 2010).

Essa insatisfação leva a comportamentos compulsivos ou invasivos na tentativa de reduzir o agravo sofrimento psíquico consecutivo e a ansiedade. Estes surgem com maior intensidade nos transtornos alimentares, principalmente anorexia e bulimia nervosa, no transtorno dimórfico corporal e nos casos, ainda não descritos, em que, na tentativa de ter um corpo idealizado, a busca por cirurgias plásticas estéticas é uma contumaz (VERAS, 2010).

Esta realidade obriga que se aumente os estudos sobre como a imagem corporal é formada e como pode ser trabalhada nos processos de terapia com o propósito de alcançar melhores resultados perante dos desafios impostos pelos pacientes que sofrem por não estarem satisfeitos com o seu corpo (VERAS, 2010).

\subsection{Transtornos alimentares}

Os transtornos alimentares são reflexos do desequilíbrio na alimentação e nos comportamentos alimentares, sendo assim, essa alteração no consumo alimentar ocorre pelas desordens psicológicas que levam a prejuízo na saúde física e mental (ALVARENGA et al., 2019).

Transtornos alimentares que existem: (a) anorexia nervosa: a anorexia nervosa é um transtorno que se caracteriza pela recusa à alimentação em busca da magreza extrema associada a dietas muitos rígidas e com medo intenso de engordar (SCHMIDT, 2008); (b) bulimia nervosa: A bulimia nervosa (BN) é um transtorno que se caracteriza por grande ingestão de alimentos, intercalados por episódios compensatórios como a indução de vômitos e uso de medicamentos 
diuréticos, inibidores de apetite e laxantes com o intuito de controle e perda de peso (ABREU, 2004); (c) transtorno de compulsão alimentar: ele se caracteriza por episódios em que a pessoa consome grandes quantidades de comida muito rápido. Neste transtorno não ocorre a indução de vômitos ou excesso da prática de atividade física, com consequência a pessoa ganha peso e podendo se tornar obesa (PALAVRAS, 2011).

A compulsão alimentar é uma desordem psicológica diários, frustrações, estresses, ansiedade, sentimentos e emoções. Após os episódios de compulsão, pode haver purgações induzidas através de vômitos ou laxantes (BANDEIRA, 2020).

$\mathrm{Na}$ compulsão alimentar, que inclusive é muito presente atualmente, principalmente devido a pandemia, o indivíduo reflete em sua alimentação um comer mais compulsivo com 11 desregramento e descontrole, motivados por vários fatores, como insatisfação corporal, dietas restritivas, tristeza, angústia, falta de perspectiva, busca por auxílio emocional e desordens psicológicas e emocionais (BANDEIRA, 2020).

Referente a característica nutricional, a alimentação tem aspecto hipercalórico, com consumo excessivo de pães, doces e salgados, no caso, o indivíduo não realiza intervalos na suaalimentação e não intercala refeições, e não realiza escoIhas alimentares conscientes, buscandoapenas fugir da realidade com ingestões altas de carboidratos e gorduras (AGUIAR, 2019).

\subsection{Efeitos das dietas restritivas}

Os seres humanos desde muito cedo possuem capacidade de reconhecer fome e saciedade, porém intervenções externas como dietas desregulam e desconectam as pessoas dossinais internos que sinalizam os estágios da digestão (OLIVEIRA, 2019). 
Bacharelado em Nutrição da UninCor e iniciação à pesquisa: Com a palavra os nossos estudantes

Segundo Alvarenga et al., (2019) a restrição alimentar com o objetivo de emagrecer reflete negativamente no comportamento alimentar, desregulando a relação dos indivíduos com seu próprio corpo, perpetuando o ciclo de dietas e gerando sensação de intenso desejo por alimentos proibidos.

A motivação estética pode levar os indivíduos a optarem por fome induzida em busca de resultados instantâneos, contudo, as dietas não têm demonstrado resultados a longo prazo, pois consideram apenas a composição dos alimentos e cálculo de macronutrientes, ignoram a importância da mudança de comportamento (BETTIN, 2017).

A recomendação de dietas com restrição calórica e a perda de peso c omo foco, adoecemos indivíduos e não promovem autonomia alimentar, podendo prejudicar psicologicamente efisiologicamente o indivíduo, já que as dietas restritivas promovem uma visão dicotômica dosalimentos, causando até mesmo terror nutricional, e em situação de pandemia, os danos deperpetuar essa "mentalidade de dietas" estão intensificados (FOCHESATTO, 2020). Diariamente, na mídia, aparecem novas dietas da moda prometendo resultados milagrosos e imediatos como a low-carb, jejum intermitente, dieta paleolítica, dieta a base deshakes, dieta ortomolecular, entre outras. Estas dietas costumam ser muito restritivas, uma vezque ocorre diminuição exagerada do valor energético, porção e/ou exclusão de algum grupoalimentar, principalmente do grupo de carboidratos, por exemplo. Além disso, está ficando cadavez mais comum os indivíduos procurarem dietas em redes sociais e por meio eletrônicos onderealizem tais dietas sem auxílio profissional, o que pode acarretar danos mais severos. Osindivíduos praticantes destes tipos de dietas preocupam-se de modo compulsivo com osalimentos que consomem, com isso ficam mais vulneráveis a comer descontroladamente após muito tempo de restrição e tendem a possuir problemas emocionais como ansiedade e depressão (OLIVEIRA,2019). 


\subsection{Comer emocional}

O comer emocional é reflexo da insuficiência na regulação das emoções de forma eficiente, em consequência aos acontecimentos emocionais, onde a comida assume papel de reduzir as emoções negativas. A adequada regulação emocional gera equilíbrio, o que poderia levar a hábitos alimentares conscientes. Em contrapartida, a inadequada regulação emocional pode ter relação com a propensão a emoções negativas, onde o alimento é usado como auxílioemocional (BETTIN, 2017).

Existe duas classificações gerais para especificar fome, a física e a emocional. $\mathrm{Na}$ fomeemocional existe uma vontade subida, imediatista e específica, decorrente de algum gatilho emocional, e chega a ser até mesmo irracional, pois existe um descontrole e um impulso intenso para satisfazer esse desejo, pode causar sentimento de culpa e resultar em exagero no consumode alimentos (FOCHESATTO, 2020).

Já a fome fisiológica acontece de forma gradual, existe um maior controle do indivíduo sobre o consumo, sendo característica de uma necessidade fisiológica do organismo e não gatilho emocional, não acompanha o sentimento de culpa e, habitualmente, existe saciedade após a ingestão de alimentos com o teor energético preciso (ALVARENGA et al., 2019).

Todo ser humano tem a capacidade de comer de tudo, o que faz com ele mesmo possa fazer suas escolhas alimentares. Porém, existem fatores que estão envolvidos na sua história individual, que irão pesar nessas escolhas (JOMORI et. al., 2008). O ato de comer vai muito além de satisfazer as necessidades fisiológicas do corpo, em determinados momentos a comidaé usada como forma de recompensa, ou uma maneira de demostrar afeto, ou também usada parareduzir emoções e sentimentos danosos, e aumentar os positivos. Sendo assim, o estado emocional interfere totalmente na forma de comer, além de levar em consideração também as crenças, medos e ansiedade (ALVARENGA et. al.,2019). 


\subsection{Ganho de peso na pandemia}

O homem é um ser social, diante do isolamento social devido a pandemia de corona vírus e durante essa realidade, várias mudanças de comportamentos físicos e emocionais ocorreram (FARAH, 2018). As emoções negativas afloraram, dentre elas a tristeza, ansiedade, depressão, desmotivação, luto, raiva, indignação e sensação de impotência, o que consequentemente reflete na alimentação, podendo levar principalmente ao ganho de peso, devido a estratégia inconsciente e emocional de buscar conforto na comida, é um comportamento de fuga, que momentaneamente leva a bons sentimentos, prazer e satisfação, mas depois vem a frustração e o reinício do ciclo (BETTIN, 2017).

A pandemia modificou a realidade, pois houve limitação das atividades física em ambientes fechados e ao livre, que geram consequências no peso, já que algumas pessoas se desmotivam em fazer exercícios em casa e entram no sedentarismo. Além disso, o isolamento reflete na piora do sono devido as preocupações, desequilibra a alimentação e expõe as pessoasa um maior tempo em frente aos aparelhos eletrônicos, recebendo notícias específicas sobre casos de COVID e mortes, o que pode provocar ansiedade e dependência midiática (ALVARENGA et al., 2019).

Diante dessa situação pode levar ao aparecimento do comer transtornado, que é caracterizado por pensamentos e sentimentos disfuncionais em relação ao ato de comer e a comida. Não é um transtorno alimentar, mas já se caracteriza como uma disfunção alimentar, porém sem tratamento, o comer transtornado pode evoluir para o TA (FARAH, 2018).

\subsection{Obesidade}

A obesidade é caracterizada pelo acúmulo excessivo de gordura no organismo que levaa danos nocivos à saúde dos indivíduos, como por exemplo dificuldades respiratórias, problemas dermatológicos e distúrbios do aparelho lo- 
Bacharelado em Nutrição da UninCor e iniciação à pesquisa: Com a palavra os nossos estudantes

comotor, além de contribuir com o surgimento de enfermidades potencialmente letais como dislipidemias, doenças cardiovasculares, Diabetes Não Insulino Dependente (Diabetes Tipo II) e certos tipos de câncer. Também é considerada uma doença do grupo de Doenças Crônicas Não Transmissíveis (DCNT)(PINHEIRO, 2004).

Essa doença pode ter sua causa definida devido a vários fatores relacionados à ingestãoexcessiva de alimentos pouco saudáveis, diminuição progressiva da atividade física, fatores genéticos, sociais, culturais, ter o metabolismo mais lento, o que facilita o acúmulo de gorduras 14 e dificulta o emagrecimento, ou ter aumento de peso por conta das oscilações hormonais. Apesar de sua definição clássica, hoje existe indicativos que mostram que a obesidade é uma patologia determinada, e mantida, por mecanismos envolvendo circuitos neurais implicados na regulação do apetite e na etiopatologia da obesidade, a partir das quais sugere-se que a essa doença pode ser considerada uma patologia neuropsicológica (RIBEIRO, 2015).

Sua classificação em adultos é indicada pelo índice de massa corpórea (IMC), representado pela razão entre o peso dado em quilogramas dividido pela estatura em metros aoquadrado. A obesidade é caracterizada quando o IMC encontrado for igual ou maior a $30 \mathrm{~kg} / \mathrm{m} 2$.A Organização Mundial de Saúde (OMS) também subdivide a obesidade em termos degravidade, classificando-a em: obesidade grau I (moderado excesso de peso, no qual o IMC encontra-se entre 30 e $34,9 \mathrm{~kg} / \mathrm{m} 2$ ); obesidade grau II (obesidade leve ou moderada, com IMCentre 35 e $39,9 \mathrm{~kg} / \mathrm{m} 2$ ) e obesidade grau III (obesidade grave ou mórbida, na qual o IMC apresenta-se com valores superiores a $40 \mathrm{~kg} / \mathrm{m} 2$ ) (SANTOS, 2012).

Atualmente a obesidade é um grave problema de saúde pública na sociedade. Várias pesquisas científicas foram feitas com o intuito de aprofundarem sobre as causas do desenvolvimento da obesidade. O predomínio da obesidade vem aumentando extraordinariamente, afetando pessoas de todas as faixas etárias (BARBIERI, 2012). 
Bacharelado em Nutrição da UninCor e iniciação à pesquisa: Com a palavra os nossos estudantes

As manifestações clínicas da doença do novo coronavírus (COVID-19) variam de doença assintomática a infecção respiratória aguda grave, a qual o indivíduo necessitará de hospitalização e suporte de oxigênio e ainda se necessário for admissão em uma unidade de terapia intensiva para ventilação assistida. Desse modo a presença de comorbidades, como a obesidade, são consideradas fatores de risco para a doença, relacionadas com um pior prognóstico e maior mortalidade (BUSETTO et al., 2020).

\subsection{Inatividade física e covid-19}

Em 11 de março de 2020 a Organização Mundial de Saúde considerou a COVID-19 (doença causada pelo SARS-CoV-2) uma pandemia. Com a ausência de tratamento específicoe efetivo, bem como sem vacinação para imunizar toda a população, medidas como as relacionadas à higiene pessoal, uso de álcool em gel, máscara e, principalmente, o distanciamento social, têm sido as melhores alternativas para diminuir a propagação da doença,evitando que os sistemas de saúde entrem em colapso (OLIVEIRA, 2020).

Neste contexto, em conjunto com as indicações de distanciamento social pelas autoridades de saúde competentes, diversas práticas sociais e de saúde foram discutidas e 15 recomendadas no contexto da pandemia, sendo a prática de atividade física um dos discursos acionados de forma enfática, principalmente abordando seus potenciais benefícios relacionadosà imunidade, doenças crônicas e saúde mental. Em consonância com o fato de que a maioria das pessoas estavam em seus domicílios, em situação de distanciamento social, um dos formatos recorrentes de atividade física estavam relacionadas a práticas mediadas por tecnologias, onde profissionais da área utilizaram redes e mídias sociais para comunicar sobre a importância desta, pois diversos locais de prática, como parques, praças e academias foram fechados no contexto da COVID-19 (SILVA et al, 2020).

Segundo Brugnerotto (2020), a atividade física pode ser definida como movimento corporal gerado em consequência da contração muscular resultan- 
Bacharelado em Nutrição da UninCor e iniciação à pesquisa: Com a palavra os nossos estudantes

do em gasto calórico, incluindo atividades realizadas durante o trabalho, brincar, realizar tarefas domésticas, viajar ese engajar em atividades recreativas. Sendo que as atividades físicas moderadas e vigorosaspodem melhorar a saúde. Já o exercício físico, vem como uma subcategoria da atividade física, ele é planejado, estruturado e repetitivo. Ele traz como resultado um aumento ou manutenção de componentes da aptidão física, sendo alguns deles, a potência aeróbica ou aptidãocardiorrespiratória, resistência muscular, força muscular, composição corporal e flexibilidade.A falta de exercício físico é o fator de risco básico para doenças crônicas não transmissíveis como Doenças Cardiovasculares, Câncer e Diabetes. Os dados mostram que 200mil pessoas morrem todos os anos de um estilo de vida sedentário, onde os exercícios físicosmoderados podem reduzir o risco de Doenças Crônicas Não Transmissíveis (DARONCO, 2021).

De acordo com Malta et al (2021), apesar de a herança genética ser fator de grande relevância na determinação da suscetibilidade à doença, o desenvolvimento dessas morbidadesse dá, primordialmente, por fatores ambientais e do estilo de vida. Estima-se que $75 \%$ dos casosnovos de doenças não-transmissíveis poderiam ser explicados por dieta e inatividade física. $\mathrm{O}$ baixo condicionamento cardiorrespiratório, a pouca força muscular e o sedentarismo, por exemplo, aumentam em três a quatro vezes a prevalecia das DCNT, se tornando ainda mais complexo quando tratamos de uma pandemia, onde o vírus acaba agravando seriamente a condição clínica, elevação do tempo de internação e as taxas de mortalidades.

Mesmo com o crescimento do número de informações, publicações científicas e consensos em atividade física, o sedentarismo entre os indivíduos ainda permanece alto e demonstra que a adoção do estilo de vida ativo, embora benéfico, pode ainda não ser de costumee prática de muitos e também pode ser visto como difícil para aqueles que acabam prejudicandosua saúde mental por se sentirem pressionados, ansiosos e com medo, se sobrecarregando mais 16 que o necessário, sofrendo assim por manifestações psicológicas. Ademais, muitos estudos epidemiológicos com atividade física integram os aspectos dietéticos e 
Bacharelado em Nutrição da UninCor e iniciação à pesquisa: Com a palavra os nossos estudantes

psicológicos, os quais podem interferir nos resultados obtidos (BEZERRA et al, 2020).

Torna-se de fundamental importância a manutenção e/ou o aumento dos níveis de atividade física na pandemia, desde quando todos os protocolos de biossegurança determinadospelas autoridades sanitárias sejam seguidos. $\mathrm{O}$ aumento dos níveis de atividade física na população pode auxiliar no combate da obesidade e outros agravos metabólicos, além de melhorar a saúde mental. Além disso, o aumento dos níveis de atividade física pode melhorar afunção imunológica e, todos estes aspectos em conjunto, podem fazer com que possamos estar mais bem preparados, tanto para a atual pandemia do COVID-19, quanto para outras futuras pandemias e, para a vida toda, garantindo um estilo de vida mais saudável, promissor em qualidade de vida e saúde (DARONCO, 2021).

É também de grande valia que se enfatize a redução do comportamento sedentário, ouseja o tempo que ficamos sentados, deitados ou reclinados em frente à televisão, computador eoutros semelhantes (PITANGA et al, 2020).

\section{MATERIAIS E MÉTODOS}

A presente pesquisa é um estudo de natureza aplicada com objetivo exploratória que buscará evidenciar consequências e causas do tema proposto, será realizada com um grupo de pessoas adultas entre de 18 e 59 anos de várias classes econômicas da cidade de Três Corações-MG e região.

A presente proposta de pesquisa é de abordagem quantitativa que será realizado um questionário utilizando o método de técnica de pesquisa Survey on-line, que é um método utilizado quando se deseja coletar opiniões e dados de um grupo específico da população a ser estudada (PEREIRA, PARREIRA \& SHITSUKA, 2018; FREITAS, OLIVEIRA, SACCOL \&MOSCAROLA, 2000).

A partir da pesquisa será realizada um questionário publicado por um outro autor(a) (VERTICCHIO, 2021) onde obterá dados sobre as condutas alimentares, 
distanciamento social, saúde física e mental e os sentimentos envolvidos durante a pandemia do COVID19, com perguntas sobre idade, sexo, escolaridade, renda familiar, cidade em que reside, ocupação atual, consumo alimentar e outras. Questionário (Anexo 1).

Neste estudo serão incluídas pessoas que residem em Três Corações e região com idadeacima de 18 anos. Serão excluídas pessoas que não residirem na região da pesquisa, menores de 18 anos e pessoas que não fizeram isolamento social (Uma das medidas de contenção da pandemia é o isolamento social, que corresponde a uma medida em que os indivíduos não doentes fiquem em casa afim de se evitar a disseminação da doença).

A análise será feita de forma quantitativa após os resultados obtidos pelo questionário on-line por meio do Google Formulário onde os dados serão tabulados em planilha de Excel e analisados por meio de gráficos.

Adicionalmente, em respeito aos sujeitos do estudo, todos os participantes deverão ter o ter o Termo de Consentimento Livre e Esclarecido (TCLE) assinado (Anexo 2). Além disso, a presente pesquisa foi submetida ao Comitê de Ética e Pesquisa (CEP) da Universidade Vale do Rio Verde - UNINCOR e foi aprovada com o CAAE 49919721.0.0000.5158.

\section{RESULTADOS E DISCUSSÃO}

Composto de 78.999 habitantes, o munícipio de Três Corações - Minas Gerais, foi o escolhido para a execução deste, devido ao maior número de pesquisados terem sido do munícipio em questão. A apresentação dos gráficos se dará referente as pesquisas realizadas com os seguintes resultados descritivos:

O questionário desenvolvido é composto por 24 perguntas simples e que foram respondidas on-line (não tendo contato nenhum, com os pesquisados). Tais questões analisamo consumo de alimentos de diversos grupos, além de ava- 
liar a faixa etária, grau de escolaridadee sexo dos entrevistados.

A pesquisa contou com a participação de 74 pessoas do gênero feminino e 28 pessoas do gênero masculino, sendo elas, de munícipios distintos, porém, com ênfase em participantesdo munícipio de Três Corações, MG.

A Figura 1 apresenta a distribuição dos entrevistados por faixa etária de acordo com gênero (masculino e/ou feminino). É notório que o menor percentual dos entrevistados se encontra na faixa dos 55 a 59 anos. É sabido que esse resultado se deu, porque grande parte depessoas com mais de 55 anos, muitas vezes não possuem acesso a redes sociais e/ou a comunicação on-line. Conforme certifica Arens e Moraes (2014):

A geração de idosos de hoje tem revelado suas dificuldades em entender a novalinguagem e em lidar com os avanços tecnológicos até mesmo nas questões mais básicascomo os eletrodomésticos, celulares, caixas eletrônicos instalados nos bancos. Consequentemente, aumenta o número de idosos iletrados em Informática, ou analfabetosdigitais, em todas as áreas da sociedade (ARENS; MORAES, 2014, p. 01).

Figura 1: Distribuição dos entrevistados por faixa etária de acordo com o gênero.

\section{Distribuição dos entrevistados: Faixa etária}

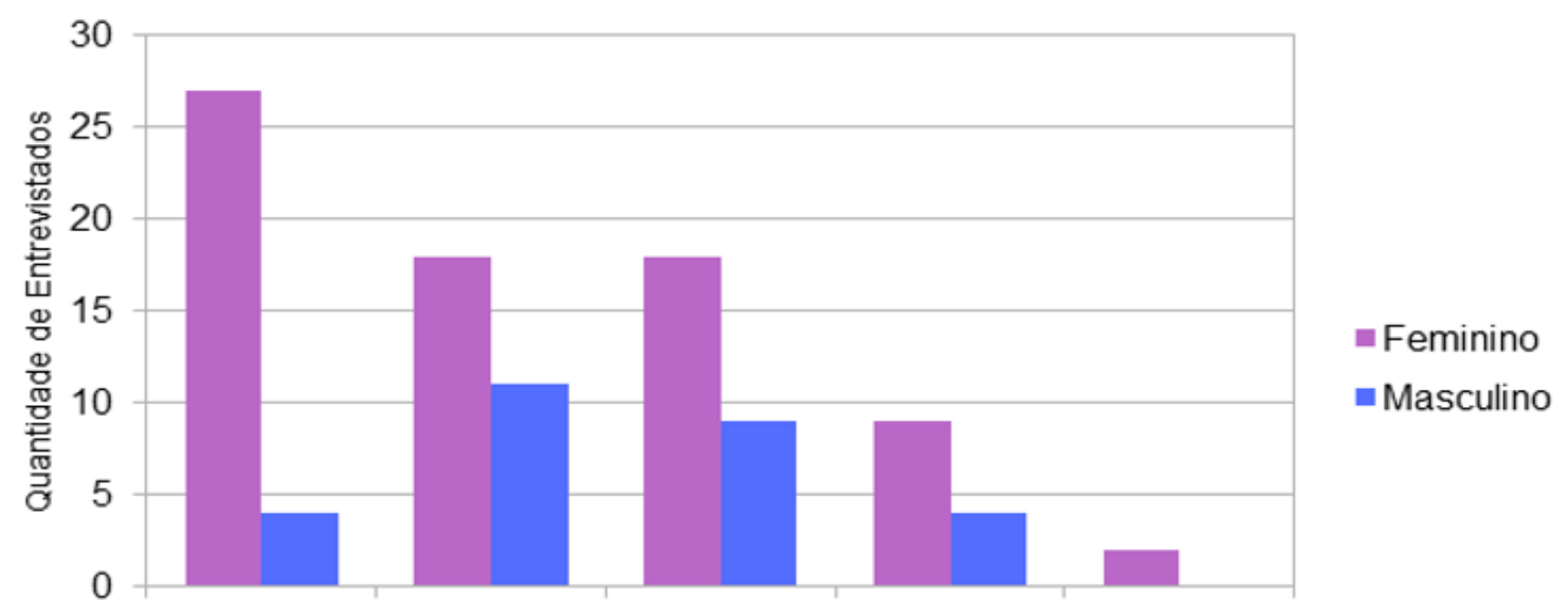

18 a $24 \operatorname{anos} 25$ a $34 \operatorname{anos} 35$ a 44 anos 45 a 54 anos 55 a 59 anos Faixa Etária

Fonte: próprio autor. 
A Figura 2 apresenta a distribuição dos entrevistados de acordo com o Município em que residem, separados por gênero. Observou-se que em Três Corações - MG, houve um maiornúmero de participantes na entrevista e sendo esses participantes do sexo feminino.

Figura 2: Distribuição dos entrevistados por município de acordo com o gênero.

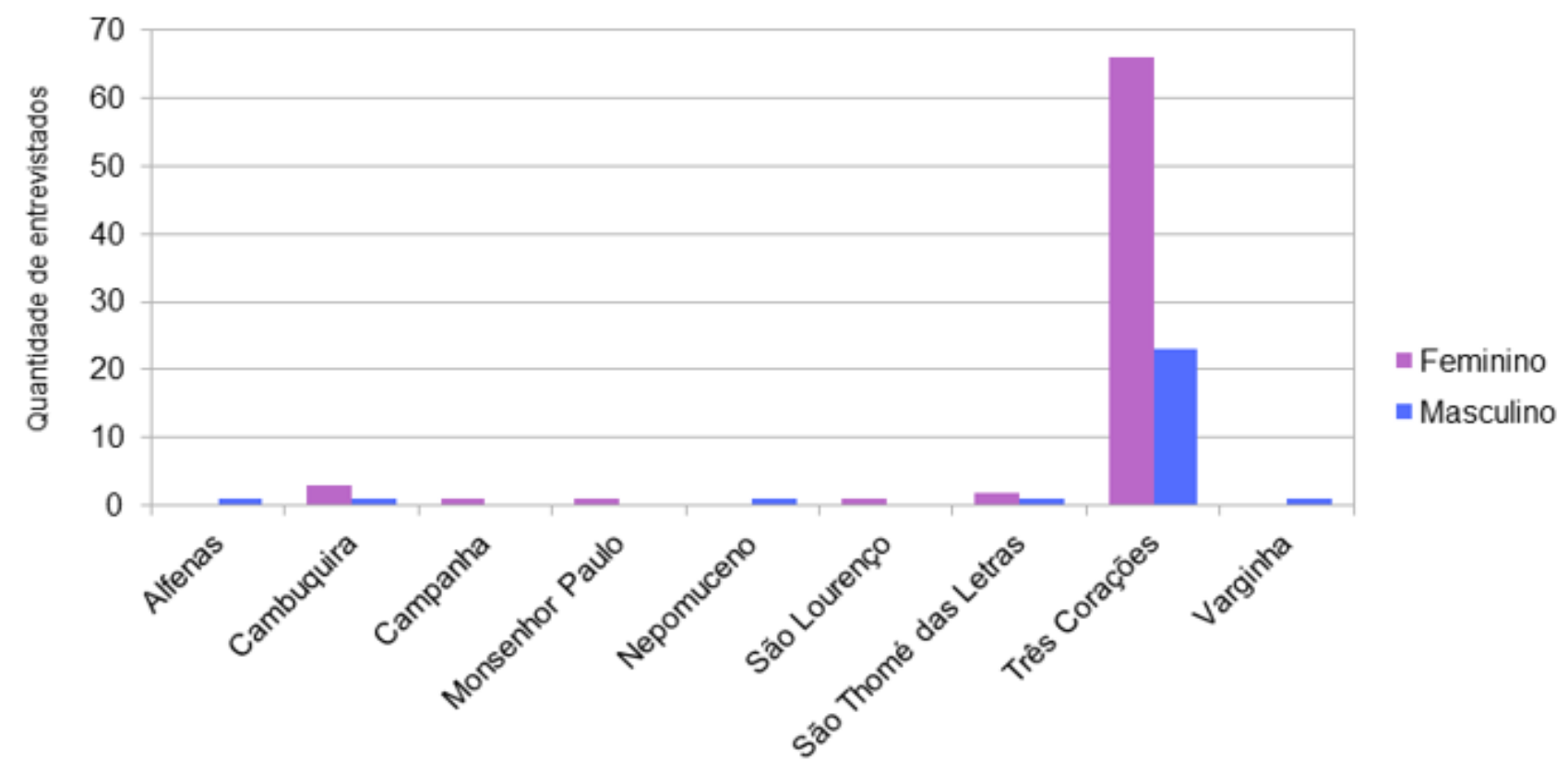

Fonte: próprio autor.

A Figura 3 mostra a distribuição dos entrevistados de acordo com o grau de escolaridade, separados por gêneros. Após observação da figura em questão, fica perceptível que a quantidade de entrevistados possui o ensino médio e são do gênero feminino. 
Bacharelado em Nutrição da UninCor e iniciação à pesquisa: Com a palavra os nossos estudantes

Figura 3: Distribuição dos entrevistados por município de acordo com o gênero.

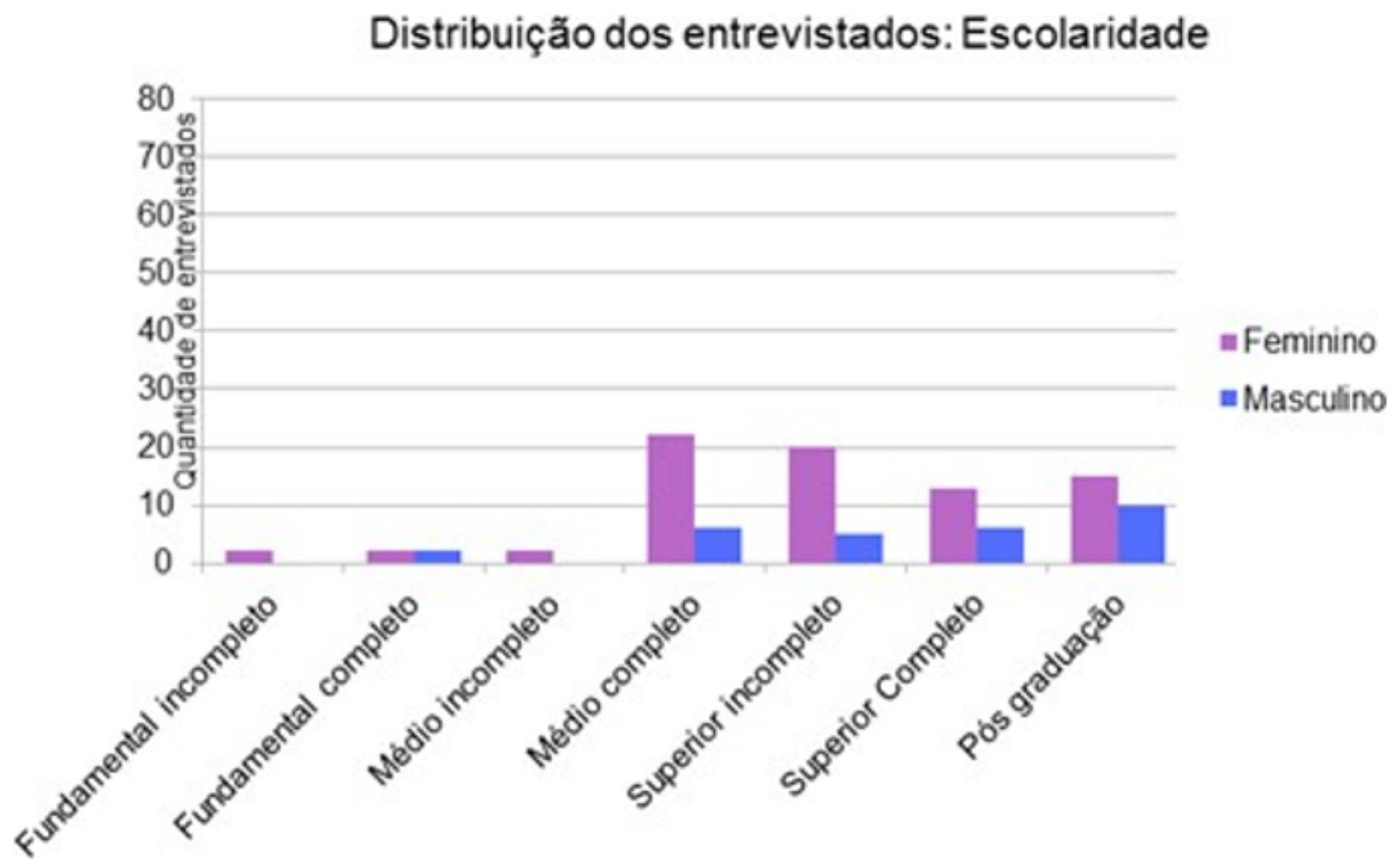

Fonte: próprio autor.

A Figura 4 apresenta a distribuição dos entrevistados de acordo com a quantidade de pessoas no grupo familiar separados por gênero. Pode-se observar e afirmar com propriedade, com base em pesquisas realizadas pelo IBGE - Instituto Brasileiro de Geografia e Estatísticas (2010), que as mulheres são predominantes nos ambientes familiares, isso quando, não estão sozinhas, neste contexto.

Segundo o IPEA - Instituto de Pesquisa Econômica Aplicada, o Brasil registra mais 71 milhões de famílias, com $42 \%$ de mulheres responsáveis pela casa, a maior parte delas, solteiras. Os lares brasileiros chefiados por mulheres dobrou na última década, saltou de 23\% para 40\%, entre 1995 e 2015, de acordo com dados da pesquisa Retrato das Desigualdades de Gênero e Raça (2018), feita pelo Instituto de Pesquisa Econômica Aplicada (Ipea). 
Figura 4: Distribuição dos entrevistados de acordo com a quantidade de pessoas no grupo familiar separados porgênero.

\section{Distribuição dos entrevistados: Grupo familiar}

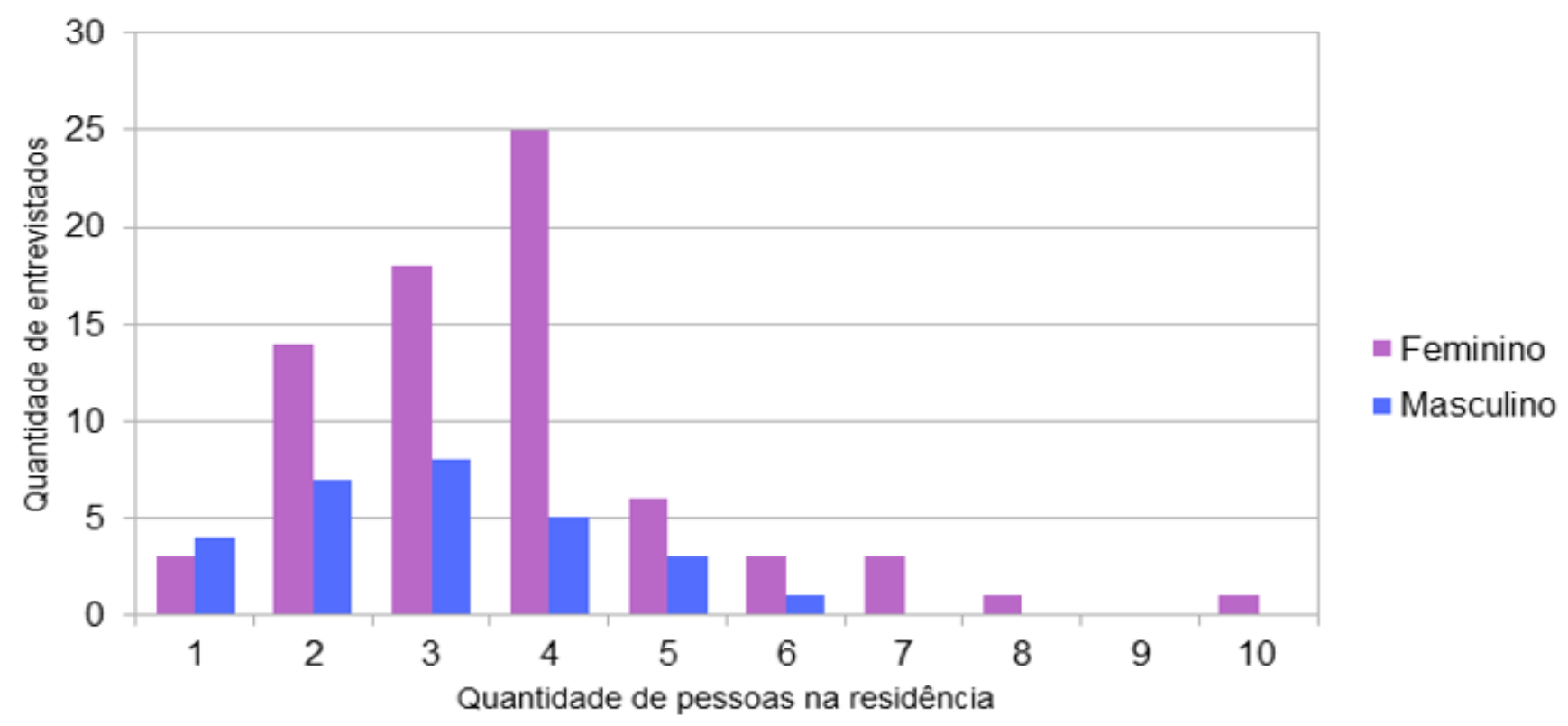

Fonte: próprio autor.

A Figura 5 apresenta a distribuição dos entrevistados de acordo com a renda. Podendoapontar que dos cento e dois entrevistados dez optaram por abster-se da informação. Sabendo que em tempos de pandemia, a renda informada que se encontra-se abaixo de $R \$ 600,00$ (seiscentos reais) faz-se referência ao auxílio emergencial e/ou renda informal. Assim, sabe-seque após observar a figura 5, que a renda do mineiro não é uma renda satisfatória, pois, boa parte dos entrevistados (acima de 40 pessoas), vivem com salários abaixo do mínimo e que nãoultrapassam três salários-mínimos. Ainda assim, se analisando o número de pessoas que compõe a família.

Segundo Queiroz (2001, p.66), “o Estado de Minas Gerais é, provavelmente, uma das regiões mais heterogêneas do país; coexistem no Estado regiões dinâmicas, modernas e com indicadores socioeconômicos de alto nível com localidades atrasadas, estagnadas, que não oferecem a mínima condição de vida para a sua população". 
Figura 5: Distribuição dos entrevistados de acordo com a renda.

Distribuiçãos dos entrevistados: Renda

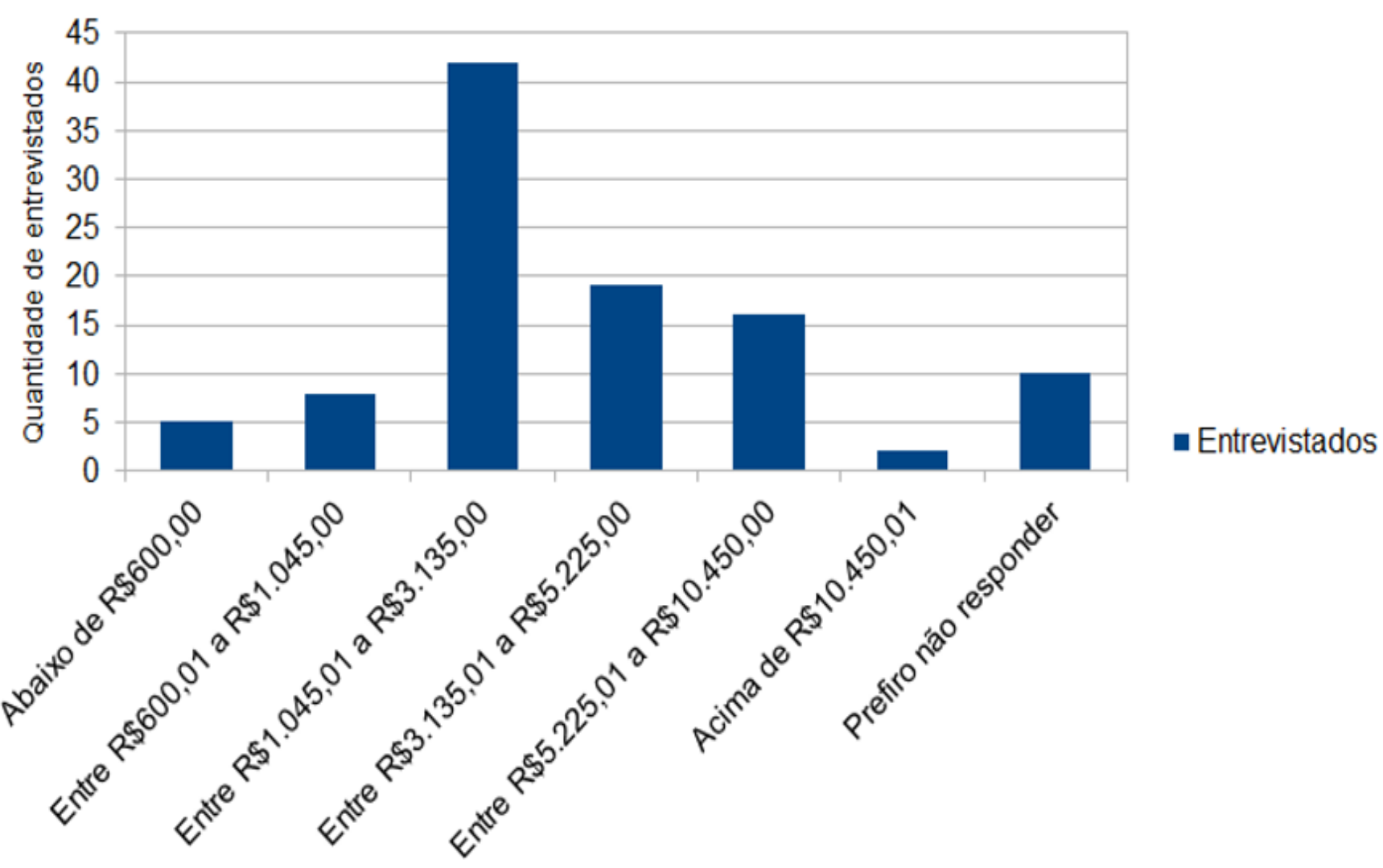

Fonte: próprio autor.

A Figura 6, mostra a distribuição dos entrevistados considerando as ações sofridas durante a pandemia. É possível observar que, a maior parte dos entrevistados ficaram em isolamento social residencial, boa parte dos entrevistados também relataram aumento com despesas médicas. E podemos dizer observando essa figura, que mais de 90 pessoas, continuamempregadas, o que de certa forma, é um ponto positivo. 
Figura 6: Ações durante a pandemia.

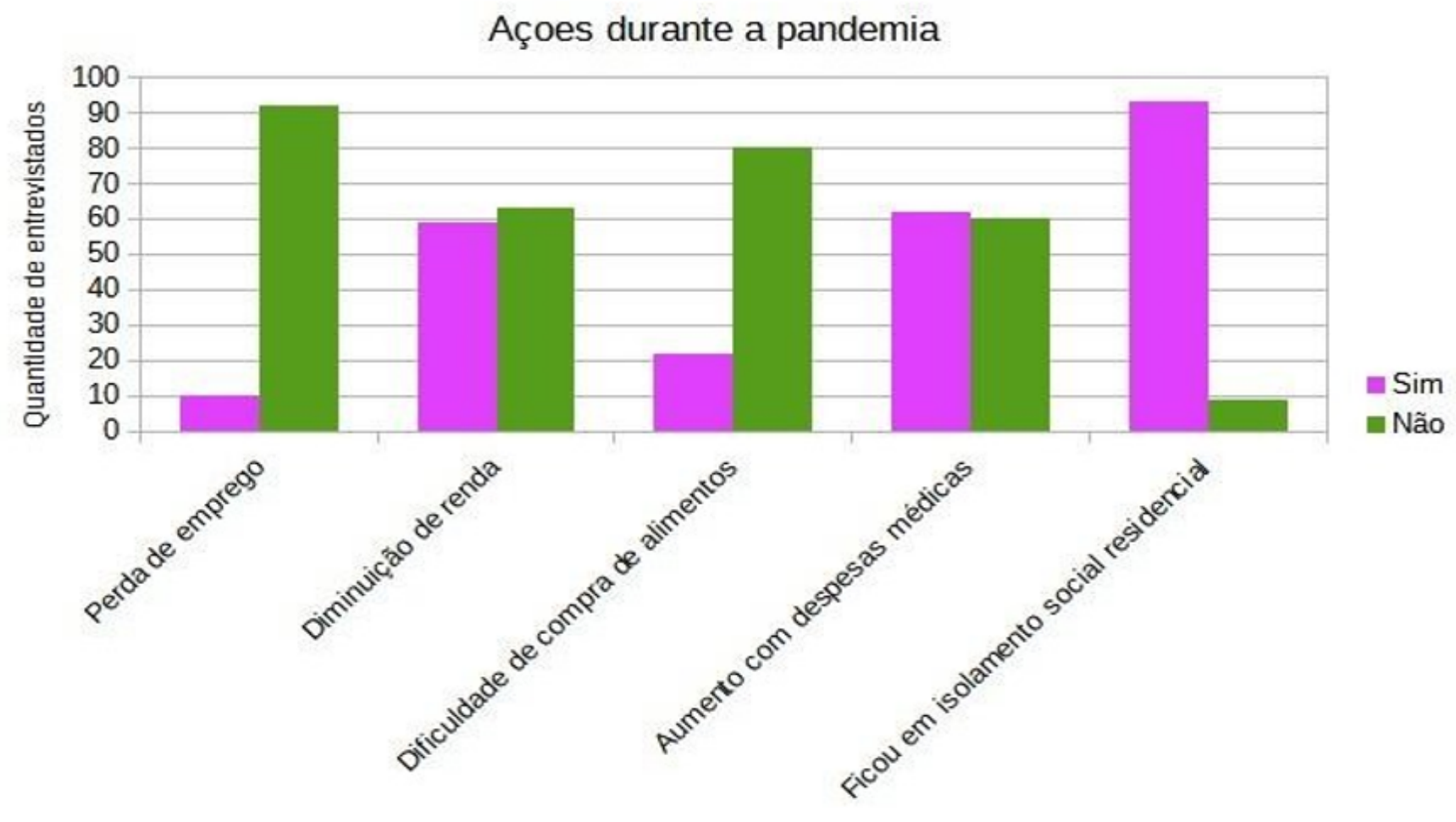

Fonte: próprio autor.

No questionário também foram registrados os sentimentos que os entrevistadosobservaram durante a pandemia. A Figura 7 mostra que a maior parte dos entrevistados sentiram medo de que algum parente ou amigo adoecessem. É possível notar também que apenas um entrevistado diz não ter ficado em isolamento. Com base em tal informação, é possível discutir sobre a questão, analisando de forma empática e tentando compreender tal situação, pois, destacando que o entrevistado que não ficou em isolamento social, teve seus motivos, podendo ser um deles, a necessidade de sair para se trabalhar, sendo o provedor da família e não podendo se manter estagnado, aguardando a situação amenizar. 
Figura 7: Sentimentos durante a pandemia.

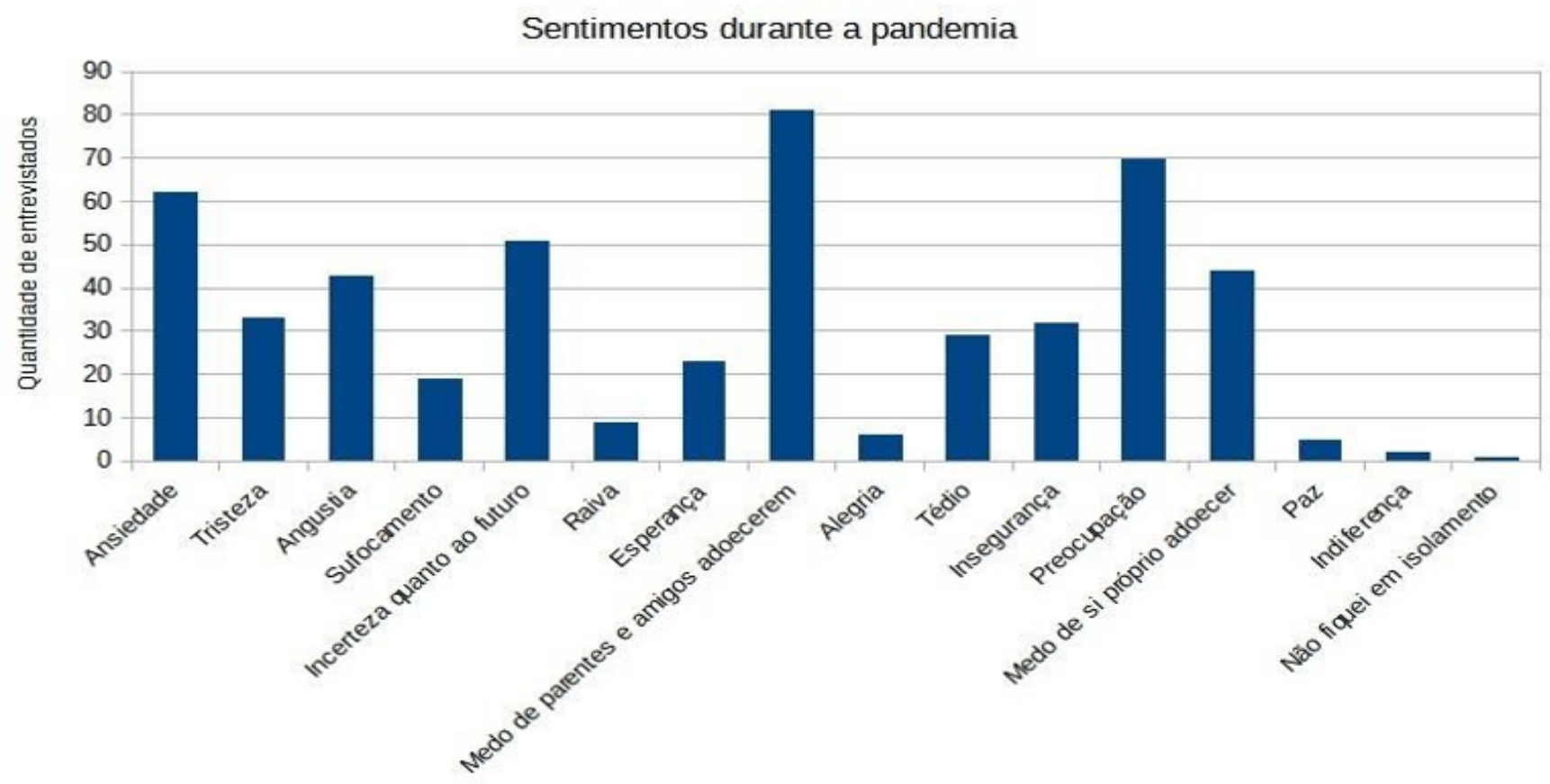

Fonte: próprio autor.

A Figura 8, apresenta outra questão que foi analisada e que é de suma importânciapara se destacar, pois os resultados obtidos sobre a alteração ou não do peso dos entrevistados, a maior parte relata ter sofrido esse ganho de peso. Esse fato pode estar atrelado tanto as ações/sentimentos durante a pandemia, quanto ao consumo de determinados alimentos e ao sedentarismo (OLIVEIRA et al., 2020).

Uma boa alimentação é aquela que mantém o organismo em estado de saúde, ou seja, com osso e dentes fortes, peso e estatura de acordo com o biótipo do indivíduo, boa disposição, resistência às enfermidades, vontade de trabalhar e divertir-se, para isso se faz necessária uma dieta balanceada que contenha variados nutrientes com múltiplas funções (MONTEIRO e COSTA, 2004). 
Figura 8: Alteração do peso durante a pandemia.

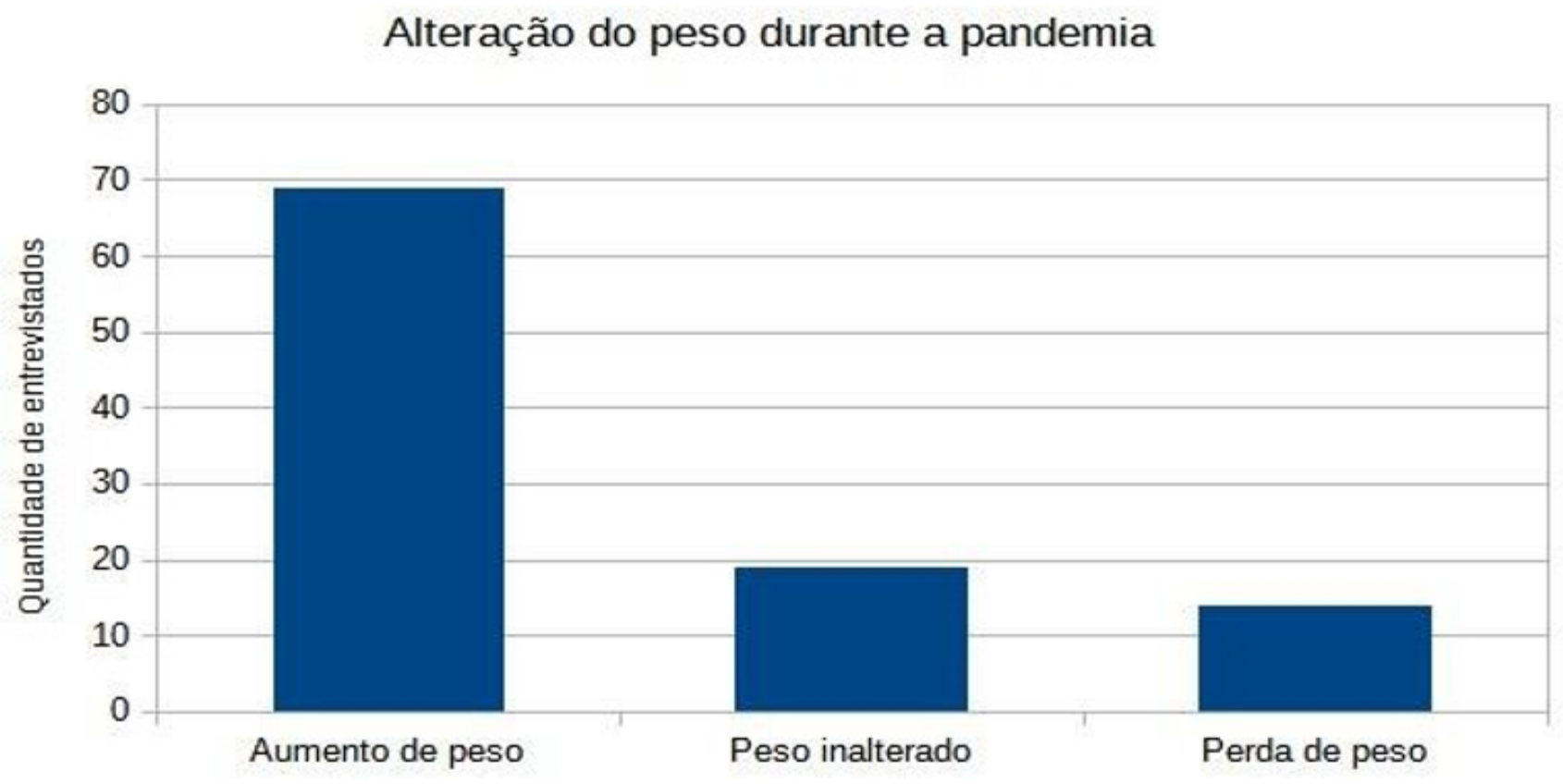

Fonte: próprio autor.

A Figura 9 apresenta o resultado de disposição para a realização das atividades diárias durante a pandemia. Como resultado obtido, pode-se dizer que o brasileiro por fim, nãopossui desde sempre, hábitos de exercícios físicos. "No Brasil, segundo dados do Vigitel (2011),14\% da população não pratica atividades físicas, ou seja, são sedentários". Assim sendo, com a pandemia e com os decretos de fechamento de estabelecimentos como parques, academias, etc, feitos pela OMS - Organização Mundial da Saúde, com o intuito de amenizar a propagação dovírus, seria uma "justificativa" a mais para não os praticar. 
Figura 9: Disposição para atividades diárias durante a pandemia

\section{Disposição para atividades diárias durante a pandemia}

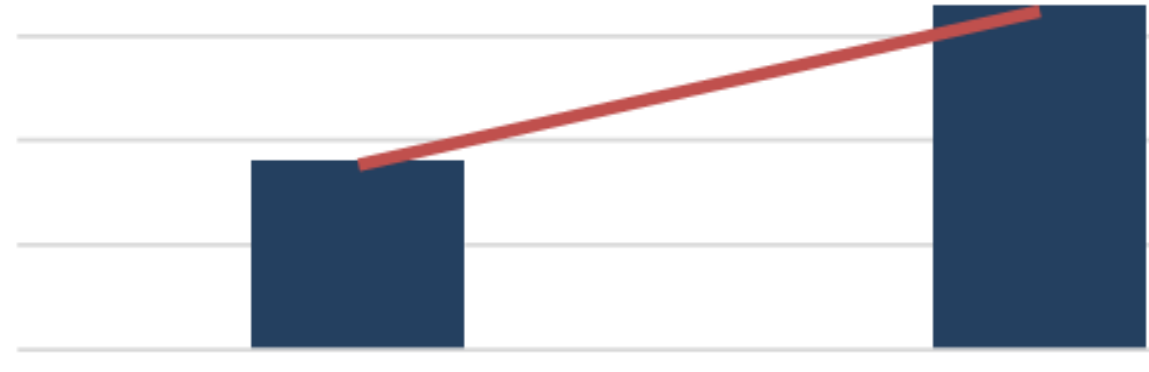

Fonte: próprio autor.

A Figura 10 apresenta a distribuição dos entrevistados de acordo com as atividades físicas praticadas antes do início da pandemia. Já a Figura 11 apresenta a relação durante a pandemia. Torna-se satisfatório afirmar que observando o gráfico abaixo, as pessoas que já praticavam atividades físicas, permaneceram com seus hábitos. Mesmo que em locais adversosde academias, optaram pela caminhada, exercícios físicos caseiros e a utilização com mais frequências das bicicletas.

Ademais, notou-se a alteração durante a pandemia pois algumas pessoas não praticavame começaram a praticar atividades físicas e outras que pararam. Em números absolutos, ocorreuuma diminuição na quantidade de pessoas praticantes de atividade física. Pode-se dizer que essa situação se deu, devido ao medo, a insegurança e a alguns protocolos sanitários. O estudo verificou que antes da pandemia $28,7 \%$ das pessoas de 12 a 63 anos, atendiam a recomendação de prática de atividade física moderada a vigorosa, enquanto durante a pandemia a prevalênciareduziu para $15,7 \%$ das pessoas (MALTA, et al., 2021). 
Figura 10: Atividades físicas antes da pandemia.

\section{Prática de atividades físicas antes da pandemia}

\section{0}

40

30

20

10

0

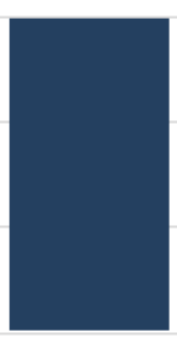

As vezes

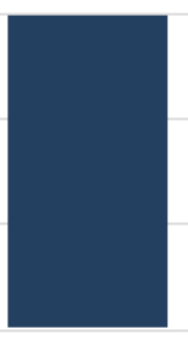

Regularmente

Fonte: próprio autor.

Figura 11: Atividades físicas durante a pandemia.

\section{Atividades físicas durante a pandemia}

45
40
35
30
25
20
15
10
5
0

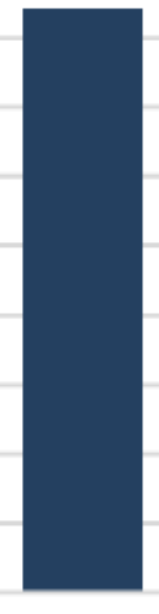

Inalterado

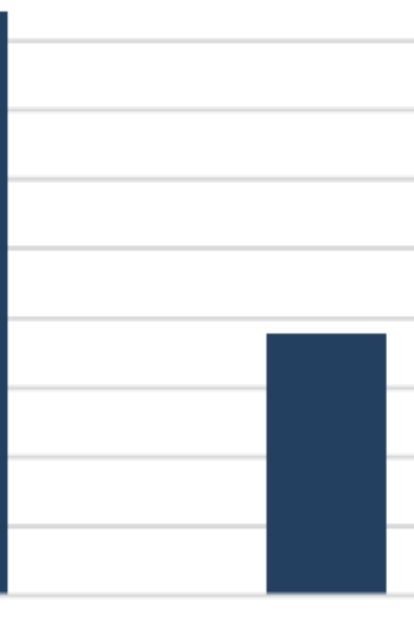

Diminuiu

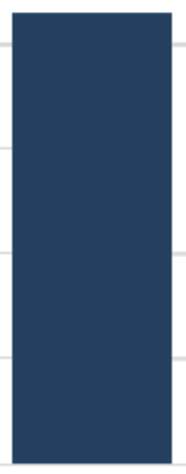

demia.

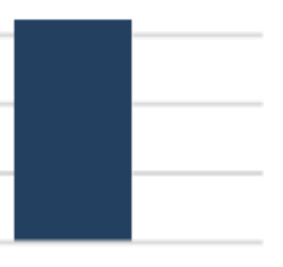

Parou de fazer atividades

Fonte: próprio autor. 
A Figura 12 apresenta a distribuição dos entrevistados de acordo com a alteração na alimentação durante a pandemia, o que destaca, a grande quantidade de pessoas que passaram a ingerir alimentos não tão saudáveis.

Figura 12: Alteração no consumo alimentar.

\section{Alteração na alimentação durante a pandemia}

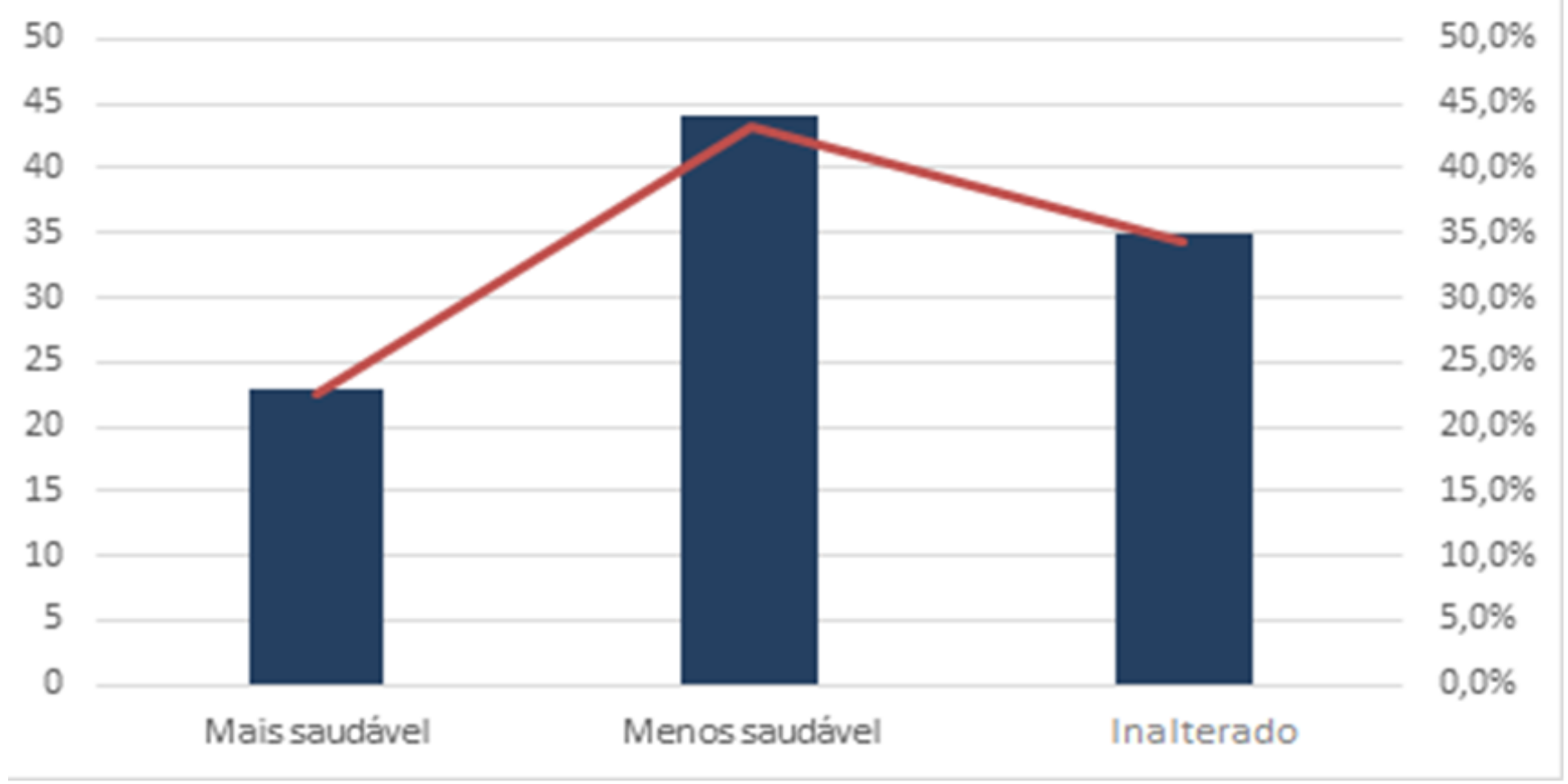

Fonte: próprio autor.

É possível analisar com essa figura, que a alteração da alimentação na pandemia, se deu devido à falta de atividades/ocupações. As pessoas optaram por criar receitas, assim, se ocupando e tendo o que fazer, se esquecendo que tais inovações, acarretariam alteração de seupeso. "Pode-se esperar um maior consumo de alimentos processados, aumento na demanda porserviços delivery de alimentos e, em alguns casos, mais tempo para se dedicar às práticas culinárias, produzindo alimentos ricos em açúcares e gorduras trans (MARRÓN-PONCE et al.,2019)".

A Figura 13 apresenta um importante dado referente a alteração no hábito alimentar desencadeado pela ansiedade, demonstrando se houve alteração ou não e se o consumoaumentou ou diminuiu. Pode-se observar que a quantidade de pessoas que tiveram aumento emseus hábitos alimentares é de aproximadamente $90 \%$ e os que diminuíram o consumo é de apenas $10 \%$ dos entrevistados. 
Figura 13: Alteração dos hábitos alimentares.

\section{Alteração na frequência de alimentação causada pela ansiedade}

$$
\begin{array}{r}
100,0 \% \\
80,0 \% \\
60,0 \% \\
40,0 \% \\
20,0 \% \\
0,0 \%
\end{array}
$$

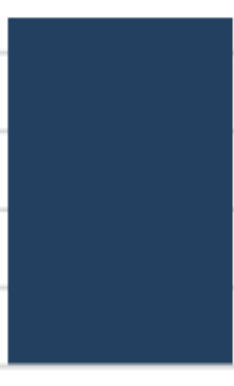

Aumento

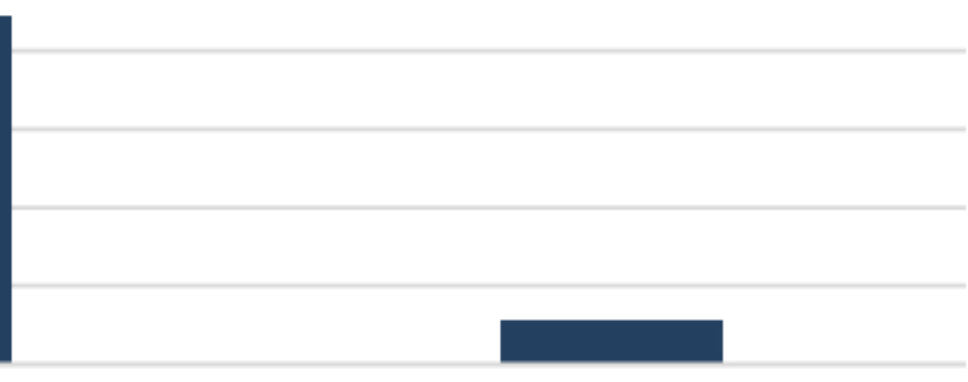

Diminuição

Fonte: próprio autor.

Figura 14: Alteração de peso durante a pandemia.

\section{Distribuição dos entrevistados: Alteração de peso (percentual) durante a pandemia}

\section{$45,0 \%$ \\ $40,0 \%$ \\ $35,0 \%$ \\ $30,0 \%$ \\ $25,0 \%$ \\ $20,0 \%$ \\ $15,0 \%$ \\ $10,0 \%$ \\ $5,0 \%$ \\ $0,0 \%$}

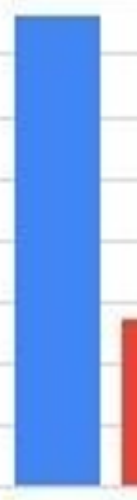

Aumento

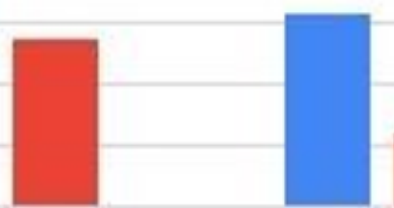

Inalterado

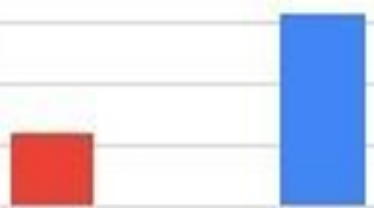

Diminuiç̧ão

\section{-Feminino Masculino}

Fonte: próprio autor. 
Ao analisar a Figura 14, percebeu-se que houve alteração de peso entre os entrevistadosdurante a pandemia. Seja pelo excesso no consumo de alimentos e/ou pela falta de exercício físico. Com a necessidade do desenvolvimento de atividades em home office, o tempo dos trabalhadores em casa, em atividades envolvendo tecnologias da informação, aumentou consideravelmente, reduzindo o gasto calórico dos profissionais com deslocamentos e outras atividades laborais. Por outro lado, o tempo gasto com o uso de tecnologias, como computadores, tablets, celulares, televisores e videogames, aumentou (MALTA, et al, 2020).

Segundo Popkin et al. (2020), essas atividades favorecem uma maior ingestão de calorias e ummenor gasto calórico, podendo predispor ao aumento de peso corpóreo e acentuar os quadros de obesidade já existentes.

Tabela 1: Consumo De Alimentos

\begin{tabular}{|c|c|c|c|c|c|c|c|c|c|}
\hline & \multicolumn{2}{|c|}{ Frutas } & \multicolumn{2}{c|}{ Legumes } & \multicolumn{2}{c|}{ Carnes } & \multicolumn{2}{c|}{ Doce } \\
\hline & $N$ & $\%$ & $N$ & $\%$ & $N$ & $\%$ & $N$ & $\%$ \\
\hline $\begin{array}{c}\text { Aumentou o } \\
\text { consumo }\end{array}$ & 31 & $30,39 \%$ & 33 & $32,35 \%$ & 18 & $17,65 \%$ & 52 & $50,98 \%$ \\
\hline \begin{tabular}{c} 
Manteve o consumo \\
\hline
\end{tabular} & 53 & $51,96 \%$ & 59 & $57,84 \%$ & 57 & $55,88 \%$ & 35 & $34,31 \%$ \\
\hline \begin{tabular}{c} 
Diminuiu o consumo \\
\hline
\end{tabular} & 18 & $17,65 \%$ & 10 & $9,80 \%$ & 27 & $26,47 \%$ & 15 & $14,71 \%$ \\
\hline $\begin{array}{c}\text { Aumentou o } \\
\text { consumo }\end{array}$ & 21 & $20,59 \%$ & 40 & $39,22 \%$ & 45 & $44,12 \%$ & 40 & $39,22 \%$ \\
\hline \begin{tabular}{c} 
Manteve o consumo \\
\hline
\end{tabular} & 69 & $67,65 \%$ & 51 & $50,00 \%$ & 42 & $41,18 \%$ & 48 & $47,06 \%$ \\
\hline Diminuiu o consumo & 12 & $11,76 \%$ & 11 & $10,78 \%$ & 15 & $14,71 \%$ & 14 & $13,73 \%$ \\
\hline
\end{tabular}


Bacharelado em Nutrição da UninCor e iniciação à pesquisa: Com a palavra os nossos estudantes

\begin{tabular}{|c|c|c|c|c|c|c|c|c|}
\hline & & Café & & bida & Rei & yerantes & & $\begin{array}{l}\text { ucos } \\
\text { Iturais }\end{array}$ \\
\hline & $\mathbf{N}$ & $\%$ & N & $\%$ & $\mathbf{N}$ & $\%$ & N & $\%$ \\
\hline $\begin{array}{c}\text { Aumentou o } \\
\text { consumo }\end{array}$ & 28 & $27,45 \%$ & 33 & $32,35 \%$ & 29 & $28,43 \%$ & 28 & $27,45 \%$ \\
\hline Manteve o consumo & 70 & $68,63 \%$ & 60 & $58,82 \%$ & 55 & $53,92 \%$ & 57 & $55,88 \%$ \\
\hline Diminuiu o consumo & 4 & $3,92 \%$ & 9 & $8,82 \%$ & 18 & $17,65 \%$ & 17 & $16,67 \%$ \\
\hline
\end{tabular}

Fonte: próprio autor.

Observando a tabela 1, que faz referência ao consumo de alimentos, pode-se concluir que as frutas, os legumes e a carne permaneceram na dieta dos mineiros, já os doces, conseguiram seu lugar ao podium, tendo assim, uma significatividade de consumo, além do esperado. Leites e derivados continuaram no cardápio, massas também, pães e bolos deram umaacrescida, pois, como pontuado anteriormente, estando em isolamento social, muitos optaram por cozinhar e muitos desses pratos, davam-se a pães e bolos, e os sanduíches, se mantiveram em sua posição. Algumas mudanças nas práticas alimentares já constatadas durante a pandemia da COVID-19 tangenciam aspectos de acesso ao alimentos, como a compra e estocagem de grande volume de alimentos e com isso o aumento na disponibilidade de alimentos nodomicílio, somado ao maior tempo que as pessoas estão em casa. Esse fatores provavelmente predispõem o aumento do consumo alimentar (POULSEN et al., 2019). Quanto as bebidas, observou-se que as bebidas alcoólicas obtiveram crescimento neste período pandêmico.

Realizou-se teste qui-quadrado com a finalidade de verificar a influência da alimentaçãoe da pandemia na qualidade de vida dos entrevistados, analisando em qual grupo foi o maior impacto, sendo separado em sexo, idade, escolaridade 
e renda. Resumidamente o teste tem como objetivo testar se uma variável influência significativamente a outra, esse resultado é evidenciado quando o p-valor calculado pelo teste é menor do que o - de interesse, usualmenteo valor de referente é $p<0,05$ que permite a afirmação com 95\% de confiança. Desta forma parainterpretar os resultados do teste observa-se o $p$-valor, caso ele seja menor do que 0,05 pode-sedizer que as variáveis que estão sendo testada estão relacionadas entre si.

A partir desse teste, verificou-se que as mulheres consomem mais alimentos do grupo de leite e derivados (91,5\%) quando comparadas aos homens $9,5 \%$ $(p<0,05)$. O consumo de cálcio é de suma importância tanto para os homens quanto para as mulheres devido a sua influência no metabolismo e na composição óssea. Sua indisponibilidade pode trazer prejuízosa saúde como a osteoporose, em especial as mulheres após menopausa (CARVALHO ETAL.,2004)

Outro dado relevante é em relação ao consumo de pães e bolos e sexo, sendo que $77,8 \%$ das mulheres da amostra do presente estudo o consumiam enquanto apenas $22,2 \%$ dos homens $(p<0,05)$. Os alimentos com funções energéticas são responsáveis por fornecer energia na formade calorias. São representados por: - Carboidratos: fornecem energia de forma rápida, é responsável pelo fornecimento de $4 \mathrm{kcal}$ (quilocalorias) a cada grama de carboidrato do alimento; - Lipídios: contém maior quantidade de energia, fornecem 9 kcal (quilocalorias) porgrama de lipídios do alimento; - Proteínas: com outras funções especificas, a proteína também contribui com o fornecimento de energia ao organismo, fornecem 4 kcal (quilocalorias) a cadagrama de proteína do alimento (GALISA; ESPERANÇA; SÁ (2008). 
Bacharelado em Nutrição da UninCor e iniciação à pesquisa: Com a palavra os nossos estudantes

\section{CONCLUSÃO}

Conclui-se que, com os últimos acontecimentos e após análise de pesquisa e de todosos gráficos inseridos neste contexto, foi possível constatar de forma concreta que as questõesde ganho de peso tiveram um aumento significativo e preocupante, em todas as faixas etárias.As mudanças acarretadas devido a esse acontecimento (COVID-19), proporcionou alteraçõesem todos os hábitos diários das pessoas, sendo um deles em especial tratado aqui, a alimentação.

O aumento da ansiedade, o medo, a incerteza e os problemas psicológicos fizeram comque as pessoas, procurassem uma alimentação mais prática e fácil de se preparar, o que prejudicou muito os antigos hábitos alimentares e aumentou em grande proporção o ganho de peso do indivíduo. As pessoas se viram cada dia mais confusas, tensas e confinadas, procurando assim, atenuar essas sensações. Esquecendo-se assim, que estariam aliviando suas tensões, porém, ocasionando um possível problema que é o ganho desmedido de peso.

Independe da classe social, foi possível detectar essa alteração de ganho de peso para todos, porém, a questão se intensificou para pessoas de uma classe social mais favorecida, tendoas mesmas, mais oportunidades e maiores recursos financeiros para o consumo de produtos ricoem gorduras e carboidratos.

Ademais, é importante destacar que, não se trata apenas da quantidade de alimentos consumidos, inseridos, mas sim, trata-se do tipo de alimentação que os indivíduos passaram a incluir em sua dieta alimentar, muitos alimentos industrializados e fast food. O que acarreta cada vez mais os problemas de saúde, sendo um deles, a obesidade.

É importante reforçar que uma boa alimentação e nutrição são fatores essenciais para semanter saudável, disposto, aumentar a imunidade (para ajudar no combate de diversas doenças, inclusive a COVID-19) e o principal, manter-se vivo. 
Bacharelado em Nutrição da UninCor e iniciação à pesquisa: Com a palavra os nossos estudantes

\section{REFERENCIAS}

ABESO. Obesidade e sobrepeso. Disponível em: https://abeso.org.br/conceitos/obesidade-e-sobrepeso/.

ABREU, Cristiano Nabuco de. Anorexia nervosa e bulimia nervosa: abordagem cognitivo-construtivista de psicoterapia. Disponível em: https://www. scielo.br/j/rpc/a/9FVpRS69MRbwMq89H74V6sK/?lang=pt.

AGUIAR, Priscilla Vasconcelos. Compulsão alimentar, depressão e ideação suicida em obesos. 2019. Dissertação (Mestrado em Neuropsiquiatria e Ciências do Comportamento) -Universidade Federal de Pernambuco, Recife, 2019.

ALVARENGA, Marle et al. Nutrição Comportamental: 2. ed. Barueri: Manole, 2019. 596 p. Nutrição.

BANDEIRA, Vivian de Freitas. $O$ trauma na infância em mulheres com compulsão alimentar. 2020. 154 f. Dissertação (Mestrado em Psicologia: Psicologia Clínica) - Programade Estudos Pós-Graduados em Psicologia: Psicologia Clínica, Pontifícia Universidade Católica de São Paulo, São Paulo, 2020.

BARBIERI, Aline Fabiane. As causas da obesidade: uma análise sob a perspectiva materialista histórica. 2012. Disponível em: https://periodicos.sbu.unicamp.br/ojs/index.php/conexoes/article/view/8637693/.

BETTIN, Bibiana Pedra Cruz. Fatores associados e instrumentos de avaliação da alimentação emocional: uma revisão narrativa da literatura. 2017. $41 \mathrm{f}$. TCC (Graduação) - Curso de Nutrição, Universidade Federal do Rio Grande do Sul, Porto Alegre, 2017.

BEZERRA, Anselmo César Vasconcelos. Fatores associados ao comportamento da população durante 0 isolamento social na pandemia de COVID-19. Ciências. Saúde Coletiva, v. 25, p. 2411, 05 jun. 2020. Disponível em: DOI: 10.1590/1413- 81232020256.1.10792020.

BOLSONI-LOPES, Andressa. Obesidade e a covid-19: uma reflexão sobre a relação entreas pandemias. 2021. Disponível em: https://www.seer.ufrgs.br/RevistaGauchadeEnfermagem/article/view/110507. 
BRUGNEROTTO, Adriano. IMPACTO DA PANDEMIA DE COVID-19 NO NÍVEL DEATIVIDADE FÍSICA DE BOMBEIROS NA CIDADE DE SÃO LUDGERO - SC. 2020. 19 f. TCC (Graduação) - Curso de Educação Física, Universidade do Sul de Santa Catarina, Santa Catarina, 2020.

FARAH, Juliana Ferreira Santos; CASTANHO, Pablo. Dimensões psíquicas do emagrecimento: por uma compreensão psicanalítica da compulsão alimentar. Rev. Latinoam.Psicopat. Fund., São Paulo, 21(1), 41-57, mar. 2018.

FLORÊNCIO JÚNIOR, Públio Gomes; PAIANO, Rone; COSTA, André dos Santos. Isolamento social: consequências físicas e mentais da inatividade física em crianças e adolescentes. Revista Brasileira de Atividade Física e Saúde, v. 25, p. 1-2, 14 set. 2020.Disponível em: https://rbafs.org.br/RBAFS/article/view/14263. Acesso em: 30 abr. 2021.

FOCHESATTO, Annelise. comportamento alimentar e percepção da imagem corporal deadultos que buscam emagrecimento por meio de dieta: 2020. 65 f. Tese (Doutorado) - Curso de Nutrição, Universidade Federal do Rio Grande do Sul, Porto Alegre, 2020.

LORENZON, Luís Felipe Lopes. Ortorexia nervosa e imagem corporal em adolescentes eadultos. Disponível em: cielo.br/j/jbpsiq/a/8rDx5nqcBZyPSJ9X54CW5Xq/?lang=pt.

MALTA, Deborah Carvalho. Doenças crônicas não transmissíveis e mudanças nos estilos de vida durante a pandemia de COVID-19 no Brasil. Revista Brasileira de Epidemiologia, Belo Horizonte, v.24, p. 1-15, 03 maio 2021. Disponível em:https://doi.org/10.1590/1980-549720210009.

OLIVEIRA, J, Figueredo, L., Cordas, T.A. Prevalência de comportamentos de risco paratranstornos alimentares e uso de dieta "low-carb" em estudantes universitários. J. bras. psiquiatr. Rio de Janeiro. Vol. 68. Num 4. 2019. p. 183190.

OLIVEIRA, Wanderson Kleber de et al . Como o Brasil pode deter a COVID19. Epidemiol. Serv. Saúde, Brasília , v. 29, n. 2, e2020044, maio 2020. Disponível em <http://scielo.iec.gov.br/scielo.php?script=sci_arttext\&pid=S167949742020000200002\&lng=pt\&nrm=iso>. 
Bacharelado em Nutrição da UninCor e iniciação à pesquisa: Com a palavra os nossos estudantes

OLIVEIRA, Nadja Thomé de; SILVA, llane Karine Martins Mendes da; LEMOS, Raphaela Costa Ferreira. ISOLAMENTO SOCIAL DURANTE A PANDEMIA DE COVID-19 E AINFLUÊNCIA DOS HÁBITOS ALIMENTARES DOS BRASILEIROS: 2020. 13 f. Tese (Doutorado) - Curso de Nutrição, Universidade Tiradentes., Alagoas, 2021.

PALAVRAS, Marly Amorim. Uma revisão dos estudos latino-americanos sobre otranstorno da compulsão alimentar periódica. 2011. Disponível em: https:// www.scielo.br/j/rbp/a/wSbnV4n8xLpxRpxRbx3wBfq/?lang=pt.

PINHEIRO, Anelise Rízzolo de Oliveira. Uma abordagem epidemiológica da obesidade.2004. Disponível em: https://www.scielo.br/j/rn/a/yb5FgzvgCVPZVsxtsNp384t/?lang=pt.

Pitanga FJG, Beck CC, Pitanga CPS. Atividade Física e Redução do Comportamento Sedentário durante a Pandemia do Coronavírus. Arq Bras Cardiol. 2020;114(6). 1058-1060. doi:10.36660/abc.20200238.

Pitanga FJG, Beck CC, Pitanga CPS. Inatividade física, obesidade e COVID-19: perspectivas entre múltiplas pandemias. Rev Bras Atividade Fisica em Saúde. 2020;25:e0114. DOI: 10.12820/rbafs.25e0114.

PITANGA, Francisco José Gondim; BECK, Carmem Cristina; PITANGA, Cristiano Penas Seara. Inatividade física, obesidade e COVID-19: perspectivas entre múltiplas pandemias. Revista Brasileira de Atividade Física e Saúde, p. 1-4, 25 out. 2020. Disponívelem: https://docs.bvsalud.org/biblioref/2020/10/1121595/ 14262-texto-do-artigo-55480-1-10- 20200914.pdf. Acesso em: 30 abr. 2021.

RAIOL, Rodolfo A. Praticar exercícios físicos é fundamental para a saúde física e mental durante a Pandemia da COVID-19. Brazilian Journal Of Health. Curitiba, p. 04-13. 03 abr. 2020. Disponível em: https://www.researchgate.net/ publication/340429983_Praticar_exercicios_fisicos_e_fundame ntal_para_a_ saude_fisica_e_mental_durante_a_Pandemia_da_COVID- 19_Physical_exercise_is_essential_for_physical_and_mental_health_during_the_COVID- 19 Pandemic. Acesso em: 30 abr. 2021.

ROCHA, Giovana Vilela. A influência da obesidade na mortalidade de adultos com COVID-19. 2021. Disponível em: https://www.brazilianjournals.com/index. php/BJHR/article/view/23255/18685. 
Bacharelado em Nutrição da UninCor e iniciação à pesquisa: Com a palavra os nossos estudantes

SANTOS, Ariene Angelini dos. Qualidade de vida de pessoas com obesidade grau III: um desafio comportamental. 2012. Disponível em: http://files.bvs.br/ upload/S/1679- 1010/2012/v10n5/a3149.pdf.

SANTOS, Gabriel Sgotti Hanczaryk dos; CAMARGO, Caroline Coletti de; MENOSSI, Berlis Ribeiro dos Santos. Projeto de extensão universitário no combate a obesidade infantil através das mídias sociais em face de pandemia por covid-19: um estudo transversal. Brazilian Journal Of Development. Curitiba, p. 86-100. 18 set. 2020. Disponível em: https://www.brazilianjournals. com/index.php/BRJD/article/view/16876.Acesso em: 30 abr. 2021.

SCHMIDT, Eder. Anorexia nervosa: uma revisão. Disponível em: https://www. scielo.br/j/jbpsiq/a/8rDx5nqcBZyPSJ9X54CW5Xq/?lang=pt\&format=pdf.

SILVA, Guilherme Faustino da. Modificações dos Hábitos Alimentares Relacionadas à Pandemia do Covid-19: uma Revisão de Literatura. 2021. Disponível em: Disponível em:https://www.scielo.br/pdf/aabc/v91n1/0001-3765-aabc-9101-e20180358.pdf.

SILVA, Inácio Crochemore et al. Prática de atividade física em meio à pandemia da COVID-19: estudo de base populacional em cidade do sul do Brasil. 10 f. Monografia (Especialização) - Curso de Educação Física, Universidade Federal de Pelotas, Rio Grande doSul, 2020.

SOARES, Thiago Tavares. Fatores associados a insatisfação da imagem corporal entre adolescentes no interior do Ceará. 2020. 1 recurso online (45 p.) Dissertação (mestrado profissional) - Universidade Estadual de Campinas, Faculdade de Odontologia de Piracicaba,Piracicaba, SP.

SWAROWSKY, Inácio. Obesidade e fatores associados em adultos. 2012. Disponível em:https://online.unisc.br/seer/index.php/cinergis/article/view/2845.

VERAS, Aimorá L. Laus. Desenvolvimento e construção da imagem corporal na atualidade: um olhar cognitivo- comportamental. 2010. Disponível em :http://pepsic.bvsalud.org/scielo.php?script=sci_arttext\&pi$d=S 1808-56872010000200006$.

VERTICCHIO, Daniela Flávia dos Reis; VERTICCHIO, Norimar de Melo. Os impactos doisolamento social sobre as mudanças de comportamento alimentar e ganho de peso durante a pandemia COVID-19 em Belo Horizonte e região metropolitana, Estado de Minas Gerais, Brasil. Pesquisa, Sociedade e Desenvolvimento, v. 9, n. 9, p. 1-13, 26 ago.2020. Disponível em: https://rsdjournal.org/index.php/rsd/article/view/7206/7468. 
doi 10.48209/97/8-65-89949-72-71

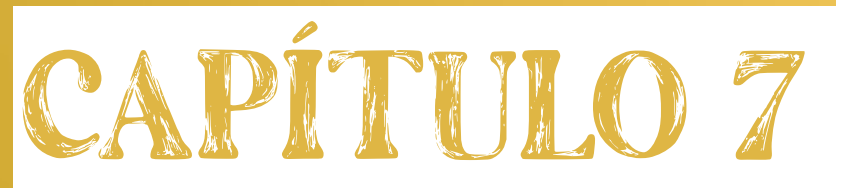

\section{SEIFEHIIDACDE}

AMTMENHAR NO IHANSHORNO DO BSPECHRO A AUHSMO (패로)

Bruna Andrade Silva Ana Luiza Rodrigues Pellegrinelli 
Bacharelado em Nutrição da UninCor e iniciação à pesquisa: Com a palavra os nossos estudantes

\section{INTRODUÇÃO}

Este trabalho é dedicado especialmente a todas ascrianças autistas que, de forma silenciosa e, até muitas vezes geniais, nos mostram um lado inexplorado do serhumano. Viviane Cintra Felício (2007, p. 4).

Observa-se que nas últimas décadas tem aumentado o diagnóstico de transtornos de origem neurobiológica na infância, destacando-se os casos de crianças portadoras de Transtornos Globais do Desenvolvimento, sendo o Transtorno do Espectro do Autismo (TEA)um desses casos. No Brasil o valor estimado de dois (2) milhões de autistas em 200 milhões dehabitantes (CHRISTENSEN et al., 2016; OLIVEIRA, 2017).

De acordo com Associação Americana de Psiquiatria (APA, 2018), o TEA é classificado como um transtorno crônico, um conjunto de distúrbios do desenvolvimento neurológico que ocorre precocemente, cujos sintomas podem estar presentes no período de desenvolvimento e acarreta prejuízos nas habilidades sociais, na comunicação, principalmente na linguagem, e nocomportamento do indivíduo. Por ser uma condição complexa, o tratamento do autismo exige a integração de diversos protocolos envolvendo terapia comportamental e social, controle ambiental e terapia nutricional, em um trabalho com equipe multiprofissional e o apoio e integração dos familiares (CORREA, 2015; LEAL et al., 2015).

Para Lima (2018) e Felipe et al. (2021), o TEA não é apenas transtorno neurológico, mas envolve um grupo de manifestações, como anormalidades metabólicas, inflamação intestinal, desequilíbrio imunológico e sintomas relacionados com o sistema gastrintestinal. Crianças com autismo são muito seletivas e persistentes ao novo, dificultando a inserção de novas experiências com alimentos, podendo levar a transtornos da alimentação. Por isto, apresentam características alimentares peculiares, como a seletividade alimentar (SA), caracterizada pela aceitação restrita de alimentos e na recusa em experimentar novos, dificultando a socialização relacionada a alimentação. Têm também aversão a alguns tipos de cores, cheiros, temperaturas e texturas. 
Seletividade Alimentar pode gerar carências nutricionais significativas na primeira infância, aspectos que tornam a alimentação uma questão delicada para os autistas. A não aceitação do alimento contribui para uma inadequação alimentar e para um futuro quadro de desnutrição (GAMA et al., 2020). A má alimentação e a falta de equilíbrio energético são motivos de especial preocupação, pois a ingestão de micronutrientes está estreitamente relacionada com a ingestão de energia. É provável que crianças, cujo consumo de energia sejamenor, também sofram de deficiência de ferro e zinco (ROCHA et al., 2019).

Portanto, a nutrição tem um papel de suma importância no tratamento e na evolução desses indivíduos, pois, a partir da intervenção nutricional, os sintomas podem ser tratados e reduzidos. Uma dieta com baixa variedade de alimentos, o baixo consumo de frutas, verduras e fibras, alimentos com muitas proteínas, ricos em açúcar e pobres em vitaminas levam a alterações no peso e distúrbio de crescimento, além de se observar também obesidade e sobrepeso (CORREA, 2015; ROCHA et al., 2019; FELIPE et al., 2021).

Tendo em vista o exposto, a presente pesquisa tem por objetivo explicar, relatar e avaliardentro de SA, características de comportamento alimentar e a dificuldade de crianças com TEA, frente a alguns grupos alimentares, das cidades de Cambuquira e Três Corações, com o intuitode melhorar a qualidade de vida tanto para o portador quanto para os envolvidos neste contexto.

\section{REVISÃO DE LITERATURA}

\subsection{Desenvolvimento infantil}

O desenvolvimento infantil é importante, mas é necessário ter uma boa alimentação. É na infância, desde os primeiros meses de vida, que se inicia a construção de hábitos saudáveis, incluindo os alimentares e os ambientais tanto o domiciliar como o escolar, podendo potencializar os processos educativos e de cuidado, bem como as relações interpessoais nessa fase da vida (OLIVEIRA; FRUTUOSO, 2021). 
CONSEA (2004), afirma que:

A alimentação e nutrição adequadas constituem direitos fundamentais do ser humano. São condições básicas para que se alcance um desenvolvimento físico, emocional e intelectual satisfatório, fator determinante para a qualidade de vida e o exercício da cidadania. Se for verdade que, muitas vezes, a falta de recursos financeiros é o maiorobstáculo a uma alimentação correta, também é fato que ações de orientação e educativas têm um papel importante no combate a males como a desnutrição e a obesidade. Ao chamar a atenção de crianças e adolescentes para os benefícios de umaalimentação equilibrada, a escola dá a sua contribuição para tornar mais saudável a comunidade em que se insere (CONSEA, 2004, p. 81).

Uma dieta equilibrada é essencial para o bem-estar e boas condições de vida, pois as deficiências alimentares podem trazer inúmeros problemas para saúde aumentando sua vulnerabilidade às infecções e gerando atrasos no processo de maturação do sistema nervoso e no desenvolvimento mental e intelectual, podendo ser irreversíveis dependendo da intensidade e da duração da deficiência (APA, 2018).

A má alimentação associada à recusa das variedades de alimentos traz consequências graves para o desenvolvimento físico e mental da criança, como a desnutrição, por não se alimentarem de macro e micronutrientes importantes, a obesidade, hipertensão, diabetes, doenças cardiovasculares, levando, muitas vezes, à hospitalização e maior estresse familiar (ROCHA et al., 2019)

\subsection{Transtorno do espectro autista (TEA)}

TEA é uma síndrome que envolve desordens e intolerâncias no comportamento e no desenvolvimento psicomotor, e apresenta significativa agressividade, com tendências a irritabilidade, autoagressão dificuldades para desenvolver, manter e compreender relacionamentos, alterações sensoriais, problemas alimentares e hiperatividade levando a um retardo mental ou, ao contrário, até mesmo a um rendimento intelectual acima da média (PINTOet al., 2016; GRIESI-OLIVEIRA; SERTIÉ, 2017). 
Bacharelado em Nutrição da UninCor e iniciação à pesquisa: Com a palavra os nossos estudantes

Gonçalves (2016) e Braga et al. (2019) corroboram comAPA $(2018$, p. 50) ao apresentarno Manual Diagnóstico e Estatístico de Transtornos Mentais- DSM-V:

(...) déficits qualitativos de comunicação, manifestados por falta ou atraso do desenvolvimento da linguagem, não compensada por outros meios (apontar, usar mímica); déficit marcado na habilidade de iniciar ou manter conversação em indivíduos com linguagem adequada; uso estereotipado, repetitivo ou idiossincráticode linguagem, com repetição atrasada ou imediata de palavras ouvidas, emissão de palavras ou frases sem intenção de se comunicar, repetição de diálogos de filmes, animações ou palavras faladas por pessoas que fazem parte de sua rotina; uso de "tu" ao referir-se a si mesmo; inabilidade de participar de brincadeiras de faz de conta ou imaginativas de forma variada e espontânea para o seu nível de desenvolvimento.

O autista se refugia na abstração, sua inventividade está diretamente proporcional ao seu afastamento do ambiente imediato. Seu aprendizado cotidiano depende de regras e leis claras, não se baseando na imitação natural e inconsciente dos comportamentos dos adultos, como ocorreria com as crianças "normais". No campo das emoções há uma alteração qualitativa, a desarmonia nas emoções (BRASIL, 2015).

Os sintomas do TEApodem ser observados no primeiro ano de vida ou ocorrer regressãodepois dos 18 meses de idade, por nenhum fator específico, genética ou até mesmos por infecções fetais e alterações genéticas. TEA é descrito por várias alterações comportamentais, essas dificuldades podem influenciar na vontade da criança pelo alimento e redução dacapacidade de prestar atenção (CARVALHO et al., 2012; CZERMAINSKI; BOSA; SALLES,2013).

Segundo APA (2018, p. 53):

O estágio em que o prejuízo funcional fica evidente irá variar de acordo com características do indivíduo e seu ambiente. Características diagnósticas nucleares estão evidentes no período do desenvolvimento, mas intervenções, compensações e apoio atual podem mascarar as dificuldades, pelo menos em alguns contextos. Manifestações do transtorno também variam muito dependendo da gravidade da condição autista, do nível de desenvolvimento e da idade cronológica; daí o uso do termo espectro. 
Bacharelado em Nutrição da UninCor e iniciação à pesquisa: Com a palavra os nossos estudantes

A expressão "autismo" ("voltar-se para si mesmo") foi utilizada pela primeira vez por Eugene Bleuler, em 1911, como a perda de contato com a realidade e a impossibilidade de comunicação com os demais, comportamento esse que ele observou em pacientes diagnosticados com quadro de esquizofrenia (MOTTA. 2017).

Sobre tal fato explicam Assumpção Júnior e Kuczynski (2015, p.25):

Alterações dessa concepção surgem a partir de Ritvo (1976), que passou a considerá-louma síndrome relacionada com um déficit cognitivo e não uma psicose, caracterizando assim um transtorno do desenvolvimento. Assim, a relação autismo-deficiência mentalpassou a ser cada vez mais considerada, levando-nos a uma situação que podemos considerar conflitante, por exemplo, entre as classificações francesa, americana e da Organização Mundial de Saúde. Assim, se as duas últimas enquadraram o autismo dentro da categoria "Transtornos Abrangentes de Desenvolvimento", enfatizando essa relação autismo-cognição, conforme os trabalhos de Baron Cohen $(1988,1991)$ em oposição flagrante aos conceitos apresentados pela CID-9; a primeira (Misés, 1990) remete-nos ao conceito de "defeito de organização ou desorganização da personalidade" (Housel, 1991), caracterizando o conceito de "psicose" em sua expressão tradicional. (ASSUMPÇÃO JÚNIOR; KUCZYNSKI, 2015, p.25).

Na Classificação Internacional de Doenças (CID 10) e DSM-V (APA, 2018), não há um diagnóstico específico a respeito dos graus de SA, cabendo aos autores delimitarem o grau de seletividade. Alguns artigos utilizam a quantidade de alimentos que o indivíduo ingesta, a quantidade de mordidas no alimento e o tempo em que o indivíduo se alimenta (SHARP et al.,2019).

Gomes et al. (2016, p. 2) notam que ainda "há desordens gastrointestinais que acometemos autistas, como diminuída produção de enzimas digestivas, inflamações da parede intestinal, permeabilidade intestinal alterada" (quadro de diarreia ou constipação), má ingestão alimentar, refluxo gastresofágico e absorção de nutrientes, fatores que pioram os sintomas dos portadoresde TEA. 


\subsubsection{Critérios diagnósticos do TEA segundo o DSM-V}

O diagnóstico é feito através de avaliação clínica e critérios de diagnósticos específicos(Ressonância Magnética (RM) e a Tomografia Computadorizada (TC)), pois ainda não existemexames laboratoriais para identificar a doença; outros exames podem descartar outras enfermidades, mas também não há possibilidade de realizar diagnóstico antes do nascimento da criança por ser uma doença de perturbação do desenvolvimento embrionário (RIBAS, 2013; GOMES et al., 2016).

Acredita-se que a etiologia do TEA tenha base genética, neurobiológica e neuropsicológicae pode estar associada a diversas enfermidades ou a síndromes genéticas já conhecidas. No entanto, "não é um transtorno degenerativo, sendo comum que aprendizagem e compensação continuem ao longo da vida" (APA, 2018, p. 56).

Alguns critérios diagnósticos do TEA, segundo APA (2018, p. 53 a 55):

Déficits nos comportamentos comunicativos ou déficits na compreensão e uso de gestos, até ausência total de expressões faciais e comunicação não verbal; déficits para desenvolver, manter e compreender relacionamentos;

Dificuldade em compartilhar brincadeiras imaginativas ou em fazer amigos, a ausência de interesse por pares;

Padrões estranhos de brincadeiras (p. ex., carregar brinquedos, mas nunca brincar comeles), e padrões incomuns de comunicação (p. ex., conhecer o alfabeto, mas não responder ao próprio nome);

Interesses fixos e altamente restritos que são anormais em intensidade ou foco ( $p$, ex., criança pequena muito apegada a uma panela ou preocupada com aspiradores de pó; adulto que gasta horas escrevendo tabelas com horário);

Forte apego ou preocupação com diferença aparente a dor e temperatura, reação contrária a sons ou texturas específicas, objetos incomuns, interesses excessivamente persistentes;

Hiper ou hiporreatividade a estímulos sensoriais ou interesse incomum por aspectos sensoriais do ambiente (p. ex., cheirar ou tocar objetos de forma excessiva, fascinaçãovisual por luzes ou movimento) (APA, 2018, p. 53 a 55$)$. 
Bacharelado em Nutrição da UninCor e iniciação à pesquisa: Com a palavra os nossos estudantes

\subsection{Seletividade alimentar (SA)}

Uma alimentação adequada é fundamental durante toda a vida, contribuindo decisivamente para o crescimento, desenvolvimento fisiológico, desempenho e produtividade, assim como para a manutenção da saúde e do bem-estar (FISBERG; TOSATTI; ABREU, 2014).A introdução de frutas e produtos hortícolas na dieta da criança autista, de forma sistemática eregular pode desempenhar papel relevante na criação de bons hábitos alimentares, e que contribuirão para o combate de distúrbios alimentares (LÁZARO; PONDÉ, 2017). Estima-se que 46-89\% das crianças com TEA têm problemas de alimentação, que podem incluir padrões alimentares incomuns, rituais e SA(SHARP et al., 2019).

Diante da problemática da SA que pode trazer influências graves no estado nutricional nos portadores de TEA com consequências no processo de melhoria e desenvolvimento dos mesmos é relevante a presença de equipe multiprofissional capacitada para fornecer tratamentonutricional especializado e direcionar os cuidadores em relação ao comportamento do pacientee sua alimentação, minimizando as rejeições alimentares e melhorando sua saúde (LEAL, et al., 2015).

Os pais e profissionais devem estar alertas quanto a esses comportamentos no momentodas refeições, com a finalidade de evitar problemas advindos do desenvolvimento da SA (CARVALHO et al., 2012). Também na parte de inclusão escolar, os profissionais devem construir atitudes e atividades que possam auxiliar as crianças aproveitando suas experiências de aprendizagem sensoriais (BARBOSA, 2018). Corroboram os estudos de Whiteley et al. (2013) sobre a intervenção dietética nas crianças com TEA para a melhora da saúde física e mental, pois estudos publicados indicam mudanças positivas na apresentação dos sintomas apósa intervenção dietética, como alterações em áreas da comunicação, atenção e hiperatividade.

Aragão (2017) cita alguns comportamentos comuns nesse quadro como birra, choro, o comer pausadamente ou em longos intervalos, beliscar alimen- 
tos ao longo do dia, além da exigência por alimentos distintos e preferência a alimentos ultraprocessados, balas e doces, quetrazem consequências nocivas à saúde dos autistas (CAETANO; GURGEL, 2018; FELIPE et al., 2021).

Segundo Magagnin $(2019,2021)$, pessoas com TEA tendem a ser vulneráveis no aspectonutricional, e predispostas para lesões cariosas e outras lesões na cavidade oral pela deficiência de micronutrientes, com alteração na composição e função da microbiota intestinal, o que acarreta sintomas gastrointestinais e disfunções cognitivo-comportamentais. Rodrigues et al. (2020) citam que autistas também podem manifestar alterações na motricidade mastigatória e dificuldade de deglutição, e necessitam ingerir líquidos para ajudar engolir durante as refeições.Essas disfunções não ocorrem somente por distúrbios físicos, mas por adaptações negativas como recusa de mastigar ou engolir ou apresentar ânsias de vômito durante o processo da alimentação.

\subsubsection{Diferenças de Seletividade Alimentar e Neofobia}

Neofobia alimentar (neo, novo, fobia, medo ligado aos alimentos), aversão e recusa de alimentos novos e desconhecidos, como SA, o consumo limitado de alimentos variados são características recorrentes na alimentação infantil e podem reforçar a ideia de patologização daalimentação de crianças autistas ou não, por serem aspectos frequentes na infância (TORRES;GOMESA; MATTOSA, 2021). Aneofobia pode apresentar diferentes níveis de rejeição, desdequando em algumas situações o alimento é aceito em pequenas porções até quando ocorre uma completa recusa de qualquer alimento considerado novo. Esse comportamento é intensificado quando em associação ao TEA, podendo estar presente por períodos prolongados desde a infância, adolescência até a juventude. Sua progressão está diretamente associada ao nível de gravidade do comprometimento social, comunicativo e cognitivo do paciente autista (APA, 2018; OLIVEIRA; FRUTUOSO, 2020). 
Bacharelado em Nutrição da UninCor e iniciação à pesquisa: Com a palavra os nossos estudantes

Isso é consistente com as conclusões da revisão sistemática de Torres, Gomesa e Mattosa(2021), ao citarem que a pressão dos pais para a criança ingerir alimentos de que não gosta resulta em maior resistência ao seu consumo. Estudos confirmam que, quanto mais autoritáriosos pais são durante a refeição, mais frequentemente a criança rejeita os produtos oferecidos, levando à "exacerbação de comportamentos neofóbicos". A aversão ocasiona a monotonia alimentar, que resulta em deficiências nutricionais, pois a falta de diversidade na alimentação restringe a ingestão de nutrientes necessários para a manutenção da homeostase corporal.

\subsection{Tratamento}

Devido à natureza do TEA, as intervenções devem ser multidisciplinares, contemplandoos aspectos da psicologia, fonoaudiologia, nutrição, entre outros. $O$ tratamento é difícil, baseia-se tanto na reabilitação multidisciplinar como em um avanço com medicamentos que se destinam a reduzir os sintomas de agitação, agressividade e irritabilidade (ALMEIDA et al., 2018).

Entretanto, Monteiro et al. (2020) explicam que a utilização de tratamentos alternativospara a melhora dos sintomas do TEAé amplamente divulgada, porém poucas evidências apoiamsua eficácia e segurança. As informações da literatura nesse campo são muito limitadas, tanto em quantidade quanto em qualidade. Os integrantes da família como os cuidadores e as pessoasdo mesmo convívio social relatam melhora visível em diversos aspectos relacionados aos sintomas clínicos e comportamentais do transtorno, assim como menor nível de efeitos colaterais, em comparação aos desencadeados pela terapia medicamentosa.

Leal et al. (2015) comentam que as deficiências nutricionais mais comuns em neuropatias são de ômega-3, vitaminas do complexo $B$, minerais e aminoácidos, que são essenciais na formação de neurotransmissores, responsáveis por trazer equilíbrio no SNC. Amorim (2018) corrobora ao apontar que a maior parte 
Bacharelado em Nutrição da UninCor e iniciação à pesquisa: Com a palavra os nossos estudantes

das crianças com autismo poderá fazeruso de ômega 3, sobretudo ácido eicosapentaenóico, que é um potente anti-inflamatório, e DHA(ácido docosahexaenóico, fundamental para os neurônios e estrutura cerebral). Algumas também têm deficiência de magnésio (o que contribui para a irritabilidade e excitação), além do zinco e selênio, e de vitamina A, C e B6, e um enorme stress oxidativo, o que altera o funcionamento celular e a expressão genética (NUNES; PAIVA; MARQUES, 2016; AMORIM, 2018).

Contudo, Bottan et al. (2020) consideram que, além do diagnóstico e acoIhimento pela equipe multidisciplinar, em especial o nutricionista, a intervenção nutricional é uma das alternativas de tratamento para essa síndrome, pois a ingestão alimentar está diretamente ligadacom o eixo intestino e cérebro, auxiliando na redução de sintomas comportamentais e gastrointestinais. Quanto mais cedo o diagnóstico e o início das intervenções terapêuticas, maiores são as chances do desenvolvimento nas áreas em que o indivíduo apresenta dificuldades (cognitivo, motor, sensorial e psicomotricidade relacional). A história, o contexto e as vivências apresentadas pela pessoa com TEA e sua família são fundamentais para o processo diagnóstico e para a construção do seu projeto terapêutico singular (BRASIL, 2015; CORDEIRO; SILVA, 2018).

Uma das abordagens exclusivas da terapia ocupacional utilizadas ao tratamento TEA éa Terapia de Integração Sensorial, com bons resultados na prática clínica. Segundo Cardoso e Branco (2019), Dra. Anna Jean Ayres, precursora do estudo e da aplicação desta terapia definiulntegração Sensorial como o processo neurofisiológico que organiza as informações sensoriais recebidas do próprio corpo e do ambiente externo, promovendo a exploração adequada dos mesmos. Refere-se à capacidade do cérebro organizar e interpretar as informações provenientes dos diferentes sistemas sensoriais, mediante as experiências de aprendizagens anteriores e memórias armazenadas no cérebro (organiza e interpreta as informações que provêm dos sentidos: toque, cheiro, paladar, visão, audição, vestibular e propriocepção). 
Bacharelado em Nutrição da UninCor e iniciação à pesquisa: Com a palavra os nossos estudantes

Cardoso e Blanco (2019) pontuam que esta terapia pode também verificar a aplicação de estratégias sensoriais no cotidiano escolar, no processo de inclusão do aluno autista. Sua eficácia é notada na melhoria de algumas características presentes no TEA, em especial do processamento sensorial, engajamento e participação nas atividades do dia-a-dia. A intervençãode Integração Sensorial consiste em oferecer oportunidades sensoriais ao autista, tais como: apresentar desafios na "medida certa"; favorecer a participação da criança na escolha das atividades; guiar auto-organização; favorecer nível de interesse; criar ambiente lúdico; maximizar sucesso da criança e assegurar sua segurança física; criar ambiente motivador e estruturar a aliança terapêutica (relação terapeuta-paciente, nutricionista-paciente).

Oliveira e Frutuoso $(2020,2021)$ propõem o emprego de dinâmica alimentar, por meiode oficinas culinárias e atividades compartilhadas com os pais, com refeições realizadas fora do contexto domiciliar e do escolar capazes de produzir caminhos e movimentos observados naalimentação do filho (a). Admitir, por exemplo, as muitas formas de interagir com o alimento, que resultam em muitas formas de cozinhar e comer significa acolher todas as possibilidades durante as oficinas, da aceitação ou não em manipular os ingredientes. Um novo olhar sobre a alimentação de crianças autistas e das práticas do nutricionista, "para além do restrito diagnóstico do consumo de nutrientes e da orientação de dietas com restrição de substâncias para remissão de sintomas, que levam a práticas controladoras e à identificação de correções a serem feitas" (OLIVEIRA; FRUTUOSO, 2021, p. 8).

Dentro desse cenário, são fundamentais a conscientização e o preparo dos profissionaisde nutrição para atuarem de forma apropriada junto aos portadores de TEA, visando melhoriasde sinais e sintomas, através da modulação da prática dietoterápica atual e, principalmente, da educação nutricional de seus responsáveis e cuidadores. Isso porque a educação nutricional iráestimular o desenvolvi- 
mento de bons hábitos alimentares desde a infância, esperando que estessejam implantados no espaço familiar (CARDOSO et al., 2019; FRANÇA et al., 2021).

Por fim, e nesse contexto, a Lei n. 12.764, de 27/12/2012, instituiu a "Política Nacionalde Proteção dos Direitos da Pessoa com Transtorno do Espectro Autista", onde, uma de suas diretrizes cita o "incentivo à formação e à capacitação de profissionais especializados no atendimento à pessoa com TEA, bem como a pais e responsáveis", bem como define o direito dessas pessoas: "O acesso a ações e serviços de saúde, com vistas à atenção integral às suas necessidades de saúde, incluindo a nutrição adequada e a terapia nutricional e informações que auxiliem no diagnóstico e no tratamento" (BRASIL, 2012).

Portanto, família e profissionais vêm contribuindo para a melhoria dos comportamentose atitudes próprias dos portadores de TEA, "mas não há um consenso entre os pesquisadores, visto que cada ser humano tem suas próprias características pessoais, psicológicas e corporais"(CARVALHO et al., 2012, p. 5).

\section{MATERIAIS E MÉTODOS}

\subsection{Delineamento e amostra}

A presente pesquisa possui caráter exploratório, documental, pesquisa de campo, com delineamento transversal e dados quantitativos, e será embasada em pesquisa bibliográfica na Biblioteca Virtual em Saúde, livros, artigos ('Quali Capes') no Portal de Periódicos da Capes (Coordenação de Aperfeiçoamento de Pessoal de Nível Superior), Scielo (Scientific ElectronicLibrary Online), PUBMED, Google Acadêmico, entre outras bases de dados eletrônicos sobre o comportamento alimentar seletivo de crianças com TEA, visando melhoria da qualidade de vida deste público-alvo.

Tal pesquisa visa trabalhar com crianças que possuem o TEA, na faixa etária de 2 a 10 anos e espera-se atender em média 30 pais ou responsáveis dessas crianças, durante os meses de agosto e setembro de 2021. 


\subsection{Procedimento de coleta}

A coleta de dados será realizada por meio de um questionário, com 30 questões, de autoria própria (Apêndice A), que será disponibilizado nas redes sociais, como o WhatsApp e através da plataforma do Google Forms com o envio do link para resposta do questionário, sendo essa disponibilização em grupos já existentes e nos quais se encontram familiares de pessoas com esta síndrome.

Adicionalmente, em respeito aos sujeitos do estudo, todos os participantes deverão ter o Termo de Consentimento Livre e Esclarecido assinado pelos pais e/ou responsáveis. Além disso, a presente pesquisa será submetida ao Comitê de Ética e Pesquisa da Universidade Valedo Rio Verde - UninCor, via plataforma Brasil, com protocolo 49911921.5.0000.5158

\subsection{Análise estatística}

A partir da coleta de dados, busca-se analisá-los e interpretá-los. Os dados coletados serão tabulados em planilha no Programa Microsoft Office Excel, tendo como principal análiseas respostas positivas e negativas. O questionário terá levantamento de dados com assuntos centrais, e foco em perguntas que apontarão se a criança é seletiva e com TEA. Por ser pesquisaaplicada os familiares de crianças que possuem o transtorno irão ajudar nas respostas a serem dadas.

\section{RESULTADOS E DISCUSSÃO}

Os resultados são aqui apresentados mediante a utilização de duas tabelas que representam dados percentuais e numéricos sobre as respostas positivas e/ ou negativas registradas com a amostra constituída de 30 pais e/ou responsáveis, sendo $25(83,33 \%)$ do sexomasculino e 05 (16,66\%) do sexo feminino, de crianças com média de idade de 02 a 13 anos.

Estes resultados foram os seguintes: 
Bacharelado em Nutrição da UninCor e iniciação à pesquisa: Com a palavra os nossos estudantes

Tabela 1: Classificação percentual da amostra das 30 perguntas e respostas positivas e negativas

\begin{tabular}{|c|c|c|c|c|}
\hline \multirow{2}{*}{ Perguntas } & \multicolumn{2}{|c|}{ Sim } & \multicolumn{2}{|c|}{ Não } \\
\hline & $\mathbf{N}$ & $\%$ & $\mathbf{N}$ & $\%$ \\
\hline Consome sempre os mesmos alimentos com frequência? & 23 & 76,67 & 7 & 23,33 \\
\hline $\begin{array}{l}\text { Está sempre pedindo algo para comer, mesmo tendo } \\
\text { comido há pouco. }\end{array}$ & 21 & 70,00 & 9 & 30,00 \\
\hline Seleciona alimentos por marca ou embalagens? & 12 & 40,00 & 18 & 60,00 \\
\hline Seleciona alimentos pela temperatura? & 10 & 33,33 & 20 & 66,67 \\
\hline Seleciona alimentos pela cor? & 14 & 46,67 & 16 & 53,33 \\
\hline Seleciona ou rejeita alimentos pela consistência ou cheiro? & 26 & 86,67 & 4 & 13,33 \\
\hline Seletivo por refeições molhadas? & 12 & 40,00 & 18 & 60,00 \\
\hline Seletivo por refeições mais secas? & 11 & 36,67 & 19 & 63,33 \\
\hline Seletivo por alimentos crocantes? & 14 & 46,67 & 16 & 53,33 \\
\hline Seletivo por alimentos macios? & 12 & 40,00 & 18 & 60,00 \\
\hline Seletivo por alimentos amassados? & 9 & 30,00 & 21 & 70,00 \\
\hline Come carne? & 21 & 70,00 & 9 & 30,00 \\
\hline Come frango? & 26 & 86,67 & 4 & 13,33 \\
\hline Come frutas? & 25 & 83,33 & 5 & 16,67 \\
\hline Come verduras? & 9 & 30,00 & 21 & 70,00 \\
\hline Come legumes? & 14 & 46,67 & 16 & 53,33 \\
\hline Toma leite puro? & 18 & 60,00 & 12 & 40,00 \\
\hline
\end{tabular}


Bacharelado em Nutrição da UninCor e iniciação à pesquisa: Com a palavra os nossos estudantes

\begin{tabular}{|c|c|c|c|c|}
\hline Toma café? & 14 & 46,67 & 16 & 53,33 \\
\hline Separa algo da comida? & 23 & 76,67 & 7 & 23,33 \\
\hline Cospe a comida após ou durante a refeição? & 14 & 46,67 & 16 & 53,33 \\
\hline Vomita durante ou depois a refeição? & 3 & 10,00 & 27 & 90,00 \\
\hline Possui ritual para comer? & 11 & 36,67 & 19 & 63,33 \\
\hline Come sempre no mesmo lugar? & 16 & 53,33 & 14 & 46,67 \\
\hline Come sempre com os mesmos talheres? & 14 & 46,67 & 16 & 53,33 \\
\hline Come sempre os mesmos alimentos? & 18 & 60,00 & 12 & 40,00 \\
\hline Possui comportamento agressivo durante a refeição? & 4 & 13,33 & 26 & 86,67 \\
\hline $\begin{array}{l}\text { Come uma grande quantidade de alimentos num período } \\
\text { curto de tempo? }\end{array}$ & 14 & 46,67 & 16 & 53,33 \\
\hline Possui agitação, dificuldade de se manter sentado à mesa? & 22 & 73,33 & 8 & 26,67 \\
\hline $\begin{array}{l}\text { Come algo diferente do que já está acostumado durante as } \\
\text { refeições? }\end{array}$ & 14 & 46,67 & 16 & 53,33 \\
\hline Varia a alimentação? & 19 & 63,33 & 11 & 36,67 \\
\hline
\end{tabular}

A Tabela 1 apresenta as respostas dos pais e/ou responsáveis sobre a alimentação em geral e a SA das crianças neste estudo. Como pode ser observado, a partir da coleta de dados, existe relação entre SAe alterações sensoriais nas crianças com TEA. Na área sensorial podemser mais sensíveis em relação aos sentidos: tátil, vestibular, proprioceptiva, visual, auditiva, gustativa e olfatória. As alterações sensoriais identificadas foram: sensibilidade sensorial oral, sensibilidade sensorial tátil e sensibilidade sensorial olfativa. A sensibilidade sensorial oral composta por recusa a ingerir alimentos devido a sua textura e sabor. A sensibilidade sensorial tátil, devido a recusa-se a tocar e a sensibilidade sensorial olfativa por cheirar os alimentos e não consumir. Assim, por exemplo, 26 (86,6\%) 
Bacharelado em Nutrição da UninCor e iniciação à pesquisa: Com a palavra os nossos estudantes

crianças selecionam ou rejeitam alimentos tanto pela sua consistência ou cheiro; $23(76,68 \%)$ consomem, frequentemente, sempre os mesmos alimentos e separam algo da comida. Porém, não existe um padrão específico para a sensibilidade (LÁZARO; PONDÉ, 217).

Segundo Lazaro e Pondé (2017) a sensibilidade pode até provocar náusea e vômito emalgumas crianças, quando determinado alimento é tocado ou percebido na boca. Outras aceitamou recusam alimentos em função de ser crocante, seco, molhado, cru, cozido, duro, amassado, pastoso ou macio. Em certos casos, algumas mães passam o alimento na peneira, senão a criançarecusa, ou ocorre o oposto quando outras mães precisam grelhar o alimento até ficar bem crocante. Nesse sentido, Cermak, Curtin e Bandini (2010) citam que fatores sensoriais como cheiro, textura, cor e temperatura podem contribuir para a sensibilidade sensorial em crianças com TEA, e consideram que esse tipo de sensibilidade pode ser uma dimensão importante na compreensão da SA.

Já em 2010, Cermak, Curtin e Bandini pesquisaram vários estudos comparando a SA em crianças com TEA. Afirmaram que os pais de crianças autistas relatam que seus filhos são comedores altamente seletivos, com repertórios muito restritos de aceitação de alimentos que podem ser limitados a apenas cinco alimentos. O manejo da SA e as preocupações com a adequação da dieta são considerados as principais razões para o encaminhamento de crianças para serviços de nutrição, pois, de fato, a alimentação seletiva é um problema significativo, estando associada à nutrição inadequada em decorrência da dieta restrita.

De uma maneira geral, observa-se que estas crianças apresentam mais problemas na alimentação e maiores comportamentos de recusa. Duas observações relevantes quanto a Tabela 1: $21(70 \%)$ crianças não comem verduras e $22(73,33 \%)$ são agitadas e têm dificuldade de se manterem sentadas à mesa no momento das refeições. Estes dados corroboram com os encontrados na revisão de literatura, tais como os de Bandini et al. (2017), que avaliaram a 
Bacharelado em Nutrição da UninCor e iniciação à pesquisa: Com a palavra os nossos estudantes

persistência da SA de 18 crianças com TEA, mas não focaram nos alimentos maisconsumidos e sim, nos menos consumidos. Os vegetais foram os que mais se destacaram e,também, a textura dos alimentos, como umdos fatores que mais provocam recusa pelos mesmos. Na mesma linha, Lázaro e Pondé (2017) investigaram 18 mães de meninos/jovens com autismo, e mostraram que o maior consumo é de carboidratos e gorduras, e o menor consumoestá entre os temperos (cebolinha, salsa, tomate, pimentão e cheiro verde), legumes,leguminosas, peixes, frutas, carne assada, comida com textura seca. Detectaram que muitos rejeitam os folhosos, e uma recusa ativa a verduras e legumes, principalmente crus. Entretanto, alguns aceitam a batata e a cenoura cozidas ou a batata na forma de purê. O peixe também érecusado com muita frequência, independente da forma de preparo. A maioria também não come fruta nenhuma ou aceita poucas.

Quanto à dificuldade e agitação no horário das refeições, nota-se na literatura, que estessão agitados e energéticos e normalmente apresentam grande dificuldade em se manterem atentos e focados numa tarefa, com inquietação motora que dificulta sentar-se à mesa, não conseguindo lidar sozinhos com o problema. Assim, com intuito de identificar informações relativas à manutenção e ao agravamento do comportamento alimentar alterado no autista, Lázaro, Siquara e Pondé (2019) elaboraram a "Escala de Comportamento Alimentar do Autismo", um novo instrumento de avaliação do comportamento alimentar para crianças com TEA, em língua portuguesa, contribuindo para um encaminhamento terapêutico mais específicoem relação às suas necessidades.

Entre seis dimensões, os autores citam as "Habilidades nas Refeições": "Tem dificuldades de sentar-se à mesa para fazer as refeições (por exemplo: almoça no chão, sofá, cama); derrama muito a comida na mesa ou na roupa quando se alimenta, e geralmente trazemalgum tipo de agitação fora do padrão" (LÁZARO; SIQUARA; PONDÉ, 2019, p. 194). 
Tabela 2: Tabela das variáveis qualitativas utilizadas quanto ao sexo e faixa etária das crianças, dos 2 a acima de 13 anos

\begin{tabular}{|c|c|c|c|c|}
\hline Sexo & \multicolumn{2}{|c|}{ Quantidade } & \multicolumn{2}{c|}{16,66} \\
\hline Feminino & \multicolumn{2}{|c|}{5} & \multicolumn{2}{c|}{83,33} \\
\hline Masculino & \multicolumn{2}{|c|}{25} & Feminino & $\%$ \\
\hline & Masculino & $\%$ & 2 & 6,66 \\
\hline De 2 a 4 anos & 10 & 33,33 & 0 & 0,00 \\
\hline De 5 a 8 anos & 10 & 33,33 & 3 & 10,00 \\
\hline $\begin{array}{c}\text { De 9 a } \\
12 \text { anos }\end{array}$ & 3 & 10,00 & 0 & 0,00 \\
\hline $\begin{array}{c}\text { Acima de } \\
13 a n o s\end{array}$ & 2 & 6,66 & & \\
\hline
\end{tabular}

Fonte: autoral.

A partir da coleta de dados, observa-se que na correlação das duas variáveis estudadas predominou crianças do sexo masculino 25 (83,33\%) e 05 do sexo feminino (16,66\%), e em relação às idades das crianças, do total de 30 (100\%), predominou a idade de 2 a 4 anos (33,33\%) e de 5 a 8 anos (33,33\%). Estes resultados têm uma correlação com resultados de Rodrigues et al. (2020), quanto ao total de crianças analisadas e ao sexo: 30 crianças dos 3 aos 10 anos de idade com diagnóstico confirmado de TEA, participaram da pesquisa, sendo a maioria delas do sexo masculino $27(90 \%)$ e 3 (10\%).

Corrobora também o estudo transversal quantitativo de Melo et al. (2020), realizado com responsáveis de pacientes diagnosticados com TEA em acompanhamento nas APAE de Goiânia e Anápolis, com a amostra de 32 pacientes sendo $84,4 \%$ do sexo masculino e $15,6 \%$ do sexo feminino. Assim, pode ser visto que, de maneira geral, o consenso na literatura é de que o sexo masculino é mais acometido entre crianças com TEA, evidenciando-se risco de problemas nutricio- 
nais nas crianças pesquisadas, sendo necessária uma intervenção adequada no que tange ao acompanhamento nutricional (MELO et al., 2020).

Porém, com relação à faixa etária e ao comportamento alimentar não houve correlação na pesquisa de Rodrigues et al. (2020), uma vez que predominou 19 crianças com idade igual ou menor a 6 anos (63,3\%) e 11 com idade maior a 6 anos (36\%), sendo que o grupo dos vegetais, frutas, leguminosas, carnes e ovos são preferidos pelas crianças maiores de 6 anos; jáas crianças menores que 6 anos preferem grupo dos alimentos não saudáveis, com maior consumo de doces, salgadinhos e guloseimas, sem diferenças entre as idades.

Figura 1: A. Alimentos que o portador de TEA deve comer; B. Alimentos que o portador de TEA não deve comer.
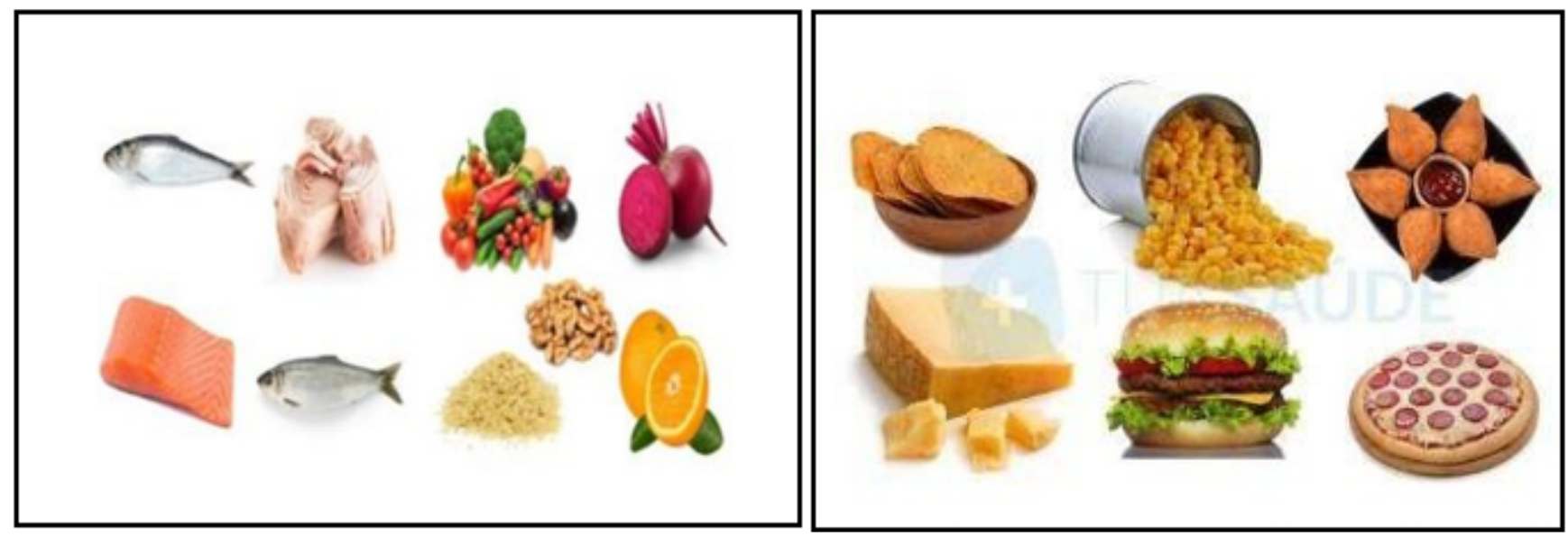

Fonte: http://www.tuasaude.com/alimentacao-para-autismo/.

Tendo em vista os alimentos apresentados (Figura1), os resultados que fundamentam esta pesquisa sugerem que para aumentar o consumo de vegetais e diminuir o consumo de guloseimas nesta população seria interessante incluir estratégias que abordassem o processamento sensório-oral, e os aspectos do comportamento alimentar como os aqui já citados. Apesar de ainda ter poucos estudos nesta área, o comportamento repetitivo, a escolha dos alimentos, o excesso ou falta de energia e o interesse restrito - entre outras características do TEA, podem ter papel importante na seletividade dietética na hora da refeição. 
Carvalho et al. (2012) resumem três aspectos mais marcantes registrados na pesquisa que realizaram e que combinam com as encontradas neste trabaIho: seletividade que leva a carências nutricionais; recusa, pois mesmo ocorrendo a seletividade é frequente a não aceitação do alimento selecionado o que pode levar a um quadro de desnutrição calórico-proteica; indisciplina que também contribui para a inadequação alimentar.
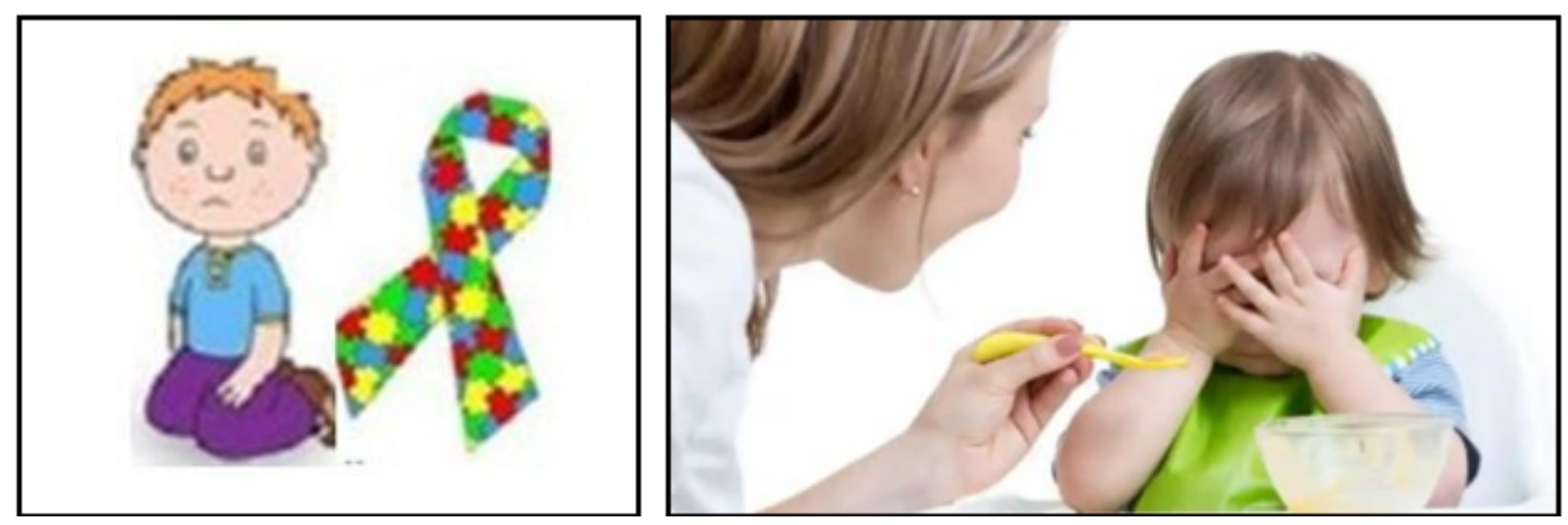

\section{CONCLUSÃO}

Frente aos resultados da pesquisa sobre crianças com Transtorno do Espectro do Autismo, além do referencial teórico utilizado, observa-se sua forte relação com seletividade alimentar, ingestão inadequada de nutrientes (a monotonia alimentar resulta em deficiências nutricionais), casos de restrição ou mesmo recusa alimentar relacionados a uma hipersensibilidade sensorial, entre outras alterações sensoriais, e a manutenção de hábitos alimentares prejudiciais à saúde.

Portanto, entende-se a necessidade de intervenções, o acompanhamento do nutricionistae orientação aos familiares, cuidadores e educadores em convívio diário com essas crianças, para que os incômodos causados, por exemplo, pela textura e cheiro do alimento, pela falta de verduras na alimentação ou por se sentirem com fome, mesmo comendo pouco e com dificuldades de sentar-se à mesa para fazer as refeições, possam ser ultrapassados, gerando uma maior flexibilização no padrão alimentar. 
Desta forma, atividades poderão ser utilizadas no meio familiar, escolar e equipe de saúde, como parte da rotina do público-alvo analisado, pois muitas vezes, o baixo desempenhodo aluno em sala de aula pode estar relacionado à sua maneira de se alimentar. Adotar e incentivar ações de educação alimentar e nutricional possibilita conhecer melhor o comer na infância, principalmente o comer de uma criança autista.

Assim, com base nas informações encontradas neste estudo, percebe-se a necessidade da oferta de uma alimentação variada, incluindo também alimentos que são recusados ou que não participam dos hábitos alimentares familiares, sem, contudo, tentar evitar, forçar ou intervirna neofobia alimentar. É preciso dar autonomia à criança em sua alimentação, apoiá-laemocionalmente e motivá-la a participar da preparação das refeições, tornando o momento agradável e afetuoso.

Nesse contexto, faz-se necessário habilitar pais e profissionais da saúde para reconheceros sinais de alerta que levam à suspeita do diagnóstico a fim de assumir esforços terapêuticos para atender as necessidades das crianças acometidos com tal transtorno, o qual tem ocupado uma posição de destaque dentre os problemas de saúde pública.

Considera-se, pois, a importância dos instrumentos de diagnóstico na compreensão da etiologia multifatorial (fatores genéticos, ambientais, entre outros), além de novos recursos terapêuticos que poderão ser aproveitados. Sugere-se a expansão dos estudos científicos sobreo tema, explorando as diferentes causas, as particularidades individuais, em especial quanto a alimentação, e as modalidades de tratamento autista. 
Bacharelado em Nutrição da UninCor e iniciação à pesquisa: Com a palavra os nossos estudantes

\section{REFERENCIAS}

ALMEIDA, S. S. de A. et al. Transtorno do espectro autista. Residência Pediátrica, v. 8, (supl 1), p. 72-78, 2018. Disponível em: https://cdn.publisher.gn1.link/ residencia pediatrica.com.br/pdf/v8s1a12.pdf. Acesso em: 06 nov. 2021.

APA. American Psychiatric Association. Manual Diagnóstico e Estatístico de Transtornos Mentais - Dsm-5. Trad. Maria Inês Corrêa Nascimento et al. 5. ed. Porto Alegre: Artmed, p. 50-2018. Disponível em:http://www.niip.com.br/wp-content/uploads/2018/06/Manual-Diagnosico-e-Estatistico -de-Transtornos-Mentais-DSM-5-1-pdf.pdf. Acesso em: 28 maio. 2021.

AMORIM, I. C. S. Gastronomia inclusiva: alimentação envolvendo crianças e jovens com Transtorno do Espectro Autista e Síndrome de Down em Recife-PE. 2018. Trabalho de Conclusão de Curso (Graduação em Nutrição). Universidade Federal Rural de Pernambuco, 2018. Disponível em: https://repository.ufrpe.br/ bitstream/123456789/714/1/tcc_eso_\%20IZABEL\%20CRISTINA\%20SILV A\%20 AMORIM.pdf. Acesso em: 20 maio. 2021.

ARAGÃO, D. Eu, Meu Filho e o Autismo: Uma jornada inesperada. Rio de Janeiro: Reflexão, 2017.

ASSUMPÇÃO JUNIOR, F. B.; KUCZYNSKI, E. Autismo: conceito e diagnóstico. In: Assumpção Jr, F. B. \& Kuczynski, E. (.Org.). Autismo Infantil: novas tendências e perspectivas. 2. ed. São Paulo: Atheneu, v. 1, p. 3-26, 2015.

BANDINI, L. et. al. Mudanças na seletividade alimentar em crianças com transtorno do espectro do autismo. J Autism Dev Disord, v. 47, n. 2, p. 439-446, fev. 2017. Disponível em: https://www.ncbi.nlm.nih.gov/pmc/articles/PMC5310968/. Acesso em: 21 maio. 2021.

BARBOSA, M. O. O transtorno do espectro autista em tempos de inclusão escolar: o foco nos profissionais de educação. Revista Educação Especial, v. 31, n. 61, abr./jun. 2018. Disponível em: https://periodicos.ufsm.br/educacaoespecial/ article/view/24248/pdf. Acesso em: 20 maio. 2021.

BRAGA, P. G. et al. Cartilha transtorno do espectro autista [recurso eletrônico]. Campo Grande (MS): Secretaria de Estado de Educação do Mato Grosso do Sul - SED/MS, 2019. Disponível em: http://www.sed.ms.gov.br/wp-content/ uploads/2019/05/Cartilha-TEA-E-Book-1.pdf. Acesso em: 20 maio. 2021. 
Bacharelado em Nutrição da UninCor e iniciação à pesquisa: Com a palavra os nossos estudantes

BRASIL. Lei n. 12.764, de 27 de dezembro de 2012. Política Nacional de Proteção dos Direitos da Pessoa com Transtorno do Espectro Autista; e altera o \$ $3^{\circ}$ do art. 98 da Lei n. 8.112, de 11 de dezembro de 1990. Disponível em: http:// www.planalto.gov.br/ccivil_03/_ato2011-2014/2012/lei/112764.htm. Acesso em: 20 maio. 2021.

BRASIL. Ministério da Saúde. Secretaria de Atenção à Saúde. Departamento de Atenção Especializada e Temática. Linha de cuidado para a atenção às pessoas com transtornos do espectro do autismo e suas famílias na Rede de Atenção Psicossocial do Sistema Único de Saúde. Brasília: Ministério da Saúde,P.1-157,2015.Disponível em: https://bvsms.saude.gov.br/bvs/publicacoes/linha_cuidado_atencao_pessoas_transtorno.pdf. Acesso em: 20 maio. 2021.

BOTTAN, G. P. et al. Analisar a alimentação de autistas por meio de revisão de literatura. Brazilian Journal of Development Braz. J. of Develop. Curitiba, v. 6, n.12,p. 100448-100470, dez. 2020. Disponível em: https://www.brazilianjournals. com/index.php/BRJD/article/view/21949/17518. Acesso em: 29 maio. 2021.

CAETANO, M.V.; GURGEL, D. C. Perfil nutricional de crianças portadoras do transtorno do espectro autista. Revista Brasileira em Promoção da Saúde, Fortaleza, v. 31, n. 1, p. 1-11, jan./mar. 2018. Disponível em: https://periodicos.unifor. br/RBPS/article/view/6714/pdf. Acesso em: 15 maio. 2021.

CARDOSO, A. A. et al. Transtorno do Espectro do Autismo. Departamento Científico de Pediatria do Desenvolvimento e Comportamento. Sociedade Brasileira de Pediatria, n. 5, abr. 2019. Disponível em: https://www.sbp.com.br/fileadmin/ user_upload/21775c-MO_Transtorno_do_Espectro_do_Autismo.pdf. Acesso em: 15 maio. 2021.

CARDOSO, N. R.; BLANCO, M. B. Terapia de Integração Sensorial e o Transtorno do Espectro Autista: Uma Revisão Sistemática de Literatura. RCO, v. 1, p. 108125, jan./abr. 2019. Disponível em: https://periodicos.feevale.br/seer/index.php/ revistaconhecimentoonline/article/view/1547/2273. Acesso em: 30 maio. 2021.

CARVALHO, J. A. et al. Nutrição e Autismo: Considerações sobre a alimentação do Autista. Revista Científica do ITPAC, Araguaína (TO), v. 5, n. 1, Pub. 1, p. 1-7, jan. 2012. Disponível em: https://assets.unitpac.com.br/arquivos/revista/51/1.pdf. Acesso em: 15 maio. 2021. 
Bacharelado em Nutrição da UninCor e iniciação à pesquisa: Com a palavra os nossos estudantes

CERMAK, S. A.; CURTIN, C.; BANDINI, L. G. Seletividade alimentar e sensibilidade sensorial em crianças com transtornos do espectro do autismo. J Am Diet Assoc. Fevereiro de 2010; 110 (2): 238- 246.

CHRISTENSEN, D.L. Prevalência e características do transtorno do espectro do autismo entre crianças de 8 anos. Rede de Monitoramento de Deficiências de Desenvolvimento e Autismo. PUMed, v. 65, n. 3, p. 1-23, abr. 2016. Disponível em: https://pubmed.ncbi.nlm.nih.gov/27031587/. Acesso em: 14 maio. 2021.

CONSEA - Conselho Nacional de Segurança Alimentar e Nutricional. Princípios e Diretrizes de uma Política de Segurança Alimentar e Nutricional: textos de referência da II Conferência Nacional de Segurança Alimentar e Nutricional. Brasília, 2004. Disponível em: http://www4.planalto.gov.br/consea/conferencia/documentos/lei-de-seguranca-alimentar-e-nutricional. Acesso em: 14 maio. 2021.

CORDEIRO, L. C.; SILVA, D. da. A contribuição da psicomotricidade relacional no desenvolvimento das crianças com Transtorno do Espectro Autista. Fac. Sant'Ana em Revista, Ponta Grossa, v. 3, p. 69- 82, set. 2018. Disponível em: https://www.iessa.edu.br/revista/index.php/fsr/index. Acesso em 18 maio. 2021.

\section{CORREIA, C. Seletividade Alimentar e Sensibilidade Sensorial em Crianças} com Perturbação do Espectro do Autismo. 2015. Projeto (Mestre em Terapia Ocupacional). Especialidade de Integração Sensorial,p.1-26,abr.2015.Disponível em:https://comum.rcaap.pt/bitstream/10400.26/9743/1/Seletividade\%20Alimentar\%20e\%20Sensibilidade $\% 20$ Sensorial\%20em $\% 20$ Crian $\%$ C3\%A7as $\% 20$ com\%20Perturba\%C3\%A7\%C3\%A3o\%20do\%20 Espectro\%20do\%20Autismo. pdf. Acesso em 14 maio. 2021.

CZERMAINSKI, F. R.; BOSA, C. A.; SALLES, J. F. Funções executivas em crianças e adolescentes com transtorno do espectro do autismo: uma revisão. Revista Psico, Porto Alegre, v. 44, n. 4, p. 518- 525, 2013.Disponível em: http://revistaseletronicas.pucrs.br/ojs/index.php/revistapsico/article/viewFile/11878/10844. Acesso em: 15 maio. 2021.

FELICIO, V. C. Epígrafe do template. Disponível em: http://www.fc.unesp.br/ upload/pedagogia/TCC\%20Viviane\%20-\%20Final.pdf. Acesso em: 08 nov. 2021. 
Bacharelado em Nutrição da UninCor e iniciação à pesquisa: Com a palavra os nossos estudantes

FELIPE, J. S. et al. Relação entre o espectro autista e os transtornos alimentares. Brazilian Journal of Health Review, Curitiba, v.4, n.1, p.1310-1324, jan./fev. 2021. Disponível em: https://www.brazilianjournals.com > download. PDF. Acesso em: 15 maio. 2021.

FISBERG, M.; TOSATTI, A. M.; ABREU, C. L. A criança que não come - abordagem pediátrico- comportamental. Blucher Medical Proceedings. In: Anais do $2^{\circ}$. Congresso Internacional Sabará de Especialidades Pediátricas, v. 1, n. 4, P. 1-13, nov. 2014. Disponível em:http://pdf.blucher.com.br.s3- sa-east 1.amazonaws.com/medicalproceedings/2cisep/019.pdf. Acesso em: 16 maio. 2021.

FRANÇA, F. A. R. da S. et al. Seletividade Alimentar na criança com TEA. In: SILVA NETO, B. R. da (.Org.). Frente diagnóstica e terapêutica na neurologia. Revista Espaço Aberto. Cap. 17, p. 132-140, Ponta Grossa (PR): Atena, 2021.Disponível em: https://www.finersistemas.com/atenaeditora/index. php/admin/api/artigoPDF/43402. Acesso em: 21 maio. 2021.

GAMA, B. T. B. et al. Seletividade Alimentar em Crianças com Transtorno do Espectro Autista (TEA): Uma Revisão Narrativa da Literatura. Revista Artigos. Com, v. 17, p. 3916, 13 jun. 2020. Disponível em: https://acervomais.com.br > article > download.PDF. Acesso em: 17 maio. 2021.

GOMES, R. N. S. et al. Nutrição e Autismo: Reflexões sobre a alimentação do autista. XX Encontro Latino Americano de Iniciação Científica, XVI Encontro Latino Americano de Pós-Graduação e VI Encontro de Iniciação à Docência, 27e 28 out. 2016. Universidade do Vale do Paraíba, p. 1-6, out. 2016. Disponível em: http://www.inicepg.univap.br/cd/INIC_2016/anais/arquivos/RE_1176_1333_01. pdf. Acesso em: 27 maio. 2021.

GONÇALVES, C. A. A. Intervenção psicomotora com crianças com perturbações do espectro do autismo no Centro de Recursos para a Inclusão da APPDA. Lisboa. J. Pediatr, v. 89, n. 3, p. 202-209, 2016. Disponível em: https://www.repository.utl.pt/bitstream/10400.5/6421/1/Relat\%c3\%b3rio\%20com\%20Resum.pdf. Acesso em: 17 maio. 2021.

GRIESI-OLIVEIRA, K. SERTIÉ, A. L. Transtornos do espectro autista: um guia atualizado para aconselhamento genético. Einstein (São Paulo), v. 15, n. 2, p. 233-238, abr./jun. 2017. Disponível em: https://www.scielo.br/j/eins/a/YMg4cNph3j7wfttqmKzYsst/?lang=pt\&format=pdf. Acesso em: 17 maio. 2021. 
Bacharelado em Nutrição da UninCor e iniciação à pesquisa: Com a palavra os nossos estudantes

LÁZARO, C. P.; PONDÉ, M. P. Narrativa de mães de crianças com transtorno do espectro do autismo: foco no comportamento alimentar. Trends Psychiatry Psychother, v. 39, n. 3, p. 180-187, 2017. Disponível em: https://www.scielo.br/j/trends/a/MqtmY9WS9BfVcGXkPzLtj9z/?lang=en\&format=pdf. Acesso em: 29 maio. 2021.

LÁZARO, C. P.; SIQUARA, G. M.; PONDÉ, M. P. Escala de Avaliação de Comportamento Alimentar no Transtorno do Espectro Autista: estudo de validação. J. bras. Psiquiatr, v. 68, n. 4, p. 191-199, out./ dez. 2019. Disponível em: https:// www.scielo.br/j/jbpsiq/a/qwqxWxDcg97YhnDJ36VKzFg/?lang=pt. Acesso em: 10 nov. 2021.

LEAL, M. et al. Terapia nutricional em crianças com transtorno do espectro autista. Cad. da Esc. de Saúde, Curitiba, v. 1 n. 13, p. 1-13, 2015. Disponível em: https://portaldeperiodicos.unibrasil.com.br/index.php/cadernossaude/article/ view/2425. Acesso em: 27 maio. 2021.

LIMA, G. B. F. A Influência da Nutrição em crianças com Transtorno do Espectro Autista. 2018. Trabalho de Conclusão de Curso (Graduação em Nutrição). Universidade de Cuiabá. Cuiabá, 2018. Disponível em: https://docplayer.com.br/ 117558654-Gabriela-bernardes-ferreira-lima-a-influencia-da- nutricao-em-criancas-com-transtorno-do-espectro-autista.html. Acesso em: 20 maio. 2021.

MAGAGNIN, T. et al. Relato de Experiência: Intervenção Multiprofissional sobre Seletividade Alimentar no Transtorno do Espectro Autista. Rev. Mult. Psic., v. 13, n. 43, p. 114-127, 2019. Disponível em: https://idonline.emnuvens.com.br > download. PDF. Acesso em: 17 maio. 2021.

MAGAGNIN, T. Aspectos alimentares e nutricionais de crianças e adolescentes com transtorno do espectro autista. Physis: Revista de Saúde Coletiva, Rio de Janeiro, v. 31, n. 1, p. 1-21, 2021. Disponível em: https://www.scielo.br/j/ physis/a/WKnC7ffTK4CJZbgbCJRcChS/?format=pdf\&lang=pt. Acesso em: 17 maio. 2021.

MELO, L. A. et al. IMC e alterações do comportamento alimentar em pacientes com Transtorno do Espectro Autista. Brazilian Journal of Development, Curitiba, v. 6, n. 7, p. 46235-46243, jul. 2020. Disponível em: https://www.brazilianjournals.com/index.php/BRJD/article/view/13117/11027. Acesso em: 10 nov. 2021. 
MONTEIRO, M. A. et al. Transtorno do Espectro Autista: Uma revisão sistemática sobre intervenções nutricionais. Rev. Paul. Pediatr, v. 38, 2020. Disponível em: https://www.scielo.br/j/rpp/a/xGHbpJGBKZvvrycJd4HHPyb/?lang=pt. Acesso em: 19 maio. 2021.

MOTTA, L. B. Autismo e Psicanálise. Monografia. 2017 (Bacharel em Psicologia). Pontifícia Universidade Católica do Rio de Janeiro - PUCRJ, p. 1-17, 2017. Disponível em: https://www.psicologia.pt/artigos/textos/TL0419.pdf. Acesso em: 09 dez. 2021.

NUNES, M. R. de A.; PAIVA, A. L. C.; MARQUES, R. C. P. Educação Inclusiva: Uso de Cartilha com considerações sobre a alimentação do autista. Universidade Federal Rural do Semi-Árido. Revista Includere, Mossoró, v. 2, n.2, p.114-118, 2016.Disponível em:https://periodicos.ufersa.edu.br/index.php/includere/article/view/6001. Acesso em: 21 maio. 2021.

OLIVEIRA, C. Um retrato do autismo no Brasil. Revista Espaço Aberto. Comunidade USP, São Paulo, 2017. Disponível em: http://www.usp.br/espacoaberto/?materia=um-retrato-do-autismo-no-brasil. Acesso em: 20 maio. 2021.

OLIVEIRA, B. M. F. de; FRUTUOSO, M. F. P. Sem receita*: deslocamentos do olhar da Nutrição sobre o comer de crianças autistas. Espaço Aberto. Interface, (Botucatu), v. 24, p. 1-16, 20 nov. 2020. Disponível em: https://scielosp.org/pdf/ icse/2020.v24/e190597/pt. Acesso em: 19 maio. 2021.

OLIVEIRA, B. M. F. de; FRUTUOSO, M. F. P. Muito além dos nutrientes: experiências e conexões com crianças autistas a partir do cozinhar e comer juntos. Cad. Saúde Pública, v. 37, n. 4, p. 1-11, 2021. Disponível em: https://scielosp. org/pdf/csp/2021.v37n4/e00132020/pt. Acesso em: 21 maio. 2021.

PINTO, R. et al. Autismo infantil: impacto do diagnóstico e repercussões nas relações familiares. Revista Gaúcha de Enfermagem, v. 37, n. 3, p. 1-9, 2016. Disponível em: https://www.scielo.br/j/rgenf/a/Qp39NxcyXWj6N6DfdWWDDrR/?lang=pt. Acesso em: 21 maio. 2021.

RIBAS, L. M. Um estudo sobre o brincar de uma criança autista atípica: intervenções psicopedagógicas. Brasília, 2013. Monografia (Especialização). Instituto de Psicologia - Departamento de Psicologia Escolar e do Desenvolvimento - PED, Universidade de Brasília, 2013. Disponível em: https://bdm.unb.br/bitstream/10483/6170/1/2013_LuanaDeMeloRibas.pdf. Acesso em: 26 maio. 2021. 
ROCHA, G. S. S. et al. Análise da seletividade alimentar de crianças com Transtorno do Espectro Autista. Revista Eletrônica Acervo Saúde, v. Sup. 24, p. 1-8, 2019. Disponível em: https://acervomais.com.br/index.php/saude/article/ view/538/483. Acesso em: 16 maio. 2021.

RODRIGUES, C. P. S. et al. O consumo alimentar de crianças com Transtorno do Espectro Autista está correlacionado com alterações sensório-oral e o comportamento alimentar. Brazilian Journal of Development Braz. J. of Develop., Curitiba, v. 6, n. 9, p. 67155-67170, set. 2020. Disponível em: https://www.brazilianjournals.com/index.php/BRJD/article/view/16420/13435. Acesso em: 16 maio. 2021.

SHARP, W. G. et al. O Autismo gerenciando aversões alimentares e plano de variedade limitada vs. educação dos pais: Um Estudo Clínico Randomizado. The Journal of pediatrics., v. 211, p. 185-192, ago. 2019. Disponível em: https://pubmed.ncbi.nlm.nih.gov/31056202/. Acesso em: 15 maio. 2021.

TORRES, T. de O.; GOMESA, D. R; MATTOSA, M. P. Fatores associados à Neofobia Alimentar em crianças: Revisão Sistemática. Rev Paul Pediatr., n. 39, p. 1-11, nov. 2021. Disponível em: https://www.scielo.br/j/rpp/a/xsn45fp4ZVngJGRBFSqPFyx/?lang=pt\&format=pdf. Acesso em: 05 nov. 2021.

WHITELEY, P. et al. Intervenção dietética sem glúten e caseína para condições do espectro do autism. Front Hum Neuroscience, v. 6, 2013.Disponível em: https://www.ncbi.nlm.nih.gov/pmc/articles/PMC3540005/. Acesso em: 16 maio. 2021. 


\section{R페소ÇÃAO FNHRE IMAGEM CORPORAL E TRANSTORNOS AHMIENHARES \\ FMA ADOLFSCFNHFS DO SEFY FEMINININO}

Eduarda Gomes dos Santos Ana Luiza Rodrigues Pellegrinelli 
Bacharelado em Nutrição da UninCor e iniciação à pesquisa: Com a palavra os nossos estudantes

\section{INTRODUÇÃO}

A adolescência é um período definido por mudanças físicas, psicológicas e mudanças comportamentais que podem afetar a saúde geral e o bem-estar na vida adulta. Durante este período, um estilo de vida sedentário levará ao aumento da ingestão de alimentos, resultando em ingestão excessiva de calorias e acúmulo de gordura corporal, que é uma das principais causas de problemas de imagem corporal, principalmente para adolescentes do sexo feminino (MIRANDA et al., 2018).

A insatisfação com a própria imagem corporal percorre entre os adolescentes em decorrência ao período de transição, rápido crescimento e desenvolvimento (JUSTINO; ENES; NUCCI, 2020). Essas insatisfações ocorrem devido aos aspectos fisiológicos, psicológicos e socioculturais (CARDOSO et al., 2020).

Todavia, é de mera importância explicar que a insatisfação com a imagem corporal pode gerar problemas físicos e emocionais na fase da adolescência, e é considerável entender que o desenvolvimento desses problemas físicos e emocionais pode vir a causar uma distorção da autoimagem e gerar comportamentos alimentares perigosos. Esta condição pode levar o adolescente a iniciar uma dieta insuficiente, desenvolver transtornos alimentares e problemas psicológicos (RIBEIRO et al., 2015).

Utilizar métodos como as restrições alimentares por um longo período, vômitos autoinduzidos, comer em excesso e fazer o uso de medicamentos como laxantes/diuréticos para que ocorra a perca de peso pode ser classificado como comportamentos perigosos para o desenvolvimento de transtornos alimentares (TA), sendo que os mesmos comportamentos participam dos critérios para o diagnóstico de anorexia e bulimia nervosa (FORTES et al., 2016). A preocupação exagerada com o peso e com a imagem corporal induz as pacientes a chegarem a um corpo idealizado por métodos impróprios optando por dietas exageradamente restritivas e prejudiciais à saúde (BARBOSA et al., 2015). 
A anorexia nervosa é qualificada pelo medo da pessoa em perder/sair do seu peso adequado, onde o mesmo começa se recusar a se alimentar, o medo excessivo de aumentar seu peso e a distorção da sua imagem corporal juntamente com a negação da sua condição doentia, a qual ela se exige na busca constante de emagrecer de forma inapropriada (PEREIRA; DA SILVA COSTA; DE ANDRADE AOYAMA, 2020).

Em contrapartida a bulimia nervosa é identificada com uma alta ingestão de alimentos, em um curto período, onde há uma perda do controle do tanto de alimentos que a pessoa ingere, fazendo com que o adolescente afetado pratique métodos inapropriados para perda rápida de peso, tais como: o vômito induzido, dietas mirabolantes, exercícios físicos inadequados, uso de drogas ilícitas e o abuso de medicamentos sem nenhuma orientação médica (PEREIRA; DA SIVA COSTA; DE ANDRADE AOYAMA, 2020). Evidências apontam que a prevalência de comportamentos alimentares perigosos com transtornos alimentares em adolescentes seja cerca de 20\% (FORTES et al., 2016).

Diante do exposto, a presente pesquisa tem por objetivo descrever a prevalência do risco de desenvolvimento de transtornos alimentares nas adolescentes do sexo feminino da escola estadual de Monsenhor Paulo, MG.

\section{REFERENCIAL TEÓRICO}

\subsection{Adolescência}

A adolescência faz parte da juventude, não se limita a uma etapa cronológica, pode ser uma experiência diferente de quem busca autonomia e para quem busca estabelecer um projeto de vida pessoal. Nessa fase, a busca por se sentir aceito pela sociedade e definir sua identidade, pode ser um fator contribuinte para o desenvolvimento dos transtornos alimentares. Considerando que esse período é caracterizado por mudanças corporais, crescimento de membros superiores e inferiores e liberação de hormônios, isso pode levar a diferenças de 
corpo idealizado para um corpo real, quanto mais distante o corpo do real, maior a possibilidade de conflito, o que prejudicará sua autoestima (RIBEIRO et al., 2015).

Ao período da adolescência, uma série de mudanças tanto físicas quanto cognitivas, emocionais e sociais, pode ser expressa pelos adolescentes como fatores estressantes (UZUNIAN; VITALLE, 2015). Essa é uma fase delicada por marcar a transição entre a infância e a idade adulta, onde a composição do corpo e características psicológicas sofre mudanças vertiginosas (MEIRELES et al., 2015).

Nesse período da ad lescência e em especial durante a maturação sexual, a massa corporal apresenta uma grande variação na sua composição, onde se pode alterar o aumento da massa corporal e adiposi ade. O alto grau de variabilidade nos escores de composição corporal observado nesta fase do ciclo de vida levou alguns autores a pré-ajustar a maturidade sexual conforme necessário para avaliações nutricionais de adolescentes e se posicionar de forma diferente (CUMPIAN - ILVA, 2018).

A adolescência é um período com características únicas no ciclo vital, durante o qual ocorrem importantes mudanças biológicas e psicossociais, que são de significado decisivo para o desenvolvimento da autonomia e a construção da identidade (MARQUES et al., 2016). Nesse estágio de desenvolvimento, as mudanças corporais da menina são inúmeras.

Provocados pela produção de hormônios, a partir dos oito ou nove anos, promovem mudanças no tamanho corporal, nas proporções e no desenvolvimento de características sexuais primárias e secundárias. O surto de crescimento da puberdade começa um ou dois anos antes do amadurecimento dos órgãos sexuais e dura de seis meses a um ano depois disso (CAMPAGNA; SOUZA, 2018). 


\subsection{Imagem Corporal (IC)}

A imagem corporal (IC) corresponde a uma descrição estabelecida pelo indivíduo em sua mente, incluindo pensamentos e sentimentos relacionados ao tamanho, aparência e forma de seu corpo, levando em consideração a subjetividade de cada pessoa. Nesse campo, a insatisfação física é um obstáculo que afeta a imagem corporal construída, ou seja, um sentimento negativo em relação à imagem corporal, neste caso, o indivíduo sofre por ser considerado um corpo ideal e atual (CARDOSO et al., 2020).

A imagem corporal é definida como se idealiza o que se tem na mente sobre as formas do seu próprio corpo, onde também se inclui os sentimentos em relação a essas características e suas partes constituintes, sendo por fatores psicológicos, biológicos, culturais e sociais (COSTA; DE LIMA; PEGOLO, 2016).

A alta preocupação com a imagem corporal e sua distorção é algo alarmante, pois esses fatores podem prejudicar a vida em um todo. O desenvolvimento da anorexia e bulimia nervosa é diretamente associado à uma insatisfação corporal, baixa autoestima e influência da mídia (PAPALIA; OLDS; FELDMAN, 2016). Observa-se uma crescente preocupação com a imagem corporal, especialmente na busca por um padrão de beleza idealizado (POLTRONIERIA et al., 2016 ).

Na sociedade atual é cada vez mais comum existir inúmeras pessoas que tentam se encaixar nos padrões de beleza considerados ideais pela mídia, acarretando uma insatisfação com a imagem corporal quando não se tem resultados bem-sucedidos. A imagem corporal faz parte do mecanismo de identidade pessoal com muitas dimensões (CARVALHO et al., 2020).

$\mathrm{Na}$ adolescência ocorrem as oscilações da autoestima por ser uma fase de importantes transformações psicológicas e sociais (RENTZ-FERNANDES et al., 2017 . Sendo esta fase repleta de inúmeras mudanças, a percepção da própria imagem corporal fica distorcida, o que passa a se tornar fator preocupante 
Bacharelado em Nutrição da UninCor e iniciação à pesquisa: Com a palavra os nossos estudantes

ao influenciar comportamentos inadequados. Dentre tantos fatores que sofrem mudanças, que necessitam de melhor atenção nessa fase da vida, a insatisfação corporal tem ocupado espaço considerável na literatura (RIBEIRO et al., 2015).

\subsection{Insatisfação Imagem Corporal}

A insatisfação com a imagem corporal pode ser promovida pelo acesso às mídias, principalmente relacionadas às redes sociais, pois muitas vezes os adolescentes entram em contato com essas mídias e se tornam um grupo de risco. $\mathrm{Na}$ sociedade atual, existe uma idealização de um corpo perfeito que, caso não se concretize, não afetará apenas a saúde e o comportamento dos adolescentes, mas também criará barreiras à imagem corporal (PINHO et al., 2019).

A insatisfação com a imagem corporal surge de acordo com os sentimentos da pessoa, quando começa a se comparar a outras pessoas e ter um sentimento de negação a si próprio (DE OLIVEIRA AINETT; COSTA; DE SÁ, 2017). A insatisfação com a imagem corporal tem uma ligação primordial por ser um dos primeiros sinais para os transtornos alimentares. Dessa forma seus sinais são de mera importância para identificar manifestações clínicas relevantes (RIBEIRO et al., 2015).

Devido às transições decorrentes no período da adolescência, onde ocorre um rápido crescimento, desenvolvimento e mudanças corporais, a insatisfação corporal tende a ser mais frequente. Essas insatisfações podem gerar uma dificuldade no adolescente como um todo, não só ao que diz respeito a sua imagem corporal, mas também ao nervosismo, estresse, depressão, dificuldades para dormir, queixas de problemas sociais, gerando consequentemente pouca qualidade de vida (JUSTINO; ENES; NUCCI, 2020).

De acordo com a pesquisa de Helfert\&Warschburger, é no período entre 10 e 19 anos, que a imagem corporal dos adolescentes se encontra mais proeminente. A visão sobre essa estrutura é avaliada como a representação mental que 
um indivíduo tem de seu próprio corpo, e uma de suas atitudes é a insatisfação. Por sua vez, refere-se a uma avaliação negativa do peso corporal e da forma corporal (MEIRELES et al., 2015).

Por ser caracterizada pela fase em que ocorrem inúmeras transformações biológicas e psicossociais com adolescentes e, também, alterações corporais juntamente com a construção da própria personalidade, o cuidado nessa fase com os adolescentes demanda uma alta necessidade nutricional onde a nutrição apresenta uma função importante no desenvolvimento do adolescente. A má alimentação acaba sendo desfavorável ao crescimento somático e a saúde na vida adulta (TEIXEIRA et al., 2015).

Ao decorrer dos anos, a alimentação da população mundial sofreu uma grande mudança, principalmente entre os jovens, a prática de hábitos alimentares e estilos de vida saudáveis têm diminuído juntamente com o consumo de arroz e feijão, automaticamente aumentando o consumo de fast food, ultraprocessados e doces. O impacto dessas mudanças ocasiona o aumento de pessoas com obesidade, hipertensão, alterações no metabolismo da glicose e novos casos de doenças ósseas e articulares. A atenção excessiva ao peso e o desejo de perder peso desencadeiam mudanças no comportamento alimentar, que podem eventualmente levar ao desenvolvimento de certos transtornos alimentares (TA), como anorexia nervosa (AN) e bulimia nervosa (BN) (TEIXEIRA et al., 2016).

\subsection{Transtornos Alimentares (TA)}

Os transtornos alimentares (TA) como a anorexia e bulimia nervosa são caracterizadas como síndromes psiquiátricas e os pacientes com o diagnóstico clínico dessas patologias apresentam sintomas comportamentais como a restrição alimentar por longos períodos, indução de vômitos, compulsão alimentar e a prática métodos purgativos como o uso de laxantes, diuréticos, de medicamentos sem a prescrição médica e a prática de exercício físico excessivo (FORTES et al., 2016). 
Bacharelado em Nutrição da UninCor e iniciação à pesquisa: Com a palavra os nossos estudantes

Devido ao aumento começou afetar diferentes na decorrência dos transtornos alimentares, onde o mesmo países, culturas e grupos socioeconômicos, os transtornos alimentares passaram a ser um dos principais problemas de saúde pública. A exagerada preocupação com a imagem corporal e com o peso ideal induz as pacientes a chegarem a um corpo idealizado por métodos impróprios optando por dietas exageradamente restritivas e prejudiciais à saúde (BARBOSA et al., 2015).

Aspectos como a autoestima estão diretamente ligados ao risco do desenvolvimento de transtornos alimentares, uma vez que a mesma é entendida como a avaliação que o indivíduo tem sobre si próprio, sobre seu corpo, seu valor e competência podendo refletir em uma atitude positiva ou negativa em relação a si mesmo (FORTES et al., 2015).

As restrições alimentares permitem a perda de peso em curto prazo, mas os indivíduos tendem a recuperar o peso com o tempo, e a recuperação do peso é uma resposta comum em longo prazo, não a exceção. Outros estudos relatam que apenas $10 \%$ a $20 \%$ dos indivíduos têm uma taxa geral de sucesso na manutenção do peso. É importante ressaltar que não é fácil deixar de comer alimentos com alto teor calórico por muito tempo, mas cerca de $90 \%$ das pessoas relatam que as tentativas anteriores não tiveram sucesso (DE JESUS et al., 2017).

De acordo com os dados estabelecidos, a prevalência de anorexia nervosa varia entre 0,3 a $3,7 \%$ e a de bulimia nervosa varia entre 1,1 a $4,2 \%$ em meninas. As complicações em decorrer aos transtornos podem ser definidas por: hipoglicemia, alterações endócrinas, perda de densidade mineral óssea, arritmia cardíaca, pressão baixa, insuficiência pulmonar e renal (TEIXEIRA et al., 2015).

Tanto a anorexia nervosa quanto a bulimia nervosa consiste em comportamentos alimentares desorganizados, precipitados ou desequilibrados e que esses pacientes aceite que possui transtornos alimentares e queira ajuda, é necessário uma completa reabilitação do mesmo, em alguns aspectos, que vai envolver toda uma equipe multidisciplinar de profissionais, sendo importante lembrar que 
com uma equipe bem preparada e completa fica mais fácil de proporcionar um amparo para esses adolescentes (PEREIRA; DA SILVA COSTA; DE ANDRADE AOYAMA, 2020).

Estima-se que a anorexia nervosa acometa 1\% das mulheres entre $12 \mathrm{e}$ 25 anos, sendo mais comum em indivíduos da classe econômica alta. Sua incidência varia de 0,24 a 7,3 casos para cada 100.000 indivíduos por ano, com a faixa etária média de surgimento entre 14 e 18 anos. Em contrapartida, a bulimia nervosa é mais comum do que a anorexia nervosa, com prevalência de $1 \%$ a $2 \%$ e idade média próxima de 20 anos. Esse distúrbio, no entanto, acomete mulheres de todas as classes socioeconômicas (DOS SANTOS et al., 2017).

\subsection{Anorexia Nervosa (AN)}

A anorexia nervosa começa a se desenvolver quando se tem uma distorção da imagem corporal, e os pacientes com essa patologia podem ser subdivididos em dois grupos, restritivos e compulsão alimentar purgativa. Os pacientes com anorexia nervosa do subtipo restritivo usam métodos como recusas alimentares e, também, a prática de atividade física de forma excessiva, são obsessivas e perfeccionistas, já os pacientes com anemia nervosa do subtipo compulsão alimentar purgativa, utilizam métodos de purgação como indução de vômitos, utilização de medicamentos sem prescrição médica, uso de drogas, diuréticos e laxantes (UCHÔA et al., 2015).

Os critérios para o diagnóstico da anorexia nervosa incluem três elementos essenciais: restrição da ingestão energética com consequente perda de peso, medo intenso de engordar e distorção da imagem corporal (SILVA et al., 2018). Alguns sintomas dec rrentes da anorexiam nervosa como: fraqueza, desidratação, baixa imunidade, debilidade física, descalcificação óssea, suscetibilidade a fraturas, entre outras, podem causar consequências devastadoras no organismo do indivíduo (MANOCHIO et al., 2020). 
Bacharelado em Nutrição da UninCor e iniciação à pesquisa: Com a palavra os nossos estudantes

Esses pacientes com anorexia nervosa apresentam sentimentos de inferioridade, insegurança e inadequação, além de traços de personalidade que abrangem perfeccionismo exagerado, obsessividade, retraimento social e condutas de esquivança (LEONIDAS; SANTOS, 2020).

Inúmeros estudos têm contribuído, mesmo que involuntariamente, para construir ou reforçar uma representação estereotipada do indivíduo que sofre de anorexia como alguém que tem "dificuldades" em lidar com suas experiências emocionais e que vivencia altos níveis de ansiedade em seus vínculos familiares e relações interpessoais (ATTILI et al., 2018).

Pesquisas apontam que cerca de $53 \%$ dos pacientes com anorexia nervosa fazem jejum restritivo e $47 \%$ têm compulsão alimentar seguida de purgação. As consequências das práticas de anorexia nervosa do subtipo purgativo apresentam alterações bucais, arritmia cardíaca, alterações endócrinas, como anemia, osteoporose, dentre outras (DOS SANTOS et al., 2017).

\subsection{Bulimia Nervosa (BN)}

Por sua vez a bulimia nervosa (BN) é caracterizada por uma ingestão exacerbada de alimentos de uma forma muito rápida, gerando a perda de controle e automaticamente sendo denominados como episódios bulímicos. Os mesmos são acompanhados de métodos inadequados para o controle de peso, como vômitos induzidos (em mais de $90 \%$ dos casos), uso de medicamentos sem prescrição médica como, diuréticos, laxantes, inibidores de apetite, dietas mirabolantes e a prática excessiva de exercícios físicos, abuso de cafeína ou uso de drogas ilícitas como a cocaína (UCHÔA et al., 2015).

Os critérios para diagnóstico da bulimia nervosa incluem algumas situações como: compulsão alimentar, sentimento de culpa que ocorre no mínimo duas vezes na semana, preocupação em comer, utilização de métodos purgativos para diminuir o ganho de gordura, preocupação em achar que vai ficar obeso e jejuns 
de forma totalmente errada (PEREIRA; DA SILVA COSTA; DE ANDRADE AOYAMA, 2020).

Os sinais mais comuns de bulimia nervosa incluem letargia, ciclos menstruais irregulares, dor abdominal no quadrante superior direito e alterações gastrointestinais leves a graves. E alguns outros sinais podem surgir na forma de queda de cabelo, edema, calos nas mãos, hemorragia subconjuntival e hemorragia nasal decorrente à indução do vômito (ROCHA et al., 2020).

Resultados de estudos citam que 1 a $2 \%$ da população do mundo sofre de bulimia nervosa, com o aparecimento dos primeiros sintomas depois dos 12 anos de idade, o transtorno é característico das mulheres, com prevalência de 1,1\% a 4,2\% (PAPALIA; OLDS; FELDMAN, 2016).

Para diagnosticar a bulimia nervosa é necessário ter muita atenção, pois seus sintomas muitas vezes não ficam tão aparentes, todavia, é preciso e recomendado saber mais sobre o paciente, suas histórias, seu cotidiano, seus hábitos alimentares e a preocupação constante com o peso são dados que precisam ser cuidadosamente observados. Uma pessoa com bulimia pode ser magra, obesa ou ter peso normal, contudo, os comportamentos, como induzir o vômito são práticas que muitas vezes são realizadas escondidas. Pessoas diagnosticadas com bulimia nervosa podem ter outros problemas, como a depressão, ansiedade e abuso de substâncias lícitas e ilícitas (DINIZ; LIMA, 2017).

\subsection{Mídia}

Exigências excessivas sobre a composição corporal de crianças e adolescentes podem ter um impacto negativo. Pais e profissionais devem ter cuidado ao orientar sobre educação nutricional e atividades físicas, por exemplo, sugerindo mudanças na forma corporal, que prejudicam a autoestima dos jovens, os deixam insatisfeitos e serão punidos (RENTZ-FERNANDES et al., 2017). 
Bacharelado em Nutrição da UninCor e iniciação à pesquisa: Com a palavra os nossos estudantes

Os fatores sociais e culturais impostos por alguma sociedade, familiares e amigos para se ter um corpo padronizado têm atingido a influência da mídia e, gradativamente, aumentam a possibilidade de distúrbios da imagem corporal e transtornos alimentares dos jovens, além de gerar uma insatisfação corporal característica até o final do seu desenvolvimento (UZUNIAN; VITALLE, 2015).

A ideia do chamado padrão corporal ideal, bem como a busca incessante por ele, focando no seu próprio senso de vaidade, tem um impacto considerável na autoimagem de quem deseja ter um corpo esguio, atraente e corpo tonificado, independentemente da sua realidade física. As pessoas que se afastam desse modelo adquirem facilmente uma autoimagem negativa, o que leva à baixa autoestima e à depressão, além de distúrbios emocionais e alimentares (RIBEIRO et al., 2015).

Além da insatisfação com o corpo, os comportamentos de risco para a TA também decorrem do medo do ganho de peso e do desejo contínuo de perder peso. Os ideais sociais e culturais podem regular a insatisfação do corpo, o que por sua vez afetará a adoção de comportamentos de risco para TA por adolescentes do sexo feminino, pois na maioria dos casos, um corpo ideal proeminente não pode ser alcançado (FORTES et al., 2015).

O uso e o impacto das redes sociais é um fenômeno relativamente novo e, também, é um tema de pesquisa em várias áreas do conhecimento para entender o impacto de sua exposição em diferentes grupos de pessoas. Essas novas mídias reforçam o narcisismo e os padrões de beleza atuais, e alguns estudos avaliaram seu impacto na imagem corporal (LIRA et al., 2017).

A influência social acima mencionada se reflete em veículos de mídia, propagandas, novelas e programas, apresentando a beleza e o corpo esguio e forte associado ao sucesso. Entende-se que esse modelo estético faz com que as mulheres tenham evidente insatisfação crônica com seu corpo, um momento se 
Bacharelado em Nutrição da UninCor e iniciação à pesquisa: Com a palavra os nossos estudantes

odiando por ganhar alguns quilos e outro momento adotando dietas altamente restritivas e exercícios físicos extenuantes para compensar a ingestão excessiva (RIBEIRO et al., 2015).

Nesse caso, fica evidente a necessidade de intervenção dos profissionais de saúde na adolescência para evitar que a insatisfação com a imagem corporal acarrete problemas psicológicos relacionados à autoimagem e aos transtornos alimentares. Portanto, a escola e a família devem estar atentas aos sinais de distorção da imagem corporal dos adolescentes e desempenhar um papel importante na identificação de situações de risco que requerem acompanhamento profissional (PINHO et al., 2019).

\section{MATERIAIS E MÉTODOS}

Esta pesquisa foi realizada de forma quantitativa e teve por finalidade aprofundar conhecimentos, por isso é uma estratégia básica que pode produzir os seus resultados, sendo uma pesquisa descritiva. A amostra do estudo foi constituída por adolescentes do sexo feminino de (12 a 18 anos) matriculadas na Escola Estadual de Monsenhor Paulo.

Inicialmente para a realização da pesquisa do trabalho foi utilizado o questionário BITE (Bulimic Investigatory Test) (Anexo 1) que é composto de 33 questões dirigidas à bulimia, que contém pontuação, sendo que o somatório delas pode variar de 0 a 30 pontos.

Esse questionário teve como objetivo avaliar principalmente os comportamentos de bulimia, como uma absurda ingestão de alimentos onde alguns métodos purgativos são utilizados para compensar estes episódios excessivos de alimentação e que levam o indivíduo a sentir-se mal, tais como provocação de vômitos, realização de , uso de laxantes, jeju diuréticos, anorexígenos e dieta.

Também foi utilizado o questionário EAT-26 (Eating Attitudes Test) (Anexo 2) que é composto de 26 questões dirigidas à anorexia, sendo que cada resposta 
possui uma pontuação e o seu somatório, pode variar de 0 a 26 pontos. Esse questionário teve como objetivo indicar a presença de padrões alimentares anormais, fornecendo um índice de gravidade de preocupações típicas de pacientes com transtornos alimentares.

Além dos dois questionários citados acima, a presente pesquisa coletou dados sociodemográficos, tais como: idade, sexo, raça e estado civil. Estes questionários foram aplicados através do Google Forms, que nada mais é do que uma plataforma de aplicativo de gerenciamento de pesquisa, sendo utilizado para coletar informações, realizar questionários e formulários de pesquisa.

Para os critérios de inclusão da pesquisa foi seguido o seguinte padrão: adolescentes (12 a 18 anos) do sexo feminino da Escola Estadual de Monsenhor Paulo, e o mesmo não poderia avaliar adultos, adolescentes do sexo masculino ou adolescentes do sexo feminino que não estavam matriculadas na escola e que sejam abaixo ou acima da faixa etária estabelecida.

Adicionalmente, em respeito aos participantes e os responsáveis pelos sujeitos da pesquisa, os participantes assinaram o Termo de Consentimento Livre e Esclarecido (TCLE) (Anexo 4). Além disso, a presente pesquisa foi aprovada pelo Comitê de Ética e Pesquisa (CEP) da Universidade Vale do Rio Verde - UninCor, via plataforma Brasil, com protocolo 48594021.7.0000.5158.

\section{RESULTADOS E DISCUSSÃO}

Para o trabalho foram utilizados dois questionários, o BITE (Bulimic Investigatory Test) (Anexo 1) que é composto por 33 perguntas já o EAT-26 (Eating Attitudes Test) (Anexo 2) é composto por 26 perguntas. Tais questões analisam o "tipo de relacionamento" das entrevistadas com a alimentação a fim de identificar a presença de comportamento alimentar compulsivo que podem vir a acarretar os transtornos alimentares como anorexia nervosa e bulimia nervosa. 
Bacharelado em Nutrição da UninCor e iniciação à pesquisa: Com a palavra os nossos estudantes

A pesquisa contou com a participação de 41 adolescentes do sexo feminino de (12 a 18 anos) matriculadas na Escola Estadual de Monsenhor Paulo. Sendo que $87,8 \%$ possuíam a idade de 18 anos, que cerca de $75,6 \%$ se declararam brancas e $80,5 \%$ eram solteiras.

Em relação ao questionário BITE (Tabela 1), as questões 1 a 5 e as questões 8,9 e 21 referem-se à dieta alimentar e hábitos alimentares regulares, entre os quais os adolescentes relataram não se importar com a dieta alimentar. Para RIBEIRO, KARLA et al., (2015) os padrões estéticos criados pela mídia em 2015 deixavam as mulheres obviamente insatisfeitas com seus corpos. Elas se odiavam por ganhar alguns quilos. Outra opção era restringir,completamente a alimentação e a prática de exercícios físicos, como para compensar a ingestão de calorias extras.

As questões de 10 a 15, 17, 18, 19, de 22 a 26, 28, 30 e 32 abordam sobre compulsão alimentar. Para OLIVEIRA, ANA PAULA GONÇALVES et al., (2020), durante o episódio obsessivo compulsivo, os indivíduos comerão mais rápido que o normal até se sentirem desconfortáveis ou até mesmo sem sentir fisicamente nenhuma fome. Relatam que, essas pessoas, sentem vergonha e culpa pela quantidade de alimentos que ingerem, como sensação de falta de controle sobre seus hábitos alimentares.

Ainda em relação ao questionário anterior, as questões 16, 29, 31 e 33 abordam sobre a preocupação com a imagem corporal incluindo pensamentos e sentimentos relacionados ao tamanho, aparência e forma de seu corpo, levando em consideração a subjetividade de cada pessoa em relação a imagem corporal. Segundo UZUNIAN; LAURA GIRON; VITALLE

(2015) a pressão para emagrecer exercida pela sociedade, família e amigos, somada à influência negativa exercida pela mídia, aumenta as chances de adolescentes desenvolverem transtornos de imagem corporal e transtornos ali- 
mentares, pois diante disso nesta fase estes indivíduos atribuem significativa importância às atitudes alimentares, predispostos além de estarem a apresentar uma insatisfação corporal característica.

Em contrapartida, na tabela descritiva do EAT-26 (Tabela 2), as questões $1,6,7,10,11,12,14,16,17,22,23,24$ e 25 abordam questões sobre alimentos com muitas calorias e a preocupação exagerada e intensa com a imagem corporal, onde as adolescentes relataram se preocuparem com as calorias dos alimentos e com sua imagem corporal. Segundo BARBOSA, ANDRÉIA et al., (2015) pela relação entre imagem corporal e transtornos alimentares, $74,4 \%$ dos adolescentes com imagem corporal distorcida também são propensos a transtornos alimentares.

Como pode ser observado, as questões 3,4 , 9, 18, 21 e 26 abordam questões sobre a compulsão alimentar seguida de métodos purgativos como indução de vômito, assim por exemplo. Segundo FORTES et al., (2015), as adolescentes com baixa autoestima comem em excesso alimentos ricos em açúcar porque induzem a secreção de neurotransmissores (como a serotonina), o que leva a uma sensação de bem-estar e felicidade. Porém, é importante ressaltar que, após comer com rapidez, as adolescentes podem buscar estratégias para o controle do peso, como comportamentos descompensados e inadequados.

Já as questões 2, 5, 8, 13, 15, 19 e 20 relatam sobre a tentativa de autocontrole sobre os alimentos. Segundo LIRA, ARIANA GALHARDI et al., (2017) aproximadamente $25 \%$ das adolescentes tentam manter um controle sobre os alimentos e o quanto comer, mas que muitas vezes ocorre comportamentos de compulsão alimentar seguidas de comportamentos purgativos e compensatórios. 
Bacharelado em Nutrição da UninCor e iniciação à pesquisa: Com a palavra os nossos estudantes

Tabela 1. Resultados descritivos Bulimic Investigatory Test

\begin{tabular}{|l|c|c|c|c|}
\hline \multicolumn{1}{|c|}{ Perguntas } & \multicolumn{2}{|c|}{ SIM } & \multicolumn{2}{|c|}{ NÃO } \\
\cline { 2 - 6 } & $\mathrm{N}$ & $\%$ & $\mathrm{~N}$ & $\%$ \\
\hline 1. Você segue um padrão regular de alimentação? & 23 & 56,1 & 18 & 43,9 \\
\hline 2. Você costuma seguir dietas de forma rigorosa? & 5 & 12,2 & 36 & 87,8 \\
\hline $\begin{array}{l}\text { 3. Você considera um fracasso quebrar a dieta uma vez? } \\
\text { 4. Você conta as calorias de tudo o que come, inclusive } \\
\text { quando não está de dieta? }\end{array}$ & 3 & 7,3 & 38 & 92,4 \\
\hline $\begin{array}{l}\text { 5. Você de vez em quando, fica sem se alimentar por um dia } \\
\text { inteiro? (Se a resposta for NÃO vá para a questão 07! Se for } \\
\text { SIM, siga para a questão 06). }\end{array}$ & 9 & 22 & 32 & 75,6 \\
\hline $\begin{array}{l}\text { 8. Os seus hábitos alimentares atrapalham sua vida? } \\
\text { 9. Você diria que a comida "domina" a sua vida? }\end{array}$ & 11 & 26,8 & 30 & 73,2 \\
\hline $\begin{array}{l}\text { 10. De vez em quando, você come até sentir-se mal fisica- } \\
\text { mente e ter que parar? }\end{array}$ & 19 & 46,3 & 22 & 53,7 \\
\hline $\begin{array}{l}\text { 11. Há momentos em que você SÓ consegue pensar em } \\
\text { comida? }\end{array}$ & 22 & 53,7 & 19 & 46,3 \\
\hline $\begin{array}{l}\text { 12. Você come moderadamente em frente aos outros e, em } \\
\text { compensação, exagera quando está sozinho? }\end{array}$ & 5 & 12,2 & 36 & 87,2 \\
\hline $\begin{array}{l}\text { 13. Você sempre consegue parar de comer quando quer? } \\
\text { quantidades de alimento (fora das refeições)? }\end{array}$ & 38 & 92,7 & 3 & 7,3 \\
\hline $\begin{array}{l}\text { 14. Você, de vez em quando, sente um desejo incontrolável } \\
\text { de comer sem parar? }\end{array}$ & 22 & 53,7 & 19 & 46,3 \\
\hline $\begin{array}{l}\text { 15. Quando você está ansioso(a), tende a comer muito? } \\
\text { 16. ideia de ficar gordo(a) a apavora? }\end{array}$ & 29 & 70,7 & 12 & 29,3 \\
\hline
\end{tabular}


Bacharelado em Nutrição da UninCor e iniciação à pesquisa: Com a palavra os nossos estudantes

\begin{tabular}{|c|c|c|c|c|}
\hline $\begin{array}{l}\text { 18. Você alguma vez, sentiu } v \text { rgonha de seus hábitos ali- } \\
\text { mentares? }\end{array}$ & 19 & 46,3 & 22 & 53,7 \\
\hline $\begin{array}{l}\text { 19. O fato de você não conseguir se controlar para comer a } \\
\text { preocupa? }\end{array}$ & 21 & 51,2 & 20 & 48,8 \\
\hline 20. Você busca na comida um conforto emocional? & 20 & 48,8 & 21 & 51,2 \\
\hline $\begin{array}{l}\text { 21. Você costuma deixar comida no prato ao final de uma } \\
\text { refeição? }\end{array}$ & 8 & 19,5 & 33 & 80,5 \\
\hline 22. Você engana os outros sobre quanto come? & 5 & 12,2 & 36 & 87,8 \\
\hline $\begin{array}{l}\text { 23. A quantidade que você co e é proporcional à fome que } \\
\text { sente? }\end{array}$ & 30 & 73,2 & 11 & 26,8 \\
\hline $\begin{array}{l}\text { 24. Você já se alimentou de grande quantidade de alimen- } \\
\text { tos em pouco tempo? (Se a resposta for NÃO vá para a } \\
\text { questão } 28 \text { ! Se for SIM, siga para a questão } 25 . \text { ) }\end{array}$ & 17 & 43,6 & 22 & 56,4 \\
\hline 25. Esse episódio o deixou de rimido? & 11 & 40,7 & 16 & 59,3 \\
\hline $\begin{array}{l}\text { 26. Esses episódios acontecem apenas quando você está } \\
\text { sozinho(a)? }\end{array}$ & 7 & 23,3 & 23 & 76,7 \\
\hline $\begin{array}{l}\text { 28. Você faria grandes sacrifícios para satisfazer uma von- } \\
\text { tade incontrolável de comer? }\end{array}$ & 10 & 25 & 30 & 75 \\
\hline $\begin{array}{l}\text { 29. Se você comer demais, sente-se muito culpado(a) por } \\
\text { isso? }\end{array}$ & 23 & 56,1 & 18 & 43,9 \\
\hline 30. Você, de vez em quando, come escondido? & 9 & 22 & 32 & 78 \\
\hline 31. Você consideraria seus hábitos alimentares normais? & 32 & 78 & 9 & 22 \\
\hline $\begin{array}{l}\text { 32. Você se consideraria uma essoa que come em exagero } \\
\text { e não consegue parar? }\end{array}$ & 4 & 9,8 & 37 & 90,2 \\
\hline $\begin{array}{l}\text { 33. Seu peso aumenta ou diminui mais que } 2 \mathrm{~kg} \text { em uma } \\
\text { semana? }\end{array}$ & 7 & 17,1 & 34 & 82,9 \\
\hline
\end{tabular}

Fonte: próprio autor (2021). 


\section{Avaliação de resultados B|TE}

1. Escala de gravidade:

1.1.Itens $6,7,27=$ maior que 5 , significativo Maior ou igual a 10 , grande intensidade

2. Escala de sintomas:

2.1. Itens $1,13,21,23,31$, pontua-se não

2.2. Outros itens, pontua-se sim

2.3. Total:

2.3.1. Máximo escore $=30$

2.3.2. Maior ou igual a $20=$ escore elevado, presença de comportamento alimentar compulsivo, grande possibilidade de bulimia.

Fonte: XIMENES et al., (2011).

Como pode ser observado cerca de $78 \%$ das adolescentes ficam sem se alimentar de vez em quando (Figura 1). Para LEAL et al., (2013), as causas dos transtornos alimentares são multifatoriais, ou seja, são diferentes fatores interagindo, levando ao desenvolvimento e à continuação da doença. Eles também acrescentaram que os transtornos alimentares têm critérios diagnósticos baseados em características psicológicas, comportamentais e físicas, que se caracterizam por graves distúrbios no comportamento alimentar e na imagem corporal.

CARVALHO et al., 2013, o comportamento alimentar pode ser definido como todas as formas de convívio com o alimento. Semelhante ao conceito de GARCIA (1999), encontrado no estudo de VAZ \& BENNEMANN (2014), o qual diz que o comportamento alimentar se refere a atitudes relacionadas às práticas alimentares em associação a atributos socioculturais, como os aspectos subjetivos intrínsecos do indivíduo e próprios de uma coletividade, que estejam envolvidos com o ato de se alimentar ou com o alimento em si. Já para FILIPPI (2019), os 
resultados obtidos, embora limitado pelo pequeno número de participantes, que já aderiram a dietas restritivas, sugerem que existe relação entre dietas restritivas com compulsão alimentar.

Nesse sentido a relação à distribuição das adolescentes entrevistadas e sobre a utilização de métodos para a perda de peso como ingerir comprimidos para emagrecer, nota-se que $85,4 \%$ nunca utilizaram esse método, 92,6\% das adolescentes nunca utilizaram diuréticos e laxantes e $97,5 \%$ das adolescentes nunca induziram vômitos e 2,4\% das adolescentes cometeram esse ato raramente (Figura 2). De acordo com CARVALHO, GIULIA XAVIER et al., (2020) a busca pelos ideais estéticos impostos, as adolescentes recorrem a dietas muito restritivas, ao exercício físico exagerado, ao uso de diuréticos e laxantes e de anabolizantes.

Corroborando com o estudo de TEIXEIRA, CARLA SOMAIO et al., (2015) que relatou que 12,7 das adolescentes cometiam hábitos alimentares inadequados, cerca de $8,5 \%$ utilizavam laxantes e $5,1 \%$ anorexígenos.

Figura 1. Frequência que as entrevistadas relataram ficar sem se alimentar por um dia inteiro.

\section{Frequência que as entrevistadas relataram ficar sem se alimentar por um dia inteiro}

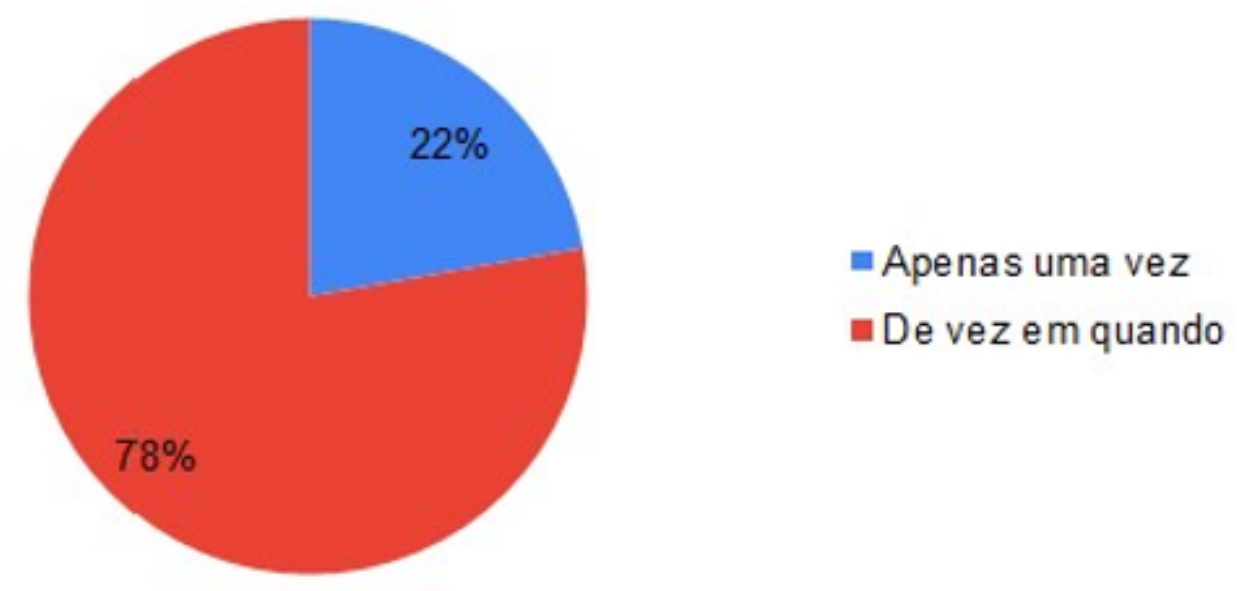

Fonte: próprio autor (2021). 
Figura 2. Distribuição das adolescentes referente a utilização e frequência de métodos para perder peso.

\section{Utiliza algum dos seguintes métodos para perderpeso?}

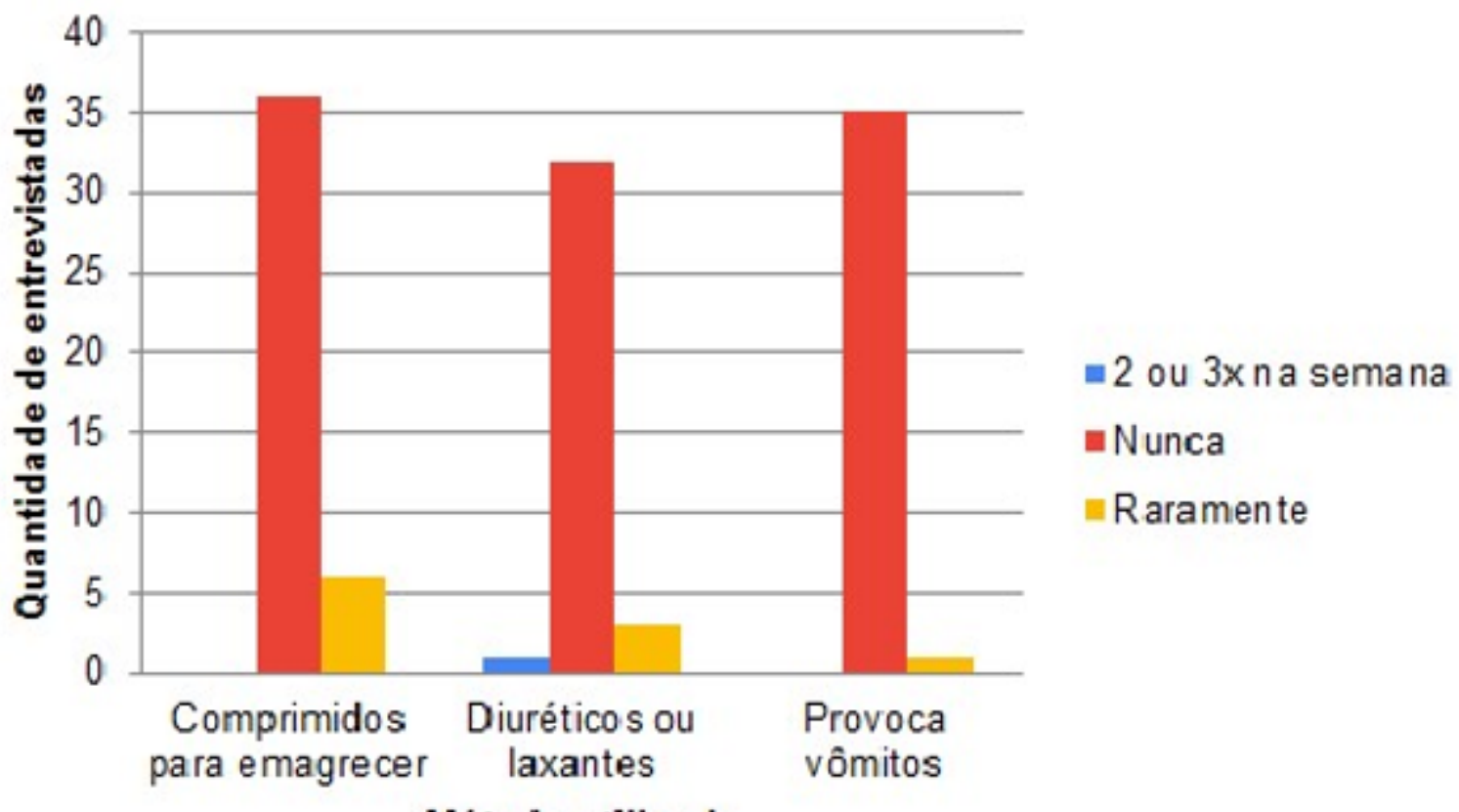

Método utilizado

Fonte: próprio autor (2021).

Observou-se que 65\% das adolescentes quase nunca apresentaram episódios de compulsão alimentar, enquanto $29 \%$ delas apresentam esses episódios uma vez por mês e 6\% das adolescentes apresentam os episódios duas ou três vezes por semana (Figura 3). Estes dados se comparam com os resultados que foram achados no estudo de LINS (2018), cujo estudo observacional verificou a compulsão presente no sexo feminino, o que sugere que esses são grupos de maior risco para desenvolver episódios de compulsão alimentar. Embora os resultados da compulsão alimentar atingiram $22 \%$ das entrevistadas.

Para BOLOGNESE et al., (2018) demonstraram os fatores associados que $56,7 \%$ das adolescentes nunca apresentaram episódios de compulsão alimentar, enquanto 28,4 apresentam uma vez por mês e $14,9 \%$ das adolescentes apresentam esses episódios duas ou três vezes na semana. 
A partir das observações de um estudo realizado por SOIHET et al., (2019), foram verificados os efeitos psicológicos e metabólicos da restrição alimentar no transtorno da compulsão alimentar e existem muitas evidências dos efeitos psicológicos e metabólicos associados às dietas restritivas.

LUZ et al., (2015), relata que indivíduos com transtornos alimentares, pelo menos durante o programa de perda de peso, a restrição calórica severa reduziu significativamente a alimentação em excesso em todas as quatro intervenções envolvendo essa população. Em estudo realizado por OLIVEIRA et al,. (2020), a prevalência de comportamentos para enfrentar o risco de transtornos alimentares, tentativas de limitar os carboidratos, juntamente com atitudes como medo de ganho de peso, deseja de perder peso e insatisfação física, parecem levar ao comportamento de compulsão alimentar.

Figura 3. Frequência com que os episódios como se alimentar de grande quantidade de alimentos em um curto período que acontecem.

\section{Com que frequência esses episódios acontecem?}

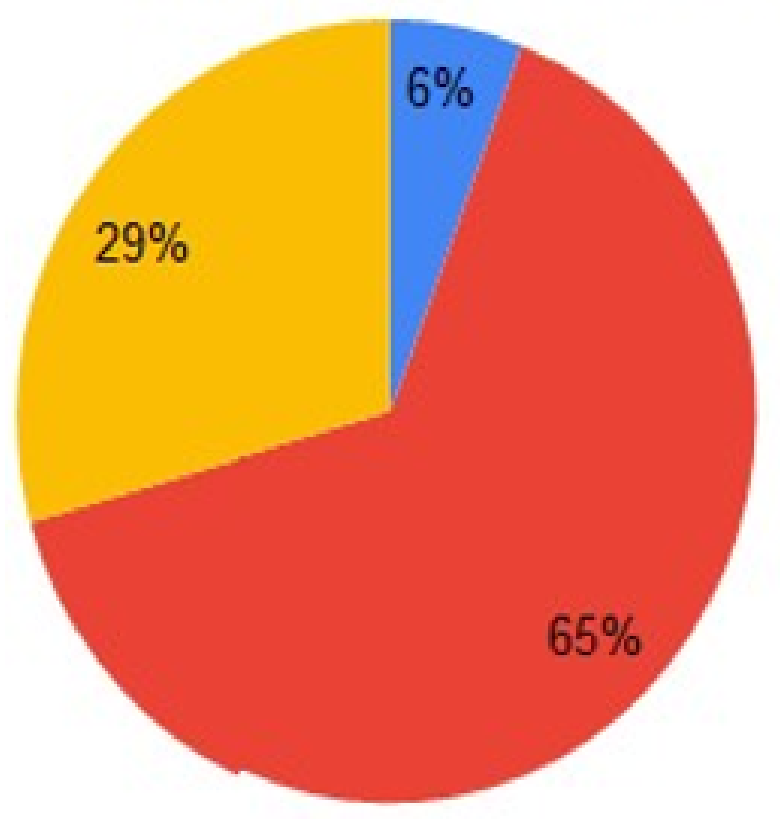

"Duas ou três vezes por semana

=Quase nunca

-Uma vez por mês

Fonte: próprio autor (2021). 
Tabela 2. Resultados descritivos Eating Attitudes Test

\begin{tabular}{|c|c|c|c|c|c|c|c|c|c|c|c|c|}
\hline \multirow{2}{*}{ Afirmativas } & \multicolumn{2}{|c|}{ Sempre } & \multicolumn{2}{|c|}{$\begin{array}{l}\text { Muitas } \\
\text { vezes }\end{array}$} & \multicolumn{2}{|c|}{ Às vezes } & \multicolumn{2}{|c|}{$\begin{array}{l}\text { Poucas } \\
\text { Vezes }\end{array}$} & \multicolumn{2}{|c|}{$\begin{array}{l}\text { Quase } \\
\text { Nunca }\end{array}$} & \multicolumn{2}{|c|}{ Nunca } \\
\hline & $\mathbf{N}$ & $\%$ & $\mathbf{N}$ & $\%$ & $\mathbf{N}$ & $\%$ & $\mathbf{N}$ & $\%$ & $\mathbf{N}$ & $\%$ & $\mathbf{N}$ & $\%$ \\
\hline $\begin{array}{c}\text { 1. Fico } \\
\text { apavorado(a) com } \\
\text { a ideia de estar } \\
\text { engordando }\end{array}$ & 16 & 39 & 10 & 24,4 & 7 & 17,1 & 2 & 4,9 & 6 & 14,6 & - & - \\
\hline $\begin{array}{l}\text { 2. Evito comer } \\
\text { quando estou com } \\
\text { fome }\end{array}$ & - & - & - & - & 9 & 22 & 8 & 19,5 & 10 & 24,4 & 14 & 34,1 \\
\hline $\begin{array}{c}\text { 3. Sinto-me } \\
\text { preocupado(a) } \\
\text { com os alimentos }\end{array}$ & 5 & 12,2 & 4 & 9,8 & 17 & 41,5 & 8 & 19,5 & 5 & 12,2 & 2 & 4,9 \\
\hline $\begin{array}{l}\text { 4. Continuar a } \\
\text { comer em } \\
\text { exagero faz com } \\
\text { que eu sinta que } \\
\text { não sou capaz } \\
\text { de parar }\end{array}$ & 3 & 7,3 & 3 & 7,3 & 11 & 26,8 & 3 & 7,3 & 5 & 12,2 & 16 & 39 \\
\hline $\begin{array}{l}\text { 5. Corto os meus } \\
\text { alimentos em } \\
\text { pequenos } \\
\text { pedaços }\end{array}$ & 2 & 4,9 & 5 & 12,2 & 8 & 19,5 & 6 & 14,6 & 6 & 14,6 & 14 & 34,1 \\
\hline $\begin{array}{l}\text { 6. Presto } \\
\text { atenção à } \\
\text { quantidade de } \\
\text { calorias dos } \\
\text { alimentos } \\
\text { que eu como }\end{array}$ & 2 & 4,9 & 4 & 9,8 & 5 & 12,2 & 5 & 12,2 & 11 & 26,8 & 14 & 34,1 \\
\hline $\begin{array}{c}\text { 7. Evito, } \\
\text { particularmente, } \\
\text { os alimentos ricos } \\
\text { em carboidratos } \\
\text { (ex. pão, arroz, } \\
\text { batatas, etc) }\end{array}$ & 1 & 2,4 & - & - & 6 & 14,6 & 7 & 17,1 & 12 & 29,3 & 15 & 36,6 \\
\hline $\begin{array}{l}\text { 8. Sinto que os } \\
\text { outros gostariam } \\
\text { que eu comesse } \\
\text { mais }\end{array}$ & 1 & 2,4 & 2 & 4,9 & 7 & 17,1 & 3 & 7,3 & 2 & 4,9 & 26 & 63,4 \\
\hline
\end{tabular}


Bacharelado em Nutrição da UninCor e iniciação à pesquisa: Com a palavra os nossos estudantes

\begin{tabular}{|c|c|c|c|c|c|c|c|c|c|c|c|c|}
\hline $\begin{array}{l}\text { 9. Vomito depois } \\
\text { de comer }\end{array}$ & - & - & - & - & - & - & 1 & 2,4 & 2 & 4,9 & 38 & 92,7 \\
\hline $\begin{array}{c}\text { 10. Sinto-me } \\
\text { extremamente } \\
\text { culpado(a) depois } \\
\text { de comer }\end{array}$ & 3 & 7,3 & 2 & 4,9 & 12 & 29,3 & 5 & 12,2 & 4 & 9,8 & 15 & 36,6 \\
\hline $\begin{array}{l}\text { 11. Preocupo-me } \\
\text { com o desejo de } \\
\text { ser magro(a) }\end{array}$ & 4 & 9,8 & 11 & 26,8 & 16 & 39 & 3 & 7,3 & 3 & 7,3 & 4 & 9,8 \\
\hline $\begin{array}{l}\text { 12. Penso em } \\
\text { queimar calorias a } \\
\text { mais quando me } \\
\text { exercito }\end{array}$ & 5 & 12,2 & 11 & 26,8 & 11 & 26,8 & 3 & 7,3 & 4 & 9,8 & 7 & 17,1 \\
\hline $\begin{array}{l}\text { 13. As pessoas } \\
\text { me acham muito } \\
\text { magro(a) }\end{array}$ & - & - & 3 & 7,3 & 7 & 17,1 & 9 & 22 & 6 & 14.6 & 16 & 39 \\
\hline $\begin{array}{l}\text { 14. Preocupo-me } \\
\text { com a ideia de } \\
\text { haver gordura em } \\
\text { meu corpo }\end{array}$ & 6 & 14,6 & 6 & 14,6 & 10 & 24,4 & 7 & 17,1 & 9 & 22 & 3 & 7,3 \\
\hline $\begin{array}{c}\text { 15. Demoro mais } \\
\text { tempo para fazer } \\
\text { minhas refeições } \\
\text { do que as outras } \\
\text { pessoas }\end{array}$ & 4 & 9,8 & 5 & 12,2 & 10 & 24,4 & 10 & 24,4 & 9 & 22 & 3 & 7,3 \\
\hline $\begin{array}{l}\text { 16. Evito comer } \\
\text { alimentos que } \\
\text { contenham açúcar }\end{array}$ & - & - & 1 & 2,4 & 9 & 22 & 7 & 17,1 & 16 & 39 & 8 & 19,5 \\
\hline $\begin{array}{c}\text { 17. Costumo } \\
\text { comer alimentos } \\
\text { dietéticos }\end{array}$ & 3 & 7,3 & 1 & 2,4 & 13 & 31,7 & 3 & 7,3 & 7 & 17,1 & 14 & 34,1 \\
\hline $\begin{array}{l}\text { 18. Sinto que os } \\
\text { alimentos } \\
\text { controlam } \\
\text { minha vida }\end{array}$ & 2 & 4,9 & 3 & 7,3 & 3 & 7,3 & 7 & 17,1 & 8 & 19,5 & 18 & 43,9 \\
\hline $\begin{array}{l}\text { 19. Demonstro } \\
\text { autocontrole } \\
\text { diante dos } \\
\text { alimentos }\end{array}$ & 9 & 22 & 9 & 22 & 18 & 43,9 & 3 & 7,3 & 2 & 4,9 & - & - \\
\hline
\end{tabular}


Bacharelado em Nutrição da UninCor e iniciação à pesquisa: Com a palavra os nossos estudantes

\begin{tabular}{|c|c|c|c|c|c|c|c|c|c|c|c|c|}
\hline $\begin{array}{c}\text { 20. Sinto que os } \\
\text { outros me } \\
\text { pressionam } \\
\text { para comer }\end{array}$ & 2 & 4,9 & 2 & 4,9 & 3 & 7,3 & 7 & 17,1 & 6 & 14,6 & 21 & 51,2 \\
\hline $\begin{array}{c}\text { 21. Passo muito } \\
\text { tempo pensando } \\
\text { em comer }\end{array}$ & 5 & 12,2 & 6 & 14,6 & 16 & 39 & 5 & 12,2 & 6 & 14,6 & 3 & 7,3 \\
\hline $\begin{array}{c}\text { 22. Sinto } \\
\text { desconforto após } \\
\text { comer doces }\end{array}$ & 1 & 2,4 & 4 & 9,8 & 11 & 26,8 & 7 & 17,1 & 7 & 17,1 & 11 & 26,8 \\
\hline $\begin{array}{c}\text { 23. Faço regimes } \\
\text { para emagrecer }\end{array}$ & 6 & 14,6 & 9 & 22 & 4 & 9,8 & 6 & 14,4 & 4 & 9,8 & 12 & 29,3 \\
\hline $\begin{array}{c}\text { 24. Gosto de } \\
\text { sentir meu } \\
\text { estômago vazio }\end{array}$ & 1 & 2,4 & 2 & 4,9 & 3 & 7,3 & 3 & 7,3 & 8 & 19,5 & 24 & 58,5 \\
\hline $\begin{array}{c}\text { 25. Gosto de } \\
\text { experimentar } \\
\text { novos alimentos } \\
\text { ricos em calorias }\end{array}$ & 2 & 4,9 & 3 & 7,3 & 16 & 39 & 10 & 24,4 & 7 & 17,1 & 3 & 7,3 \\
\hline $\begin{array}{c}\text { 26. Sinto vontade } \\
\text { de vomitar após } \\
\text { as refeições }\end{array}$ & - & - & - & - & 2 & 4,9 & - & - & 2 & 4,9 & 37 & 90,2 \\
\hline
\end{tabular}

Fonte: próprio autor (2021).

\section{Avaliação dos Resultados EAT-26}

Sempre $=3$

Muitas vezes $=2$

Às vezes $=1$

Outros $=0$

Exceção: questão 25

Poucas vezes $=1$

Quase nunca $=2$

Nunca $=3$

Pontuação: 21 pontos $=$ Anormalidade

Fonte: GARNER et al., (2002). 


\section{CONCLUSÃO}

Este trabalho buscou estudar possíveis fatores que estejam dentre as causas que permeiam a insatisfação com a imagem corporal e que compactua diretamente com o desenvolvimento dos transtornos alimentares, fato este muito comum na adolescência, fase em que o corpo está sujeito a diversas mudanças.

Os dados apresentados ressaltam a importância da avaliação da insatisfação com a imagem corporal nas adolescentes do sexo feminino, uma vez que a percepção distorcida da própria imagem corporal pode influenciar a práticas alimentares inadequadas, podendo causar danos à saúde física e mental.

O desenvolvimento de estratégias educacionais se faz necessário para estimular a conscientização das adolescentes em adotar um estilo de vida mais saudável, com repercussões na saúde física e psicológica. As adolescentes devem ter uma relação saudável com seu corpo, não supervalorizando a estética, o que leva à insatisfação exacerbada. Pais, profissionais da saúde e professores tem papel importante na orientação neste sentido.

\section{REFERENCIAS}

ALCKMIN-CARVALHO, Felipe et al. Anorexia Nervosa e estilos parentais. Perspectivas Em Psicologia, v. 24, n. 1, 2020.

AMARAL, Ana Carolina Soares et al. Apreciação corporal e aspectos associados entre adolescentes e mulheres jovens. Jornal Brasileiro de Psiquiatria, v. 68, n. 1, p. 16-22, 2019.

BARBOSA, Aline LP; MIRANDA, Hávylla Samara L. de. Psicologia e transtornos alimentares: produção científica sobre anorexia e bulimia nervosa. 2019.

BARBOSA, Andréia et al. Associação da imagem corporal e transtornos alimentares em adolescentes de Minas Gerais (Brasil). Nutr. clin. diet. hosp, p. 48-56, 2015. 
BITTAR, Carime; SOARES, Amanda. Mídia e comportamento alimentar na adolescência. Cadernos Brasileiros de Terapia Ocupacional, v. 28, p. 291-308, 2020.

BOLOGNESE, Marciele et al. Transtorno de compulsão alimentar periódica: fatores associados em adolescentes sobrepesados e obesos. Psicologia, Saúde \& Doenças, v. 19, n. 3, p. 755-763, 2018.

CARDOSO, Larissa et al. Insatisfação com a imagem corporal e fatores associados em estudantes universitários. Jornal Brasileiro de Psiquiatria, n. AHEAD, 2020.

CARVALHO, Giulia Xavier de et al. Insatisfação com a imagem corporal e fatores associados em adolescentes. Ciência \& Saúde Coletiva, v. 25, p. 2769-2782, 2020.

CARVALHO, Pedro Henrique Berbert de et al. Checagem corporal, atitude alimentar inadequada e insatisfação com a imagem corporal de jovens universitários. Jornal Brasileiro de Psiquiatria, v. 62, p. 108-114, 2013.

COSTA, Aline Neves; DE LIMA, Nayara Vieira; PEGOLO, Giovana Eliza. Insatisfação corporal e rastreamento do risco para Transtornos Alimentares em adolescentes. e Saude, v. 13, n. 1, p. 16-26, 2016.

DE CARVALHO, Renata Silva; AMARAL, Ana Carolina Soares; FERREIRA, Maria Elisa Caputo. Transtornos alimentares e imagem corporal na adolescência: uma análise da produção científica em psicologia. Psicologia: teoria e prática, v. 11 , n. 3, p. 200-223, 2009.

DE JESUS, Aline Dantas et al. Comportamento alimentar de pacientes de pré e pós-cirurgia bariátrica. RBONE-Revista Brasileira De Obesidade, Nutrição E Emagrecimento n. 63, p. 187-196, 2017.

DE OLIVEIRA AINETT, Waléria do Socorro; COSTA, Vanessa Vieira Lourenço; DE SÁ, Naíza Nayla Bandeira. Fatores associados à insatisfação com a imagem corporal em estudantes de Nutrição. RBONE-Revista Brasileira de Obesidade, Nutrição e Emagrecimento, v. 11, n. 62, p. 75-85, 2017. 
DINIZ, Neyanne Otaviano; LIMA, Deyseane Maria Araújo. A atuação do psicólogo no atendimento a pacientes com transtorno alimentar de bulimia nervosa. Revista de Humanidades, v. 32, n. 2, p. 214-222, 2017.

FERNANDES, Ana Caroline Castro Ferreira et al. Avaliação da auto-imagem corporal e o comportamento alimentar de mulheres. RBNE-Revista Brasileira de Nutrição Esportiva, v. 11, n. 63, p. 252-258, 2017.

FERREIRA, Gabriel Lins. A restrição alimentar e seus impactos no comportamento alimentar. 2018.

FILIPPI, C. R. Dietas Restritivas e Compulsões Alimentares. 2019. 27 f. Monografia (Graduação em Enfermagem e Nutrição) - Universidade de Taubaté, Taubaté, 2019.

FORTES, Leonardo de Sousa et al. Autoestima, insatisfação corporal e internalização do ideal de magreza influenciam os comportamentos de risco para transtornos alimentares?. Revista de Nutrição, v. 28, n. 3, p. 253-264, 2015.

FORTES, Leonardo de Sousa et al.Modelo etiológico dos comportamentos alimentares desordenados em adolescentes brasileiras. Cadernos de Saúde Pública, v. 32, 2016.

GARNER, Olmsted, Bohr, \&Garfinkel, 1982; Lee et al., 2002; Mintz \&O'Halloran, 2000 The EatingAttitudes Test (EAT-26).

GOMES, Ana Paula Fernandes et al. Fatores antropométricos relacionados à insatisfação com a imagem corporal em adolescentes. Revista Baiana de Saúde Pública, v. 42, n. 3, 2018.

JUSTINO, Maraísa IC; ENES, Carla Cristina; NUCCI, Luciana Bertoldi. Imagem corporal autopercebida e satisfação corporal de adolescentes. Revista Brasileira de Saúde Materno Infantil, v. 20, n. 3, p. 715-724, 2020.

KESSLER, Amanda Luisa; POLL, Fabiana Assmann. Relação entre imagem corporal, atitudes frente aos transtornos alimentares e estado nutricional em universitários da área da saúde. Jornal Brasileiro de Psiquiatria, v. 67, n. 2, p. 118-125, 2018. 
LEAL, G. V., Tucunduva, P. S., Ozores, P. V., Athanássios, C. T., \& Santos, A. M. (2013). O que é comportamento de risco para transtornos alimentares em adolescentes?. Jornal Brasileiro de Psiquiatria, 62(1), 62-75. http://dx.doi.org/10.1590/ S0047-20852013000100009.

LEONIDAS, Carolina; SANTOS, Manoel Antônio dos. Percepção do Apoio Social e Configuração Sintomática na Anorexia Nervosa. Psicologia: Ciência e Profissão, v. 40, 2020.

PEREIRA, Ellen Rodrigues Monteiro; DA SILVA COSTA, Matheus Nicolas; DE ANDRADE AOYAMA, Elisângela. ANOREXIA E BULIMIA NERVOSA COMO RANSTORNOS ALIMENTARES NAAD 2020.

LESCÊNCIA. Revista Brasileira Interdisciplinar de Saúde, PINHO, Lucinéia de et al. Percepção da imagem corporal e estado nutricional em adolescentes de escolas públicas. Revista Brasileira de Enfermagem, v. 72, p. 229-235, 2019.

POLTRONIERI, Taiara Scopel et al. Insatisfação com a imagem corporal e fatores associados em mulheres do sul do Brasil. Ciência \& Saúde, v. 9, n. 3, p. 128134, 2016.

RENTZ-FERNANDES, Aline R. et al. Autoestima, imagem corporal e epressão de adolescentes em diferentes estados nutricionais. Revista de salud pública, v. 19, p. 66-72, 2017.

RIBEIRO, Karla Carolina Silveira et al. A (in) satisfação com o corpo e a vulnerabilidade aos transtornos alimentares em adolescentes. Cad Ed Tec Soc, v. 9, n. 2, p. 194-203, 2016.

RIBEIRO, Karla et al. Vulnerabilidade aos Transtornos Alimentares em Adolescentes: fatores que afetam à satisfação com o corpo. CIAIQ2015, v. 1, 2015.

ROCHA, Giulia Alves Filippozzi et al. Prevalência e fatores associados a Bulimia ou Anorexia Nervosa em universitárias da área de saúde. BrazilianJournalofDevelopment, v. 6, n. 11, p. 90174-90198, 2020.

SANTOS, Natália Fernandes Henrique. Bulimia em adolescentes praticantes de atividade física. Research, Society andDevelopment, v. 10, n. 6, p. e29110615874-e29110615874, 2021. 
SILVA, Paola Frassinette de Oliveira Albuquerque et al. Intervenção nutricional em adolescente com anorexia nervosa e componente bulímico: relato de caso. Nutrición Clínica Y Dietética Hospitalaria. Pernambuco, v. 38, n. 3, p. 56-60, 2018.

TEIXEIRA, Carla Somaio et al. Transtornos alimentares em adolescent s de uma escola estadual do noroeste paulista. Arquivos de Ciências da Saúde, v. 22, n. 2 , p. 84-87, 2015.

UCHÔA, Francisco Nataniel Macêdo et al. Causas e implicações da imagem corporal em adolescentes: um estudo de revisão. Cinergis, v. 16, n. 4, 2015.

UZUNIAN, Laura Giron; VITALLE, Maria Sylvia de Souza. Habilidades sociais: fator de proteção contra transtornos alimentares em adolescentes. Ciência \& Saúde Coletiva, v. 20, p. 3495-3508, 2015.

XIMENES, Rosana Christine Cavalcanti et al. Versiónbrasileña de lo BITE para su uso en adolescentes. Arquivos Brasileiros de Psicologia, v. 63, n. 1, p. 52-63, 2011. 
doi $10.48209 / 978-65-89949-7 / 2-9$

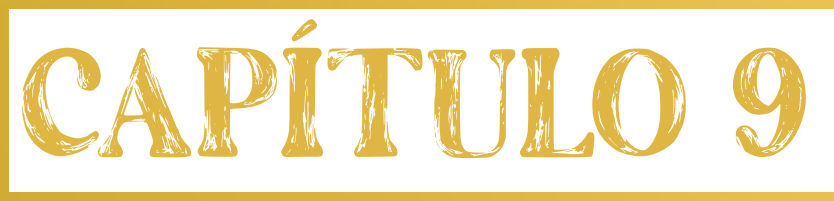

O USO DOS

NUHRICOSMIFHICOS NO IHRATHMIENHO

PARA IONGEVIDADE

Elaine de Jesus Oliveira

Simone da Silva Rodrigues Vivian Silva Borges 


\section{INTRODUÇÃO}

Visto que a beleza é cada vez mais associada ao padrão atual, mulheres procuram constantemente aperfeiçoar a aparência em busca da autoimagem (GONÇALVES, 2017).

Em um mundo em que todos querem envelhecer na idade e não na aparência as clínicas de estética e cosmética atinge a demanda facilmente. Cada vez mais o mercado cosmetodológico juntamente com a parte nutricional elevam os estudos para que a beleza esteja associada com a saúde, uma vez que estudos apontam que as substâncias ingeridas têm o poder de absorção melhor do que as tópicas. Devido o envelhecimento ser um processo natural muitas vezes pode estar também relacionado ao estilo de vida, levando muitas pessoas também desenvolvem problemas psicológicos, sociais e comportamentais por conta da estética, os cuidados diários são considerados medidas preventivas para amenizar os danos causados pela idade cronológica e forma de estilo de vida. Sendo de grande relevância para a ciência, uma vez que existem poucos estudos comprovados nessa área a busca por comprovações é primordial para que os nutricosméticos tenham sua classe subdividida (ZANETI; SPECK; MEDEIROS, 2019).

O organismo com o passar dos anos tende a reduzir a produção de substâncias essenciais como, por exemplo, substâncias que mantem a sustentação das células e dos tecidos como colágeno, elastina e proteínas (MARQUES; SANTOS, 2013).

São elas que deixam a pele com aspecto firme, um viço saudável e jovial. Já quando há falta desses componentes, ao analisar os aspectos ficam envelhecidos e desnutridos, aparentemente nota-se falta de cuidados que muitas vezes cosméticos tópicos não alcançam os lugares de mais necessidades, e precisam de um tratamento de dentro pra fora. Os nutricosméticos chamados por muitos pesquisadores como "Pílula da Beleza" surgiu com o propósito de nutrir o corpo 
com minerais e vitaminas que auxiliam no rejuvenescimento cutâneo (SANTOS, 2019).

Mas a dúvida surge entre muitos com a ênfase de: Qual a melhor idade para começar a suplementação? Assim como: Quais substâncias auxiliam para o fator de rejuvenescimento?

São dúvidas que atinge milhares de mulheres que buscam melhorias através da ingestão, levando-as a cometer alguns erros que influenciam os resultados e não obtém o resultado desejado, é preciso muita cautela ao manipular as vitaminas e minerais com as substâncias que o corpo realmente necessita, fazendo-o trabalhar de forma vantajosa e refletindo do meio interno para o meio externo.

\section{REFERENCIAL TEÓRICO}

\subsection{Componentes de sustentação}

Formado por osteoblastos, osteoclastos e osteócitos (NOGUEIRA et al., 2021). Entre a primeira e segunda década de vida o corpo está em constante crescimento da massa óssea, após a segunda década de vida a perda é progressiva, incluindo vários meios que podem influenciar também essa perda, como: medicamentos, patologias, peso, fototipo, fraturas. Embora a perda de massa óssea cause patologias mais agravantes em idosos, os cuidados devem começar bem antes desse tempo, os estímulos devem começar na infância e adolescência controlando os meios prejudiciais para o declínio dos componentes dos ossos (LINARD et al., 2020). Durante o processo de envelhecimento e notável a osteopenia e fragilidade da massa óssea, por volta dos 35 anos (VARGAS et al., 2020).

Outro importante componente de sustentação é o musculo estriado, composto por fibras em feixes tipo I e tipo II que dão sustentação e movimento 
para o corpo, nos músculos estão presentes tecido conjuntivo responsável por: fornecer suporte estrutural serve de meio para troca dos eletrólitos e água, ajuda na defesa e proteção. O tecido conjuntivo está presente fibras colágenas, composição responsável por dar resistência a trações envolvendo o tecido e dando sustentação (RAMÍREZ, 2018). O colágeno enquadra um papel primordial para a estruturação das fibras fazendo com que as mantem alinhadas e realizam a contração (BERNARDO; SANTOS; SILVA, 2019).

Outra estrutura que faz a sustentação é o tecido adiposo que teve seu conceito mudado desde 1994, a função dela foi amplamente estudada e documentada que além de reserva calórica, termorreguladora e de sustentação ele é crucial na função endócrina, e na homeostase energética que também é dependente dele (RAPOSO, 2020).

Existem as cartilagens que é um grande favorecedor contra o envelhecimento conhecido como colágeno, uma potente proteína de origem animal, de grande abundância no organismo, as cartilagens são é encontrada nos ossos, pele, músculos e entre outras partes do corpo, com função estrutural. Constituído de uma cadeia peptídica contorcida entre presentes aminoácidos glicina, prolina e hidoxiprolina, esses componentes ajudam na resistência e elasticidade na estrutura onde se encontram. Existem vários tipos de colágeno, mais precisamente o de maior importância na integridade da pele é do tipo 1 e 3 (FERREIRA-SILVA; ALVES; MORAES, 2018).

A pele é considerada o maior órgão do sistema, aproximadamente $16 \%$ do peso corporal. Tem sua função de isolante térmico, entre o meio interno e externo, possui três camadas na constituição sendo elas: epiderme camada mais externa, é avascular e contém células epiteliais sobrepostas. (BERNADO; SANTOS; SILVA, 2019).

Na epiderme há estratificação em cinco camadas, sendo elas: camada córnea a mais superficial, camada lúcida, camada granulosa, camada espinhosa e camada germinativa ou basal. Na epiderme existe presença de queratinócitos 
Bacharelado em Nutrição da UninCor e iniciação à pesquisa: Com a palavra os nossos estudantes

que fazem a sintetização da queratina, uma proteína que da firmeza a pele garantindo permeabilidade seletiva e proteção contra os agentes externos. Encontram-se também os melanócitos responsáveis na sintetização da melanina, pigmento que protege o organismo contra os raios ultravioleta, além das células de Langherans células que ativam o sistema autoimune; estão presentes também entre a epiderme e a derme as células de Merkel receptores de toque e pressão (BERNARDO; SANTOS; SILVA, 2019).

A derme (figura 1) é composta por tecido conjuntivo, irregulares e denso são ricamente vascularizadas, possuem terminações nervosas, folículos pilos sebáceos. A derme também possui extensas fibras de colágeno e elastina com propriedade promover a sustentação e elasticidade (BERNARDO; SANTOS; SILVA, 2019).

Hipoderme é a última do tegumento, estão presentes adipócitos e é considerado em muitas literaturas como órgão endócrino, é um reservatório energético, protetor contra impactos e choques, faz parte dos componentes de sustentação e modelagem, além de ser termorregulador dos órgãos vitais como músculos lisos, estriado e cardíaco (BERNARDO; SANTOS; SILVA, 2019).

A pele ao longo dos anos passa por modificações, desde o embrião até a morte e possui ligação direta com o sistema nervoso central (SNC) através de células nervosas sendo mensageiro de um sistema para com o outro (BERNARDO; SANTOS; SILVA, 2019).

Os fatores que são agravantes no envelhecimento fazem com que as mudanças acontecem e acentuem o processo prejudicando a formação de fibroblastos, deixando a pele fica com aspecto mais fina, o transporte hídrico é prejudicada, a permanência de ácido hialurônico começa com irregularidade, a oxigenação tecidual é comprometida e o glicogênio tende-se a diminuir sua formação. A pele na infância é uma pele em formação, com pouca maturidade mais sensível, já com o passar dos anos os processos fisiológicos sofrem alterações devidas a processos hormonais, principalmente na fase da puberdade. Seguindo 
os parâmetros etários, mesmo com o sistema imunológico elevado na fase adulta a resistência dos componentes de sustentação é rígida e madura, porém há um declínio na produção devido a divisão mitótica e o surgimento dos processos de envelhecimento (BERNADO; SANTOS; SILVA, 2019).

Conforme Bernardo, Santos e Silva (2019, p. 1228):

\begin{abstract}
Diante desses fatores a pele idosa apresenta alterações que serão descritas a seguir: A vascularização da pele idosa tem uma redução de $60 \%$, assim, diminuindo o fator de crescimento endotelial, sua espessura é de $65 \%$ a $70 \%$ da espessura da pele de um adulto, decorrente do apoptose abaixo da camada granulosa e diminuição da superfície derme papilar. Na derme ocorre diminuição de $10 \%$ a $20 \%$ no número ativo de melanócitos a cada década, deixando essa pele mais suscetível (PELE: ALTERAÇÕES ANATÔMICAS E FISIOLÓGICAS DO NASCIMENTO À MATURIDADE).
\end{abstract}

Figura 1 - Corte transversal da pele onde a derme representa o tom mais claro.

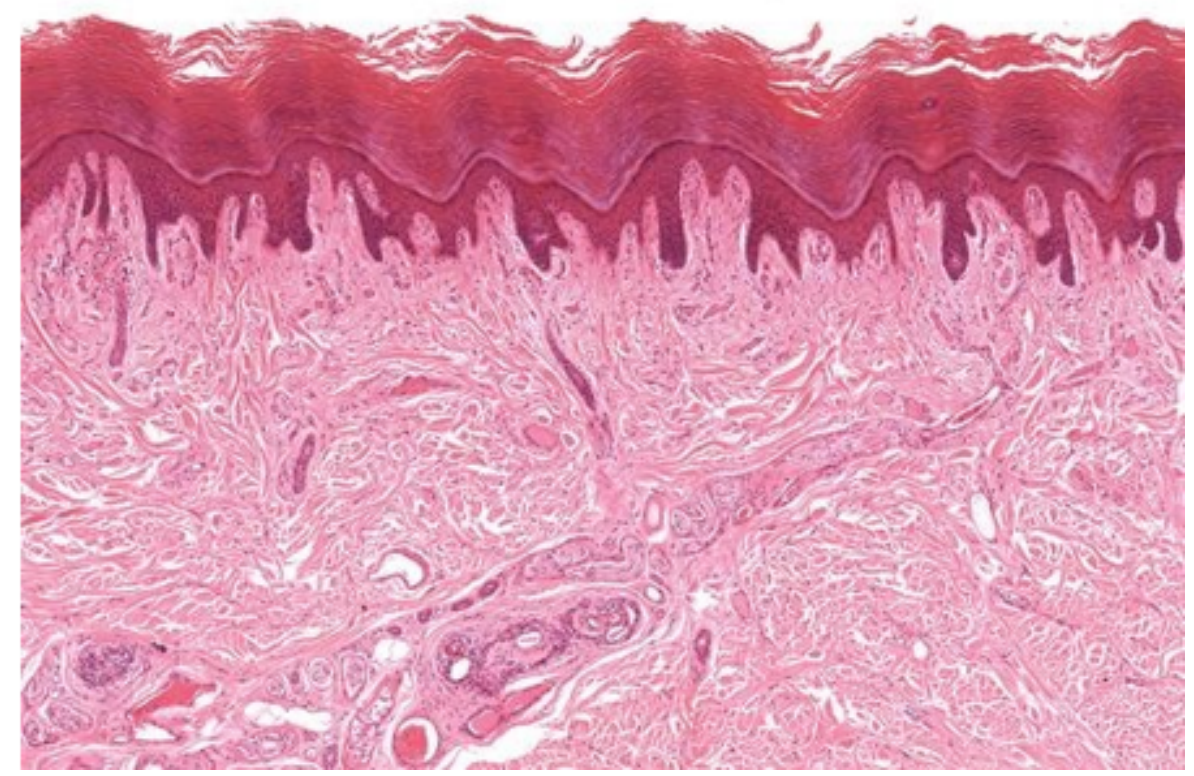

Fonte:www.todamateria.com

\title{
2.2 Envelhecimento
}

A pele é a "interface social" entre um indivíduo e o meio em que vive o fato de envelhecer está associada a fatores multifatoriais como sendo intrínsecos (modificações químicas, hormonais, celular e genética) e extrínsecos (estilo de 
Bacharelado em Nutrição da UninCor e iniciação à pesquisa: Com a palavra os nossos estudantes

vida, patologias, exposições entre outros). O dito envelhecer é cronologicamente variável de indivíduo para indivíduo, contudo depois da $3^{a}$ década o corpo não produz as substâncias com o mesmo pico que produzia anos anteriores, visto que a aparência externa apresenta modificações que indica a regressão cronológica cutânea, e as alterações celulares começam a sofrer o declínio. Já internamente o metabolismo já não tem a mesma velocidade para produção. É notável a perda de elasticidade, a diminuição das trocas aquosas, o aumento da rigidez, perante esses fatores é o que levam as pessoas a buscar melhora dos sinais de envelhecimento. Perante os sinais de envelhecimento que caracterizam na pele como linhas de expressão e rugas (MARQUES; SANTOS, 2013).

Adicionamos outros sinais visíveis como flacidez, lesões teciduais, alterações pigmentares notáveis na epiderme (AZEVEDO, 2018).

Os sinais de envelhecimento como linhas de expressão e rugas são consequências fisiológicas da perda da função do tecido conjuntivo e degradação do colágeno, diminuição da elasticidade das fibras, redução hídrica entre outros processos que leva o tecido a desestruturar. As rugas ou linhas de expressão são sulcos ou ditos pregas do estrato superficial e falta de hidratação das demais profundidades que origina no decorrer da $3^{a}$ idade. Por falta das substâncias essenciais o tecido conjuntivo faz com que as camadas adipócitos não se mantem uniformes assim degradando as fibras elásticas, contudo prejudicando as trocas de oxidação. Dependendo do nível e local denomina-se rugas profundas e superficiais. Além dessa denominação elas também são classificadas em estáticas, dinâmicas e gravitacionais. Distinguindo como, as que surgem através da fadiga estrutural são nomeadas como estática, as dinâmicas surgem a partir dos movimentos repetitivos constantes em expressão facial (SILVA, 2017).

As rugas gravitacionais são devido a uma flacidez cutânea em associação a ptose estrutural. Ambas as flacidez iniciam se gradualmente com a ausência de tecidos estrutural como as fibras musculares, transformando o tegumento seco, delgado, enrugado e sem brilho (DUTRA; ASSIS; MACHADO, 2021). 
Figura 2 - Envelhecimento cutâneo

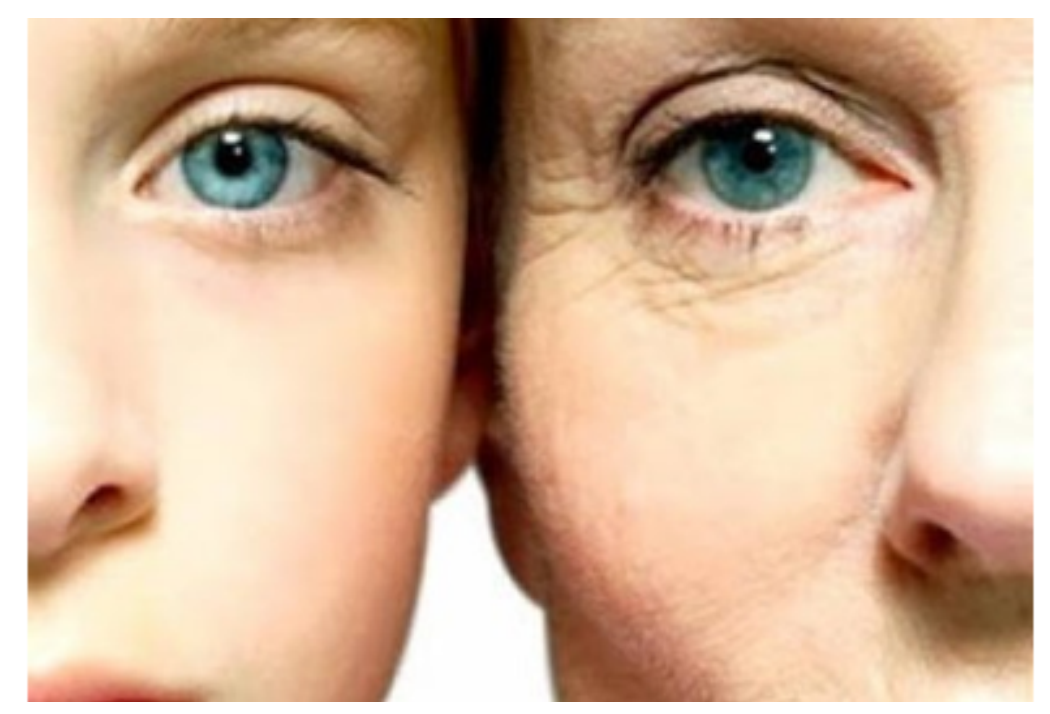

Fonte: http://clinicaesportivajaneteneves.blogspot.com/2012/08/envelhecimento-cutaneo.html

Durante o processo de envelhecimento e notável a osteopenia e fragilidade da massa óssea, por volta dos 35 anos (VARGAS et al., 2020), em um estudo feito por relatou que a sarcopénia e elasticidade dos tendões e ligamentos sofrem também um declínio assim como, a viscosidade e os líquidos sinoviais, já o tecido adiposo é aumentado, devido a diminuição da massa magra a proporção em mulheres é maior $(1,7 \%)$ em relação aos homens (1,5\%) (FECHINE; TROMPIERI, 2015).

\subsection{Radicais livres}

Primeiro relato dos radicais livres no processo de envelhecimento cutâneo originou-se através de estudos por um médico norte americano DR. Denham Herman em 1956, onde enfatizou que o envelhecimento seria resposta de danos causados nas células pelo excesso de radicais livres, Produzindo efeitos maléficos no interior do tecido danificando moléculas de no citoplasma, nas mitocôndrias, e nas membranas principalmente de proteínas, lipídicas, e de carboidratos inclusive na desestruturação do DNA (IMBROINISE, 2018).

Ao ser produzido de forma homeostática os radicais livres dão suporte na defesa metabólica com efeito bactericida, porém quando há um descontrole entre 
os compostos antioxidantes e oxidantes em virtude aos radicais livres ocorre um fenômeno chamado de estresse oxidativo, esse fenômeno ocorre gerando danos celulares voltados ao fator de envelhecimento (GOMES et al., 2020).

\subsection{Nutricosméticos}

São apresentações dos nutricosméticos ingeridos como: cápsulas, líquidos e alimentos. Compostos por vitaminas, minerais e antioxidantes que auxiliam a complementação alimentar. Chamado também de "pílula da beleza" por muitos estudiosos tem como objetivo tratar a saúde sem deixar de lado a estética. Ao ver da população apenas produtos tópicos auxiliam para o rejuvenescimento, contudo esse método veio para aprimorar ambas as partes pensando sempre em manter o sistema interno saudável para beneficiar o sistema externo. Sendo enquadrada no termo de suplemento alimentar pela Agência Nacional de Vigilância Sanitária (ANVISA) os estudos recorrentes para a classificação vem crescendo do decorrer da década (SANTOS, 2019).

Sua composição é de bioativos antioxidantes, com propriedade antiinflamatória, antiglicante entre outros componentes que beneficia o organismo como um todo, atuando em partes primordiais como: cabelos, unhas, e pele atuando de maneira sistêmica (SANTOS, 2019).

Com o enfoque voltado para o rejuvenescimento e longevidade as principais composições são à base de luteína e selênio. São alguns exemplos de composições que está presente nos nutricosméticos (SALVADOR; CECHINELZANCHETT, 2019).

Apresentando em sua classe molecular como C40H56O2, a luteína possui características singulares como o seu pigmento com coloração que é distinguida através das cores amarelo alaranjadas, sendo um dos 600 carotenoides, diferenciando dos demais por possuir dois grupos de hidroxilas. São encontrados em grande parte dos alimentos como: folhas verdes, frutos e algumas flores. 
Bacharelado em Nutrição da UninCor e iniciação à pesquisa: Com a palavra os nossos estudantes

Em algumas matrizes são encontradas em forma de éster de ácidos graxos, consequentemente é necessário passar por algumas etapas de extração através de solvente orgânico ou por CO2 (dióxido de carbono) até chegar à forma livre (SILVA, 2017).

A Luteína conhecida popularmente faz parte dos antioxidantes, também tem a função de filtrar os danos induzidos por radiações da luz azul e ultravioleta (UV), como também previne a degeneração molecular com ênfase no envelhecimento (FERRREIRA-SILVA; ALVES; MORAES, 2017).

Sendo assim a luteína tem capacidade de atenuar na energia dos radicais livres, fatores tão prejudiciais à saúde, no entanto, a luteína capacita no organismo o poder de proteção atuando nas moléculas de lipídeos, assim como nas moléculas proteicas entre outros componentes de baixa densidade. Através da alimentação é notório que boa parte de sua concentração é encontrada nos alimentos de folhas verdes (STRINGHETA et al., 2006), como a couve, espinafre, repolho entre outras verduras. Presente também em legumes frutas e flores de coloração amarela e laranja (SILVA, 2017).

Estudos apontam que indivíduos que fazem uso da luteína, seu organismo apresentou redução da radiação UVA (Ultravioleta A) e UVB (Ultravioleta B), comprovando que a luteína $10 \mathrm{mg}$ ingerida por indivíduos apresentou fator de proteção contra a radiação solar (BATISTA et al., 2020).

Também é conhecida por outras fontes benéficas a saúde dos olhos, possui propriedades anti-inflamatórias, auxilia na diminuição de danos no fígado e intestino, previne a degradação do DNA e doenças cardiovasculares (SILVA, 2017).

Segundo a $A B C$ Pharmus as indicações da luteína 10mg age a prevenção da degeneração macular relacionada à idade, antioxidante, como também mantem a saúde dos olhos e prevenção de patologias oculares como glaucoma e 
Bacharelado em Nutrição da UninCor e iniciação à pesquisa: Com a palavra os nossos estudantes

cataratas. Em cada capsula composta por luteína 10mg, a melhor maneira usar é uma capsula diariamente por via oral, não apresenta efeitos colaterais resultando nenhum registro de interações medicamentosas. O uso deve ser prescrito através de um profissional habilitado como documenta a empresa.

Já o selênio pertence ao conjunto de proteínas (selenoproteínas) agem diretamente nas membranas celulares formando um bloqueio contra danos presentes caudados pelos radicais livres. A ingestão de selênio é composta nos nutricosméticos com objetivo de prevenção do envelhecimento, garante níveis nutricionais, atenuando também no stress oxidativo como forma antioxidante (NOBREGA, 2015).

Os antioxidantes podem ser de origem endógena que o próprio organismo produz ou exógena que adquirimos através de alimentação e suplementação. Contudo eles são classificados como enzimáticos que contribui na defesa do organismo e não enzimáticos através de consumo de carotenoides. Um antioxidante muito usado em estudos é o licopeno, por agir no combate contra o envelhecimento, sendo de alto índice no valor da terapia, contudo evidências apontam para o uso consciente da substância (AZEVEDO, 2018).

Porém dentre os principais oxidantes encontramos a vitamina C, vitamina E, carotenoides, licopeno e selênio, o organismo não tem meios de sintetização desses alimentos, pois a fonte vem da alimentação e suplementação, podendo ser ingeridos pequenas quantidades diariamente. Os componentes já presentes na pele existem como exemplo os ácidos Hialurônico. Existem estudos que relata também a importância de vitaminas para o funcionamento do metabolismo humano, como a manutenção estrutural (ZANETI; SPECK; MEDEIROS, 2019).

O colágeno Hidrolisado vem usado na forma de suplementação oral com o intuito de barrar os sinais do envelhecimento cutâneo. Mesmo assim existem poucos estudos comprovados cientificamente e publicações voltadas a esse 
Bacharelado em Nutrição da UninCor e iniciação à pesquisa: Com a palavra os nossos estudantes

conceito, o que coloca em dúvida o seu real efeito. Porém esse tema volta a ser discutido após a expansão da tecnologia que possibilitaram realizar o isolamento de peptídeos para ingestão via oral, o resultado foi o surgimento de uma nova linha de suplementos à base de colágeno: peptídeos específicos com habilidade de ampliar a expressão de determinadas moléculas relacionadas à produção de colágeno (ADDOR, 2015).

\section{ASPECTOS METODOLÓGICOS}

A pesquisa tratará de uma análise quali-quantitativa que abordará mulheres com idade entre 25-40 anos que começaram a notar ou não os efeitos do envelhecimento. Todas as mulheres que se submeterem para responder e participar dessa pesquisa irão preencher um termo de livre de consentimento, que participará por livre e espontânea vontade, pois a pesquisa será para fins acadêmicos e comprometemos em resguarda-las de exposições e privacidade pessoal. Na pesquisa será abordado sobre as possíveis causas e que levaram a queixa principal que é o envelhecimento cutâneo. Através de um questionário onde faremos perguntas de múltipla escolha buscando os possíveis motivos da disfunção, tais como: alimentação, exposições climáticas e fontes de luzes, atividades físicas, se usam nutricosméticos. Visto que para manter o corpo em homeostasia é preciso aderir alguns cuidados. Será realizado um gráfico que mostrará em porcentagem os resultados. Após a pesquisa será a etapa de realização do experimento com seis mulheres com idade de 30- 40 anos de idade para ingerir um suplemento a base de luteína $10 \mathrm{mg}$ em capsulas um dos elementos abordados no presente trabalho que tem benefícios comprovados cientificamente como fotoprotetor oral atuando nos danos causados por radiações e radicais livres (BATISTA, 2020). Iremos analisar os resultados notórios que irão apresentar no tecido cutâneo. Uma vez que os raios solares e fontes de luz são um dos maiores causadores do envelhecimento. As mulheres que farão 
Bacharelado em Nutrição da UninCor e iniciação à pesquisa: Com a palavra os nossos estudantes

o experimento não serão portadoras de nenhuma doença aguda ou crônica não serão gestantes e lactantes apenas com a disfunção do envelhecimento, iremos colher os dados semanais através de fotografias paras compararmos os resultados notórios macroscopicamente. Não iremos submetê-las ao uso inapropriado sem orientação do profissional capacitado, ou seja, o nutricionista, como também orientações sobre o medicamento assim como: forma de ingestão, dosagem, recomendações, indicações e contra indicações, efeitos colaterais e adversos. Os resultados serão de cunho acadêmico e reservado, apenas os resultados finais comparado com a fotografia inicial. Serão abordados no presente trabalho, fotos faciais apenas do local tecidual sem exposição das características completa da face da modelo, entretanto analisaremos semanalmente a evolução. Das seis mulheres que irão participar do experimento será passado as seguintes orientações: Seguir a rotina diária para que possamos notar os melhores resultados, assim proposto, no entanto após os resultados obtendo melhora iremos norteá-las o melhor caminho. Informaremos também em caso de sensibilidade ou alergia dos componentes presentes na luteína $10 \mathrm{mg}$ interromperem a ingestão imediatamente e nos comunicar, embora não existe contraindicação o uso deverá ser somente para as pessoas com idade de 30-40 anos seguindo os dados da pesquisa, o medicamento não deverá ser mastigado, é necessária a água para ajudar na ingestão.

\section{RESULTADOS E DISCUSSÃO}

Segundo os autores Bernardo, Santos e Silva (2019), a pele passa por diversas transformações com o passar dos anos, devido a fatores fisiológicos e parâmetros etários.

Das 42 mulheres responderam o questionário online e foram divididas em faixa etária de 25-30 anos (45,2\%), 30-40 anos (38,1\%), 40-50 anos (9,5\%), acima de 50 anos $(7,1 \%)$. Como mostra no gráfico 1 . 
Gráfico 1- apresentando as mulheres divididas em faixa etária.

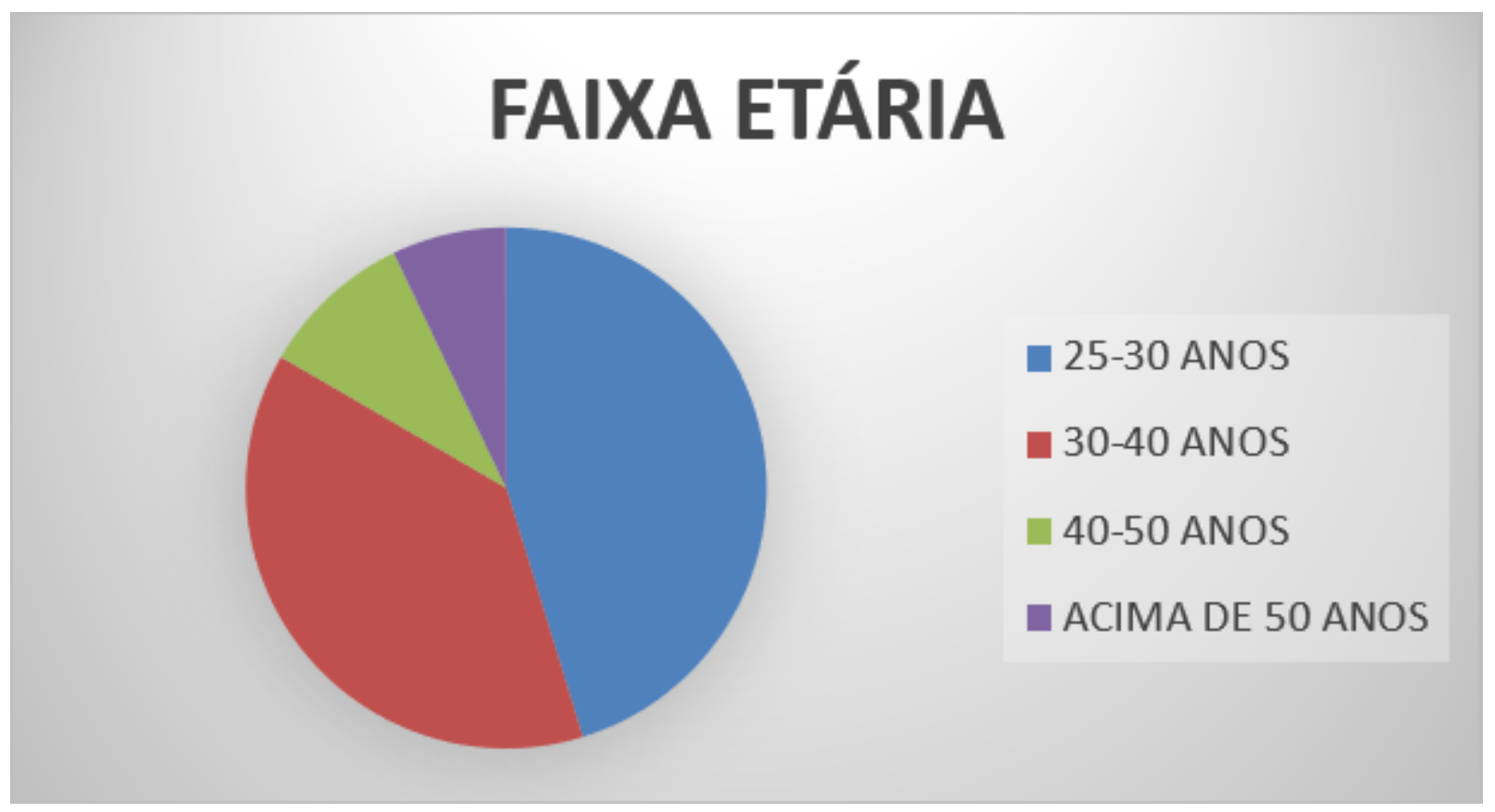

Fonte: Criado pelo pesquisador

Araújo, Bertolini e Junior (2014), relatou que os músculos também sentam os efeitos do envelhecimento. Contudo a pratica de atividade física faz com que os músculos se hipertrofiam e aumentam a massa magra resultando em aumentar o tecido de sustentação.

Foi pesquisado sobre o total dessas mulheres que fazem atividade física e qual encontra-se sedentária. Indivíduos que praticam atividade física regulares se beneficiam para um envelhecimento saudável capacitando-as em flexibilidade, coordenação motora, potência e velocidade. Já o sedentarismo tende-se a ter perda de força física, aumento reserva calórica, Lipodistrofia localizada, e aparecimento de patologias (ROLIM; SILVA; MACHADO, 2020). Sendo 61,90\% praticantes e 38,1\% consideradas sedentárias como mostra no gráfico 2 . 
Gráfico 2- Mulheres que praticam atividade física.

\section{PRATICANTES DE ATIVIDADE FISICAS}

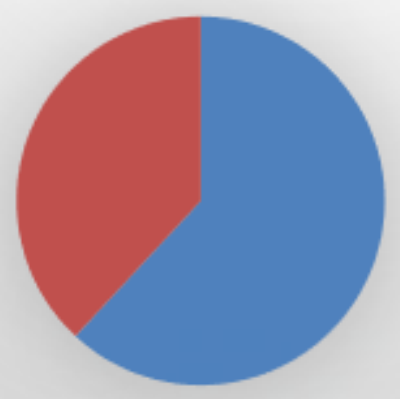

Fonte: Criado pelo pesquisador

Sabe-se que a radiação solar é uma das maiores causas de envelhecimento e muitas pessoas não se protegem ao ficar expostas as radiações UVA e UVB, nem com protetor solar tópico, nem com protetor solar oral, dados mostram na pesquisa que $54,8 \%$ se expõe as vezes no sol, $33,3 \%$ não ficam expostas e $11,9 \%$ se expõe com mais frequência como mostra no gráfico 3.

Gráfico 3- Total de mulheres que ficam expostas no sol.

\section{EXPOSIÇÃO SOLAR}

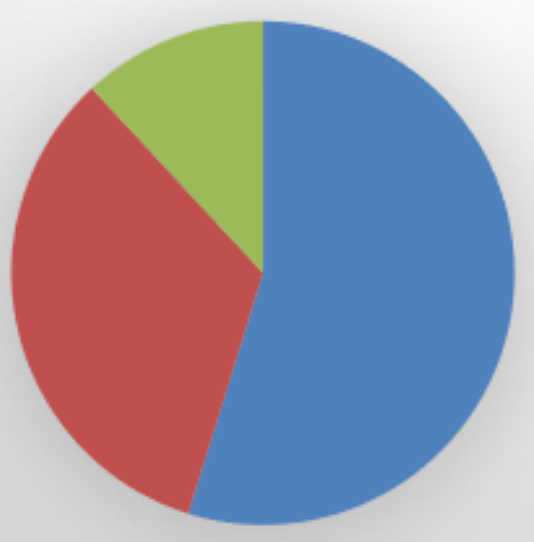

AS VEZES

— NÃO

- SIM

Fonte: Criado pelo pesquisador 
O envelhecimento é uma queixa muito grande entre as mulheres quando frequenta as clinicas de estéticas, e muitas queixam notar os sinais de expressões quando se olham no espelho, isso faz com que a auto estima fica prejudicada, levando-as sofrerem desordem emocionais.

Cada indivíduo possui uma idade social que em alguns em particular difere da idade cronológica, idade documental, fisiológica social, psicológica e emocional (ROLIM; SILVA; MACHADO, 2020). Entretanto os dados da pesquisa apontam que $83,3 \%$ das mulheres notam os sinais de envelhecimento ao se olharem no espelho $16,7 \%$ não notam os sinais de envelhecimento como mostra no gráfico 4 .

Grafico 4- Mulheres que notam sinais e linhas de expressão ao se olharem no espelho.

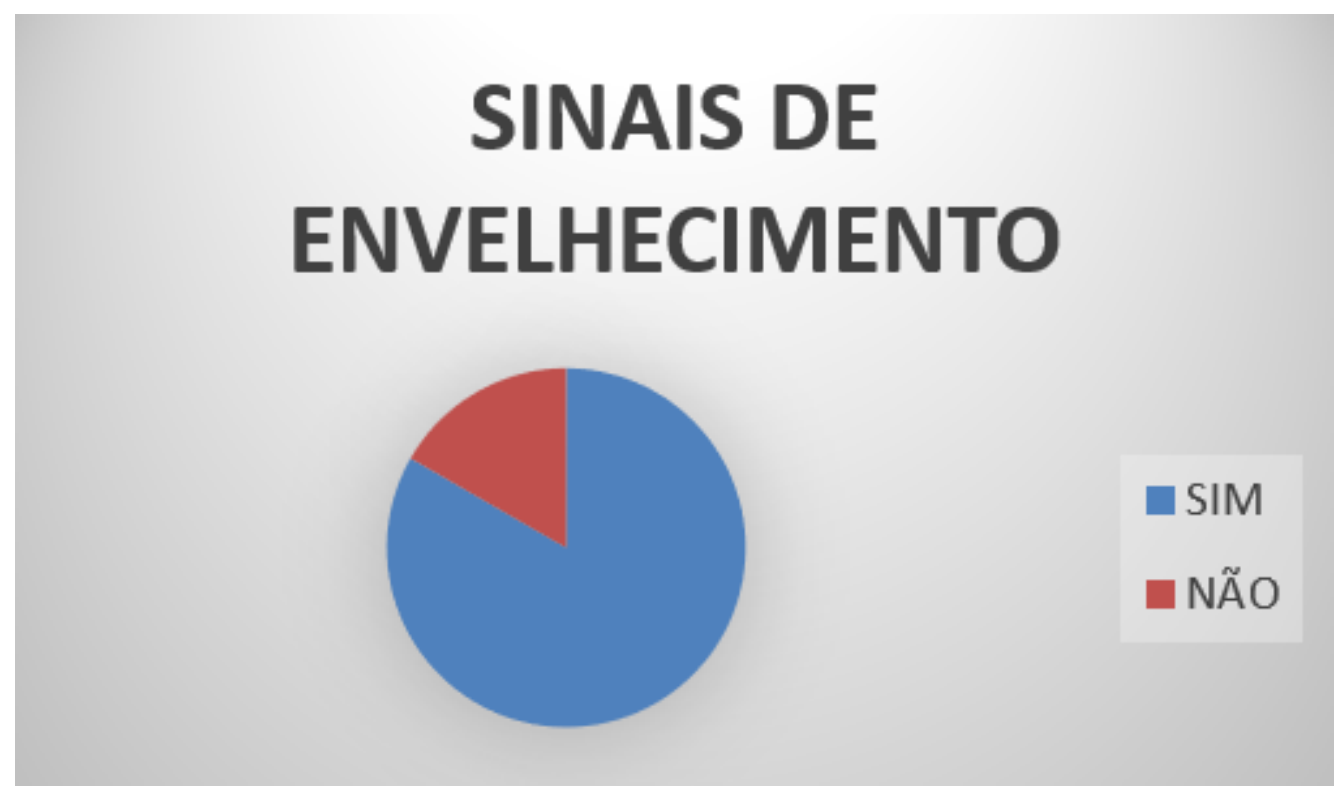

Fonte: Criado pelo pesquisador

O nutricosmético é um bioativo, antioxidante, com propriedades antiinflamatório entre outros benefícios que nutre o metabolismo de dentro pra fora e atua em diversas regiões do organismo (RUIZ, 2014). Na atualidade ouve-se muito esse termo "pílula da beleza", entretanto a pergunta foi quantas mulheres abordadas já fez a ingestão do suplemento alimentar. Visto que da pesquisa foi analisado que $67 \%$ nunca consumiu um nutricosmético, $17,5 \%$ já consumiu anos alguns anos atrás, $12,5 \%$ consome atualmente, e $3 \%$ consumiu no ano de 2020 , como mostra no gráfico 5 . 
Gráfico 5- Sobre o consumo de nutricosméticos.

\section{JÁ TOMARAM NUTRICOSMETICOS}

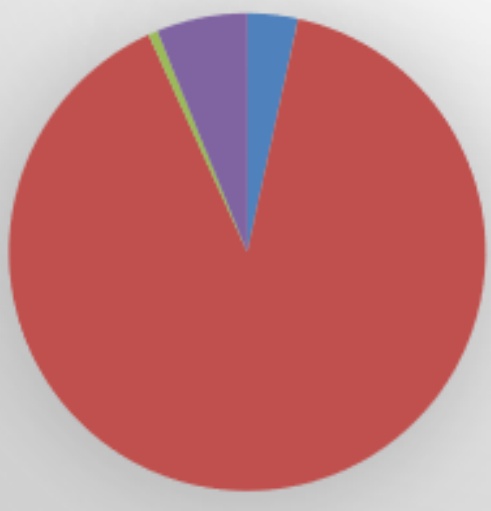

NUNCA CONSUMIRAM

- JÁ CONSUMIRAM EM ANOS ATRAS

- CONSOME ATUALMENTE

Fonte: Criado pelo pesquisador

Visto os benefícios da luteína foi realizado um teste com mulheres na faixa etária de 30-40 anos que já apresenta imperfeições causadas pelo envelhecimento, mulheres que se expõe a radiações e não fazem uso correto do protetor solar, serão analisados semanalmente os efeitos macroscópicos no tegumento.

São seis voluntárias que irão fazer o teste com a luteína $10 \mathrm{mg}$, todas elas apresentam disfunções causadas pelo envelhecimento com linhas de expressões, rugas e manchas pigmentares. Dando início no dia 16 de setembro de 2021 e finalizando dia 16 de novembro de 2021. Das mulheres participantes todas são saudáveis sem patologias agudas ou crônicas.

Após a primeira semana dia 22 de setembro foi observado os efeitos notórios no tecido tegumentar foram: pele com o aspecto mais hidratada e sendo levando em conta o relato das voluntarias a respeito de melhora do viço da pele e clareamento.

Após a segunda semana dia 29 de setembro foi observado os aspectos notórios no tegumento foram: pele com viço, hidratada e nota-se que os sinais de 
expressões já estão com melhora em uma das voluntarias notam-se que houve melhora na região frontal, nasogeniano, e região mandibular além dela citar melhoras nas acnes. Em outra voluntaria nota-se melhora na região orbicular, frontal, clareamento em todas as manchas presentes na face pigmentares.

Após a terceira semana dia 06 de outubro foi observado que a pele das 6 voluntarias continuam com aspectos hidratado, claro e sentindo que os sinais de envelhecimento continuam melhorando.

Após a quarta semana dia 13 de outubro todas as 6 participantes estão satisfeita com a ingestão e notam uma pele mais saudável. Em uma das voluntarias notam-se que nas mãos também ouve clareamento e melhora do viço do tegumento.

Após a quinta semana dia 20 de outubro o estado da pele das participantes continuam apresentando respostas positivas.

Após a sexta semana dia 27 de outubro foi observada que as respostas benéficas continuam nas seis participantes

Após a sétima semana dia 03 de novembro foi observada que a pele continua apresentando melhora nos sinais de envelhecimento.

Após a oitava semana dia 10 de novembro foi observada que a pele continua apresentando melhora nos sinais de envelhecimento.

Após a nona semana dia 16 de novembro foi observado que a pele visivelmente há redução das linhas finas de expressão.

Após o teste realizado nota-se melhora no aspecto do tegumento em relação a primeira e a última fotografia como mostra nas figuras 3 e 4 do início da ingestão da luteína $10 \mathrm{mg}$ em relação após o teste. 
Figura 3- Início da ingestão da luteína 10mg
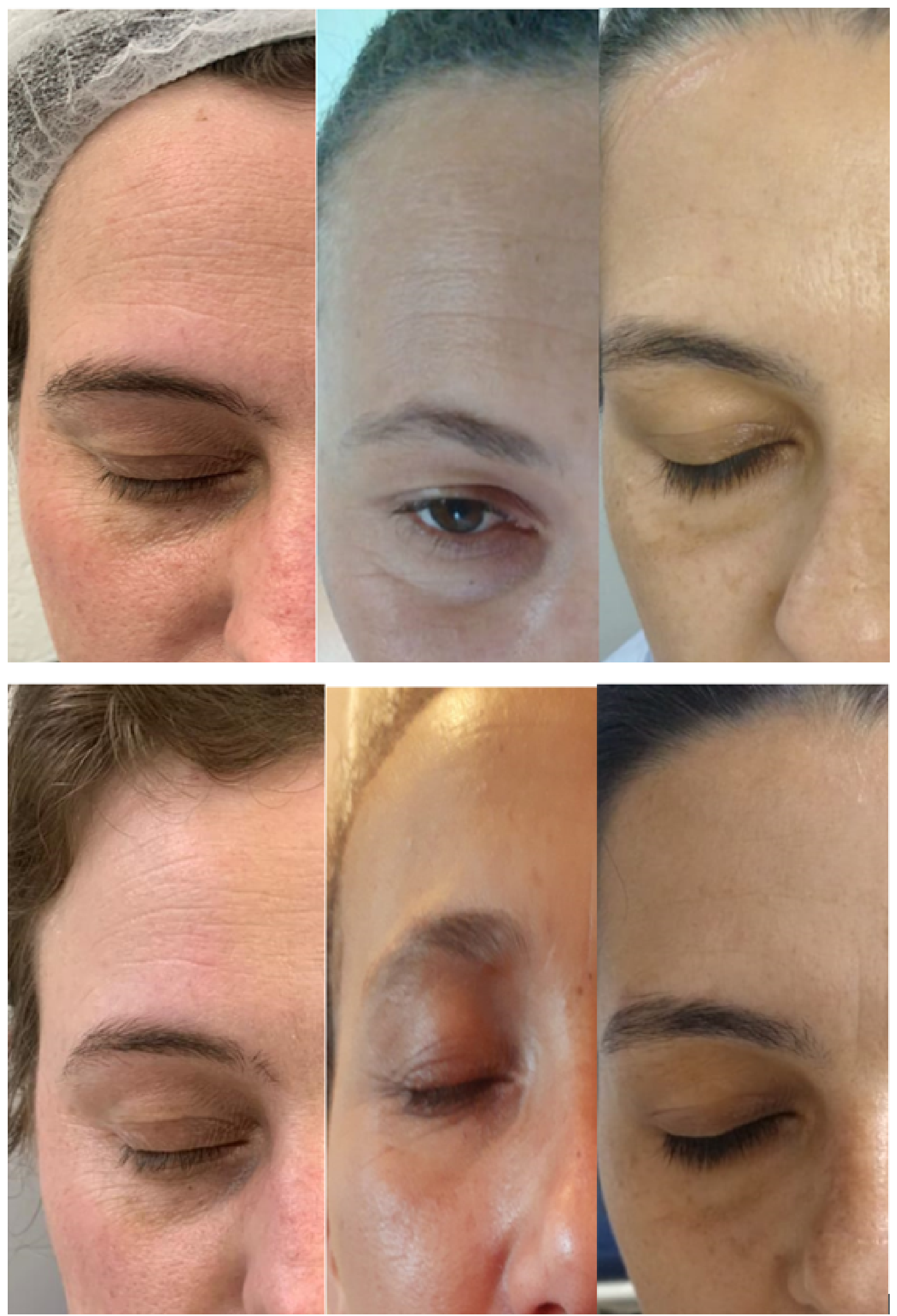

Fonte: Criada pelo pesquisador 
Figura 4- Início da ingestão da luteína 10mg
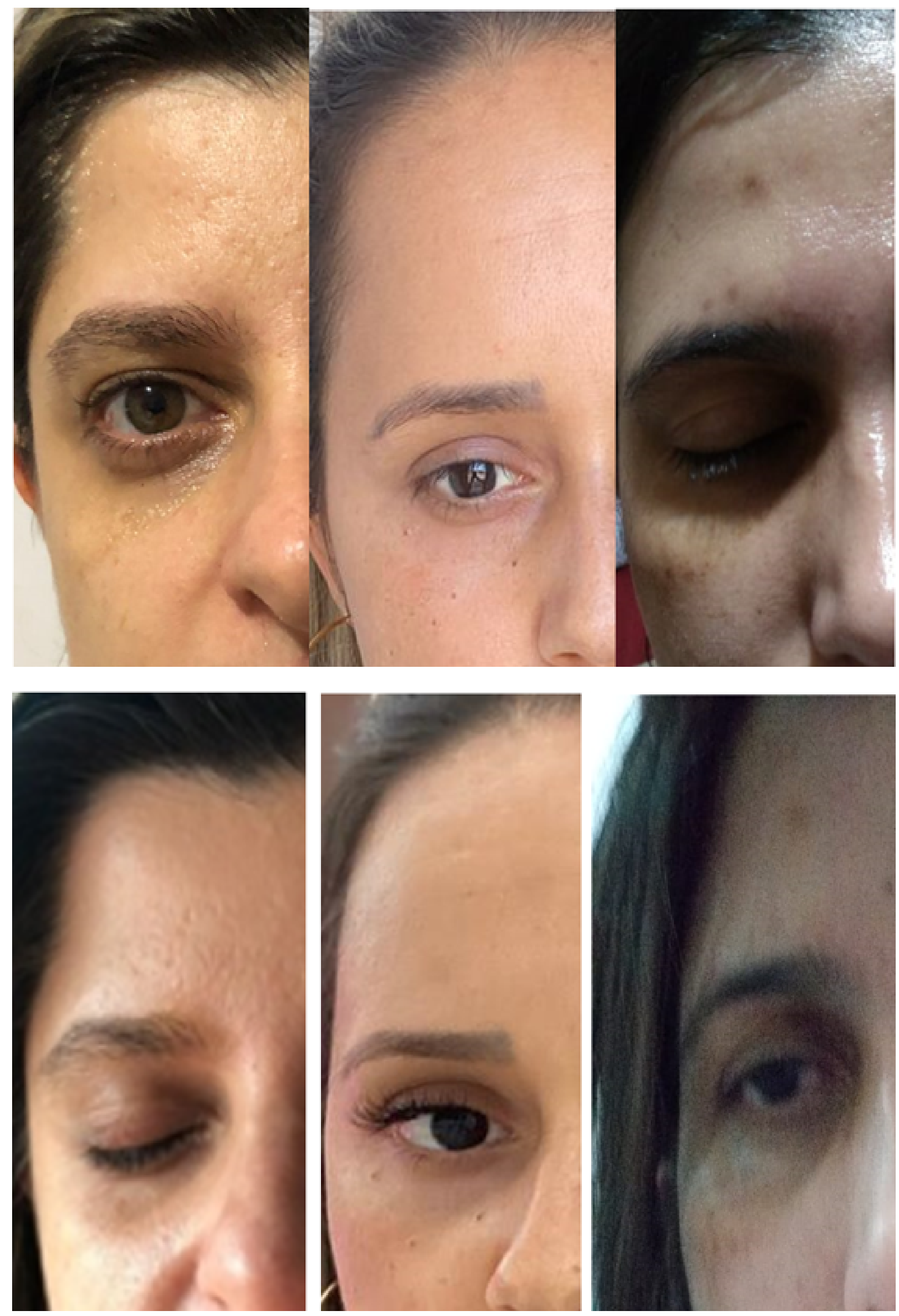

Fonte: Criada pelo pesquisador 
Bacharelado em Nutrição da UninCor e iniciação à pesquisa: Com a palavra os nossos estudantes

\section{CONSIDERAÇÕES FINAIS}

De caráter multidisciplinar esta pesquisa representa grande contribuição para o setor cosmético. $\mathrm{O}$ estudo por meio do experimento das seis voluntaria apresentaram melhora dos sinais de envelhecimento cutâneo macroscopicamente. Acredita-se que é necessário estudos mais profundo onde é necessário avaliar microscopicamente o tecido cutâneo e sua resposta fisiológica. Já a pesquisa por meio do questionário mostra que o numero de mulheres que sofrem com os sinais de envelhecimento pode estar predomina na $3^{\circ}$ década de vida, e que a relação com a exposição solar tem contribuído para esse favor potencializar, mesmo praticando atividade física deixando o corpo ativo, o organismo necessita de nutrientes essenciais para compor um sistema homeostático e contudo favorecer para longevidade.

\section{REFERENCIAS}

SALVADOR, Maitê Mascarello Giotti; CECHINEL-ZANCHETT. Nutricosméticos em desordens estéticas: foco na acne e envelhecimento cutâneo. Disponível em: https://doi.org/10.21270/archi.v8i12.4662 .ARCHIVES OFHEALTH INVESTIGATION 8 (12). Acesso em 29 junho de 2020.

AZEVEDO, Felícia Ferrer. Ação do licopeno no envelhecimento cutâneo e orientação farmacêutica em nutricosméticos: uma revisão., 2018. Disponível em: $<$ http:// dspace.sti.ufcg.edu.br:8080/jspui/bitstream/riufcg/6859/1/FELL\%c3\%8dCIA\%20 FERRER\%20AZEVEDO\%20-\%20TCC\%20FARM\%c3\%81CIA\%202018.pdf>.

BERNARDO, Ana Flavia; SANTOS, Kamilla dos; SILVA, Debora Pereiras da. Pele: alterações anatômicas e fisiológicas do nascimento a maturidade. Revista Saúde em Foco. Itajubá, n. 11, 2019. Disponível em: <https://portal.unisepe.com. br/unifia/wpcontent/uploads/sites/10001/2019/11/PELE-ALTERA\%C3\%87\%C3\%95ESANAT\%C3\%94MICAS-E-FISIOL\%C3\%93GICAS-DO-NASCIMENTO-\%C3\%80- MATURIDADE-1.pdf>. Acesso em: 01 jun. 2021.

SANTOS, Ana Karla Souza. Saúde e estética da pele: O conhecimento sobre alimentos e o uso dos nutricosméticos. Repositório Institucional Faculdade Maria Milza, 2019. Disponível em: http://131,0,244.66:8082/jspui/12356789/1939 Acesso em: 01 jun. 2021. 
Bacharelado em Nutrição da UninCor e iniciação à pesquisa: Com a palavra os nossos estudantes

CONGRESSO INTERNACIONAL DE ENVELHECIMENTO HUMANO, 7., 2021, Campina Grande-PB. Percepção de pacientes sobre o uso de cosmecêutico no processo de envelhecimento. Campina Grande: Realize Editora, 2021. Disponível em: http://www.editorarealize.com.br/editora/ebooks/cieh/2020/TRABALHO_EV136_MD7_SA1 00_ID224_07072020153234.pdf . Acesso em: 01 jun. 2021.

FERREIRA-SILVA, Ellen Crityne; ALVES, Mariana Rocha Sales; MORAES, Ana Maria Junqueira de. Utilização das vitaminas "A", "C", "E" em produtos cosméticos antienvelhecimento de uso oral e tópico. Centro Universitário do Triangulo Mineiro, v.8, n. 1, 2018. Disponível em: <http://computacao.unitri.edu.br/erac/index.php/erac/article/view/1195/899>. Acesso em: 22 mar. 2021.

IMBROINISE, Rebeca Cavalcanti Ribeiro. Avaliação do potencial antioxidante dos extratos e sistemas carreadores a partir de variedades de vitis vanífera. Repositório Institucional UFBA. Universidade Federal da Bahia. Disponível em: https://rpcd.fade.up.pt/_arquivo/artigos_soltos/vol.4_nr.3/2.01_joana_carvalho. pdf . Acesso em: 01 jun. 2021.

NÓBREGA, Patrícia Teixeira. Selênio e a importância para o organismo humano- benefício e controvérsias. Universidade Fernando Pessoa. Porto, novembro 2015. Disponível em: < https://bdigital.ufp.pt/handle/10284/5418?mode=full>. Acesso em 02 jun. 2021.

PEREIRA, Maria de Fatima Lima; MARQUES, Maria Alice et al. Cosmetologia: Nutricosméticos. 1edição. São Caetano do Sul: Difusão editora, agosto 2013.

RAPOSO, Helena Fonseca. Tecido adiposo: suas cores e versatilidade. HU Revista. Campinas, v 46.31268, 2020 Disponível em: https://periódicos.ufjf.br/indexphp/hurevista/article/view/31268/21660 Acesso em: 01 jun. 2021.

FECHINE, Basílio Rommel Almeida; TROMPIERI; Nicolino. O processo de enveIhecimento: As principais alterações que acontecem com o idoso com o passar dos anos.

RUIZ, Bruna Fernanda et al. Nutricosméticos: Um Conceito Inovador. Biblioteca Digital de Periódicos, Curitiba, v. 15, n.2, 2014. Disponível em: https://revistas. ufpr.br/academica/article/view/36722/23392

Acesso em: 01 jun. 2021. 
Bacharelado em Nutrição da UninCor e iniciação à pesquisa: Com a palavra os nossos estudantes

VARGAS, Jefry Alberto; BONATO, Rafaela Carolina Soares; ORENHA, Eliel Soares; SALES- PERES, Silvia Helena de Carvalho. Avaliação do padrão ósseo alveolar em mulheres obesas e não obesas, antes e após a cirurgia bariátrica: um estudo de coorte prospectivo.

SILVA, Marises Costa da. Tratamento das rugas de expressão pela acupuntura facial. Manaus, 2017. Disponível < https://portalbiocursos.com.br/ohs/data/ docs/227/143- Tratamento_das_rugas_de_expressYo_pela_acupuntura_Facial. pdf> Acesso em: 02 jun. 2021.

SPECK, Milena Moreira; ZANETI, Larissa Aparecida; MEDEIROS, Fabiana Durante de. Revisão Sistemática: Nutricosméticos utilizados nos tratamentos das disfunções estéticas, Universidade do Sul de Santa Catarina, 2019. Disponível em: <https://vitalatman.com.br/blog/vitaminas-e-minerais-que-podem-te-deixar-mais-belo-e-commais-saúde/> . Acesso em: 02 jun. 2021.

STRINGHETA, Paulo Cesar; NACHTIGALL, Aline Manke; OLIVEIRA, Tania Toledo de; RAMOS, Afonso Mota; SANT'ANA, Helena Maria Pinheiro; GONÇALVES, Maria Paula Junqueira Conceição. Luteína: Propriedades antioxidantes e benefícios à saúde, Alim. Nutr., Araraquara, v.17, n.2, p.229-238, abr/jun. 2006. Disponível em: https://pt.scribd.com/document/410470743/artigo-luteina Acesso em: 02 jun. 2021.

BATISTA, F. C.; SUZUKI, V. Y.; SANGIULIANO, L. D.; GOMES, H.C.; DE OLIVEIRA FILHO, R. S.; OLIVEIRA, C. R.; FERREIRA, L. M. Alimentos com ação fotoprotetora: Possível prevenção no câncer de pele? Brazilian Journal Of Natural Sciences, v.3, n.1, p.268, 2

020. DOI: 10.31415/bjns.v3i1.87. Disponível em: <http://bjns.com.br/index.php/ BJNS/article/view/87. Acesso em: 2 jun. 2021.

SILVA, Jessica Thais do Prado. Nanoencapsulação de luteína e avaliação in vivo da sua influência sobre a memória. 2017. 62f. Dissertação (mestrado em Tecnologia de Alimentos) - Universidade Tecnológica Federal do Paraná, Campo Mourão, 2017. Disponível http://riut.utfpr.edu.br/jspui/handle/1/2188 Acesso em 02 jun. 2021. 
ANVISA. Justificativas para os limites mínimos e máximos de nutrientes, substâncias bioativas e enzimas da proposta regulatória de suplementos alimentares. Gerencia-Geral de Alimentos, Brasília, janeiro 2018. Disponível em: http:// artigo.anvisa.gov.br/documents/3845226/0/justifictiva_Limites_Suplementos.pdf/ e265ccd0-8361-4d8e-a33f-ce8b2ca69424 Acesso em: 17/05/2021.

ABC PHARMUS MANIPULAÇÕES. Luteína 10mg. São Paulo. Disponível em: < https://www.abcpharmus.com.br/luteina-10mg>. Acesso em: 17/05 2021.

RAMÍREZ; Carolina Quintero. Análise não linear geométrica de músculos esqueléticos via método dos elementos finitos posicional, biomecânica, músculo esquelético. Método dos Elementos Finitos Posicional. Hiperelástico. Disponível em <https://web.set.eesc.usp.br/static/media/producao/2018do_CarolinaQuinteroRamires_kzosk10.pdf.

Gomes Nogueira, I.B.; Moreira da Nóbrega, C.M., Azevedo Ferreira Júnior, J. N., Van den Brule Matos Netto, L.A., de Alencar Tavares Norões, M.E., \& Faustino Cavalcanti, F. (2021). O uso do whey protein no processo de formação óssea pós-fratura. Revista Saúde Coletiva (Baruei), disponível em https://doi. org/10.36489/saudecoletiva.2021 v1li63p5304-5311.

GONÇALVES, Viviane Pacheco. Caracterização do perfil dos clientes atendidos na clínica escola do curso de cosmetologia e estética. Repositório Institucional Unisul. Disponível em: http://www.riuni.unisul.br/handle/12345/2195. 
doi $10.48209 / 978-65-89949-72-A$

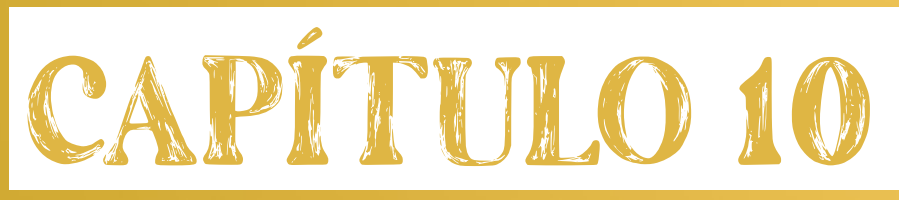

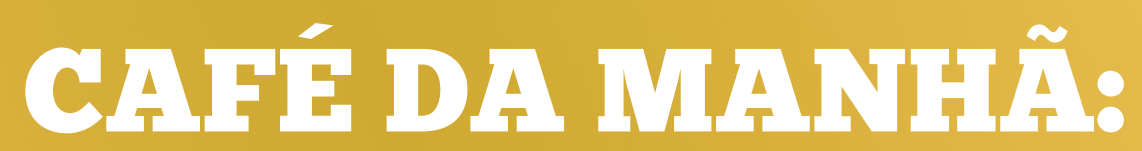
PREVAIHACAIA DO CONSUMO E QUAMTDADE NUTHICIONATI ENHRE ATDOLFSCENHES

Mateus do Carmo e Silva Vivian Silva Borges 


\section{INTRODUÇÃO}

A correria das rotinas diárias e com necessidades de se fazer tudo e resolver tudo às pressas tem moldado os hábitos e comportamentos das pessoas. Os comportamentos e práticas alimentares também são afetados por esse estilo de vida, onde as escolhas dos alimentos tendem a ser a cerca de tudo que é prático e rápido, surgindo o costume também de pular refeições onde a omissão do café da manhã tem se mostrado bastante comum entre as pessoas (TEIXEIRA, HAHN, 2018).

O café da manhã é uma das principais refeições do dia onde seu consumo diário é relacionado a uma escolha alimentar saudável composta por alimentos considerados boas fontes de nutrientes essenciais para nossa alimentação e também com baixas quantidades de energias, sendo dessa forma aliado para uma dieta de qualidade (CECATO, 2015).

Sendo assim, partimos da seguinte questão problema: Qual a prevalência de consumo e qualidade nutricional do café da manhã entre adolescentes da cidade de Monsenhor Paulo - MG? Onde, esperamos responder tal questão com uma hipótese de pesquisa de que grande parte dos jovens entrevistados possuem o hábito de pular o café da manhã e aliado a uma baixa qualidade nutricional na alimentação.

Como objetivo, vamos analisar os padrões de consumo alimentar entre jovens da cidade de Monsenhor Paulo - MG, avaliando os hábitos alimentares e também a qualidade nutricional durante a realização do café da manhã. Serão analisados os alimentos mais consumidos, a prevalência de consumo de leite e derivados e de frutas na realização da refeição, se o consumo de energia e micronutrientes importantes como cálcio e fibra alimentar estão dentro das recomendações necessárias, se possui uma alta prevalência de jovens que costumam omitir a refeição. 
A discussão a respeito desse tema se mostra relevante uma vez que o café da manhã é considerado uma das três principais refeições do dia pelo Guia Alimentar da População Brasileira, onde conciliado com almoço e jantar, deve garantir uma quantidade aproximada das porções diárias recomendadas e nos garantindo assim todo aporte energético e nutricional necessário (MINISTÉRIO DA SAÚDE, 2014).

Mesmo com informações sobre uma alimentação saudável e balanceada estando presente com maior frequência em meio as mídias atuais e chegando com maior facilidade para a população, boa parte das pessoas ainda se distanciam de uma alimentação adequada e saudável quanto as recomendações nutricionais necessárias, principalmente quando se trata da fase da adolescência onde entre as inúmeras características que envolvem as particularidades dessa fase quanto a alimentação, tem - se o ato de omitir refeições, onde o café da manhã é em muitas vezes deixado de lado (FEREIRA; MELO; TORAL, 2019).

Assim, o texto está organizado em quatro sessões sendo elas uma revisão de literatura sobre o tema e assuntos que os norteiam, materiais e métodos trazendo sobre como está sendo realizada a pesquisa, resultados e discussões expondo os resultados após todas as análises do material adquirido na pesquisa de campo e finalizando com as considerações finais do trabalho realizado.

\section{REFERENCIAL TEÓRICO}

\section{Adolescência}

\section{Características da fase e desenvolvimento}

A adolescência é uma fase em que o indivíduo passa por diversas transformações, sendo assim muito importante para o seu desenvolvimento. Alterações físicas, psicológicas e sociais se fazem presentes, fazendo com que seja uma fase repleta de particularidades e determinante para a continuidade da vida (COSTA et al., 2015) 
Sendo a transição para a vida adulta, são expostos durante essa fase diversos saberes, moldando conhecimentos e hábitos que influenciarão diretamente em seu futuro. Um comportamento alimentar adequado durante essa fase é imprescindível, onde as práticas alimentares estarão diretamente ligadas a prevenção de doenças crônicas não transmissíveis, manutenção e promoção à saúde (BARUFALDI et al., 2016)

Se atentar aos hábitos alimentares desenvolvidos e aos alimentos consumidos durante essa fase e também durante a infância torna-se então muito importante visto os benefícios que a alimentação pode acarretar para a vida adulta e também pelo fato de que durante a adolescência são bastante comuns hábitos e práticas não saudáveis como a realização de jejuns e dietas restritivas, podendo trazer malefícios para a saúde (SILVA et al., 2015)

\section{Consumo alimentar}

Atualmente no Brasil, a alta ingestão de alimentos ultraprocessados e alimentos de fácil preparo é uma das características do perfil alimentar dos adolescentes, ao mesmo tempo em que as refeições se encontram carentes de alimentos in natura, ricos em vitaminas e minerais (MAIA et al., 2018).

Diversos estudos nos confirmam tais características, como podemos observar os resultados do Inquérito Nacional de Alimentação (INA) de 2008-2009 e também no Estudo de Riscos Cardiovasculares em Adolescentes (ERICA) de 2013-2014:

Foi observado agravamento da inadequação de nutrientes como cálcio e vitaminas $A$ e $E$, que desempenham papel importante para o crescimento e desenvolvimento adequado do adolescente. Essas inadequações coexistem com a elevada ingestão de nutrientes relacionados ao desenvolvimento de DCNT, em especial o alto consumo de sódio, gordura saturada e açúcar livre, que refletem o aumento da prevalência de

ingestão de alimentos ultraprocessados como refrigerantes, sucos, refrescos e biscoitos e a baixa participação de alimentos marcadores de alimentação saudável como leite e frutas na dieta deste grupo etária (SOUZA et al., 2016, pág.11). 
Os sanduiches e lanches fast foods também se encontram entre as preferências e hábitos alimentares dos adolescentes. Esses alimentos possuem grandes quantidades de calorias onde consumidos em excessos e presentes em alta frequência na rotina alimentar de uma pessoa pode ser um fator de risco e corroborativo a quadros de sobrepeso, obesidade e consequentemente, patologias relacionadas como hipertensão e doenças cardiovasculares (ANDRADE et al, 2019). O consumo frequente tente a se transformar em hábitos alimentares o que é preocupante por conta das características dos mesmos (OLIVEIRA, PETER E MUNIZ, 2019).

\section{Influências na alimentação}

\section{Aspectos psicológicos e insatisfação corporal}

O adolescente é exposto a diversos fatores que vão interferir diretamente em sua percepção com relação ao seu corpo. Deste modo, com o corpo em constantes desenvolvimentos morfológicos e o indivíduo passando por fatores psicossociais que vão influenciar em seu bem-estar e em sua vivência, todo isso gera um combinado que normalmente levam o adolescente a essa busca por mudanças quando ao seu físico (PINHO, et al., 2019).

Nessa fase da vida existe uma busca por aceitação das pessoas que estão ao seu redor associado a uma imposição por parte da mídia da existência de um padrão de corpo perfeito. Com isso, passam a se comparar com outras pessoas e com aquele padrão imposto gerando insatisfação e distorção de autoimagem (RIBEIRO et al,.2016).

Essa insatisfação corporal é conciliada com uma busca por um corpo ideal. Isso tende a acarretar em comportamentos alimentares inadequados, gerando uma construção de hábitos que podem ser prejudiciais para a saúde do indivíduo e aliado a todos os aspectos psicológicos, podem resultar em episódios de transtornos alimentares (BITTARA e SOARES, 2020). 


\section{Influência da mídia}

A mídia possui grande influência sobre seus espectadores e públicos expostos aos seus conteúdos, tendo o poder de moldar pensamentos, comportamentos, modos de agir, influenciando diretamente em suas escolhas, exercendo um papel persuasivo muito forte podendo se tornar um fator de risco. Um dos conteúdos que exercem influência negativa sobre as pessoas é a da existência de um corpo perfeito padrão, fazendo com que uma grande maioria se vejam insatisfeitos com sua imagem corporal (COPETTI; QUIROGA, 2018).

Outra influência negativa é quanto a padrões alimentares que possam ser desenvolvidos. Propagandas para a aquisição de produtos industrializados são cada vez mais fortes e comuns em todos os meios midiáticos, com o intuito central de persuadir e convencer, colaborando para o consumo desses tipos de produtos (MORAES et al., 2018).

Relacionando o incentivo a práticas alimentares calóricas e inadequadas com a imposição de um corpo padrão, a mídia se torna um fator de risco para um estilo de vida não saudável, que pode resultar em um aumento do peso corporal e com isso também uma insatisfação com a forma física sendo por isso um risco para o desenvolvimento de transtornos alimentares como já foi citado no título anterior (BITTAR; SOARES, 2020).

\section{Pais e responsáveis, o convívio familiar}

O ambiente familiar exerce influência direta nos ensinamentos desde o período da infância, saberes esses que uma vez adquiridos tendem a prevalecerem durante a fase da adolescência e também na vida adulta. Diante disso, os comportamentos alimentares também são adquiridos nesse momento onde os pais possuem sua importância para que hábitos saudáveis de alimentação sejam inseridos, trazendo consigo uma ação de promoção e prevenção para a saúde futura de seus filhos (TOSATTI, 2017). 
As práticas alimentares em ambiente familiar, onde a família possui o hábito de realizar as refeições todos juntos, contribui diretamente para que hábitos alimentares e escolhas alimentares mais saudáveis sejam desenvolvidos (TOSATTI, 2017).

\section{Rotinas e hábitos}

O tempo corrido aliado a pressa e a necessidade de se resolver tudo de forma rápida tem feito parte cada vez mais do estilo de vida atual onde o tempo é colocado com um dos bens mais preciosos. Porém, essa forma de levar tudo na correria exerce influências de diversas maneiras em nosso dia a dia como nas práticas alimentares, caracterizadas por hábitos não saudáveis de alimentação, devido a necessidade de uma alimentação prática onde se destacam alimentos prontos, industrializados, alimentos que não são adequados para um consumo diário e constante (ENGLER; GUIMARÃES; LACERDA, 2016).

Tais características juntamente com a necessidade de realizar as refeições longe de casa tendem a estimular o consumo de alimentos ultraprocessados, muito por conta dessa economia de tempo presente no dia a dia (CECCATTO et al., 2018).

Além da rotina, os hábitos também influenciam na alimentação. Realizar refeições na frente da TV por exemplo é um marcador de risco para uma alimentação inadequada uma vez que esse costume é ligado ao consumo de alimentos ricos em açúcar, alimentos gordurosos e com teor elevado de sódio. Essas são características de alimentos preferidos para realização de lanches na frente da TV, tais como bolachas recheadas, chocolates, refrigerantes (ENES; LUCCHINI, 2016). 


\section{Café da manhã}

\section{A importância do café da manhã}

Considerado uma das principais refeições realizada ao longo do dia, o consumo do café da manhã tem sido associado diretamente a uma dieta de qualidade. (MARCHONI, et al., 2015. Uma alimentação com maior aporte nutricional onde se atinjam com mais facilidade as recomendações nutricionais são características dos indivíduos que possuem o hábito de realizar essa refeição. (PEREIRA, et al., 2018).

Ela tem como característica o estímulo para uma alimentação saudável e balanceada por ter normalmente em sua composição, alimentos fontes de nutrientes e vitaminas, ao mesmo tempo que tende a ofertar alimentos com baixos níveis de gorduras e colesterol. Quanto aos nutrientes, no café da manhã o cálcio, se destaca por sua alta concentração, uma vez que leite e derivados que fornecem grandes quantidade do nutriente são bastante consumidos durante essa refeição (BARUFALDI et al., 2015).

O cálcio é um nutriente importantíssimo sendo fundamental para a saúde dos ossos e assim podendo contribuir prevenindo problemas como osteoporose e fraturas, quadros que podem surgirem no decorrer da vida. $\mathrm{Na}$ adolescência ele é fundamental pelos fatores fisiológicos que norteiam essa fase, onde grande parte do acréscimo de massa óssea ocorre nesse período da vida e o cálcio atua diretamente em sua manutenção e desenvolvimento (ASSUMPÇÃO et al., 2016).

O consumo de frutas também se mostra otimista com relação ao consumo de café da manhã. O hábito de realizar a refeição todos os dias tende a colaborar para que a recomendação diária desse grupo alimentar seja atingida. As frutas são alimentos que por características costumam ser ofertados durante a refeição tendo seu consumo recomendado para compor um café da manhã nutritivo e variado (FEREIRA; MELO; TORAL, 2019). 
Bacharelado em Nutrição da UninCor e iniciação à pesquisa: Com a palavra os nossos estudantes

\section{Omissão da refeição}

A omissão do café da manhã pode ser prejudicial à saúde em um longo prazo, isso por que como já dito anteriormente é uma refeição que se associa a uma dieta de qualidade. O hábito de omitir essa refeição, pode ser um colaborador para o consumo de alimentos com grandes quantidades de energia, alimentos que oferecem poucas quantidades de nutrientes e consequentemente deficiências nutricionais podendo resultar em excessos de peso caso consumidos com frequência. Esses impactos acontecem devido a qualidade dos alimentos que normalmente são ofertados durante a refeição (FEREIRA; MELO; TORAL, 2019).

São muitos os fatores que podem estar associados a omissão do café da manhã. Fatores socioeconômicos, hábitos e rotinas da pessoa como falta de tempo e excesso de sono, fatores comportamentais como auto estima baixa aliando-se com insatisfação corporal (FEREIRA; MELO; TORAL, 2019).

Muitas pessoas deixam de consumir o café da manhã por terem um pensamento equivocado de que estão deixando de consumir calorias, com a ideia de que essa prática auxiliará no controle ou perda de peso. O que realmente acontece é que por necessidades fisiológicas nosso corpo precisa em algum momento de consumir essas necessidades calóricas que foram deixadas para trás e normalmente essa reposição é feita com alimentos com muito mais calorias fazendo com que o resultado final do consumo de energia seja maior (CECATO, 2015).

Por essas características, o consumo do café da manhã de forma balanceada e frequente pode exercer uma contribuição direta no combate aos riscos de sobrepeso e obesidade onde negligenciar essa refeição tende a ser favorável a prováveis deficiências de micronutrientes importantes para nossa alimentação (BARUFALDI et al,.2016). 


\section{MATERIAIS E MÉTODOS}

Foi realizada uma pesquisa aplicada e exploratória, que partiu do interesse por conhecimentos acerca das práticas alimentares na realização do café da manhã durante a fase da adolescência, onde foram analisados os padrões de consumo durante essa refeição. Uma pesquisa de campo que trouxe uma abordagem quantitativa onde todos os resultados alcançados foram relacionados e analisados de maneira a compreender as características da população estudada.

O estudo foi realizado na cidade de Monsenhor Paulo - MG e contou com uma amostra de 45 adolescentes de ambos os sexos, com idade de 14 a 19 anos, que para o levantamento dos dados responderam a um questionário online via Google Forms compartilhado nas redes sociais Whatssapp e Instagram.

A primeira seção do questionário foi referente a participação da pesquisa onde todos os adolescentes tinham a opção de selecionar se concordavam ou não em participar. Para os que sinalizaram positivamente e concordaram em dar prosseguimento, foram validados com o e-mail pessoal ou no caso de menores de idade o e-mail do responsável legal consentindo com a participação do adolescente, sendo obrigatório a seleção do Termo de Consentimento Livre e Esclarecido.

O questionário aplicado foi de autoria própria do pesquisador onde se deu pelo seguinte roteiro, iniciando com dados gerais referente as características dos adolescentes (idade e sexo) e continuando com as questões a seguir: "Com qual frequência você toma café da manhã durante sua semana?", "Aponte os motivos que na sua opinião te levam a não realizar a refeição:", "Se realiza o café da manhã, com qual frequência você consome frutas nessa refeição?", "Com qual frequência você consome leite ou iogurte em seu café da manhã?”, "Onde realiza o café da manhã?", "Possui o hábito de realizar o café da manhã na presença da 
família?" e "O café da manhã é realizado na frente de computadores, celulares ou TV?" Sendo finalizado com um recordatório 24 horas, método de coleta de dados dietéticos, sobre o café da manhã daqueles que realizaram a refeição no dia em que o questionário foi respondido ao no dia anterior.

Com o questionário aplicado, os dados foram lançados no Microsoft Excel e organizados para aplicação de análises estatísticas dos dados. Foram analisados todos os recordatórios, obtendo dados com relação à percentual, média, desvio padrão e analisado também todo o questionário buscando correlação entre as variáveis.

Por fim, foi criado um projeto de intervenção onde foi desenvolvido um informativo com o objetivo de ser uma ferramenta de educação alimentar e assim fazer com que conhecimentos a cerca de uma prática alimentar saudável chegue ao público alvo dessa pesquisa.

A pesquisa de campo ocorreu no período de outubro a novembro de $2021 \mathrm{e}$ foi submetida e aprovada pelo Comitê de Ética e Pesquisa da Universidade Vale do Rio Verde - UninCor, via plataforma Brasil e aprovado sob o CAAE de número 51223321.3 .0000 .5158$.

\section{RESULTADOS E DISCUSSÃO}

Dos 50 adolescentes que responderam a primeira seção do questionário referente a participação da pesquisa, 45 concordaram em participar e foram avaliados. Desses 45 que participaram, 33 enviaram o recordatório de 24 horas. Com relação aos dados socioeconômicos da amostra, $60 \%$ dos entrevistados foram do sexo feminino com uma média de idade 17,22 anos DP $\pm 2,6$ (Tabela 1). 
Tabela 1 - Resumo dos dados socioeconômicos

\section{Idade}

Média

17,22

Mediana

Desvio Padrão

Sexo

Masculino

Feminino
17,00

2,20

\begin{tabular}{ccc} 
Masculino & 18 & $40 \%$ \\
Feminino & 27 & $60 \%$ \\
\hline
\end{tabular}

Fonte: próprio autor (2021).

Analisando os recordatórios enviados, o consumo de calorias totais durante a realização do café da manhã entre os adolescentes do estudo teve uma média de 414,06 Kcal (DP $\pm 268,63)$, com um consumo médio de $167 \mathrm{mg}$ de cálcio e 2,4g de fibra alimentar.

O café da manhã deve nos garantir um aporte energético de $25 \%$ do total das necessidades energéticas diárias (CECATO, 2015). Levando em consideração que o Guia Alimentar para a População Brasileira sugere um consumo médio diário de 2000 Kcal e que o café da manhã é uma das três principais refeições do dia ao lado do almoço e jantar conciliado com lanches entre essas refeições, analisamos um consumo médio próximo do recomendado.

Já o consumo de cálcio e fibra alimentar, se comparados ao valor recomendado da Dietary Reference Intakes DRI, usando como base os valores de RDA (Ingestão Dietética Recomendada), onde a recomendação de consumo diário de cálcio é de 1300 mg e o de fibras é de $38 \mathrm{~g}$ para homens e $26 \mathrm{~g}$ para mulheres para a faixa etária estudada, podem ser consideradas abaixo do valor de referência. 
Os alimentos que apareceram com mais frequência obtendo assim maior prevalência de consumo entre os adolescentes foram, pães (58\%), café (52\%), leite (42\%), margarina (42\%). A prevalência de alimentos industrializados foi relativamente baixa, como a de bolachas $(15 \%)$, refrigerante $(1 \%)$, cereal matinal $(1 \%)$ e sucos de saquinho (1\%) (Tabela 2$)$.

Os alimentos consumidos com maior frequência aparecendo entre as principais escolhas para compor o café da manhã são o pão branco, o café, manteiga/margarina e o café com leite, sendo o pão o alimento que mais aparece com 65\% (PEREIRA, et al., 2017), confirmando os resultados obtidos com esse estudo.

Tabela 2 - Frequência simples e percentual dos alimentos

\section{Alimento}

Pão francês

Café

Leite

Margarina

Banana

Pão de queijo

Bolacha

Mamão

Aveia

Ovo

Requeijão
ก

19

17

14

14

9

6

5

4

4

3

2
$\%$

$58 \%$

$52 \%$

$42 \%$

$42 \%$

$27 \%$

$18 \%$

$15 \%$

$12 \%$

$12 \%$

$9 \%$

$6 \%$ 
Suco natural

Suco industrializado

mel

Achocolatado

logurte

Sucrilhos

Bolo

Toddynho

Pão doce

Mortadela

Morango

Adoçante

Refrigerante

Maçã

Mozarela

Presunto

Crepioca
2

2

$6 \%$

2

$6 \%$

2

$6 \%$

$3 \%$

$3 \%$

$3 \%$

$3 \%$

$3 \%$

$3 \%$

$3 \%$

$3 \%$

$3 \%$

$3 \%$

1

$3 \%$

1

$3 \%$

1

$3 \%$

Fonte: próprio autor (2021).

Avaliando o hábito dos adolescentes com base nas questões do questionário, observou - se que $58 \%$ realizam a refeição todos os dias da semana e dentre aqueles adolescentes que não consomem café da manhã em nenhum dos dias (7\%), 33\% responderam acordar tarde como motivo e outros 33\% alegam não terem tempo para realizar a refeição (Figura 1). 
Muitos estudos trazem valores distintos quanto a omissão dessa refeição. $A$ pesquisa realizada por Pereira et al,. (2017) intitulada "Prevalência de consumo e conteúdo nutricional da refeição matinal entre adolescentes da Pesquisa Nacional de Alimentação", apresentam valores mais semelhantes ao da pesquisa atual, com $81 \%$ dos adolescentes sendo consumidores de café da manhã e $7 \%$ os que não realizam a refeição. Já Marchioni et al,. (2015) que destaca a importância do café da manhã como uma das principais refeições do dia, aponta em sua pesquisa um valor bem maior daqueles que omitem o café da manhã (38\%). Esses valores podem ser influenciados pelas características, hábitos e costumes de cada amostra pesquisada.

Figura 1 - Fluxograma do hábito de tomar o café da manhã

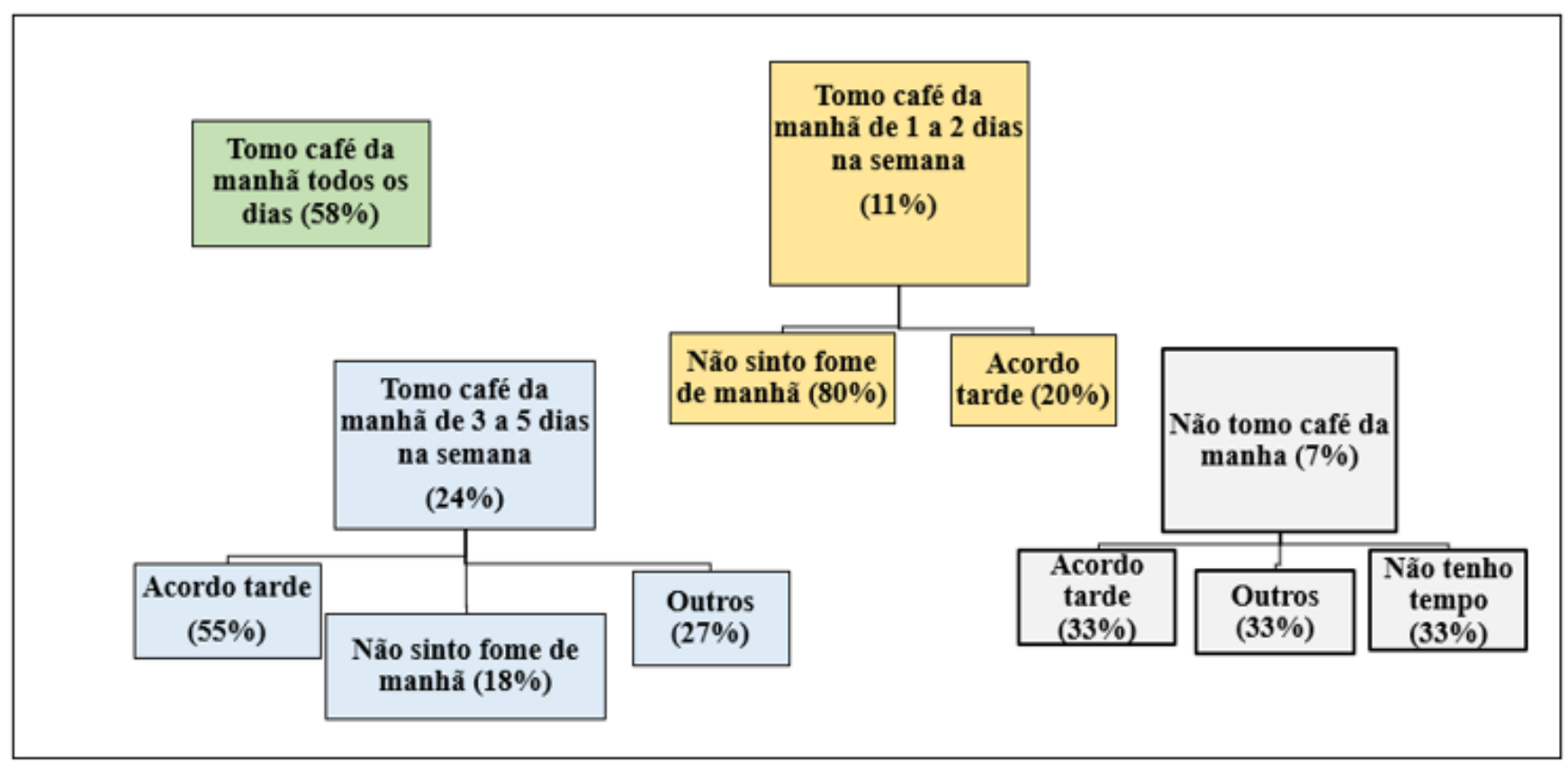

Fonte: próprio autor (2021).

Ao analisar o consumo de leite e iogurte ou frutas durante a semana, verificamos que $29 \%$ e $44 \%$ dos entrevistados respectivamente, não consomem esses alimentos, e apenas $9 \%$ apresentam o hábito de consumirem frutas todos os dias da semana (Gráfico 1). 
Uma característica na fase da adolescência é a preferência por alimentos ultra processados, o que é um motivo de preocupação já que na maioria das vezes, são consumidos substituindo alimentos como frutas, cereais, e leites, grupos alimentares fonte de nutrientes importantes (OLIVEIRA, PETER E MUNIZ,2019).

Gráfico 1 - Consumo de Frutas e Leite (ou iogurte) no café da manhã

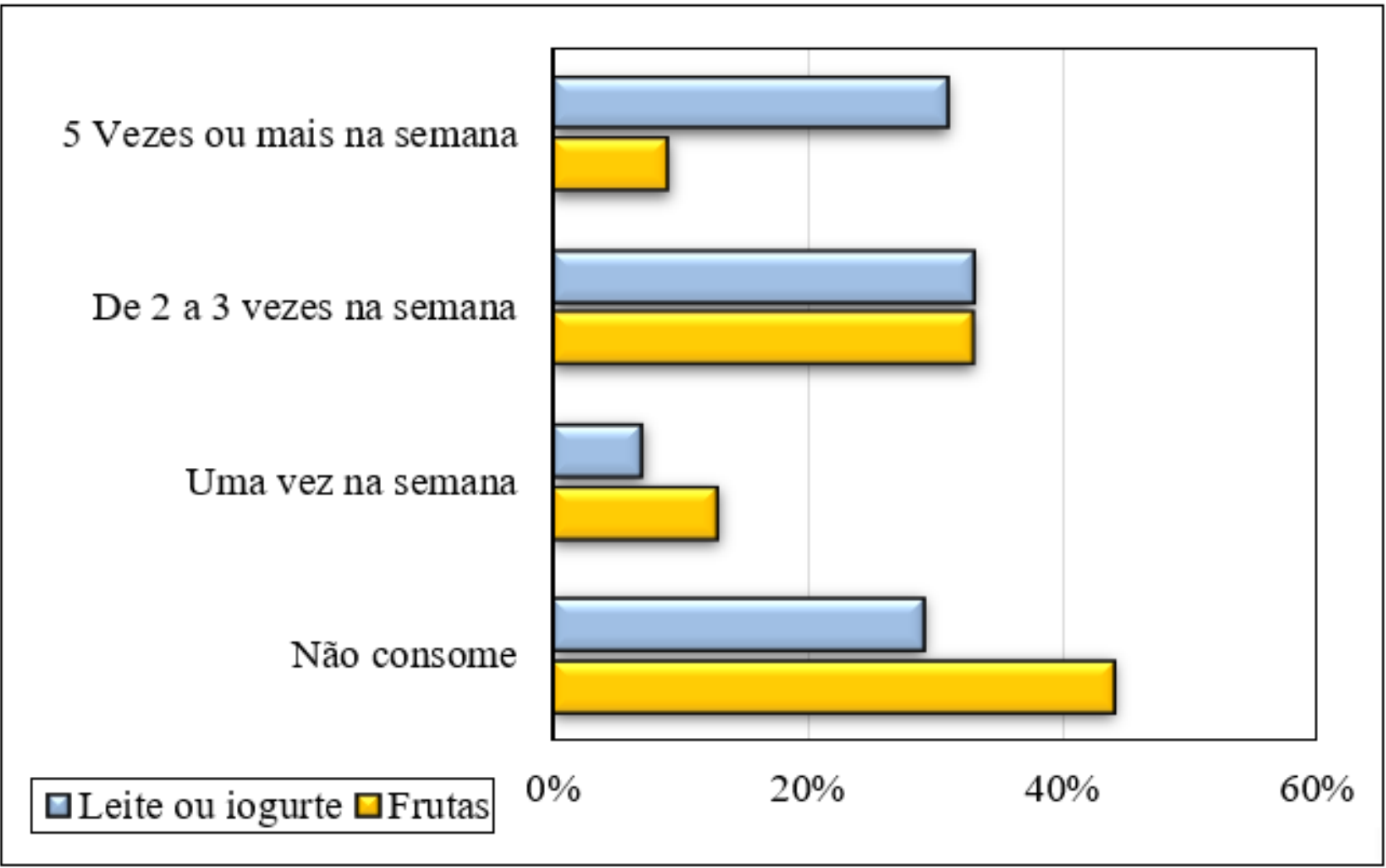

Fonte: próprio autor (2021).

Sobre o local da realização do café da manhã $93 \%$ da amostra $(n=42)$ realizam em casa. Sobre a presença da família durante a refeição $31 \%(n=14)$ realizam o café da manhã em família e $69 \%(n=31)$ responderam que realizam a refeição sozinhos. E sobre o uso de telas $60 \%(n=27)$ realizam o café da manhã na frente de computadores, celulares ou TV e os demais $40 \%(n=18)$ não fazem uso de telas durante as refeições (Tabela 3).

A realização do café da manhã na presença da família é apontado por Barufaldi et al, . 2016 como um importante aspecto na influência de uma alimentação 
saudável durante a adolescência. Já Moraes et al., (2019), associa o hábito de comer em frente à televisão como um facilitador para escolhas não saudáveis de alimentos. Mesmo não apontando relação entre as variáveis, o alto número $(60 \%)$ daqueles que realizam a refeição em frente a telas e ao baixo percentual $(31 \%)$ daqueles que tomam café da presença da família podem ser fatoras colaborativos para os baixos consumos de cálcio e fibras na amostra estudada.

Tabela 3 - Hábitos durante o café da manhã

\begin{tabular}{|c|c|c|}
\hline $\begin{array}{c}\text { Onde realiza o café } \\
\text { da manhã? }\end{array}$ & $n$ & $\%$ \\
\hline Em casa & 42 & $93 \%$ \\
\hline Outro lugar & 3 & $7 \%$ \\
\hline $\begin{array}{c}\text { Possui o hábito de realizar o café da } \\
\text { manhã na presença da família? }\end{array}$ & $n$ & $\%$ \\
\hline Sim & 14 & $31 \%$ \\
\hline Não & 31 & $69 \%$ \\
\hline Sim & $n$ & $\%$ \\
\hline coafé da manhã é reallizado na frente de & 27 & $60 \%$ \\
\hline Não & 18 & $40 \%$ \\
\hline
\end{tabular}

Fonte: próprio autor (2021).

Realizou-se o teste Qui-quadrado com o objetivo de verificar se o sexo e o uso de tela na hora de realizar o café da manhã exercem influência nas demais variáveis "frequência do café da manhã", "consumo de frutas", "consumo de leite ou iogurte", o "local onde o café da manhã é realizado" ou a "presença da família" (Tabela 3). 
O ato de se alimentar em frete a telas vem se tornando cada vez mais como no cotidiano das pessoas, onde tende a favorecer a hábitos inadequados de alimentação como o de não se atentar ao que se está consumindo e também não mastigar o alimento da maneira correta. (OLIVEIRA et al., 2016). Esse ato pode influenciar também nas escolhas alimentares, como aponta Rossi et al., 2010 que o tempo assistindo TV foi significativamente associado ao menor consumo de frutas e verduras e maior consumo de porções de salgadinhos, doces e bebidas e elevado teor de açúcar.

No presente estudo o teste foi realizado e analisando os resultados, é possível observar que nenhuma varável apresentou relação de maneira significativa. Esses resultados se deram possivelmente pelo tamanho da amostra que foi uma limitação durante a realização desse estudo.

\section{CONCLUSÃO}

Comos resultados apresentados concluímos que um percentual considerável de adolescentes possui o costume de consumir a refeição todos os dias da semana, porém o consumo de cálcio e fibras se mostraram relativamente baixos. Podemos notar o quanto pode ser variada a alimentação dos adolescentes na realização do café da manhã, tendo em sua composição alimentos diversificados e grupos alimentares também muito variados.

Em contrapartida, o estudo apresentou algumas limitações, as quais podem exercer influência nos resultados alcançados ao final da pesquisa. Por se tratar de um método onde o entrevistado necessita usar de sua memória para recordar de uma de suas refeições, o recordatório 24 horas pode não ser totalmente exato. Outra limitação foi quanto ao número da amostra, que foi muito reduzido, dificultando bastante na análise dos resultados na hora de apontar possíveis correlações de variáveis. Uma sugestão para estudos futuros de outros pesquisadores referente ao tema é o de coletar um volume maior de dados, expandindo o tamanho da amostra para que se possa fazer análises mais apuradas. 
Considerando a influência dos hábitos que norteiam a alimentação para escolhas de alimentos variados e com maiores qualidades nutricionais, percebe - se a necessidade de novos estudos e também campanhas, práticas educativas alimentares para a população, gerando assim uma amplitude de conhecimentos e podendo alcançar as pessoas de uma forma mais ampla e facilitada.

\section{REFERENCIAS}

ANDRADE, Lilian Moreira Moraes, et al. Estado nutricional, consumo de alimentos ultraprocessados e imagem corporal de adolescentes de uma escola privada do município de Juiz de Fora - MG. Hu Revista, v. 45, n. 1, p. 40-46, 2019.

ASSUMPCÃO, Daniela de, et al. Calcium intake by adolescents: a populationbased health survey. Sociedade Brasileira de Pediatria: Jornal de Pedriatria, Rio de Janeiro, v. 92, n. 3, p. 251-259, 2016.

BARUFALDI, Laura Augusta; ABREU, Gabriela de Azevedo; OLIVEIRA, Juliana Souza; SANTOS Debora França; FUJIMON Elizabeth; VASCONCELOS Sandra Mary Lima; VASCONCELOS Francisco de Assis Guedes; TAVARES Bruno Mendes. ERICA: prevalência de comportamentos alimentares saudáveis em adolescentes brasileiros. Revista de Saúde Pública, São Paulo, v. 50, n. 1, p. 1-9, fev. 2016

BARUFALD, Laura Augusta; MAGNANINI, Mônica Maria Ferreira; ABREU, Gabriela de Azevedo; BLOCH, Katia Vergetti. Café da manhã: vinculado a consumo e comportamentos alimentares em adolescentes. Adolescência e Saúde, Rio de Janeiro, v. 12, n. 2, p. 7-16, abr./jun. 2015.

BITTARA, Carime; SOARES, Amanda. Mídia e comportamento alimentar na adolescência. Cadernos Brasileiros de Terapia Ocupacional. v. 28, n. 1, p. 291308, 2020.

CECATO, Daiane. O consumo do café da manhã na manutenção e redução de peso: uma revisão da literatura. Revista de Atenção à Saúde, Caxias do Sul, v.13, n 44, p 80-84, jun. 2015. 
Bacharelado em Nutrição da UninCor e iniciação à pesquisa: Com a palavra os nossos estudantes

CECCATTO, Daiane; SPINELLI, Roseana Baggio; ZANARDO, Vivian Polachini Skzypek; RIBEIRO Leonice Alzira. A Influência da Mídia no Consumo Alimentar Infantil: Uma Revisão de Literatura. Perspectiva, Erechim, v. 42, n. 157, p. 141 149, março 2018.

COPETTI, Aline Vieira Sá; QUIROGA, Carolina Villanova. A influência da mídia nos transtornos alimentares e na autoimagem em adolescentes. Revista de Psicologia da Imed, Passo Fundo, v. 10, n. 2, p. 161-177, 2018.

COSTA, Rachel Franklin; ZEITOUNE, Regina Célia Gollner; QUEIROZ, Maria Veraci Oliveira; GARCIA, Carmem Isabel Gomes; GARCIA, Maria Jesus Ruiz. Redes de apoio ao adolescente no contexto do cuidado à saúde: interface entre saúde, família e educação. Rev. Esc. Enferm. USP, São Paulo, v. 49, n. 5, p. 741-747, jul. 2015

ENES Carla Cristina; LUCCHINI Beatriz Guerra. Tempo excessivo diante da televisão e sua influência sobre o consumo alimentar de adolescentes. Revista de Nutrição, Campinas, v. 29, n. 3, p. 391-399, maio/jun. 2016.

ENGLER Rita de Castro; GUIMARÃES Letícia Hilário; LACERDA Ana Carolina Godinho de. Design e Consumo: A influência da mídia sobre a obesidade infantil. Bucher Design Proceedings, Belo Horizonte, v. 9, n. 2, outubro 2016.

FERREIRA, Isabel Barcelos; MELO, Giselle Rha-Isa; TORAL, Natasha. Café da manhã e sua associação com consumo alimentar e perfil antropométrico de adolescentes de Brasília-DF. O Mundo da Saúde, São Paulo, v. 43, n.1, p. 211-226, jan. 2019.

GOMES Helen Mara dos Santos; TEIXEIRA Estelamar Maria Borges. Pirâmide Alimentar: guia para alimentação saudável. Instituto Federal de Educação, Uberaba, v.2, n.3, p. 10-15,set/dez,2016.

MAIA, Emanuella Gomes, et al. Padrões alimentares, características sociodemográficas e comportamentais entre adolescentes brasileiros. Revista Brasileira de Epidemiologia, v. 21, n. 1, p. 1-13, 2018. 
MARCHIONI, Dirce Maria Lobo; GORGULHO, Bartira Mendes; TEIXEIRA, Juliana Araújo; JUNIOR, Eliseu Verly; FISBERG, Regina Mara. Prevalência de omissão do café da manhã e seus fatores associados em adolescentes de São Paulo: estudo ISA-Capital. Nutrire, v. 40, n. 1, p. 10 -20, abr. 2015.

MORAES, Dandara Madsen, et al. Exposição a mídia e hábitos alimentares de adolescentes em uma escola privada de São Luís-MA. Rev. Investig, Bioméd., São Luís, v. 10, n. 2, p. 165-171, 2018.

OLIVEIRA, Riceli Rodeghiero; PETER, Nathalia Brandão; MUNIZ, Ludmila Correa. Consumo alimentar segundo grau de processamento entre adolescentes da zona rural de um município do sul do Brasil. Ciência e Saúde Coletiva, Pelotas, v. 26, n. 3 , p. $1105-1114,2021$.

PEREIRA, Jaqueline $L$, et al. Prevalence of consumption and nutritional content of breakfast meal among adolescents from the Brazilian National Dietary Survey. Sociedade Brasileira de Pediatria: Jornal de Pedriatria, Rio de Janeiro, v. 94, n. 6 , p. 630-641, 2018.

PINHO, Lucinéia de, et al. Percepção da imagem corporal e estado nutricional em adolescentes de escolas públicas. Revista Brasileira de Enfermagem, v. 72, n. 2, p. 240-246, 2019.

RIBEIRO, Karla Carolina Silveira, et al. A(in)satisfação com o corpo e a vulnerabilidade aos transtornos alimentares em adolescentes.Cad. Ed. Tec. Soc., Inhumas, v. 9, n. 2, p. 194-203, 2016.

SILVA, Dayanne Caroline de Assis; FRAZÃO Iracema da Silva; OSÓRIO Mônica Maria; VASCONCELOS Maria Gorete Lucena. Percepção de adolescentes sobre a prática de alimentação saudável. Ciência \& Saúde Coletiva, Rio de Janeiro, v. 20, n. 11 , p. $3299-3308$, nov. 2015

SOUZA, Amanda de Moura, et al. ERICA: ingestão de macro e micronutrientes em adolescentes brasileiros. Revista de Saúde Pública, v. 50, n. 1, p. 1-15, 2016.

TOSATTI, Abykeyla Mellisse, et al. Fazer refeições em família tem efeito protetor para a obesidade e bons hábitos alimentares na juventude? Revisão de 2000 a 2016. Revista Brasileira de Saúde Maternidade Infantil, Recife, v. 17, n. 3, p. 435-445, 2017. 
doi 10.48209/97/8-65-89949-72-B

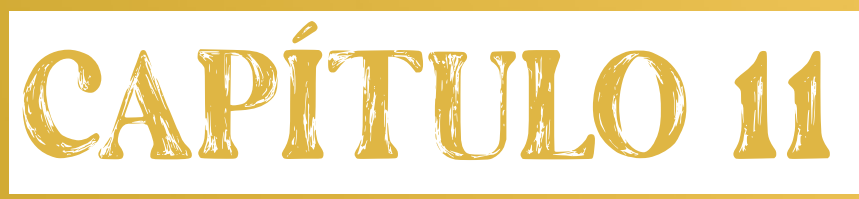

\section{AVA CONSUMO DE AMIMIFNHOS FUNCIONATS EMA ADULIOS}

Maria Eduarda de Oliveira Nepomuceno Vivian Silva Borges 


\section{INTRODUÇÃO}

Os alimentos funcionais além de suas funções nutricionais básicas eles trazem efeitos benéficos a saúde, com o uso correto e contínuo dos alimentos podem ocasionar melhoria, prevenção e tratamento de muitas doenças crônicas não transmissíveis, melhorando a qualidade de vida (CARVALHO et. al., 2013, p.2).A pirâmide alimentar na qual é dividida em oito grupos sendo eles, cerais, pães e tubérculos; hortaliças; frutas; leguminosas; carnes e ovos; leite e derivados; óleos e gorduras; açucares; São recomendados a utilização de inúmeros alimentos que estão presentes nesses grupos alimentares, no qual possuem ação funcional no organismo, como por exemplo, a soja, linhaça, alho, cebola, abacate, peixes, brócolis, rabanete entre outros alimentos que fazem parte dos grupos da pirâmide alimentar (USDA, 1992; PHILIPPI, 2000; CUPPARI, 2005; BRASIL, 2014).

Além de ressaltar a importância do consumo de alimentos funcionais diariamente, para auxiliar no tratamento e prevenção de doenças crônicas não transmissíveis, como diabetes, hipertensão, câncer, hipercolesterolemia, entre outras doenças. Demonstrando a importância de uma alimentação rica em nutrientes, que são de significativa importância no metabolismo dos indivíduos, e seus benefícios quando utilizados adequadamente (BASHO; BIN,2010; ALVES, 2015).

Perante o assunto a hipótese da pesquisa são os possíveis baixo e alto consumo dos alimentos funcionais ou o não conhecimento dos benefícios da utilização de alimentos funcionais. Onde também será abordado a seguinte problemática: Qual o consumo e conhecimento dos alimentos funcionais por adultos de 18 a 59 anos?

Tendo como objetivo a analisar a frequência alimentar dos alimentos funcionais em adultos de 18 a 59 anos de idade, também esclarecer a importância do consumo de alimentos funcionais quando consumidos com frequência na 
prevenção de doenças crônicas não transmissíveis e descrever os alimentos funcionais mais consumidos pelos adultos.

A discussão a respeito desse tema se torna cada dia mais relevante pois vem crescendo as pesquisas sobre alimentos funcionais, no qual podem ajudar na prevenção de doenças crônicas não transmissíveis e, melhorar a qualidade de vida de quem adere a esse estilo alimentar.

\section{REFERENCIAL TEÓRICO}

\subsection{Alimentos Funcionais e seu Surgimento}

No começo dos anos 80 surge no Japão o conceito de alimentos funcionais, o desenvolvimento de alimentos que podem beneficiar a saúde e com isso fazem a diminuição dos gastos com saúde pública no país, juntamente com esse fator consegue também atingir a prevenção de algumas doenças, sendo elas doenças crônicas não transmissíveis. Então o Japão inicia sua gama de pesquisas e produções a respeito dos alimentos funcionais, no qual foi apoiado por estudiosos, pesquisadores, universidades, fabricas de alimentos e até mesmo pelo governo. Surge então o chamado FOSHU (Foods For Specified Health Uses) (Alimentos para usos específicos para a saúde) (BATISTA et al. 2013; COSTA e ROSA, 2016).

Para que os alimentos funcionais sejam eficazes é necessário o uso contínuo juntamente com hábitos alimentares saudáveis. Os alimentos considerados funcionais devem ser consumidos preferencialmente em sua forma original, ou seja, in natura, no qual devem fazer parte de sua alimentação cotidiana, pois apenas desta forma eles podem fazer e mostrar seus benefícios, fazendo parte de uma alimentação regular regada por frutas, hortaliças, fibras e alimentos considerados integrais (VIDAL et al., 2012). 


\subsection{Alimentos Funcionais e suas Ações}

Os alimentos funcionais definidos em termos práticos, é todo alimento inalterado que tenha capacidade natural funcional, ou seja, alimentos habitualmente consumidos em uma dieta, e também qualquer alimento que sua natureza de um ou mais componentes que foram modificados sinteticamente, sendo a adição ou remição de um componente com o processo realizado por meio de tecnologia ou biotecnologia, substituição de componentes por outros favoráveis, o aumento de algum componente, modificação da bioatividade ou biodisponibilidade de determinado componente e também a combinação de um ou mais componentes (CROWE e FRANCIS, 2013; MENDES, 2014).

\subsubsection{PROBIÓTICOS E PREBIÓTICOS}

Os probióticos são definidos como "microrganismos vivos que, administrados em quantidades adequadas, conferem efeito benéfico à saúde do hospedeiro". Porém a origem da linhagem é essencial para que o microrganismo probióticos façam suas funções (FERREIRA, 2012).

Os benefícios do consumo de prebióticos são: melhoramento das funções intestinais e microbiota colônica, saúde digestiva e sua manutenção, alivio de constipação, tratamento de diarreias, aumento da absorção de minerais, como o cálcio, diminuição dos riscos de osteoporose, produção de nutrientes, síntese de vitaminas, redução do nível de bactérias patogênicas, redução de toxinas, protege contra a gastroenterites, reduz o câncer de cólon, melhoramento da síndrome do intestino irritável, aumenta sistema imunológico, melhora tolerância a lactose, evita alergias alimentares, manutenção do peso, níveis saudáveis de glicose no sangue (PRUDENCIO, 2012).

\subsubsection{FLAVONOIDES E FLAVONÓIS}

Tendo mais de 6000 tipos flavonoides identificados em plantas. São pertencentes aos grandes grupos de compostos fenólicos nos quais estão 
presentes nas hortaliças, frutas e alguns produtos como: vinho, suco de uvas e chá (COSTA e ROSA, 2016).

São classificados por suas características químicas e biosintéticas, como: antocianinas, flavononas, flavonas, flavonóis e isoflavonoides. Antocianinas são as que dão a cor azul ou vermelha aos alimentos de origem vegetal. Alguns estudos mostram a diminuição do risco de infarto e rigidez arterial em mulheres com uma alimentação rica em antocianinas (GALLOWAY et al., 2015).

Os componentes que mais se destacam nos flavonóis são: miricetina, kaempferol e quercetina. Sendo a mais a quercetina a mais abundante, no qual podem ser encontradas em alimentos como maçã, cebola, frutas cítricas, frutas vermelhas e brócolis. Sua quantidade nos alimentos é medida devido ao solo em que foi cultivado sua colheita e o armazenamento (NABAVI et al., 2015).

\subsubsection{ISOFLAVONAS}

São encontradas em mais de 300 tipos de plantas, a soja e seus derivados contêm quantidades relevantes de isoflavonas. A isoflavonas se relaciona diretamente com o fitoestrógenos pois tem estruturas bem similares ao 17- $\beta$-estradiol, que se ligam e ativam os receptores de estrógeno Alfa e Beta. Exerce função de sinalização, estrogênicas e antiestrogênicas. Estudos mostram que a diferença de fogachos, no qual é o responsável pelos principais sintomas da menopausa. A osteoporose também é um aspecto da utilização de isoflavonas, após a baixa de estrogênio na menopausa ocorre uma condição chamada osteoporose pós menopausa, que é uma diminuição na massa óssea. Por essa condição a estrutura com o 17- $\beta$-estradiol, podem beneficiar na ação para diminuir os riscos de perda de massa óssea na pós menopausa com a ajuda do fitoestrógenos (LAGARI e LEVIS, 2013). 


\subsection{4 ÁCIDOS GRAXOS DO GRUPO ÔMEGA 3 E 6}

Tem sido estudados os efeitos epidemiológicos dos ácidos graxos ômega 3 , tendo respostas da associação inversa entre o consumo de ácidos graxos com os processos de marcadores inflamatórios (MOZAFFARIAN e WU, 2011). As inflamações estão envolvidas com as doenças cardiovasculares, notou-se um processo terapêutico com os ácidos graxos ômega 3 nas doenças cardiovasculares com redução na pressão arterial, melhoramento na função endotelial e reduz a agregação plaquetária (KROMHOUT et al., 2012).

\subsubsection{FIBRAS}

As fibras alimentares podem ser tanto solúveis como insolúveis, ou fermentáveis e não fermentáveis (CHAVES, 2015). Muitos estudos mostram uma relação inversa entre uma dieta rica em frutas e verduras com o número de doenças cardiovasculares. Devido a ação conhecida como hipocolesterolemiante e hipotensora, que é feita pela ação das fibras, seu mecanismo de explicação é a diminuição da absorção lipídica e a reabsorção de colesterol e dos ácidos biliares, alteração na produção hepática e na produção de ácidos graxos de cadeia curta (PALIYATH et al., 2011; MOGHADASIAN e ESKIN, 2012).

\subsection{Mudanças dos HábitosAlimentares}

A indução de que os alimentos ultra processados são enriquecidos nutricionalmente vem sendo implantada cada dia mais na população, o que os tornam mais atraentes e utilizados com frequência (BRASIL, 2014).Porém uma pequena parcela da população se sensibiliza pelos efeitos provocados pelos hábitos alimentares adequados, com isso nota-se uma pequena, porém significante mudança no comportamento alimentar da sociedade (FERREIRA, 2018). 


\subsection{Mercado dos Alimentos Funcionais}

Os alimentos funcionais comercializados são agrupados em três categorias sendo elas convencionais, modificados e sintetizados. Os convencionais são definidos como alimentos com componentes bioativos naturais como: frutas, cereais integrais, verduras, peixes e lacticínios, como exemplo as vitaminas antioxidantes que estão no sumo da laranja, os probióticos e probióticos que estão nos iogurtes. Outro grupo são os modificados sendo então alimentos enriquecidos ou fortificados com componentes bioativos, sendo eles a margarinas e ovos com um aumento de ômega 3 na sua composição, cerais com aumento de vitaminas e minerais. A última categoria são os sintetizados sendo sintetizados industrialmente como por exemplo o amido resistente (CROWE e FRANCIS, 2013).

\subsection{Doenças Crônicas não Transmissiveis}

Doenças crônicas fazem parte das doenças de condições crônicas, estão relacionadas a múltiplas causas, identificadas por um início gradual, de prognóstico incerto, com uma longa ou não duração, apresentando quadros agudos podendo até levar a incapacidades. Necessitando então mudanças no estilo de vida, pois será um processo de cuidado contínuo, e grande parte não tendo cura (BRASIL, 2013).

Um dos maiores problemas a respeito das DCNT são a falta de adesão ao tratamento seja ele feito por medicamentos ou não, no qual o paciente deve assumir a responsabilidade sobre seu tratamento, se tornando um participante ativo em um processo que se pode variar a intensidade do estado biológico, e deve ser monitorado e acompanhado regularmente pela equipe de saúde (COELHO; AMARAL, 2012). 


\subsubsection{HIPERTENSÃO ARTERIAL SISTÊMICA}

É quando a pressão arterial se encontra persistentemente alta, é atualmente definida no qual a pressão sistólica é $140 \mathrm{~mm}$ hg, ou a pressão diastólica é de $90 \mathrm{~mm}$ hg ou superior a esses valores (SOCIEDADE BRASILEIRA DE CARDIOLOGIA/ SOCIEDADE BRASILEIRA DE HIPERTENSAO/ SOCIEDADE BRASILEIRA DE NEFRALOGIA/ SOCIEDADE BRASILEIRA DE CARDIOLOGIA, 2016).

\subsubsection{DIABETES MELLITUS}

Quando se tem o diagnostico deve ser feito o controle glicêmico, no qual é realizado para no tratamento, na prevenção e no retardo de mais complicações agudas e crônicas, aumentando a qualidade de vida e reduzindo as taxas de mortalidade (SOCIEDADE BRASILEIRA DE DIABETES, 2016 apud FIGUEIRA et al., 2017, p.2).

No tratamento da diabetes do tipo dois deve-se fazer mudanças no estilo de vida, como praticar exercícios físicos regularmente e ou fazer uma dieta adequada, caso o tratamento por medicamentos não fizer seus resultados esperados, é iniciada então os antidiabéticos orais, e em algumas situações faz o uso juntamente com a insulina (SOCIEDADE BRASILEIRA DE DIABETES, 2016 apud FIGUEIRA et al., 2017, p.2).

\subsubsection{DOENÇAS CARDIOVASCULARES}

Sabe-se que para ter de efetuar a redução das complicações cardiovasculares é de suma importância manter o controle da PA evitando então agravos e complicações, isso acontece devido a adesão ao tratamento na mudança do estilo de vida, tendo também alguns fatores nutricionais que podem interferir na pressão arterial como por exemplo: obesidade, consumo de gorduras, sódio, potássio e bebidas alcoólicas (COSTA, 2013). 


\section{MATERIAIS E MÉTODOS}

Para a obtenção dos resultados e respostas a respeito da avaliação do consumo de alimentos funcionais em adultos, o método utilizado foi por meio de uma pesquisa de natureza aplicada e descritiva, tendo como finalidade do estudo traçar uma investigação e obter os resultados a respeito do tema abordado, no qual foi aplicado um questionário de frequência alimentar. A coleta de informações e consolidação da pesquisa foi realizado um estudo de campo, na qual permite a extração de dados diretamente da fonte objetivada que são os adultos de 18 a 59 anos de idade, e ocasionalmente utilizando de entrevistas para reunir dados sólidos e objetivos dessa pesquisa. A pesquisa é de caráter quantitativo, e exposição de números e estatísticas. A pesquisa foi realizada via Google Forms, uma plataforma gratuita via Google para criação e execução de formulários on-line, podendo produzir pesquisas de múltipla escolha, elaborar questões discursivas, entre outras opções, com o total de 44 amostras.

Foi aplicado um questionário com diversos alimentos sendo divididos segundo a pirâmide alimentar (2005), são eles: cerais, pães e tubérculo; hortaliças; frutas; leguminosas; carnes e ovos; leite e derivados; óleos e gorduras; açúcares. Foram selecionados tanto alimentos comuns e cotidianos, quanto fonte de alimentos funcionais. Para responder o questionário o adulto teve que se recordar dos alimentos consumidos no último mês e sua frequência. Após a análise temos os níveis de frequência e conhecimento dos alimentos citados no questionário que foram relatados em porcentagem. Os dados obtidos a partir do questionário foram tabulados via planilha do Excel.

Questionário adaptado (MOLINA et al., 2013) de frequência alimentar é composto por 48 alimentos, divididos em alimentos, frequência alimentar no qual possui 9 opções de resposta sendo elas, "1 vez ao dia ", "2 vezes ao dia ", "3 vezes ou mais ao dia ", "1 vez por semana ", "2 a 3 vezes por semana ", "4 a 5 vezes por semana ", "6 vezes ou mais por semana ", "1 a 3 vezes ao mês "e "quase 
nunca ", e por fim alimentos "que nunca consome" ou "não conhece o alimento". Adicionalmente, em respeito aos sujeitos do estudo todos os participantes tiveram que assinar pelos pais e/ou responsáveis o Termo de Consentimento Livre e Esclarecido (TCLE). Além disso, a presente pesquisa foi submetida e aprovada pelo Comitê de Ética e Pesquisa (CEP) da Universidade Vale do Rio Verde Unincor, via plataforma Brasil, com protocolo 51216521.5.0000.5158.

\section{RESULTADOS E DISCUSSÃO}

\subsection{Resultados Descritivos}

Foram analisados 44 indivíduos, sendo $68,2 \%$ do sexo feminino e $31,8 \%$ do sexo masculino, com idade média de 38,2 e $\pm 12,26$ anos. Na figura 1 foram apresentados os dados relativos à distribuição por faixa etária dos entrevistados.

Figura 1. Distribuição dos entrevistados segundo faixa etária.

\section{Distribuição dos entrevistados: Faixa Etária}

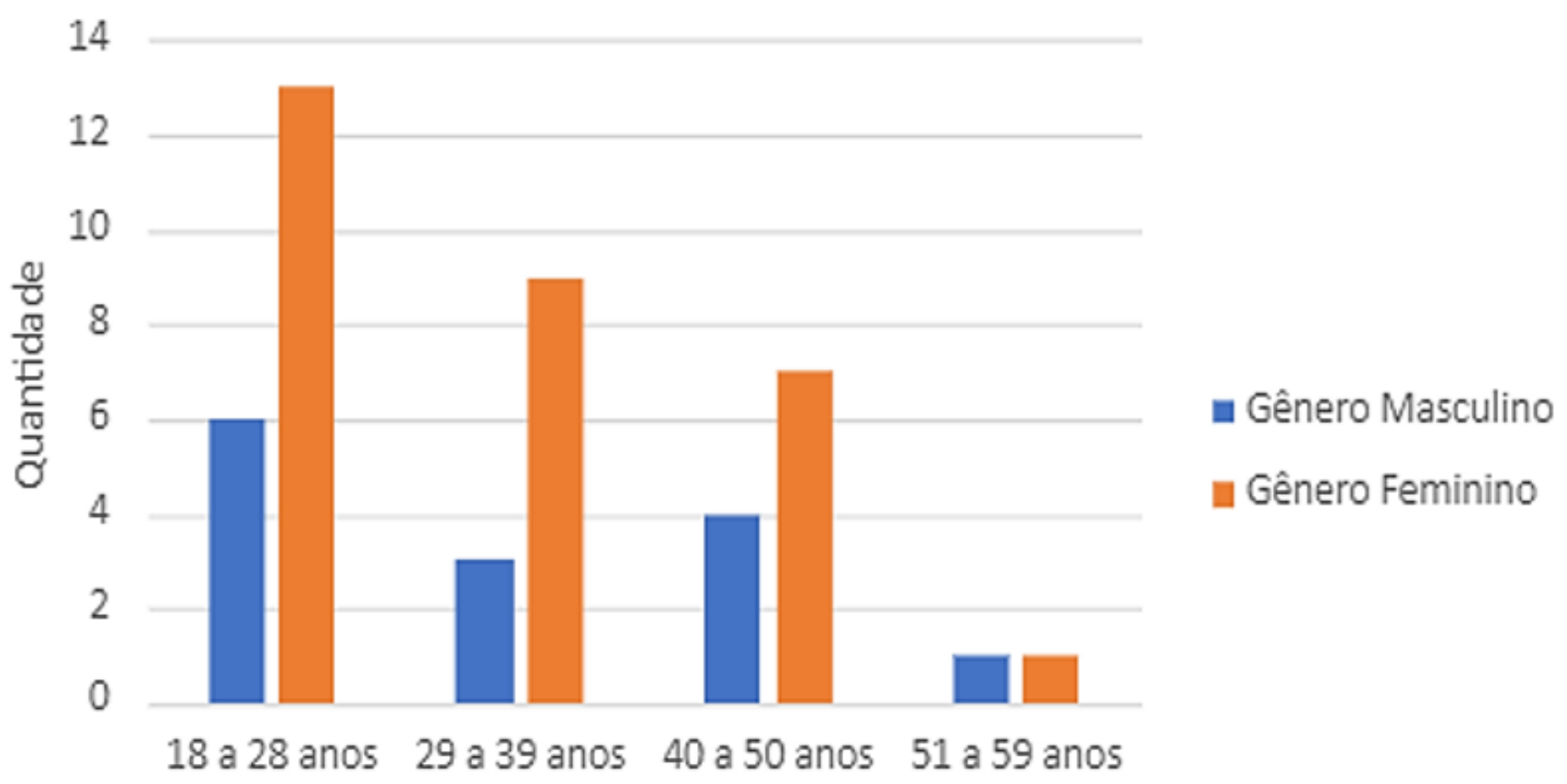

Faixa Etária

Fonte: Próprio autor (2021). 
Na Figura 2 foram apresentados os dados relativos à distribuição do grau de escolaridade de acordo com o gênero. Observou-se que o gênero feminino teve maior prevalência sobre o ensino superior incompleto, e do gênero masculino, teve menor prevalência com ensino fundamental completo.

Figura 2. Distribuição dos entrevistados segundo escolaridade.

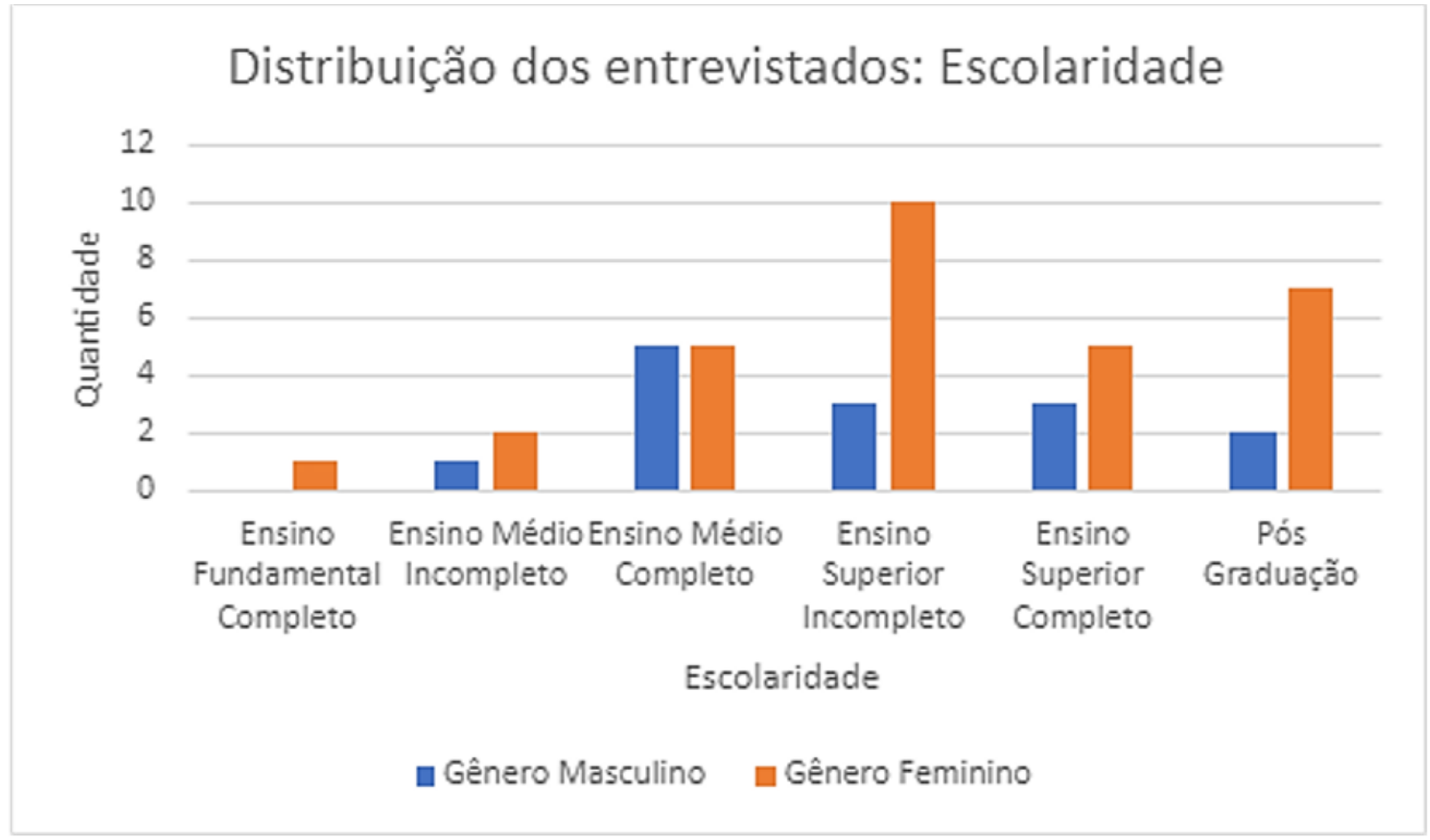

Fonte: Próprio autor (2021).

Quando questionados sobre seus hábitos alimentares, grande parte dos indivíduos consome com frequência alimentos fontes de carboidratos simples. $\mathrm{Na}$ tabela 1 foram apresentados os dados característicos em relação ao consumo de alimentos pertencentes aos grupos dos cereais, pães e tubérculos.

De acordo com dados obtidos por Figueirêdo-Ronaldo et al.,2015, o padrão alimentar contemporâneo adotado gradativamente nos últimos 20 anos, é caracterizado pelo elevado consumo de alimentos ricos em carboidratos simples, sódio e gorduras saturadas, bem como por reduzida ingestão de alimentos fontes de fibras, ácidos graxo insaturados, o que pode justificar o consumo elevado dos participantes. 
Bacharelado em Nutrição da UninCor e iniciação à pesquisa: Com a palavra os nossos estudantes

Tabela 1. Sobre o consumo dos indivíduos de cereais, pães e tubérculos.

\begin{tabular}{|c|c|c|c|c|c|c|c|c|}
\hline \multicolumn{9}{|c|}{ Cerais, pães e tubérculos } \\
\hline & \multicolumn{2}{|c|}{ Arroz } & \multicolumn{2}{|c|}{ Macarrão } & \multicolumn{2}{|c|}{ Pão francês } & \multicolumn{2}{|c|}{ Millho } \\
\hline & $\mathbf{N}$ & $\%$ & $\mathbf{N}$ & $\%$ & $\mathbf{N}$ & $\%$ & $\mathbf{N}$ & $\%$ \\
\hline Frequente & 42 & $\begin{array}{c}95,45 \\
\%\end{array}$ & 23 & $\begin{array}{c}52,27 \\
\%\end{array}$ & 31 & $\begin{array}{c}70,45 \\
\%\end{array}$ & 14 & $\begin{array}{c}31,82 \\
\%\end{array}$ \\
\hline Raramente & 2 & $\begin{array}{c}4,55 \\
\%\end{array}$ & 20 & $\begin{array}{c}45,45 \\
\%\end{array}$ & 9 & $\begin{array}{c}20,45 \\
\%\end{array}$ & 27 & $\begin{array}{c}61,36 \\
\%\end{array}$ \\
\hline \multirow[t]{3}{*}{ Nunca } & 0 & $\begin{array}{c}0,00 \\
\%\end{array}$ & 1 & $\begin{array}{c}2,27 \\
\%\end{array}$ & 4 & $\begin{array}{c}9,09 \\
\%\end{array}$ & 3 & $\begin{array}{c}6,82 \\
\%\end{array}$ \\
\hline & \multicolumn{2}{|c|}{ Batata } & \multicolumn{2}{|c|}{ Tapioca } & \multicolumn{2}{|c|}{ Aveia } & \multicolumn{2}{|c|}{ Granola } \\
\hline & $\mathbf{N}$ & $\%$ & $\mathbf{N}$ & $\%$ & $\mathbf{N}$ & $\%$ & $\mathbf{N}$ & $\%$ \\
\hline Frequente & 27 & $\begin{array}{c}61,36 \\
\%\end{array}$ & 7 & $\begin{array}{c}15,91 \\
\%\end{array}$ & 15 & $\begin{array}{c}34,09 \\
\%\end{array}$ & 4 & $\begin{array}{c}9,09 \\
\%\end{array}$ \\
\hline Raramente & 17 & $\begin{array}{c}38,64 \\
\%\end{array}$ & 21 & $\begin{array}{c}47,73 \\
\%\end{array}$ & 18 & $\begin{array}{c}40,91 \\
\%\end{array}$ & 23 & $\begin{array}{c}52,27 \\
\%\end{array}$ \\
\hline Nunca & 0 & $\begin{array}{c}0,00 \\
\%\end{array}$ & 16 & $\begin{array}{c}36,36 \\
\%\end{array}$ & 11 & $\begin{array}{c}25,00 \\
\%\end{array}$ & 17 & $\begin{array}{c}38,64 \\
\%\end{array}$ \\
\hline
\end{tabular}

Fonte: Próprio autor (2021).

Em relação ao consumo de hortaliças, nota-se que o consumo dos indivíduos apresenta índices mais baixos. Na Tabela 2 foram apresentados os dados e valores referentes à quantidade absoluta e percentual do número de entrevistados que consomem hortaliças. 
Algo parecido ocorreu no trabalho de Macedo, Sousa e Fernandez (2018), onde constataram que uma pequena parte consumia verduras com frequência. Esse baixo consumo de hortaliças como o repolho, almeirão, funcho, brócolis e couve-flor, pode ser associado a diversos motivos visto que, os econômicos, culturais e acesso facilitado a informações e aos alimentos são os que mais interferem no consumo alimentar de uma população.

Tabela 2. Sobre o consumo dos indivíduos de hortaliças.

\begin{tabular}{|c|c|c|c|c|c|c|c|c|c|c|c|c|}
\hline \multicolumn{10}{|c|}{ Hortaliças } \\
\hline & \multicolumn{2}{|c|}{ Alface } & \multicolumn{2}{|c|}{ Repolho } & \multicolumn{1}{|c|}{ Almeirão } & \multicolumn{2}{|c|}{ Funcho } & \multicolumn{2}{|c|}{ Brócolis } & \multicolumn{2}{|c|}{ Couve-filor } \\
\hline & $N$ & $\%$ & $N$ & $\%$ & $N$ & $\%$ & $N$ & $\%$ & $N$ & $\%$ & $N$ & $\%$ \\
\hline Frequente & 43 & $97,73 \%$ & 18 & $\begin{array}{c}40,91 \\
\%\end{array}$ & 9 & $20,45 \%$ & 3 & $\begin{array}{c}6,82 \\
\%\end{array}$ & 21 & $\begin{array}{c}47,73 \\
\%\end{array}$ & 20 & $\begin{array}{c}45,45 \\
\%\end{array}$ \\
\hline Raramente & 1 & $\begin{array}{c}2,27 \\
\%\end{array}$ & 23 & $\begin{array}{c}52,27 \\
\%\end{array}$ & 24 & $54,55 \%$ & 24 & $\begin{array}{c}54,55 \\
\%\end{array}$ & 21 & $\begin{array}{c}47,73 \\
\%\end{array}$ & 21 & $\begin{array}{c}47,73 \\
\%\end{array}$ \\
\hline Nunca & 0 & $\begin{array}{c}0,00 \\
\%\end{array}$ & 3 & $\begin{array}{c}6,82 \\
\%\end{array}$ & 11 & $25,00 \%$ & 17 & $\begin{array}{c}38,64 \\
\%\end{array}$ & 2 & $\begin{array}{c}4,55 \\
\%\end{array}$ & 3 & $\begin{array}{c}6,82 \\
\%\end{array}$ \\
\hline
\end{tabular}

Fonte: Próprio autor (2021).

Nota-se que a alface é o alimento desse grupo que os entrevistados mais consomem, sendo o único alimento que todos os entrevistados consomem mesmo que raramente. Dado encontrado pela pesquisa de Silva et al., 2016 que consumo dos vegetais, como por exemplo a alface, vem crescendo devido à mudança nos hábitos alimentares. No Brasil, a alface é a hortaliça mais consumida e comercializada. Este alimento é um dos componentes básicos no preparo de saladas, pois apresenta um baixo valor calórico, boa fonte de vitaminas e de sais minerais e fácil aquisição.

Sobre o consumo de frutas, observou-se que a maioria da amostra consome frequentemente frutas, com o consumo relatado de banana, maçã e laranja 
Bacharelado em Nutrição da UninCor e iniciação à pesquisa: Com a palavra os nossos estudantes

se destacando na maior parte da amostra participante da pesquisa. Já as frutas: abacaxi, abacate, melancia, maracujá e uva têm a baixa frequência de consumo, sendo mais raramente consumidas.

Os dados obtidos no presente estudo, demonstraram que uma grande maioria da amostra tem o consumo de algumas frutescem baixa frequência. Resultado também encontrado no estudo de Soares et al., 2018, que constatou que o baixo consumo de frutas pode ser fundamentado por vários fatores, incluindo um nível financeiro inferior ou até mesmo por falta de alimentos de qualidade, que são fortemente afetados pela cultura e estação do ano.

Tabela 3. Sobre o consumo dos indivíduos de frutas.

\begin{tabular}{|c|c|c|c|c|c|c|c|c|}
\hline \multirow{2}{*}{} & \multicolumn{2}{|c|}{ Banana } & \multicolumn{2}{|c|}{ Maça } & \multicolumn{2}{|c|}{ Laranja } & \multicolumn{2}{|c|}{ Abacaxi } \\
\hline & $N$ & $\%$ & $N$ & $\%$ & $N$ & $\%$ & $N$ & $\%$ \\
\hline Frequente & 34 & $\begin{array}{c}77,27 \\
\%\end{array}$ & 29 & $\begin{array}{c}65,91 \\
\%\end{array}$ & 30 & $\begin{array}{c}68,18 \\
\%\end{array}$ & 16 & $\begin{array}{c}36,36 \\
\%\end{array}$ \\
\hline Raramente & 9 & $\begin{array}{c}20,45 \\
\%\end{array}$ & 15 & $\begin{array}{c}34,09 \\
\%\end{array}$ & 14 & $\begin{array}{c}31,82 \\
\%\end{array}$ & 26 & $\begin{array}{c}59,09 \\
\%\end{array}$ \\
\hline Nunca & 1 & $\begin{array}{c}2,27 \\
\%\end{array}$ & 0 & $\begin{array}{c}0,00 \\
\%\end{array}$ & 0 & $\begin{array}{c}0,00 \\
\%\end{array}$ & 2 & $\begin{array}{c}4,55 \\
\%\end{array}$ \\
\hline \multirow{2}{*}{ Frequente } & 5 & $\begin{array}{c}11,36 \\
\%\end{array}$ & 11 & $\begin{array}{c}25,00 \\
\%\end{array}$ & 10 & $\begin{array}{c}22,73 \\
\%\end{array}$ & 17 & $\begin{array}{c}38,64 \\
\%\end{array}$ \\
\hline Raramente & 30 & $\begin{array}{c}68,18 \\
\%\end{array}$ & 30 & $\begin{array}{c}68,18 \\
\%\end{array}$ & 29 & $\begin{array}{c}65,91 \\
\%\end{array}$ & 24 & $\begin{array}{c}54,55 \\
\%\end{array}$ \\
\hline Nunca & 9 & $\begin{array}{c}20,45 \\
\%\end{array}$ & 3 & $\begin{array}{c}6,82 \\
\%\end{array}$ & 5 & $\begin{array}{c}11,36 \\
\%\end{array}$ & 3 & $\begin{array}{c}6,82 \\
\%\end{array}$ \\
\hline
\end{tabular}

Fonte: Próprio autor (2021). 
Em relação ao consumo de leguminosas, observou-se no presente estudo, que a maioria da amostra consome frequentemente e alguns alimentos fontes de fibras como o feijão, possuem um índice de consumo elevado e outras fontes de fibras como grão de bico, lentilha e ervilha, possuem um índice mais baixo de consumo. Na tabela 4 foram apresentados os dados relativos ao consumo de leguminosas pelos indivíduos participantes da pesquisa.

Tabela 4. Consumo de Leguminosas.

\begin{tabular}{|c|c|c|c|c|c|c|c|c|c|c|}
\hline & \multicolumn{2}{|c|}{ Feijão } & \multicolumn{2}{|c|}{ Lentilha } & \multicolumn{2}{c|}{$\begin{array}{c}\text { Grão de } \\
\text { Bico }\end{array}$} & \multicolumn{2}{c|}{ Ervilha } & \multicolumn{2}{c|}{ Amendoins } \\
\cline { 2 - 11 } & $N$ & $\%$ & $N$ & $\%$ & $N$ & $\%$ & $N$ & $\%$ & $N$ & $\%$ \\
\hline Frequente & 41 & $\begin{array}{c}93,18 \\
\%\end{array}$ & 1 & $\begin{array}{c}2,27 \\
\%\end{array}$ & 1 & $\begin{array}{c}2,27 \\
\%\end{array}$ & 2 & $\begin{array}{c}4,55 \\
\%\end{array}$ & 10 & $\begin{array}{c}22,73 \\
\%\end{array}$ \\
\hline Raramente & 3 & $\begin{array}{c}6,82 \\
\%\end{array}$ & 14 & $\begin{array}{c}31,82 \\
\%\end{array}$ & 15 & $\begin{array}{c}34,09 \\
\%\end{array}$ & 18 & $\begin{array}{c}40,91 \\
\%\end{array}$ & 25 & $\begin{array}{c}56,82 \\
\%\end{array}$ \\
\hline Nunca & 0 & $\begin{array}{c}0,00 \\
\%\end{array}$ & 29 & $\begin{array}{c}65,91 \\
\%\end{array}$ & 28 & $\begin{array}{c}63,64 \\
\%\end{array}$ & 24 & $\begin{array}{c}54,55 \\
\%\end{array}$ & 9 & $\begin{array}{c}20,45 \\
\%\end{array}$ \\
\hline
\end{tabular}

Fonte: Próprio autor (2021).

O feijão é o único alimento que todos os entrevistados consomem e também o alimento desse grupo que os entrevistados consomem com maior frequência. De acordo com os dados relatados por DEPEC, 2017 o feijão é uma leguminosa relevante no âmbito nacional, em destaque pela combinação habitual nas refeições brasileiras na forma de "arroz e feijão", sendo o Brasil o principal consumidor mundial de feijão.

Segundo dados obtidos, os indivíduos consomem frequentemente o feijão, tendo uma queda na frequência do consumo de alimentos como lentilha, grão 
de bico, ervilha e amendoim. Dados parecidos foram encontrados no estudo de Silva Junior, Abreu e Silva (2017), os resultados sobre o consumo de fibras foram bem a baixos.

A Tabela 5 apresenta os valores referentes à quantidade absoluta e percentual do número de entrevistados que consomem carnes. Em relação ao consumo de carnes e outras fontes de proteína animal, os alimentos fontes de gordura saturadas como carnes bovinas, suínas e aves, queijos e leite de vaca, apresentam um consumo elevado e frequente pela a amostra.

Tabela 5. Consumo de Carnes.

\begin{tabular}{|c|c|c|c|c|c|c|c|c|c|c|}
\hline & \multicolumn{2}{|c|}{$\begin{array}{c}\text { Carne } \\
\text { Bovina }\end{array}$} & \multicolumn{2}{c|}{$\begin{array}{c}\text { Carne } \\
\text { Suina }\end{array}$} & \multicolumn{2}{c|}{$\begin{array}{c}\text { Carne } \\
\text { de Aves }\end{array}$} & \multicolumn{2}{c|}{ Peixes } & \multicolumn{2}{c|}{ Ovos } \\
\cline { 2 - 11 } & $N$ & $\%$ & $N$ & $\%$ & $N$ & $\%$ & $N$ & $\%$ & $N$ & $\%$ \\
\hline Frequente & 41 & $\begin{array}{c}93,18 \\
\%\end{array}$ & 27 & $\begin{array}{c}61,36 \\
\%\end{array}$ & 41 & $\begin{array}{c}93,18 \\
\%\end{array}$ & 10 & $\begin{array}{c}22,73 \\
\%\end{array}$ & 41 & $\begin{array}{c}93,18 \\
\%\end{array}$ \\
\hline Raramente & 3 & $\begin{array}{c}6,82 \\
\%\end{array}$ & 16 & $\begin{array}{c}36,36 \\
\%\end{array}$ & 3 & $\begin{array}{c}6,82 \\
\%\end{array}$ & 33 & $\begin{array}{c}75,00 \\
\%\end{array}$ & 3 & $\begin{array}{c}6,82 \\
\%\end{array}$ \\
\hline Nunca & 0 & $\begin{array}{c}0,00 \\
\%\end{array}$ & 1 & $\begin{array}{c}2,27 \\
\%\end{array}$ & 0 & $\begin{array}{c}0,00 \\
\%\end{array}$ & 1 & $\begin{array}{c}2,27 \\
\%\end{array}$ & 0 & 0,00 \\
$\%$
\end{tabular}

Fonte: Próprio autor (2021).

O peixe é de menor alimento consumido entre os entrevistados. Segundo Campos et al., 2015 O consumo de peixes pela população brasileira é considerado baixo quando comparado com países europeus ou latino-americanos, nos quais o consumo atinge facilmente o dobro do consumo no Brasil, pois o valor do peixe em algumas regiões do Brasil é consideravelmente alto para ser consumido com certa frequência. 
Em relação ao consumo de leites e derivados observou-se que a maioria da amostra constatou que a amostra entrevistada tem o consumo com maior frequência do leite de vaca, logo após os queijos, iogurtes e por último e com o maior percentual de que nunca é consumido, o leite de soja. Na tabela 6 foram apresentados os dados relativos ao consumo de leite e derivados pelos indivíduos participantes da pesquisa.

Pessoa et al., 2018, encontrou em sua pesquisa dados opostos, apresentando entre as preferências com maiores consumos sendo em primeiro lugar o queijo e em seguida o iogurte. De acordo com Siqueira et al., 2018, o leite de vaca e seus derivados estão entre as fontes mais baratas de proteína, vitamina $D$, cálcio e vitamina A no Brasil.

Tabela 6. Sobre o consumo dos indivíduos de leites e derivados.

\begin{tabular}{|c|c|c|c|c|c|c|c|c|}
\hline & \multicolumn{2}{|l|}{ Leite de Vaca } & \multicolumn{2}{|c|}{ Leite de Soja } & \multicolumn{2}{c|}{ Queijos } & \multicolumn{2}{c|}{ logurtes } \\
\cline { 2 - 9 } & $N$ & $\%$ & $N$ & $\%$ & $N$ & $\%$ & $N$ & $\%$ \\
\hline Frequente & 34 & $\begin{array}{c}77,27 \\
\%\end{array}$ & 3 & $\begin{array}{c}6,82 \\
\%\end{array}$ & 33 & $\begin{array}{c}75,00 \\
\%\end{array}$ & 25 & $\begin{array}{c}56,82 \\
\%\end{array}$ \\
\hline Raramente & 6 & $\begin{array}{c}13,64 \\
\%\end{array}$ & 8 & $\begin{array}{c}18,18 \\
\%\end{array}$ & 11 & $\begin{array}{c}25,00 \\
\%\end{array}$ & 15 & $\begin{array}{c}34,09 \\
\%\end{array}$ \\
\hline Nunca & 4 & $\begin{array}{c}9,09 \\
\%\end{array}$ & 33 & $\begin{array}{c}75,00 \\
\%\end{array}$ & 0 & $\begin{array}{c}1,00 \\
\%\end{array}$ & 4 & $\begin{array}{c}9,09 \\
\%\end{array}$ \\
\hline
\end{tabular}

Fonte: Próprio autor (2021). 
Em relação ao consumo de óleos e gorduras observou-se que a maioria da amostra consome frequentemente azeite de oliva e com o menor consumo de óleo de coco. Na tabela 7 foram apresentados os dados relativos ao consumo de óleos e gorduras dos indivíduos participantes da pesquisa.

Segundo Lima et al., 2015, chegou aos resultados o consumo não frequente de óleos vegetais e azeite de oliva. Resultados sãos divergentes perante o encontrado na pesquisa em relação ao consumo de óleos vegetais e azeite de oliva foram consumidos com grande frequência pelos participantes da amostra.

Tabela 7. Consumo de Óleos e Gorduras.

\begin{tabular}{|c|c|c|c|c|c|c|c|c|c|c|c|c|}
\hline & \multicolumn{2}{|c|}{ Manteiga } & \multicolumn{2}{|c|}{ Margarina } & \multicolumn{2}{|c|}{$\begin{array}{l}\text { Óleos } \\
\text { Vegetais }\end{array}$} & \multicolumn{2}{|c|}{$\begin{array}{l}\text { Óleo de } \\
\text { Coco }\end{array}$} & \multicolumn{2}{|c|}{$\begin{array}{c}\text { Azeite de } \\
\text { Oliva }\end{array}$} & \multicolumn{2}{|c|}{$\begin{array}{l}\text { Castanhas } \\
\text { em Geral }\end{array}$} \\
\hline & $\mathbf{N}$ & $\%$ & $\mathbf{N}$ & $\%$ & $\mathbf{N}$ & $\%$ & $\mathbf{N}$ & $\%$ & $\mathbf{N}$ & $\%$ & $\mathrm{~N}$ & $\%$ \\
\hline Frequente & 22 & $\begin{array}{c}50,00 \\
\%\end{array}$ & 22 & $\begin{array}{c}50,00 \\
\%\end{array}$ & 30 & $\begin{array}{c}68,18 \\
\%\end{array}$ & 2 & $\begin{array}{c}4,55 \\
\%\end{array}$ & 33 & $\begin{array}{c}75,00 \\
\%\end{array}$ & 7 & $\begin{array}{c}15,91 \\
\%\end{array}$ \\
\hline Raramente & 18 & $\begin{array}{c}40,91 \\
\%\end{array}$ & 16 & $\begin{array}{c}36,36 \\
\%\end{array}$ & 8 & $\begin{array}{c}18,18 \\
\%\end{array}$ & 10 & $\begin{array}{c}22,73 \\
\%\end{array}$ & 11 & $\begin{array}{c}25,00 \\
\%\end{array}$ & 24 & $\begin{array}{c}54,55 \\
\%\end{array}$ \\
\hline Nunca & 4 & $\begin{array}{c}9,09 \\
\%\end{array}$ & 6 & $\begin{array}{c}13,64 \\
\%\end{array}$ & 6 & $\begin{array}{c}13,64 \\
\%\end{array}$ & 32 & $\begin{array}{c}72,73 \\
\%\end{array}$ & 2 & $\begin{array}{c}0,00 \\
\%\end{array}$ & 13 & $\begin{array}{c}29,54 \\
\%\end{array}$ \\
\hline
\end{tabular}

Fonte: Próprio autor (2021).

Nesse grupo, o azeite de oliva é o alimento consumido com maior frequência pelos entrevistados. Segundo dados obtidos por Louzada et al., 2015 o azeite de oliva tem alto índice de consumo e é preferível se comparado às opções de fonte de gorduras saturadas, pois são gorduras que agem reduzindo processos inflamatórios, evitam o surgimento de coágulos, reduzindo danos vasculares e 
desempenhando importante papel em alergias, enquanto que a gordura saturada tem propriedades que contribuem para o surgimento de problemas de saúde.

Em relação ao consumo de açúcares observou-se que a maioria da amostra consome frequentemente o açúcar cristal, com o menor consumo do açúcar mascavo. Na tabela 8 foram apresentados os dados relativos ao consumo de açúcares dos indivíduos participantes da pesquisa.

Segundo Louzada et al., 2015 um impacto do consumo desse grupo de açúcares, ainda há um consumo excessivo do açúcar cristal, ou vindo de outras fontes. Dado condizente com a pesquisa, no qual o açúcar cristal é um alimento consumido frequentemente e o chocolate com a maioria dos entrevistados das amostras consumindo com frequência. Já os alimentos bolos, sorvetes e mel são consumidos raramente e o açúcar mascavo grande maioria da amostra nunca consomem o alimento.

Tabela 8. Consumo de Açúcares.

\begin{tabular}{|c|c|c|c|c|c|c|c|c|c|c|c|c|}
\hline \multicolumn{13}{|c|}{ Açúcares } \\
\hline & \multicolumn{2}{|c|}{ Chocolates } & \multicolumn{2}{|c|}{ Sorvetes } & \multicolumn{2}{|c|}{ Bolos } & \multicolumn{2}{|c|}{$\begin{array}{l}\text { Açúcar } \\
\text { Cristal }\end{array}$} & \multicolumn{2}{|c|}{ Mel } & \multicolumn{2}{|c|}{$\begin{array}{l}\text { Açúcar } \\
\text { Mascavo }\end{array}$} \\
\hline & N & $\%$ & N & $\%$ & N & $\%$ & N & $\%$ & N & $\%$ & N & $\%$ \\
\hline Frequente & 25 & $\begin{array}{c}56,82 \\
\%\end{array}$ & 11 & $\begin{array}{c}25,00 \\
\%\end{array}$ & 15 & $\begin{array}{c}34,09 \\
\%\end{array}$ & 33 & $\begin{array}{c}75,00 \\
\%\end{array}$ & 7 & $\begin{array}{c}15,91 \\
\%\end{array}$ & 0 & $\begin{array}{c}0,00 \\
\%\end{array}$ \\
\hline Raramente & 18 & $\begin{array}{c}40,91 \\
\%\end{array}$ & 31 & $\begin{array}{c}70,45 \\
\%\end{array}$ & 28 & $\begin{array}{c}63,64 \\
\%\end{array}$ & 10 & $\begin{array}{c}22,73 \\
\%\end{array}$ & 25 & $\begin{array}{c}56,82 \\
\%\end{array}$ & 15 & $\begin{array}{c}34,09 \\
\%\end{array}$ \\
\hline Nunca & 1 & $\begin{array}{c}2,27 \\
\%\end{array}$ & 2 & $\begin{array}{c}4,55 \\
\%\end{array}$ & 1 & $\begin{array}{c}2,27 \\
\%\end{array}$ & 1 & $\begin{array}{c}2,27 \\
\%\end{array}$ & 12 & $\begin{array}{c}27,27 \\
\%\end{array}$ & 29 & $\begin{array}{c}65,91 \\
\%\end{array}$ \\
\hline
\end{tabular}

Fonte: Próprio autor (2021). 
Bacharelado em Nutrição da UninCor e iniciação à pesquisa: Com a palavra os nossos estudantes

O açúcar cristal comum é o alimento desse grupo que a maior parte dos entrevistados consome frequentemente, já o açúcar mascavo é o alimento nenhum dos entrevistados consomem com frequência. De acordo com os dados obtidos por Luchini, 2014 o açúcar mascavo vem sendo cada vez mais valorizado por ser um produto natural e sem aditivos químicos. O seu consumo cresceu nos últimos anos por ser um alimento mais nutritivo em sua composição e vem sendo cada vez mais utilizado para substituir o açúcar refinado, resultado encontrado divergente no presente estudo, no qual a maioria dos entrevistados nunca consomem o alimento.

\section{CONCLUSÃO}

As principais conclusões do estudo mostram que a população avaliada tem baixo consumo frequente de alimentos funcionais tais como alimentos fontes probióticos, probióticos, flavonoides, flavonóis, isoflavonas, fibras e ácidos graxos. Foi confirmado também que a idade tem influência no consumo de alguns alimentos que estavam na aplicação da pesquisa pais como hortaliças, frutas, carnes, leites e derivados, óleos e gordura e açucares, sendo o de maior influência no consumo dos alimentos contidos na pesquisa.

Longe de esgotar a discussão nesse tema, e considerando que o consumo frequente de alimentos bioativos podem colaborar para melhoria da qualidade da saúde, cabe então destacar a importância da realização de estudos que se aprofundem mais no consumo frequente destes alimentos funcionais, para que o desenvolvimento de caráter específicos a respeito do tema possam colaborar cada vez mais para melhoria da saúde de todos, podendo diminuindo o risco de doenças crônicas não transmissíveis e ajudando no controle daqueles que já possuem essas doenças, trazendo mais qualidade de vida e bem estar. Sugerindo então que outros autores continuem a realizar o presente estudo, considerando o número atual de amostras no qual devem ser maiores. 


\section{REFERÊNCIAS}

BAPTISTA, I. C.; GENTA, T. M. S.; CALDERELLI, V. A. S.; MAURÍCIO, A. A.; PORTILHO, M. e MATIOLI, G. Conhecimento da comunidade universitária em relação aos alimentos funcionais. Acta Scientiarum - Health Sciences, v. 35 , n. 1, p. 15-21, 2013.

BRASIL. Ministério da Saúde. Gabinete do Ministro. Portaria n. 2.436 de 21 de setembro de 2017. Aprova a Política Nacional de Atenção Básica, estabelecendo a revisão de diretrizes para a organização da Atenção Básica, no âmbito do Sistema Único de Saúde (SUS).

CAMPOS, J. L.; ONO, E. A.; ISTCHUK, P. I. Tambaqui, considerações sobre a cadeia de produção e o preço. Panorama da Aquicultura, v. 25, n. 149, p. $42-$ 45, 2015.

COELHO, C. R.; AMARAL, V.L.A.R. Análise dos comportamentos de adesão ao tratamento em adultos portadores de diabetes mellitus tipo 2. RevBras Ter ComportCogn.v.14, n. 1, p. 4-15, 2012.

COSTA, N. M. B. e ROSA, C. D. O. B. Alimentos funcionais: componentes bioativos e efeitos fisiológicos. $2^{\mathrm{a}}$ ed. Rio de Janeiro: Rubio, 2016.

DEPEC. Departamento de Pesquisas e Estudos Econômicos/ Feijão - BRADESCO. 2017.

FIGUEIRÊDO-REINALDOED, DA SILVA MRF, NARDOTO GB et al. Mudanças de hábitos alimentares em comunidades rurais do semiárido da região Nordeste do Brasil. Inter ciência, 2015;

GALLOWAY, K. R.; BRETZ, S. L. e NOVAK, M. Paper chromatography and UVVis spectroscopy to characterize anthocyanins and investigate antioxidant properties in the organic teaching laboratory. Journal of Chemical Education, v. 92 , n. 1 , p. $183-188,2015$.

LIMA GS, PORTOKAO, SOUZATKM et al. Avaliação do estado nutricional e consumo alimentar de alcoolistas atendidos em um centro de reabilitação de Caruaru-PE, Brasil. Nutrición Clinica y Dietética Hospitalaria, 2015.

LOUZADA, M. L. et al. Alimentos ultraprocessados e perfil nutricional da dieta no Brasil.RevSaude Publica, v. 49, p. 38, 2015. 
Bacharelado em Nutrição da UninCor e iniciação à pesquisa: Com a palavra os nossos estudantes

LOUZADA, Maria Laura da Costa et al. Ultra-processed foods and the nutritional dietary profile in Brazil. Revista de Saúde Pública, [s.I.], v. 49, p.1-11, 2015.

LUCHINI, P. D. Teores de nutrientes minerais e metais pesados em açúcar mascavo produzido por diferentes sistemas orgânicos e convencionais. 2014. $66 \mathrm{f}$.

MACEDO, T. S.; Sousa, A. L.; Fernandez, N. C. Suplementação e consumo alimentar em praticantes de musculação. Revista Brasileira de Nutrição Esportiva. São Paulo. Vol. 11. Num. 68. p. 974-985. 2018.

PESSOA, R. M. S.; GOIS, G. C.; SILVA, A. A. F.; CAMPOS, F. S.; LIMA, C. A. $B$. Perfil dos consumidores de leite e derivados lácteos do município de Olho D'água - Paraíba. Nutritime Revista Eletrônica, on-line, Viçosa, v.15, n.02, p.8142-8146, mar./abr, 2018.

SILVA, OMP et al. Qualitative performance of lettuce cultivars in four seasons in Mossoró, Rio Grande do Norte State, Brazil. Rev Ceres. v.63, n.6, p.843-852, 2016.

SILVA-JUNIOR, R.; Abreu, W. C.; Silva, R. F. Composição corporal, consumo alimentar e hidratação de praticantes de musculação. Revista Brasileira de Nutrição Esportiva. São Paulo.Vol. 11. Num. 68. p. 936-946. 2017.

SIQUEIRA, K. B.; BINOTI, M. L.; NUNES, R. M.; BORGES, C. A. V.; PILATI, A. F.;

MARCELINO, G. W.; GAMA, M. A. S.; SILVA, P. H. F. Custo benefício dos nutrientes dos alimentos consumidos no Brasil. Ciencia\&Saude Coletiva, ago. 2018.

SOARES, T. C.; Alves, A. E. S.; Barros, E. C. S.; Barros, N.V. A.; Cavalcante, R. M.S. Avaliação do consumo de suplementos nutricionais, frutas e vegetais por usuários de academias em de Picos-PI. Revista Brasileira de Nutrição Esportiva. São Paulo. Vol. 12. Num. 75. p. 951-960. 2018.

SOCIEDADE BRASILEIRA DE CARDIOLOGIA/SOCIEDADE BRASILEIRA DE HIPERTENSAO/SOCIEDADE BRASILEIRA DE NEFROLOGIA. VII Diretrizes Brasileiras de Hipertensão. ArqBras Cardiologia. São Paulo, v. 95, Supl 1, 2016. 


\section{SOBRE O ORGANIRADOR}

\section{GALDINO SOUSA}

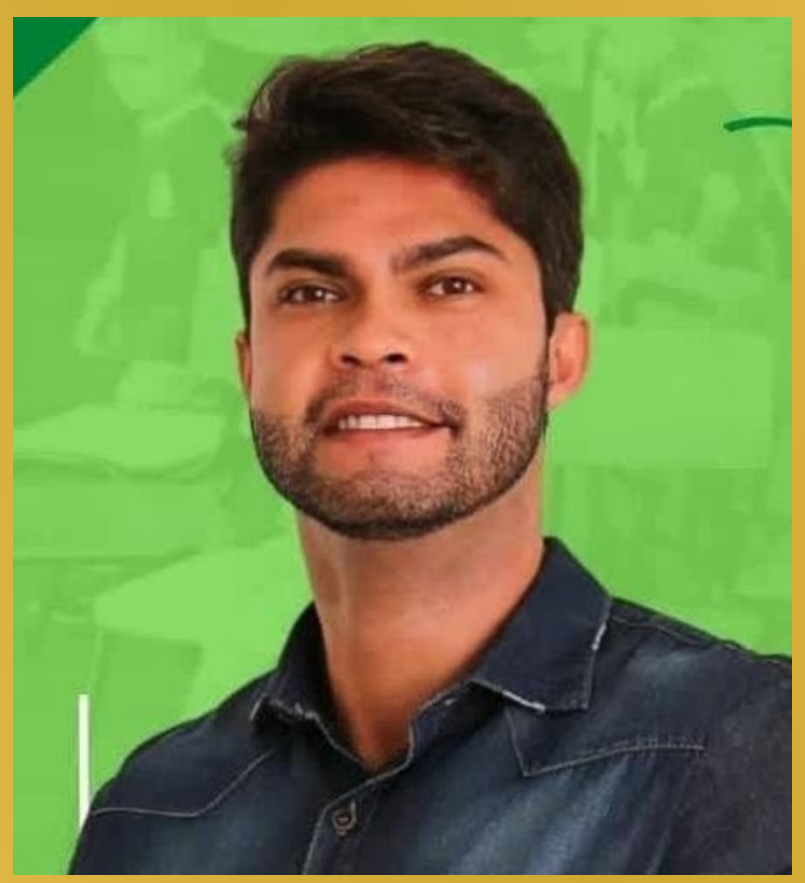

Doutor em Educação Fúsica (UFES), mestre em Educação (UFJF), especialista em Ensino de Educação Fúsica (PUC/MG), licenciado em Educação Física (UFSJ). Foi professor dos cursos de licenciatura e bacharelado em Educação Fúsica da Universidade Federal do Espírito Santo (UFES). Foi professor de Educação Básica do Estado de Minas Gerais, do município de Cariacica-ES e do Estado do Espírito Santo, atuando em todas as etapas de ensino (infantil, fundamental, médio) e na modalidade EJA. É doutorando em Educação (UFJF), é professor da Faculdade de Educação da UFJF e também é professor/orientador do Programa de Mestrado em Gestão, Planejamento e Ensino da UninCor. É Líder do Grupo de Pesquisa Interdisciplinar e Práticas Pedagógicas em Educação Fúsica (UFSJ/UFJF). Tem experiência nos seguintes temas: Educação Fúsica escolar; Formação de Professores; Mídia-Educação (Física); Currículo; Fillosofia e Epistemologia da Educação Física; Teorias críticas e pós-críticas.

E-mail: galdinorodrigues@yahoo.com.br 


\section{SOBRE AS AUTORAS E OS AUTORES}

\section{Brunna Sullara Vilela Rodrigues}

Docente/mestra Universidade Vale do Rio Verde.

Email: prof.brunna.vivela@unincor.edu.br

ORCID: https://orcid.org/0000-0002-4096-8337

\section{Ana Luiza Rodrigues Pellegrinelli}

Nutricionista, Mestre. Professora Universidade Vale do Rio Verde - UninCor.

E-mail: prof.ana.pellegrinelli@unincor.edu.br

ORCID: https://orcid.org/0000-0003- 0134-8861

\section{Bruna Andrade Silva}

Graduanda em Curso de Nutrição. Universidade Vale do Rio Verde - Unincor.

E-mail: brunaandrade_silva@hotmail.com

ORCID: https://orcid.org/0000-0002-2757-3525

\section{Bruna Marina Melo de Andrade}

Graduanda em Curso: Nutrição, Universidade Vale do Rio Verde - UninCor.

E-mail: brunameloandradetc859@gmail.com

ORCID: https://orcid.org/0000-0003-3173- 5192

\section{Eduarda Gomes dos Santos}

Graduanda em Nutrição pela Universidade Vale do Rio Verde.

E-mail: dudasantos44@gmail.com.

ORCID (https://orcid.org/0000-0003-0791-5521).

\section{Elaine de Jesus Oliveira}

Graduando(a) em Estética e Cosmética. Universidade Vale do Rio Verde. E-mail: ejoholiveira@gmail.com

ORCID: https://orcid.org/0000-0002-0212-6286

\section{Jean Henrique Delfino}

Graduando(a) em Nutrição. UninCor Universidade Vale do Rio Verde.

E-mail: jeean_nep@hotmail.com

ORCID: https://orcid.org/0000-0001-6371-5335 


\section{Luís Gustavo Borges}

Graduando em Nutrição pela Universidade Vale do Rio Verde.

E-mail: luis_gusttavo22@hotmail.com

ORCID: https://orcid.org/0000-0003-3752-5698

\section{Letícia Aparecida Costa Luz}

Graduanda em Nutrição. Universidade Vale do Rio Verde.

Email: leticialuz21.11@gmail.com

ORCID: https://orcid.org/0000-0002-4981-7279

\section{Maria Eduarda de Oliveira Nepomuceno}

Graduanda em Nutrição pela Universidade Vale do Rio Verde.

E-mail: mariaeduarda9817@gmail.com

ORCID: https://orcid.org/0000-0001-7775-0940

\section{Mateus do Carmo e Silva}

Graduando (a) em Nutrição. Universidade Vale do Rio Verde-UNINCOR. Email: mateus.silva94@outlook.com

ORCID: https://orcid.org/0000-0003-0467-8655

\section{Pâmela Rodrigues Inácio}

Graduanda em Curso de Nutrição. Universidade Vale do Rio Verde.

Email: pamela.rodrigues@aluno.unincor.edu.br

ORCID: https://orcid.org/0000-0002-1513-4795.

\section{Simone da Silva Rodrigues}

Graduanda(a) em Estética e Cosmética. Universidade Vale do Rio Verde.

Email: simonyrodrigues79@gmail.com

ORCID: https://orcid.org/0000-0002-9048-6192

\section{Vivian Silva Borges}

Docente/titulação. Universidade Vale do Rio Verde.

Email: Prof.vivian.borges@unincor.edu.br

ORCID: https://orcid.org/0000-0002-4059-5761

\section{Yanka Lorena Gomes de Assis}

Graduanda em Curso de nutrição na Instituição Universidade Vale do Rio Verde.

Email: 1yankalorena@hotmail.com.

ORCID: https://orcid.org/0000-0002-9350-072X 


\section{Ans}

www.arcoeditores.com

(6) contato@arcoeditores.com (3) (3) (55)99723-4952

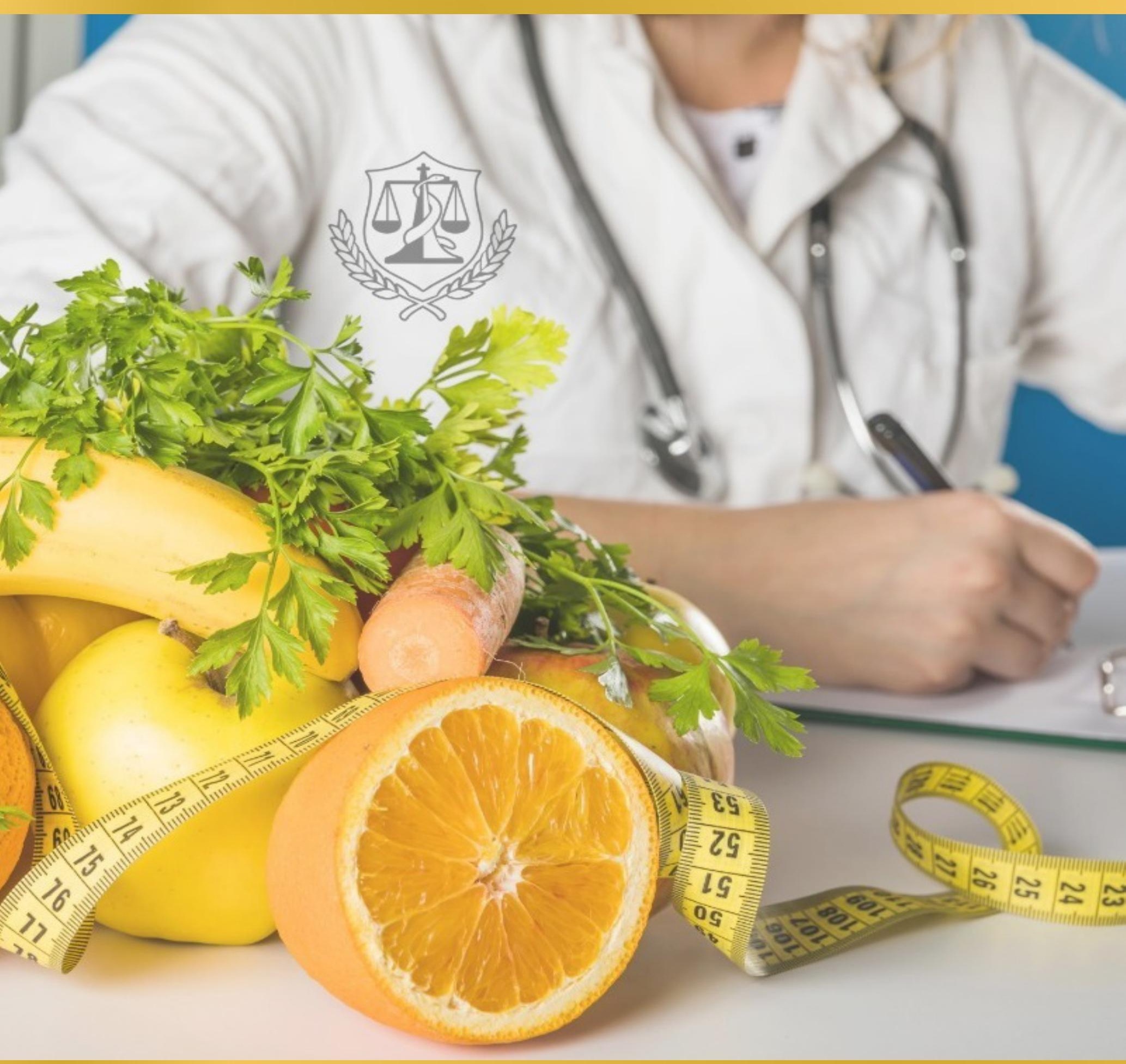

$\underset{E D T T O R E S}{\infty}$ 